\title{
Distribution, Patchiness, and Behavior of Antarctic Zooplankton, Assessed Using Multi-Frequency Acoustic Techniques
}

\author{
by \\ Gareth L. Lawson \\ B.Sc., McGill University, 1996 \\ M.Sc., Memorial University of Newfoundland, 1999 \\ Submitted to the MIT Department of Biology and the WHOI Biology Department \\ in partial fulfillment of the requirements for the degree of \\ Doctor of Philosophy \\ at the
MASSACHUSETTS INSTITUTE OF TECHNOLOGY
and the \\ WOODS HOLE OCEANOGRAPHIC INSTITUTION \\ September 2006 \\ (C) 2006 Gareth L. Lawson. All rights reserved.
}

The author hereby grants to MIT and WHOI permission to reproduce and to distribute publicly paper and electronic copies of this thesis document in whole or in part in any medium now known or hereafter created.

Signature of Author

Joint Program in Oceanography/Applied Ocean Science and Engineering Massachusetts Institute of Technology and Woods Hole Oceanographic Institution June 28, 2006

Certified by

Dr. Peter H. Wiebe

Senior Scientist, WHOI

Thesis Supervisor

Certified by

Dr. Timothy K. Stanton

Senior Scientist, WHOI

Thesis Supervisor

Accepted by

Prof. Edward F. DeLong

Chair, Joint Committee for Biological Oceanography

Massachusetts Institute of Technology and Woods Hole Oceanographic Institution 


\section{Distribution, Patchiness, and Behavior of Antarctic Zooplankton, Assessed Using Multi-Frequency Acoustic Techniques}

by

Gareth L. Lawson

Submitted to the MIT Department of Biology and the WHOI Biology Department on June 28, 2006, in partial fulfillment of the requirements for the degree of

Doctor of Philosophy

\section{ABSTRACT}

The physical and biological forces that drive zooplankton distribution and patchiness in an antarctic continental shelf region were examined, with particular emphasis on the Antarctic krill, Euphausia superba. This was accomplished by the application of acoustic, video, and environmental sensors during surveys of the region in and around Marguerite Bay, west of the Antarctic Peninsula, in the falls and winters of 2001 and 2002. An important component of the research involved the development and verification of methods for extracting estimates of ecologically-meaningful quantities from measurements of scattered sound. The distribution of acoustic volume backscattering at the single frequency of $120 \mathrm{kHz}$ was first examined as an index of the overall biomass of zooplankton. Distinct spatial and seasonal patterns were observed that coincided with advective features. Improved parameterization was then achieved for a theoretical model of Antarctic krill target strength, the quantity necessary in scaling measurements of scattered sound to estimates of abundance, through direct measurement of all necessary model parameters for krill sampled in the study region and survey period. Methods were developed for identifying and delineating krill aggregations, allowing the distribution of krill to be distinguished from that of the overall zooplankton community. Additional methods were developed and verified for estimating the length, abundance, and biomass of krill in each acoustically-identified aggregation. These methods were applied to multifrequency acoustic survey data, demonstrating strong seasonal, inter-annual, and spatial variability in the distribution of krill biomass. Highest biomass was consistently associated with regions close to land where temperatures at depth were cool. Finally, the morphology, internal structure, and vertical position of individual krill aggregations were examined. The observed patterns of variability in aggregation characteristics between day and night, regions of high versus low food availability, and in the presence or absence of predators, together reinforced the conclusion that aggregation and diel vertical migration represent strategies to avoid visual predators, while also allowing the krill access to shallowly-distributed food resources. The various findings of this work have important implications to the fields of zooplankton acoustics and Antarctic krill ecology, especially in relation to the interactions of the krill with its predators.

Thesis Supervisors: Peter H. Wiebe and Timothy K. Stanton

Titles: Senior Scientists, Woods Hole Oceanographic Institution 


\section{ACKNOWLEDGMENTS}

First and foremost, I thank my two advisors, Peter Wiebe and Tim Stanton. The research presented in this dissertation is highly inter-disciplinary and makes advances in the fields of both zooplankton ecology and acoustics, and thus reflects the fact that I received the full benefit of two dedicated co-advisors. Much as the ecological insights gained via this work would not have been possible without the acoustic methods I first had to develop, my completion of the degree would not have been possible without the advice and support of both Peter and Tim. The rest of my thesis committee, Carin Ashjian, Glenn Flierl, and Meng Zhou, have likewise provided me with excellent advice in their respective fields of expertise. I have an enormous amount of respect for all of my advisors and committee members; they have provided me with complementary but distinct role models, and I feel that I have gained from them a solid understanding of what makes a good scientist.

My personal funding was provided by a Fulbright Scholarship, a Natural Sciences and Engineering Research Council of Canada Post-Graduate Scholarship, an Office of Naval Research Graduate Traineeship Award in Ocean Acoustics (Grant N00014-03-1-0212), the Comer Science and Education Foundation, and the Woods Hole Oceanographic Institution (WHOI) Academic Programs Office. The generosity of these agencies in funding a Canadian foreign national through nearly six years of graduate school is very much appreciated. The research was supported by N.S.F. U.S. Office of Polar Programs Grant OPP-9910307 to Carin Ashjian, Cabell Davis, Scott Gallager, and Peter Wiebe.

I also would like to thank a number of collaborators for their generosity in providing the various ancillary datasets considered in this work. Maria Vernet shared her data on chlorophyll $a$ concentrations; Chris Fritsen, Christine Ribic, and Alice Doyle provided ice observations; Joe Donnelly, Melanie Parker, and Jose Torres provided data on fish catches; Kendra Daly provided data on krill abundance by species from net catches; Carlos Moffat and Jason Hyatt provided assistance and code for processing satellite ice 
data; Ryan Dorland and Meng Zhou provided ADCP data as well as processing code; Jennifer Burns, Dan Costa, Ari Friedlaender, Christine Ribic, and Deborah Thiele provided data from predator surveys.

Finally, this research would not have been possible without the support and advice of a number of additional people. I am very grateful to Nancy Copley and Phil Alatalo, who performed all of the analyses of net catches considered here, assisted by various summer students, including Celli Hull and Gaelin Rosenwaks. Dezhang Chu and Andone Lavery provided excellent advice for matters concerning acoustics. Andy Solow and Mark Baumgartner provided much-appreciated assistance on statistical issues. Cabell Davis, Scott Gallager, and Qiao Hu helped with the interpretation of VPR observations. I would also like to acknowledge the support received at sea from the officers and crew of the RVIB N. B. Palmer and the Raytheon Polar Services Technical Support group, as well as all members of the BIOMAPER-II and MOCNESS teams: Phil Alatalo, Dicky Allison, Mari Butler, Mark Dennett, Karen Fisher, Andy Girard, Erich Horgan, Amy Kukulya, Peter Martin, Gaelin Rosenwaks, Jay Peterson, Alec Scott, Jan Szelag, Philip Taisey, Maureen Taylor, and Joe Warren. Various earlier versions of individual thesis chapters benefited substantially from the comments of Yoshi Endo, Ken Foote, Chuck Greene, Stein Kaartvedt, Andone Lavery, Jon Watkins, as well as three anonymous reviewers. The staff of the WHOI Academic Programs Office and Biology Department provided invaluable logistic assistance. Finally, I would like to thank all the friends and family who provided important support of a non-scientific kind. 


\title{
Table of Contents
}

\author{
Chapter 1 - Introduction
}

1.1 MOTIVATION

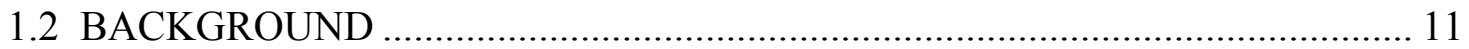

1.2.1 History of krill research and the krill fishery.............................................. 11

1.2.2 Ecology of the Antarctic krill .................................................................. 12

1.2.3 Southern Ocean GLOBEC program …………….................................... 15

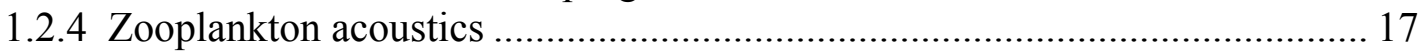

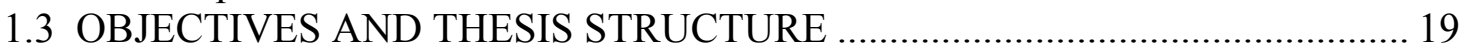

\section{Chapter 2 - Acoustically-Inferred Zooplankton Distribution in Relation to} Hydrography West of the Antarctic Peninsula

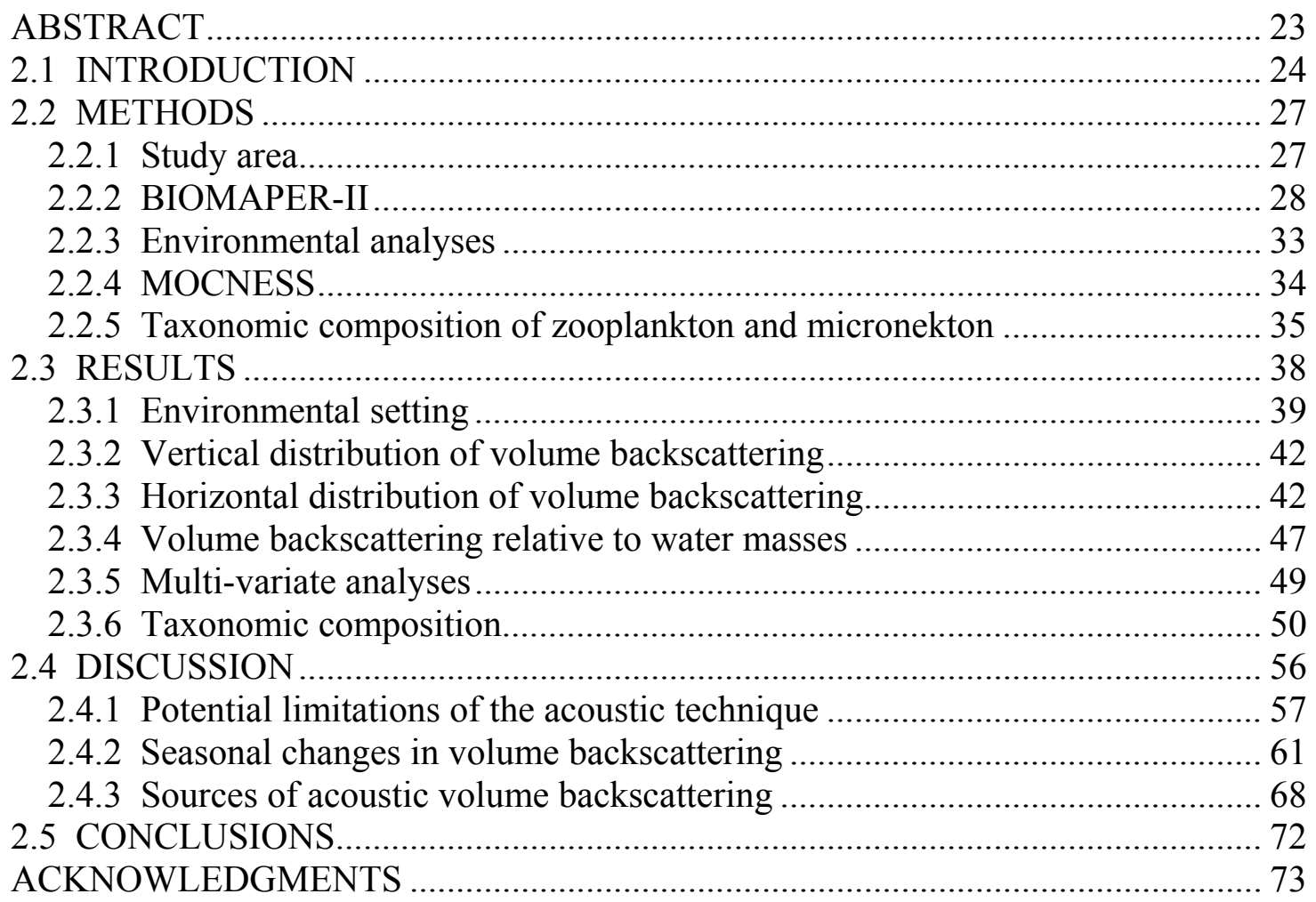


Chapter 3 - Improved Parameterization of Antarctic Krill Target Strength Models

ABSTRACT

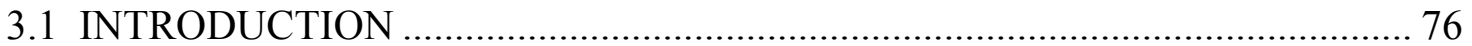

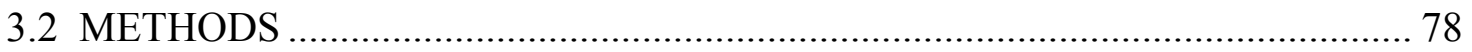

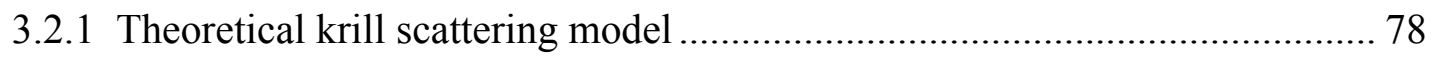

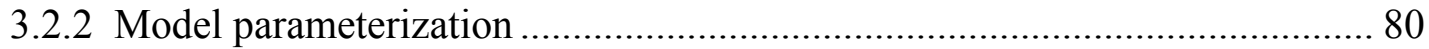

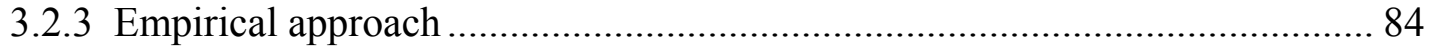

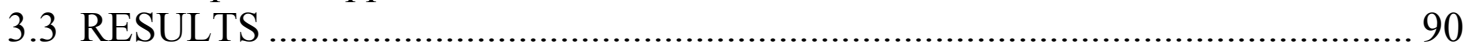

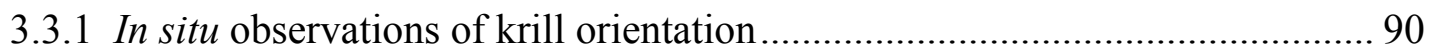

3.3.2 Scattering model predictions......................................................................... 92

3.3.3 Model verification with empirical in situ target strength observations .......... 95

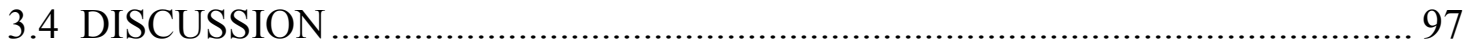

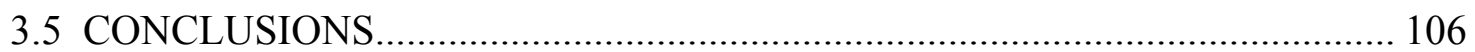

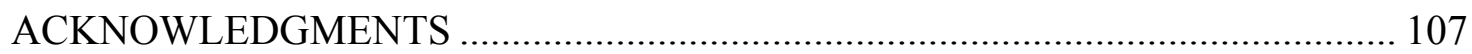

Chapter 4 - Krill Distribution Along the Western Antarctic Peninsula and Associations With Environmental Features, Assessed Using Multi-Frequency Acoustic Techniques

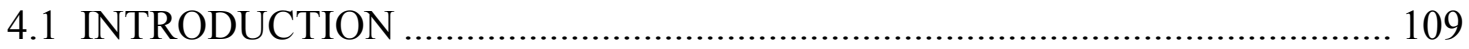

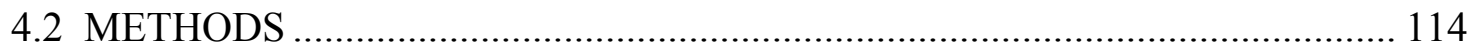

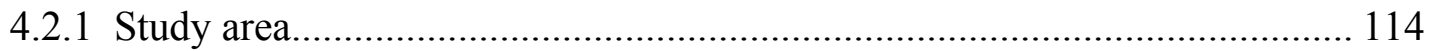

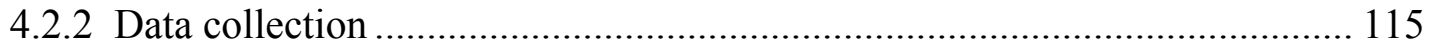

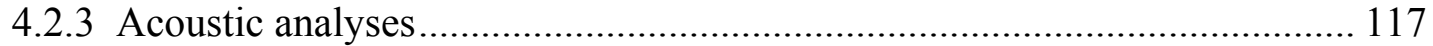

4.2.4 Estimation of krill biomass .................................................................. 125

4.2.5 Analysis of krill distribution in relation to environmental features .............. 131

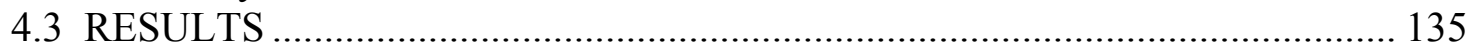

4.3.1 Application and verification of acoustic methodologies ............................. 135

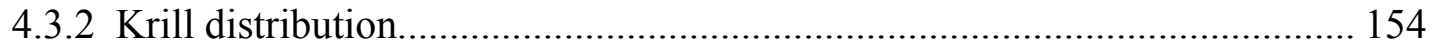

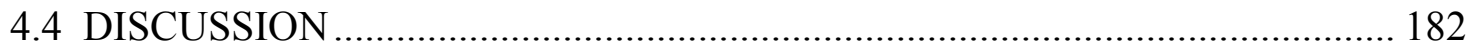

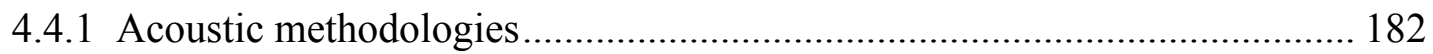

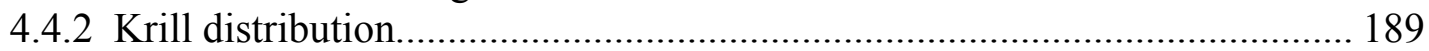

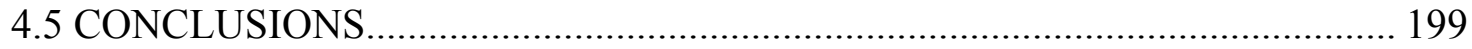

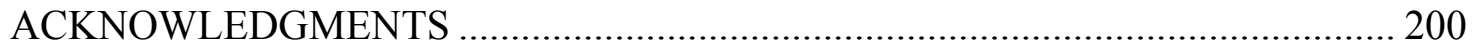


Chapter 5 - Krill Aggregation Structure and Vertical Migration in Relation to Features of the Physical and Biological Environment

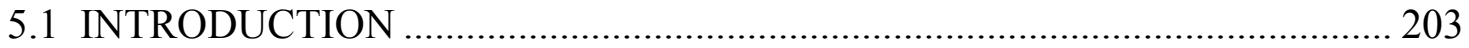

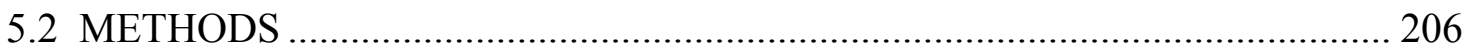

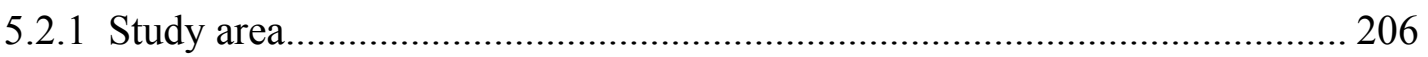

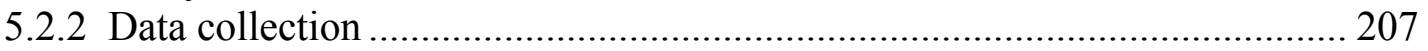

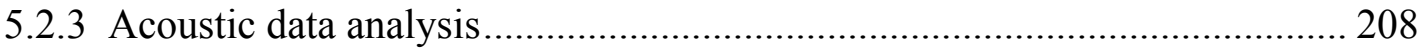

5.2.4 Measurements of aggregation features .................................................... 212

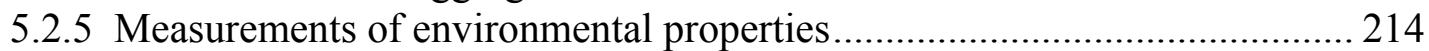

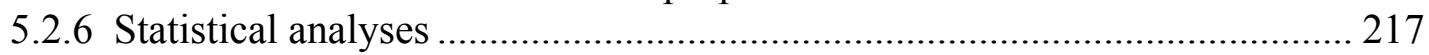

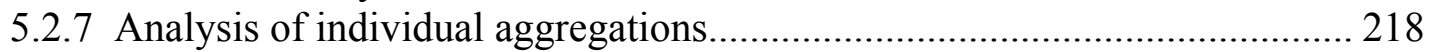

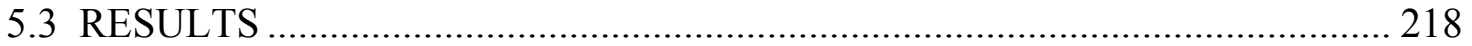

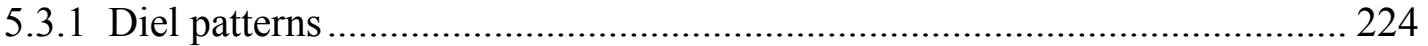

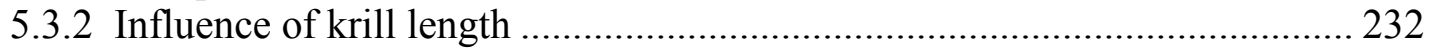

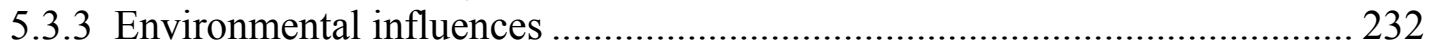

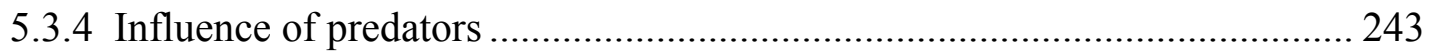

5.3.5 Variability in density and size within individual aggregations...................... 258

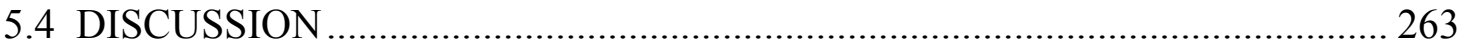

5.4.1 Strengths and weaknesses of the acoustic analyses ..................................... 265

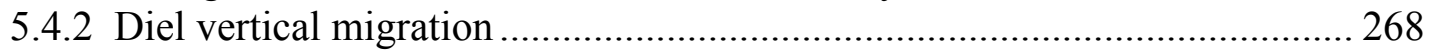

5.4.3 Variability in aggregation size ............................................................... 276

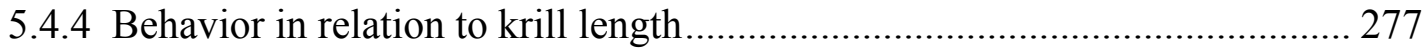

5.4.5 Intra-aggregation variability in animal density and size.............................. 278

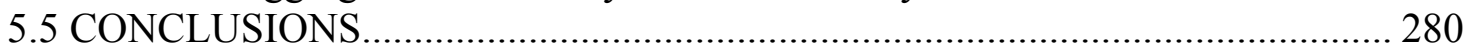

Chapter 6 - Conclusions

6.1 ANTARCTIC ZOOPLANKTON ACOUSTICS .................................................. 283

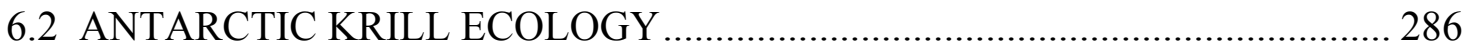

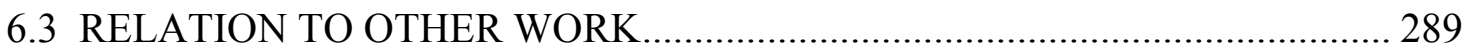

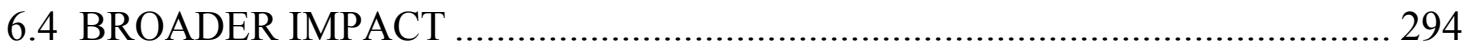

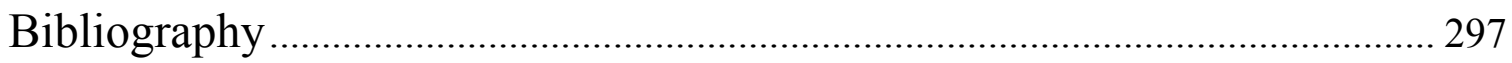




\section{Chapter 1}

\section{Introduction}

\subsection{MOTIVATION}

The distribution of zooplankton is characterized by extreme variability at a range of spatial and temporal scales (Cassie, 1963; Haury et al., 1978); 'patchiness' is the term used to describe the intermittent nature and strong spatial heterogeneity typical of the distribution of many animals (Steele, 1974). Zooplankton patchiness likely stems from a complex interaction of physical processes, food availability, population dynamics, predation, and behavior (Folt and Burns, 1999). As a characteristic feature of marine systems, zooplankton patchiness must be taken into account in any consideration of ecosystem processes such as predator-prey interactions or carbon flux. In addition, patchiness has important consequences to the error associated with abundance estimates from low-resolution sampling techniques such as net surveys, and thereby to stock assessment surveys for commercially-exploited species (McClatchie et al., 1994). Despite this convincing impetus, however, a comprehensive understanding concerning zooplankton patchiness remains elusive, perhaps due to an historical lack of appropriate tools able to resolve small-scale variability (Greene et al., 1998).

Zooplankton play a pivotal role in the antarctic continental shelf ecosystem, providing both a trophodynamic link between phytoplankton and higher predators, and, via their faecal pellets, a mechanism by which newly fixed carbon can be exported from the euphotic zone (Priddle et al., 1992). The Southern Ocean is estimated to be responsible for $15 \%$ of global primary production (Huntley et al., 1991), much of which is consumed 
by zooplankton. Understanding heterogeneity in the distribution of zooplankton as it relates to heterogeneity in that of primary producers is thus key to understanding carbon export in this important region, and to predicting the likely impacts of climate change.

Among antarctic zooplankton, much attention has focused on the Antarctic krill (Euphausia superba Dana), as the subject of one of the world's largest crustacean fisheries (Ichii, 2000), and the key prey item for numerous species of birds, seals, and whales (Laws, 1985). Many of these seal and whale species have still not recovered from over-exploitation in previous decades and centuries, such that understanding the interaction of krill and their predators, and the potentially competitive impact of the krill fishery, is of great importance (Everson, 2000a). In addition, the krill is notable for its consistent formation of highly cohesive aggregations, and is a strong swimmer capable of overcoming most prevailing currents (Hamner et al., 1983). It therefore represents an attractive model species for the study of how active behaviors interact with physical oceanographic processes to generate patchiness in the distributions of zooplankton.

This thesis examines the forces that drive zooplankton distribution and patchiness in antarctic continental shelf regions, with particular attention given to the krill. The ultimate goal is to understand how physical oceanographic processes and environmental conditions are linked to krill distribution at the broad-scale and behavior at the level of the individual aggregation. The work is motivated both by the fascinating nature of the phenomenon of zooplankton patchiness in its own right, and by a desire to understand how krill distribution and behavior are linked to the dynamics of higher predators and the Southern Ocean ecosystem as a whole. 


\subsection{BACKGROUND}

\subsubsection{History of krill research and the krill fishery}

Early recognition of the central importance of Antarctic krill to the diets of many higherlevel Southern Ocean predators was made by the sealers and whalers of the $19^{\text {th }}$ and $20^{\text {th }}$ centuries (summarized in Marr, 1962). Ecological interest in krill originated in attempts to manage the whale hunt on a scientific basis, resulting in the highly ambitious Discovery Expeditions of the 1930s and 40s. The collected reports of the Expeditions painted the picture of an enormously abundant species, distributed in vast swarms about the entire antarctic continent (Marr, 1962), and which displayed a complex succession of life history stages (Fraser 1936). These somewhat qualitative studies laid the foundation for all later krill research.

With the precipitous decline in the whale catch during the 1960s (Laws, 1977), the potential of Antarctic krill as an apparently vast source of protein began to be considered (Moiseev, 1970). Estimates of krill abundance of the day ranged from 14 to 7000 million metric tons (Mt), implying the potential for a major fishery. Of particular notoriety was the 'krill surplus' hypothesis, which held that the deficit of $41.7 \mathrm{Mt}$ of whale biomass culled by the whaling industry must have led to a 'surplus' annual production of $150 \mathrm{Mt}$ of krill no longer being consumed and thus available for harvest (Gulland, 1970). Despite the concern of some that this potential surplus would simply be consumed by increasing populations of other apex predators (Laws, 1977), the notion of a harvestable $150 \mathrm{Mt}$ at a time when the total combined yield of the world's fisheries was $60 \mathrm{Mt}$ led to enormous optimism that a krill fishery would solve the problem of "supplying ever-increasing human populations with food" (Moiseev, 1970). Soviet exploratory fishing operations had demonstrated that krill were easy to find and catch (Makarov et al., 1970), and so by the end of the 1970s the krill fishery had begun in earnest. The Southern Ocean krill fishery peaked at a total catch of $0.5 \mathrm{Mt}$ in the $1980 \mathrm{~s}$ and presently extracts approximately $0.1 \mathrm{Mt}$ of krill annually, and thus is among the largest crustacean fisheries in the world (Ichii, 2000). 
Recognition of the central role played by the krill in the antarctic marine ecosystem, coupled with the memory of the drastic over-exploitation of the Southern Ocean seal and whale populations of previous decades and centuries, however, has led to concerns that even light levels of fishing pressure might lead to a collapse of the food web (Nicol, 1994). Many antarctic top predators are dependent on krill as their primary prey item, and population dynamics for some species have been shown to vary with krill abundance, at least at a local scale (Reid and Croxall, 2001). This introduces the possibility of competition between the commercial fishery and natural predators. The linkages between the dynamics and distribution of krill populations and those of their predators thus represent an important avenue of investigation.

Scientific interest in krill has also been prompted by the role this highly abundant secondary producer might play in global carbon cycling and its response to climate change. The extent to which the vast area of the Southern Ocean sequesters atmospheric carbon dioxide is of global biogeochemical relevance (Huntley et al., 1991). As a central member of the Antarctic food web, krill may exert a substantial influence over the degree to which carbon dioxide drawn down from the atmosphere and fixed into organic particulate material by primary producers is exported from the shallow euphotic zone where primary production occurs and sequestered in the deep ocean (Priddle et al., 1992). The dense fecal pellets of krill and other zooplankton are known to constitute an important mechanism for such carbon export (LeFèvre et al., 1998), and the abundance and spatial distribution of the krill, in relation to that of primary producers, are likely to be important considerations in the Southern Ocean carbon cycle.

\subsubsection{Ecology of the Antarctic krill}

There are seven species of commonly occurring euphausiid in the Southern Ocean: Euphausia superba, E. crystallophorias, E. vallentini, E. triacantha, E. frigida, and Thysanoessa macrura and T. vicina. The distributions of these various species show a great deal of overlap, but there is a general latitudinal gradation, with E. crystallorophias 
mostly limited to continental shelf regions, E. vallentini restricted to waters north of the Antarctic polar front, and the other species found in between (Mauchline, 1980c; Everson, 2000b). Of these species, perhaps the most abundant, and certainly the most commercially important, is the Antarctic krill, Euphausia superba.

The Antarctic krill has a circumpolar distribution strongly linked to large-scale circulation features and characterized by enhanced concentrations located in two bands about the continent: one in continental shelf regions within the westerly-flowing East Wind Drift, and the other in oceanic waters between the easterly-flowing Antarctic Circumpolar Current (ACC) and the Antarctic Polar Front (Marr 1962; Amos, 1984). Both regions display large temporal variability in krill abundance between seasons (e.g., Lascara et al., 1999) and years (e.g., Brierley et al., 1997). The seasonal advance and retreat of the pack ice (from 20 million $\mathrm{km}^{2}$ in winter to 4 million $\mathrm{km}^{2}$ in summer) is generally believed to have a strong influence on the broad-scale distribution of krill, both through direct effects and indirectly through the association of the retreat of the ice with enhanced primary productivity at the ice edge (Miller and Hampton, 1989). Krill distribution also varies meridionally, with particularly enhanced abundances found in the Ross, Weddell, and Bellingshausen Seas, along the western Antarctic Peninsula, in the western Scotia Sea around the productive krill fishing grounds of South Georgia, and in the region south of the Indian Ocean (Figure 1.1; Amos, 1984). Genetic analysis of krill mitochondrial DNA from some of these regions has suggested that krill near South Georgia are genetically distinct from those of the Weddell Sea, although otherwise no differences were found for krill sampled from these two location as well as the Ross and Bellingshausen Seas (Zane et al., 1998).

The krill is a long-lived species, reaching ages of 6-7 years, and spawning at age 2-3 during the summer in oceanic waters along or beyond the continental shelf break (Siegel, 2005). There is some suggestion that post-spawning adult krill then migrate in fall to over-winter in coastal regions (Siegel, 1988). Surveys in the Gerlache Strait along the Western Antarctic Peninsula have suggested that some krill, particularly small adults, 


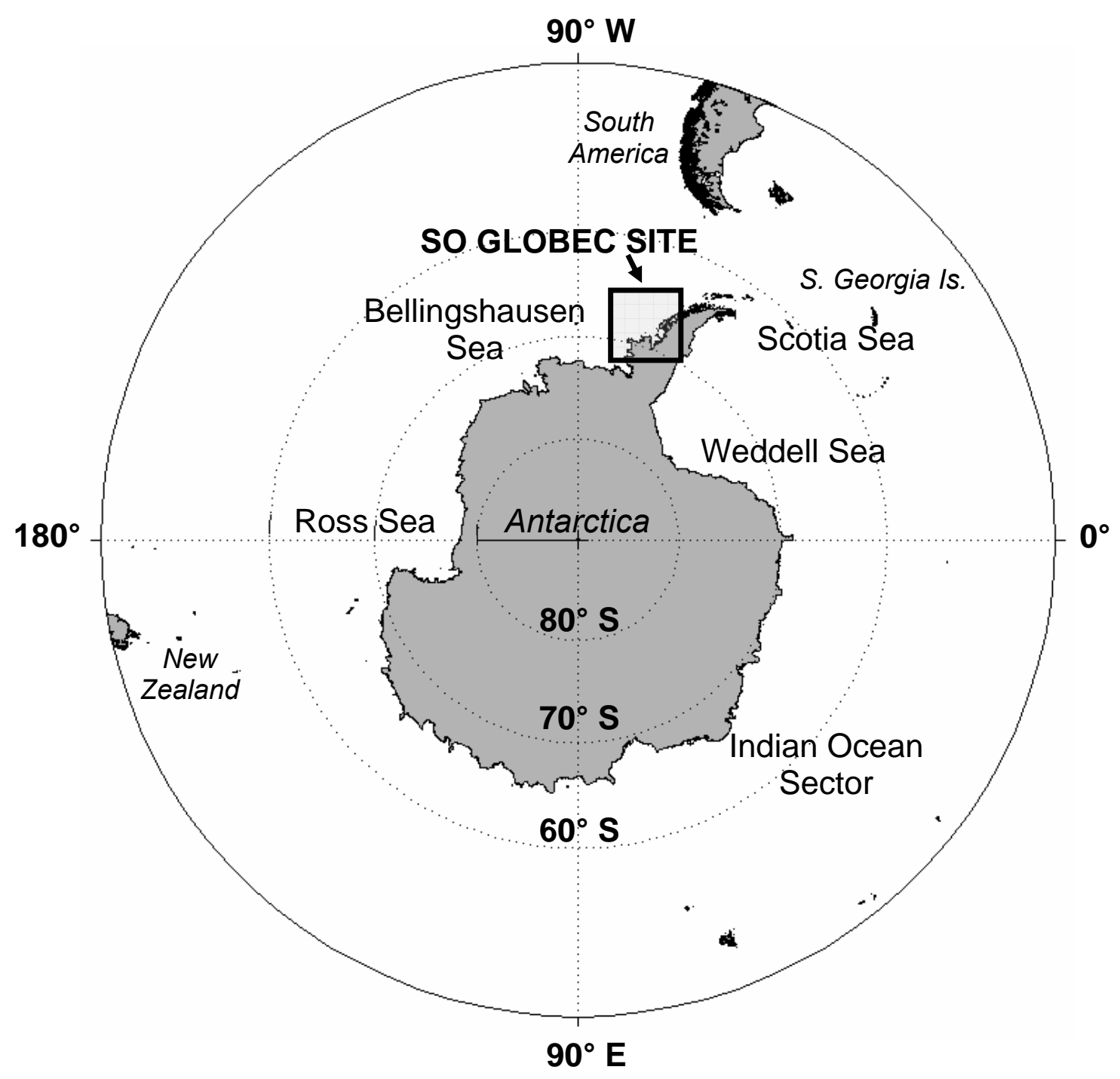

Figure 1.1 - The antarctic continent, showing major seas and the location of the U.S. Southern Ocean GLOBal ECosystems Dynamics (SO GLOBEC) program study site. 
may also spawn in the deep basins and troughs of more coastal regions (Brinton, 1991). The developing embryos sink and hatch at depths greater than $700 \mathrm{~m}$ (Siegel, 2000). Post-hatch larvae progress through a series of developmental stages as they migrate upwards to shallower waters by fall and are thought to spend the winter in association with the immediate under-ice environment (Marr 1962; Nicol, 2006). Some evidence suggests that krill recruitment is highest after winters of extensive sea-ice, and is influenced by competition with salps for phytoplankton food resources (Loeb et al., 1997). Larval krill as small as $10 \mathrm{~mm}$ have been observed to form aggregations under sea ice (Hamner et al., 1989), and post-larval krill are thought to spend the majority of their time in aggregations. The high degree of cohesion and synchronized behavior in such aggregations revealed by the observations of divers has led some authors to suggest that the term 'school' is in fact most appropriate (Hamner et al., 1982), and the persistent occurrence of krill in aggregations has led others to suggest that the krill aggregation constitutes the basic ecological unit of the species (Watkins, 1986).

The emphasis of the present work is on the distribution of krill at the meso-scale and the structure and behavior of individual krill aggregations. More thorough reviews of the current state of understanding of these topics will be presented as introductory material in subsequent chapters. These subjects have received substantial attention, and interesting insights have emerged concerning the associations of krill with both physical oceanographic and biological factors. Most of this previous work has been conducted during the austral spring and summer, however, when antarctic continental shelf regions are most accessible. Previous studies of krill distribution and aggregative behavior in fall and winter have been few, and it is in addressing this deficiency that this work makes one of its most important contributions.

\subsubsection{Southern Ocean GLOBEC program}

The present research was conducted as one component of the U.S. Southern Ocean GLOBal ECosystems Dynamics (SO GLOBEC) program, one of the many GLOBEC 
projects around the world, which in broad terms are charged with understanding variability in the populations of marine organisms in response to environmental change. The SO GLOBEC program's primary objective is "to understand the physical and biological factors that contribute to enhanced Antarctic krill growth, reproduction, recruitment, and survivorship throughout the year" (Hofmann et al., 2002). The program's goals also include an understanding of what factors contribute to the availability of krill to higher predators, including whales, seals, and penguins, and in this respect the program is quite unusual. The concurrent collection of information on physical processes, nutrient dynamics, primary producers, zooplankton, as well as higher predators, provides an important opportunity to understand biological-physical linkages at all levels of the ecosystem.

The SO GLOBEC program selected as its primary study site the continental shelf region in and around Marguerite Bay, west of the Antarctic Peninsula (Figure 1.1). This region is thought to sustain large abundances of Antarctic krill (Marr, 1962; Lascara et al., 1999), and may act as a source for the down-stream krill populations that support the major krill fishery around South Georgia (Atkinson et al., 2001; Fach et al., 2002). The area is also home to large populations of predators dependent on krill as their central prey (Fraser and Trivelpiece, 1996; Costa and Crocker, 1996). Few previous studies of the region have considered the fall and winter seasons (Lascara et al., 1999), although the region is hypothesized to be an important krill over-wintering ground. Given the general dearth of previous wintertime studies of krill anywhere about the Antarctic, and in the Marguerite Bay region in particular, the SO GLOBEC program targeted austral fall and winter for periods of detailed study. The program approached its goals through a combination of broad-scale survey cruises with an ice-capable survey vessel conducted concurrent to process-oriented studies by a second vessel, coupled with more long-term deployments of satellite tags affixed to predators, weather stations, drifters, and moored instrument packages (reviewed in Hofmann et al., 2002, and see references therein to individual projects). 
The Marguerite Bay region is characterized by a variety of physical features that may contribute to its support of such a productive ecosystem. The regional hydrography is reviewed in greater detail in the chapters that follow, but in brief, large gyres (100-400 $\mathrm{km}$ in horizontal extent along-shelf, 100-150 km across-shelf) have been observed over the western Antarctic Peninsula continental shelf, and the Antarctic Circumpolar Current (ACC) is typically positioned immediately beyond the shelf break (Smith et al., 1999). The continental shelf is overall quite deep, often exceeding depths of $400 \mathrm{~m}$, and is intersected by a number of deep troughs. Warm and nutrient-rich rich waters present at depth beyond the shelf-break are pumped up onto the shelf by the action of the ACC at the points where these troughs intersect the shelf break (Klinck et al., 2004). These intruding waters are thought to be an important driver of primary production in the region and the dominance of large diatoms over other primary producers (Prézelin et al., 2004). The entire region is covered by sea ice in winter and is ice-free in summer (Stammerjohn and Smith, 1996). The complex interplay of these various forcings undoubtedly has important impacts on the distribution of krill and other zooplankton in the region.

\subsubsection{Zooplankton acoustics}

Stock assessment for management of the krill fishery, understanding the role of krill in the Southern Ocean carbon cycle, and quantification of the interactions of the krill with its predators, all require an ability to measure accurately the distribution of krill abundance. Estimation of krill abundance, however, is made difficult by the extreme spatial patchiness typical of the species, its enormous potential range (the area of the Southern Ocean is $36 \times 10^{6} \mathrm{~km}^{2}$ ), and limited access to much of this range because of sea-ice (Everson, 2000b). Early estimates of krill abundance were derived from broad extrapolations of sparse measurements of krill density made with nets, or indirectly from calculations of the potential abundance of krill that could be supported based on measured levels of primary production (e.g., Gulland, 1970). These estimates were generally high and showed little consistency between studies. A turning point was reached in the late 1970s, when the Biological Investigations of Marine Antarctic 
Systems and Stocks (BIOMASS) research initiative focused attention on the use of hydroacoustics to quantify krill abundance (Everson and Miller, 1994).

High-frequency acoustic sensors are ideally suited to the study of zooplankton distribution and patchiness, due to their fast sampling rates and concomitant ability to survey a large fraction of the water column at high resolution over large areas (Foote and Stanton, 2000). Acoustic techniques are particularly powerful when applied in conjunction with independent measurements of the physical and biotic environment (e.g., hydrographic casts, net and video samples). In the Antarctic, acoustic sensors are now used routinely in ecological studies of krill, as well as in the stock assessment surveys employed in managing the krill fishery (see review by Hewitt and Demer, 2000).

Acoustic techniques rely on the fact that many marine organisms scatter sound in a predictable manner. Measurements of the intensity of echoes returned from sonic pulses emitted into the water column therefore can be used to make estimates of more biologically-meaningful quantities such as animal abundance and size. This process of inferring the abundance and distribution of zooplankton in a quantitative sense from acoustic measurements, however, is not straightforward (Stanton et al., 1994; Wiebe et al., 1996). Scattering in the water column can result from both physical oceanic processes (e.g., microstructure; Warren et al., 2003) and the biota, where scattering from the latter is a complex function of the taxonomic composition of animals present, and the associated variability in their size, shape, physical properties, and behavior. Accurate inference of organismal parameters such as abundance from acoustic measurements thus requires a comprehensive understanding of the scattering processes involved.

In the Antarctic, substantial progress has been made in discriminating Antarctic krill from other acoustic scatterers that may be present (reviewed in Watkins and Brierley, 2002). Historically, however, many Southern Ocean acoustic studies have simply assumed that all acoustic measurements above some minimum threshold level stemmed solely from krill (e.g., Macaulay et al., 1984; Lascara et al. 1999), thereby discarding potential 
information on the abundance and distribution of other zooplankton, and possibly resulting in an overestimation of krill abundance. Discrepancies also exist in the predictions of the scattering by individual krill (i.e., target strength) from the semiempirical model developed by Greene et al. (1991) that is in common use for krill surveys and theoretical models based on scattering physics (e.g., Stanton et al., 1993, 1998; McGehee et al., 1998). Target strength is a critical quantity in making abundance estimates from acoustic data, and the Greene et al. (1991) model marked a substantial improvement over earlier target strength models developed during the BIOMASS program (see review in Miller and Hampton, 1989), but these discrepancies have yet to be fully reconciled. Furthermore, developments made in zooplankton acoustics elsewhere involving the use of multi-frequency acoustic data to estimate simultaneously the abundance and size of animals (e.g., Warren et al., 2003) have as yet not been applied in the Southern Ocean beyond individual test-case krill aggregations. Thus while the field of Antarctic krill acoustics has achieved a reasonable level of sophistication, there still exist opportunities for improvement.

It is important to note that even the advanced acoustic methodologies developed and employed in the present work are unable to distinguish at the specific level between the various species of aggregating euphausiids that may be present in the region (notably Euphausia superba and E. crystallophorias, and possibly Thysanoessa macrura); below these species therefore will be referred to collectively as 'krill.' The consequences of this inability are explored later in relation to the ecological conclusions made in each thesis chapter.

\subsection{OBJECTIVES AND THESIS STRUCTURE}

In this thesis, I examine the physical and biological forces that drive the distribution and patchiness of zooplankton in an antarctic continental shelf region. Both the broad-scale distribution of animals across the continental shelf and the scale of individual krill aggregations are considered. This is achieved by the application of a suite of sensors, 
including multi-frequency acoustic, video, and net sampling systems, of which acoustic instruments provide the majority of the data considered. As such, an important component of the research involves the development and verification of methods for extracting estimates of ecologically-meaningful quantities such as animal abundance from measurements of scattered sound. The study area is that selected by the Southern Ocean GLOBEC program, the continental shelf region in and around Marguerite Bay, west of the Antarctic Peninsula, and the survey period the falls and winters of 2001 and 2002.

The thesis research is divided into four inter-related components, each of which has been prepared as a stand-alone document intended for publication as a refereed journal article, and each of which is presented here as a thesis chapter. Consequently, there is some redundancy in the various chapters, most notably in their respective introductions. Chapters 2 and 3 repeat mostly verbatim the material of Lawson et al. (2004) and Lawson et al. (2006), respectively; the changes made here to the text of those publications were done in an effort to keep the language consistent with the rest of the thesis.

Chapter 2 takes an overview-approach to the question of the distribution of zooplankton and micronekton in the study region. Spatial and temporal patterns in the distribution of acoustic volume backscattering strength at a single frequency during the fall and winter of 2001 are examined, as a coarse index of the overall biomass of zooplankton and micronekton. These patterns are considered in light of hydrographic features of the region. Calculations are then made of the likely taxonomic composition of animals responsible for the observed levels of volume backscattering, based on net catches and models of how individual animals scatter sound. This exercise demonstrates that euphausiids were the dominant scatterer at only very particular locations and depths, emphasizing the need for caution when seeking to study euphausiids separately from other zooplankton using acoustic data. 
Motivated by discrepancies that emerged during the analyses of Chapter 2 between theoretical and empirical approaches to understanding acoustic scattering by Antarctic krill, Chapter 3 seeks to improve parameterization of a theoretical scattering model on the basis of direct measurement of all necessary model parameters for animals sampled in the study region and survey period. This novel parameterization is then verified on the basis of comparisons of model predictions to in situ observations of krill target strength (i.e., the level of scattering from one animal). This chapter thus establishes a validated krill target strength model for the acoustic analyses of krill distribution that follow in later thesis chapters.

Chapter 4 builds on the analyses of Chapter 2 by focusing in particular on the distribution of krill in the study region, and expanding to a consideration of both survey years. Given its broad-scale survey coverage and high resolution, this is again done on the basis of the acoustic dataset, although unlike Chapter 2, the full multi-frequency dataset is employed. The first component of the chapter involves the development of methods that capitalize on differences predicted by the model of Chapter 3 between the scattering of krill versus that of other taxa and in the scattering of krill of different sizes, in order to identify krill aggregations in the acoustic data, and then estimate the length, abundance, and biomass of constituent members. These methods are verified through comparisons to independent net and video samples. In the second component of the chapter, these methods are applied to the full multi-frequency dataset collected during all four broad-scale surveys of the study region. The resultant descriptions of the temporal (seasonal and inter-annual) and spatial (vertical and horizontal) variability in distribution of krill along-track biomass are then considered in relation to aspects of the physical and biological environment.

Chapter 5 complements the examination of the distribution of krill aggregation biomass conducted in Chapter 4 by focusing on the characteristics of individual acousticallyidentified krill aggregations, in order to make inferences concerning the behaviors and forces underling krill aggregation and diel vertical migration. The morphology, internal structure, and vertical position of aggregations are considered in relation to a variety of 
properties of the physical and biological environment, including time of day, food availability, currents, and the occurrence of predators. In addition, aggregation characteristics are studied relative to the acoustically-estimated mean length of constituent members in order to identify size- or age-related changes in aggregative behavior. Certain large aggregations are also selected for more detailed examination of intra-aggregation variability in krill length and density.

Chapter 6 then provides a summary of the major findings of the research and their broader significance. In particular, the implications of the present work to the field of zooplankton acoustics and to current understanding of the interactions between krill and higher predators, including whales, seals, and birds, are considered. 


\title{
Chapter 2
}

\section{Acoustically-Inferred Zooplankton Distribution in Relation to Hydrography West of the Antarctic Peninsula}

\begin{abstract}
The relationship between the distribution of zooplankton, especially euphausiids

(Euphausia and Thysanoessa spp.), and hydrographic regimes of the Western Antarctic Peninsula continental shelf in and around Marguerite Bay was studied as part of the Southern Ocean GLOBEC program. Surveys were conducted from the RVIB N.B. Palmer in austral fall (April-June) and winter (July-August) of 2001. Acoustic, video, and environmental data were collected along 13 transect lines running across the shelf and perpendicular to the Western Antarctic Peninsula coastline, between 65 and $70^{\circ} \mathrm{S}$. Depth-stratified net tows conducted at selected locations provided ground-truthing for acoustic observations. In fall, acoustic volume backscattering strength at $120 \mathrm{kHz}$ was greatest in the southern reaches of the survey area and inside Marguerite Bay, suggestive of high zooplankton and micronekton biomass in these regions. Vertically, highest volume backscattering was in the depth range from 150 to $450 \mathrm{~m}$, associated with modified Circumpolar Deep Water (CDW). The two deep troughs that intersect the shelf break were characterized by reduced volume backscattering, similar to levels observed off-shelf and indicative of lower zooplankton biomass in recent intrusions of CDW onto the continental shelf. Estimates of dynamic height suggested that geostrophic circulation likely caused both along- and across-shelf transport of zooplankton. By winter, scattering
\end{abstract}


had decreased by an order of magnitude $(10 \mathrm{~dB})$ in the upper $300 \mathrm{~m}$ of the water column in most areas, and high volume backscattering was found primarily in a deep (>300 m) scattering layer present close to the bottom. The seasonal decrease is potentially explained by advection of zooplankton, vertical and horizontal movements, and mortality. Predictions of expected volume backscattering strength based on net samples suggested that large euphausiids were the dominant scatterer only at very particular locations and depths, and that copepods, siphonophores, and pteropods were more important in many locations.

\subsection{INTRODUCTION}

Zooplankton play a pivotal role in the antarctic continental shelf ecosystem, providing both a trophodynamic link between phytoplankton and higher predators, and, via their fecal pellets, a mechanism by which newly fixed carbon can be exported from the euphotic zone (Priddle et al., 1992). Historically, much attention has focused on Antarctic krill (Euphausia superba) due to its status as a key prey item for many whales, birds, seals, and fishes (Laws, 1985) and as the subject of a commercial fishery (Ichii, 2000). Although less studied, other zooplankton also represent important ecosystem members: copepods, for example, frequently exceed Antarctic krill in abundance and are the main prey of invertebrates, sei whales, and fish (Voronina, 1998), while salps may account for more carbon export to depth than Antarctic krill (Le Fèvre et al., 1998).

High-frequency acoustic sensors are often used in the study of zooplankton distribution, due to their high sampling rates and concomitant ability to survey the entire water column over large areas (Foote and Stanton, 2000). In the Antarctic, acoustic techniques are used routinely to survey the biomass and distribution of Antarctic krill (see review by Hewitt and Demer, 2000), but have been used much less frequently to study other zooplankton taxa (Weeks et al. 1995; Brierley et al., 1998). Substantial progress has been made in discriminating Antarctic krill from other acoustic scatterers that may be present (Madureira et al., 1993; Brierley et al., 1998; Watkins and Brierley, 2002; Hewitt et al., 
2003). Historically, however, many Southern Ocean acoustic studies have simply assumed that all volume backscattering strength measurements above some minimum threshold stemmed from Antarctic krill (e.g., Macaulay et al., 1984; Lascara et al. 1999; Nicol et al., 2000). The contribution to acoustic observations from other zooplankton taxa often has been assumed to be negligible, which discards potential information on the biomass and distribution of such taxa, and may result in an overestimation of Antarctic krill abundance.

The continental shelf region in and around Marguerite Bay, west of the Antarctic Peninsula (Figure 2.1), is hypothesized to be an important over-wintering ground for Antarctic krill, and may act as a source for the down-stream krill populations in the Bransfield Strait and at South Georgia (Atkinson et al., 2001; Fach et al., 2002). Little is known about the distribution of Antarctic krill or other zooplankton in this area during winter, however, although studies of the nearby Bransfield Strait region have been more numerous (e.g., Siegel 1989; Zhou et al., 1994). In the only previous acoustic survey of the region, Lascara et al. (1999) examined Antarctic krill distribution in Marguerite Bay and the region immediately to the north, and found distinct seasonal variability in biomass and vertical distribution, with krill more abundant and found shallower during the summer and spring than fall and winter. The acoustic system employed reached to only $189 \mathrm{~m}$ in depth, and so this study was unable to conclude whether the seasonal decrease in biomass resulted from vertical or horizontal movements. Given the dearth of previous studies, the U.S. Southern Ocean GLOBal ECosystems Dynamics (SO GLOBEC) program has targeted austral fall and winter as periods for detailed study of the Marguerite Bay region (Hofmann et al., 2002). The program's primary objective is to understand the physical and biological factors that contribute to Antarctic krill overwintering success. As such, one goal of the program is to link physical processes with the distribution of Antarctic krill and other members of the zooplankton community, and ultimately with higher predators. 


\section{A - STUDY AREA}

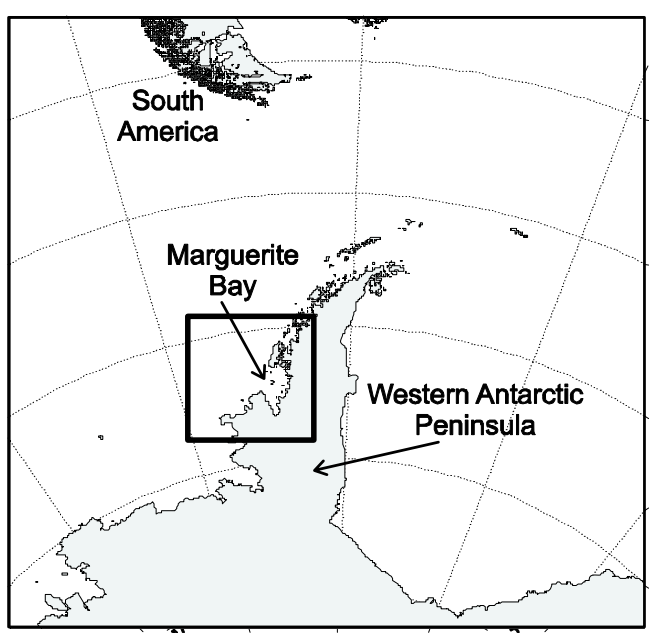

C - FALL

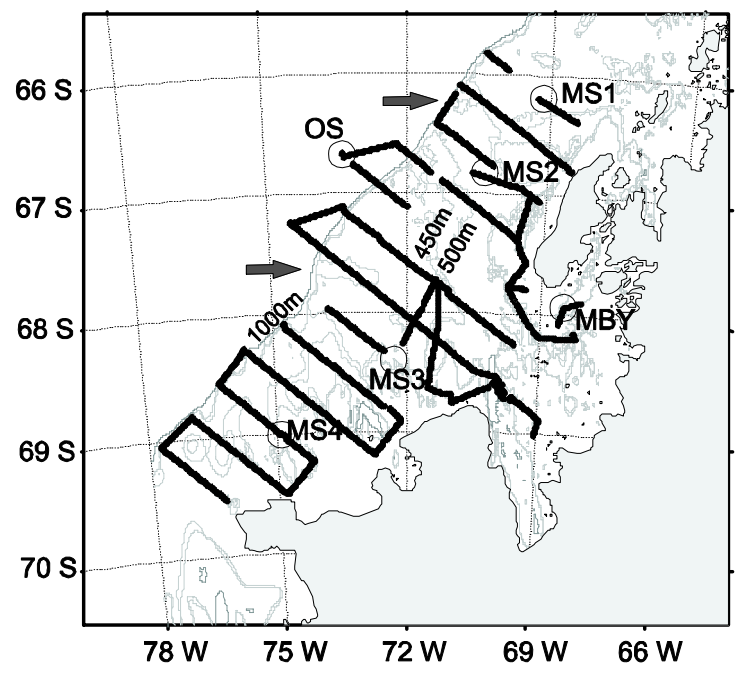

B - SURVEY BLOCKS

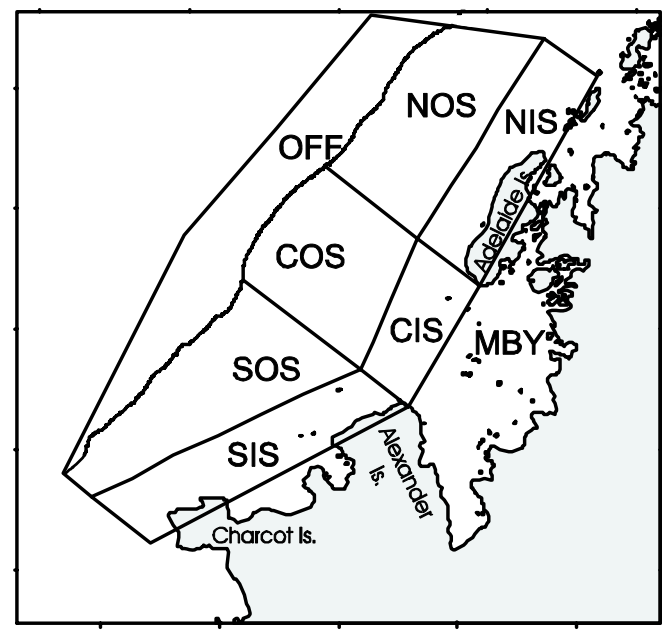

D - WINTER

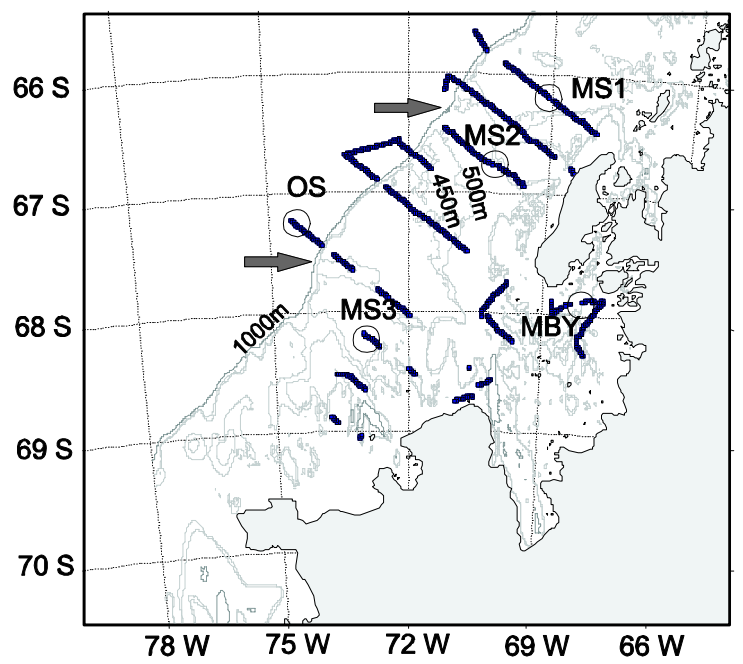

Figure 2.1 - U.S. SO GLOBEC survey area. Shown are (A) the overall geographical context of the survey area, (B) the location of survey blocks, and the cruise tracks in (C) fall and (D) winter of 2001. The latter show only those portions of the overall cruise-track where acoustic data were collected. Note the lower survey coverage in winter relative to fall. Block name abbreviations are: Northern Outer-Shelf (NOS), Northern Inner-Shelf (NIS), Central Outer-Shelf (COS), Central Inner-Shelf (CIS), Southern Outer-Shelf (SOS), Southern Inner-Shelf (SIS), Off-Shelf (OFF), and Marguerite Bay (MBY). Circles indicate where the MOCNESS tows analyzed here were conducted, with tow locations abbreviated as mid-shelf 1-4 (MS1-4), off-shelf (OS), and Marguerite Bay (MBY). Gray arrows show where the deep troughs that run diagonally across the continental shelf meet the shelf break. 
In this paper, we describe measurements of acoustic volume backscattering strength made over most or all of the water column during austral fall and winter of 2001, in relation to hydrography in the vicinity of Marguerite Bay. We then use depth-stratified net samples and taxon-specific models of acoustic target strength to predict the likely sources of scattering, with particular emphasis on understanding the contribution of zooplankton taxa other than Antarctic krill. On the basis of these measurements and predictions, we make certain inferences concerning seasonal and spatial variability in zooplankton and micronekton biomass in the region.

\subsection{METHODS}

\subsubsection{Study area}

The U.S. SO GLOBEC Program study site was located on the continental shelf to the west of the Western Antarctic Peninsula, extending from the northern tip of Adelaide Island to the southern portion of Alexander Island and including Marguerite Bay (Figure 2.1). Two cruises were conducted in the area on the RVIB Nathaniel B. Palmer: a cruise during austral fall from April 23 to June 6, 2001 (cruise number NBP0103), and a cruise during winter from July 21 to September 6, 2001 (cruise number NBP0104). The cruise track in fall was determined by the position of 84 station locations distributed along 13 transect lines spaced $40 \mathrm{~km}$ apart and running across the continental shelf and perpendicular to the Peninsula coastline. On the winter cruise, eight additional stations were added to the survey grid and the entire grid was shifted south by two kilometers so that acoustic mapping of the sea floor would take place over unmapped sea floor. In order to allow spatial comparisons across the region, the overall study area was subdivided into eight functional blocks (Figure 2.1b). The survey region first was subdivided from northeast to southwest into three sectors (southern, central, and northern), each of which was divided into inner-shelf (i.e., coastal) and outer-shelf blocks. An off-shelf block was defined as the region beyond the $1000 \mathrm{~m}$ isobath, and a final block corresponded to the interior of Marguerite Bay. 


\subsubsection{BIOMAPER-II}

The BIo-Optical Multi-frequency Acoustical and Physical Environmental Recorder, or BIOMAPER-II, is a towed system designed to conduct quantitative surveys of the spatial distribution of plankton and nekton (Wiebe et al., 2002). The system consists of a multifrequency echosounder, a Video Plankton Recorder (VPR, Davis et al., 1992), and an environmental sensor package (Conductivity, Temperature, and Depth sensor (CTD); fluorometer; transmissometer). To enhance the performance of the BIOMAPER-II in high sea states, a slack tensioner was used to damp the motion of the ship (see Wiebe $e t$ al., 2002 for additional details).

\subsection{2.a Acoustic definitions}

Volume scattering strength, or $S_{v}$ (where $S_{v}=10 \log _{10}\left(S_{v}\right)$ in units of decibels relative to 1 $\mathrm{m}^{-1}$, and $s_{v}$ is the observed volume scattering coefficient), is a measure of the intensity of emitted sound that is scattered towards the acoustic receiver per cubic meter. When the source and receiver are co-located, the direction of scattering is back towards the source, and this quantity is commonly referred to as the volume backscattering strength. Under the assumption made in zooplankton acoustics that scattering from individual targets in the ensonified volume sums incoherently, the volume backscattering strength is equal to the sum of the scattering contributions from each target, normalized by the sample volume. For simplicity, this quantity of measured backscattered sound per unit volume will be referred to as 'volume backscattering' and we will distinguish between the arithmetic and logarithmic forms of 'volume backscattering coefficient' and 'volume backscattering strength' only when necessary.

Volume backscattering is related to both the number and size of scatterers in the path of the incident sound, to the efficiency with which these objects scatter sound, and thereby to their taxonomic composition. Although the relationship between volume backscattering and the biomass of scatterers is thus highly complex, we assume that the 
large spatial and temporal differences in volume backscattering observed in the present study are related to differences in zooplankton and micronekton biomass. In the discussion we show how the confounding influences of animal size, sound scattering efficiency, and taxonomic composition, are minimized in this study.

\subsection{2.b Acoustic data collection}

The BIOMAPER-II collected acoustic data from five pairs of transducers, with frequencies of 43,120, 200, 420, and $1000 \mathrm{kHz}$. All transducers had $3^{\circ}$ half-power beamwidths, with the exception of the $43 \mathrm{kHz}$ transducers, which had beamwidths of $7^{\circ}$. One of each pair of transducers was mounted on the top of the tow-body looking upward, while the other was mounted on the bottom looking downward. This arrangement allowed acoustic data to be collected over most or all of the water column as the instrument was 'towyoed' obliquely up and down through the water column between depths of 20 and $300 \mathrm{~m}$. The vessel proceeded along the track-line between stations at speeds of 4 to 6 knots, and surveying was conducted around the clock.

Multi-frequency acoustic data were collected over much of both surveys, although prohibitively thick pack ice in portions of the survey area led to the area surveyed in winter being less than in fall (Figure 2.1c,d). Due to episodic malfunctions at the different acoustic frequencies, $120 \mathrm{kHz}$ represents the frequency at which data were collected with the greatest spatial coverage. In order to allow examinations of the seasonal distribution of zooplankton over the broadest scales possible and best complement the scales at which data were collected by other projects conducted during the cruises (e.g., top predator surveys), this paper deals only with acoustic data collected at $120 \mathrm{kHz}$. Analyses of the multi-frequency data will be the subject of future work.

Measurements of volume backscattering at $120 \mathrm{kHz}$ were collected in intervals of $1.5 \mathrm{~m}$ in vertical extent, starting at $6 \mathrm{~m}$ from the transducer face (the end of the acoustic nearfield) and extending to a maximum range of $300 \mathrm{~m}$ from the instrument. A $10 \mathrm{kHz}$ 
bandwidth chirp pulse was used (Ehrenberg and Torkelson, 2000), with an effective pulse duration of $0.18 \mathrm{~ms}$, and a ping rate of 0.3 pings s $\mathrm{s}^{-1}$. The system's dynamic range allowed these data to be collected between -100 and $-40 \mathrm{~dB}$. Profiles of noise levels (ship's noise, ambient noise, and system noise combined) vs. depth were made in situ near the start of each cruise. Volume backscattering measurements for each ping were compared to these profiles, and those bins where measured volume backscattering did not exceed noise levels were set to zero. Each measurement was the result of echo-integration performed over a 4-ping interval (i.e., $35 \mathrm{~m}$ along-track).

All transducers were calibrated by the manufacturer (Hydroacoustic Technologies Inc., Seattle, WA, USA) prior to each cruise for source level, receive sensitivity, as well as transmit and receive beam patterns. An in situ calibration also was performed at the end of the winter cruise with a $38 \mathrm{~mm}$ tungsten carbide ( $6 \%$ cobalt) standard target, following established practices (Foote et al., 1987). After volume backscattering data were normalized by the results of these calibrations, there was evidence of higher volume backscattering levels observed by the up-looking $120 \mathrm{kHz}$ transducer relative to the down-looking transducer in some portions of the water column (Figure 2.2). This discrepancy was particularly evident in low-scattering areas such as the northern portion of the survey area in fall, and much of the continental shelf during winter; in highscattering areas like Marguerite Bay, no such difference was evident. Furthermore, the enhanced volume backscattering in the up-looking data was restricted to the pycnocline and was especially prominent in regions of rapid vertical changes in density. We believe that these enhancements do not represent scattering from biological sources, but rather represent an as-yet unexplained artifact. They may result from sound scattering off vortices shed by the tow cable as it passes through the pycnocline. Since the tow cable extends above the towed body, only the up-looking transducer would observe such artifactual scattering. It therefore was excluded from all quantitative analyses, representing a $7 \%$ reduction in data (varying from 0 to $24 \%$ on a by-transect basis), primarily between depths of 0 and $200 \mathrm{~m}$. 

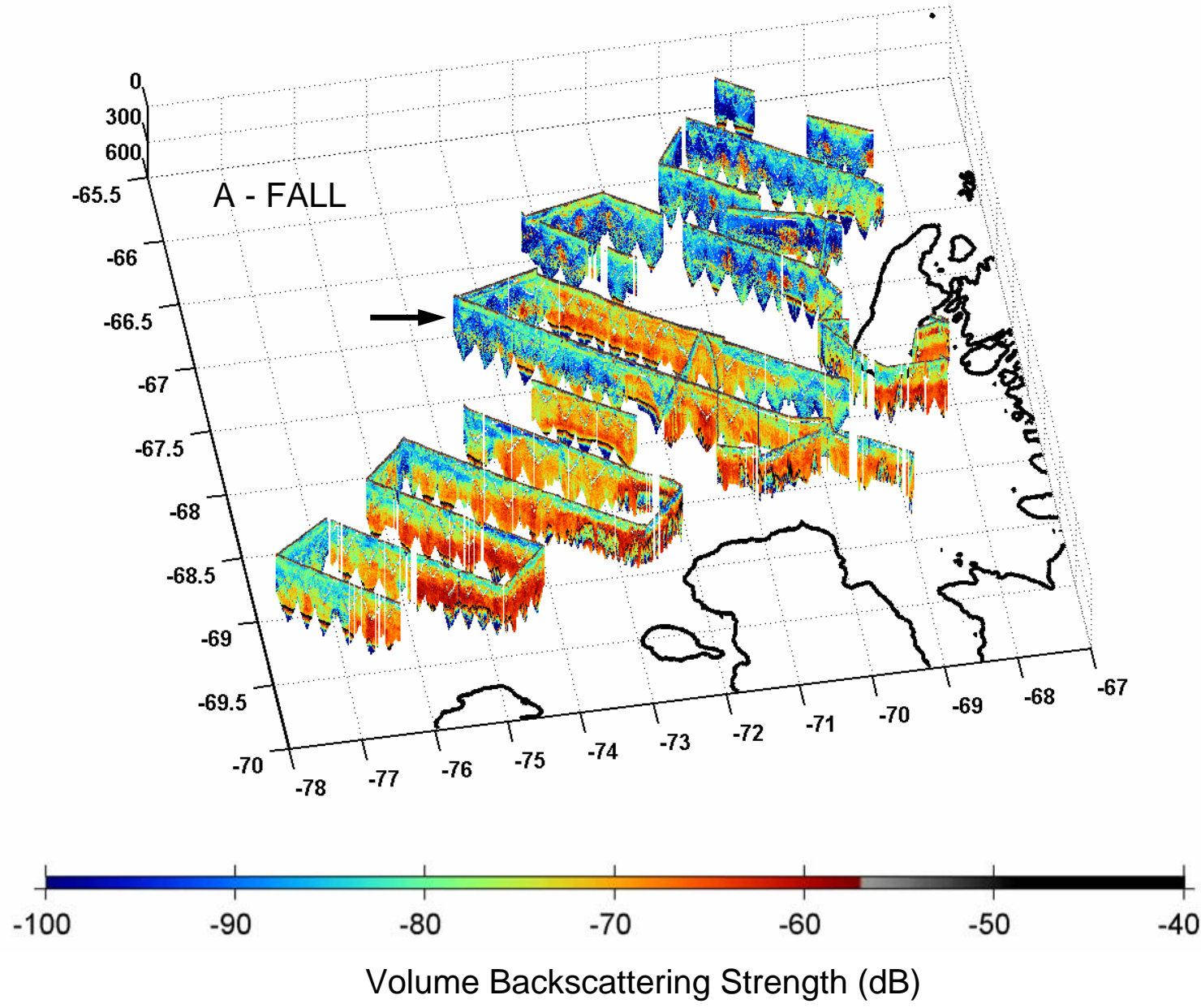

Figure 2.2 - Acoustic data collected in (A) fall and (B) winter of 2001. Volume backscattering strength is plotted on the color scale in decibels, according to the depth and position of measurement. Blue indicates low levels of zooplankton volume backscattering, while red to black indicate high levels. High volume backscattering near the surface corresponds to the surface bubble layer. Strong (i.e., black) returns at depth are from the strongly scattering bottom. Both the bottom and surface layer were edited out for quantitative analyses. The $\mathrm{V}$-shape of the maximum depth of observation is due to the BIOMAPER-II being towyoed up and down through the water column as the vessel proceeded along-track. Arrows indicate typical regions of the pycnocline where enhanced volume backscattering measured by the up-looking transducer (i.e., in the upper portion of the towyo's V) was believed to represent an artifact rather than scattering from biological sources. 


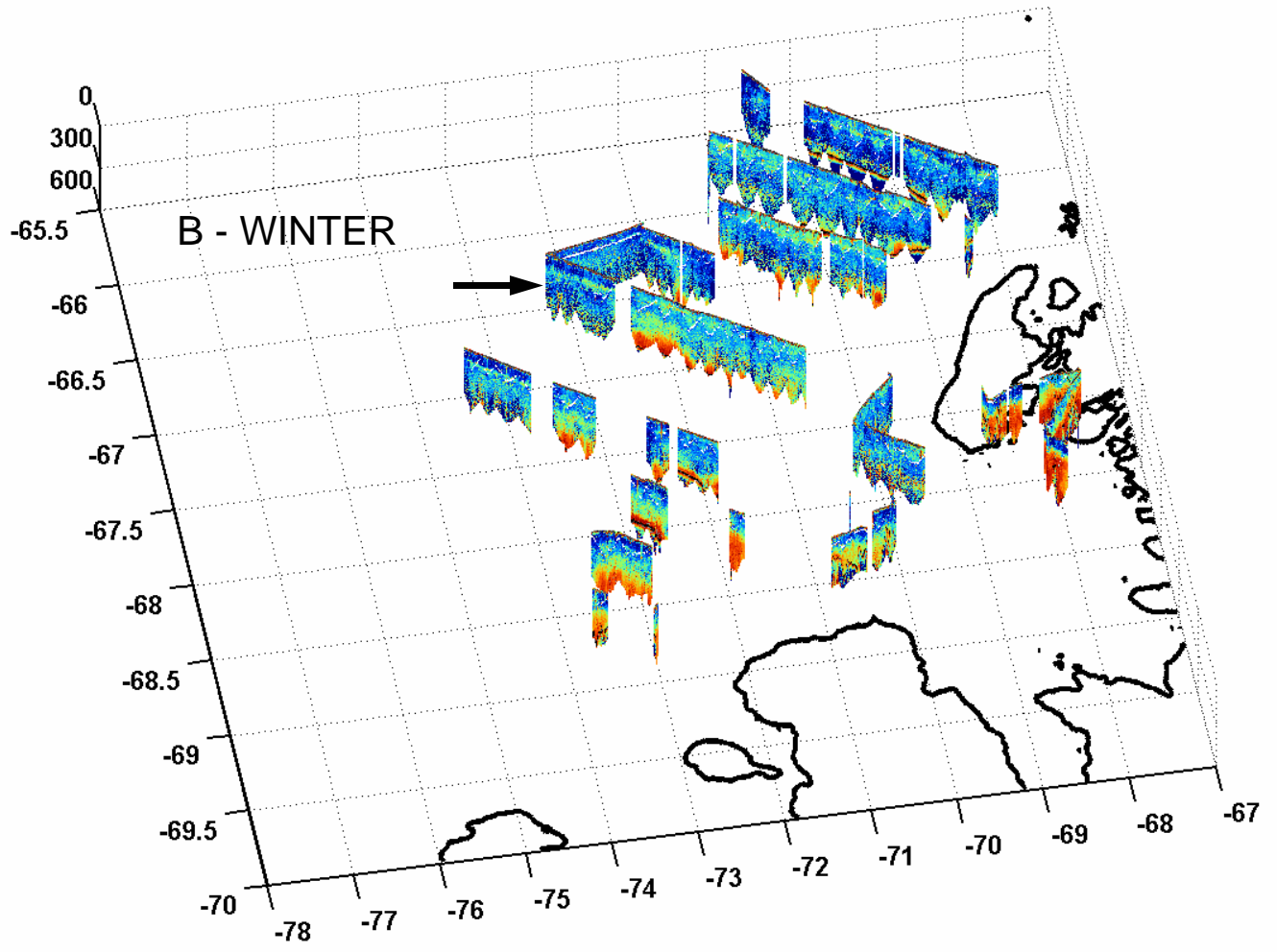

Figure 2.2 - continued 


\subsection{2.c Acoustic data post-processing}

Acoustic data from the up- and down-looking transducers were combined to provide a vertically-continuous acoustic record extending from the surface to a depth of at least 300 $\mathrm{m}$, and at most $550 \mathrm{~m}$, depending on the position of the BIOMAPER-II along its towyo path. This acoustic record then was edited using custom MATLAB-based routines to remove unwanted returns from the surface bubble layer and the bottom, as well as noise spikes from the ship's engines or ice-breaking.

For many of the following spatial analyses, measurements of volume backscattering in each $1.5-\mathrm{m}$ depth bin were averaged over 1-km along-track intervals and also over depth, in intervals of 25 to $100 \mathrm{~m}$ (shallow layer), 100 to $300 \mathrm{~m}$ (mid-water layer), and 300 to $500 \mathrm{~m}$ (deep layer). These depth ranges were chosen since the surface bubble layer obscured most measurements shallower than a depth of $25 \mathrm{~m}$, the mixed layer depth was generally around $100 \mathrm{~m}$, and $300 \mathrm{~m}$ represents the depth to which the BIOMAPER-II always made acoustic observations despite being towyoed up and down through the water column. These averages, as well as all other simple descriptive statistics, were performed on the arithmetic quantity of the volume backscattering coefficient $\left(s_{v}\right)$. The arithmetic form also was used in between-block statistical comparisons, since the tests employed were rank-based (see below) and so insensitive to whether the data were transformed or not. The logarithmic quantity of the volume backscattering strength $\left(S_{v}\right)$ was used in regression analyses, since this test is parametric and the log-transformed data better approximated a normal distribution. The decibel form is also used in figures and in the text.

\subsubsection{Environmental analyses}

Acoustic data were combined with environmental data to examine the association of volume backscattering with environmental properties and water masses. Depth, temperature, conductivity, fluorescence, and transmissometry data were collected by the 
BIOMAPER-II along its towyo path at 4-second intervals. In order to provide details of the environmental structure at greater depths than sampled by the towed body, however, data from CTD casts made at the survey stations by Klinck et al. (2004) were used as the primary source for quantitative analyses. The CTD rosette package made measurements of salinity, fluorescence, transmittance, photosynthetically active radiation (PAR), potential temperature, and oxygen concentration at 1-m depth intervals from the surface to between 5 and $20 \mathrm{~m}$ off the bottom. In analyses of volume backscattering in relation to environmental conditions, each environmental measurement was associated with the acoustic measurement averaged in 1-km intervals made nearest to that depth and location.

\subsubsection{MOCNESS}

A 1- $\mathrm{m}^{2}$ Multiple Opening/Closing Net and Environmental Sensing System (MOCNESS; Wiebe et al., 1985) was used to sample the zooplankton at selected stations distributed throughout the survey grid (24 locations in fall and 17 in winter). The MOCNESS was equipped with nine $335 \mu \mathrm{m}$ mesh nets, a suite of environmental sensors including temperature, conductivity, fluorescence, and light transmission, and a strong strobe light, that flashed at 4-second intervals. The rationale behind the strobe system was to shock or blind the animals temporarily so that the net would not be perceived and avoided, and catches of large euphausiids were significantly enhanced when using the strobe (Sameoto et al., 1993; Wiebe et al., 2004). The MOCNESS was towed obliquely from near-bottom to the surface, sampling eight depth intervals on the up-cast. The deepest tows sampled to a depth of $1000 \mathrm{~m}$. Typically, the upper $100 \mathrm{~m}$ was sampled in $25-\mathrm{m}$ intervals, with $50-\mathrm{m}$ intervals at intermediate depth ranges, and greater intervals (150- or 200-m) for the deepest depth ranges (see Ashjian et al., 2004, for additional details). The depth-specific samples were preserved upon recovery in $4 \%$ buffered formalin.

The size distributions of plankton for six MOCNESS tows from each of the two cruises have been analyzed to date (Ashjian et al., 2004). Following the nomenclature of Ashjian et al. (2004), tow locations will be referred to as off-shelf, Marguerite Bay, and mid-shelf 
1 - 4 (Figure $2.1 \mathrm{c}, \mathrm{d}$ ). Note that no acoustic data were collected in the vicinity of the midshelf 4 site during winter. Lengths of individuals of each sampled taxon were determined for an aliquot of each net sample using the silhouette method of Davis and Wiebe (1985).

\subsubsection{Taxonomic composition of zooplankton and micronekton}

The ultimate goal of our research is to use VPR observations and taxon-specific differences in scattering at increasing frequencies, in addition to net catches, to partition accurately our measurements of volume backscattering among taxonomic groups, and then to make biomass estimates for each taxon. Here, we make preliminary inferences concerning the sources of acoustic volume backscattering measurements by conducting the forward problem: an exercise where predictions are made of expected volume backscattering strength based on MOCNESS catches and models of the scattering from individual sampled animals (Wiebe et al., 1996). By comparing these predictions to observed levels, it is possible to assess whether the animals collected by the nets could account for measured volume backscattering. Provided that this assessment is favorable, inferences can then be made about the likely relative contributions of different taxa to observed volume backscattering in the vicinity of each tow.

In addressing the forward problem, predicted volume backscattering for each depth stratum sampled by the MOCNESS was calculated as the linear (i.e., incoherent) sum of expected echo intensities from each captured animal. Expected echo intensities, or backscattering cross-sections $\left\langle\sigma_{\mathrm{bs}}\right\rangle$, were estimated based on the length of each individual determined by silhouette analysis and models of acoustic scattering appropriate to the individual's taxonomic group. These models were developed by Stanton et al. (1994, 1998), are reviewed in Stanton and Chu (2000), and are sensitive to numerous parameters in addition to animal length, including animal orientation and material properties (Chu et al., 2000a; Table 2.1). Discrete values were used for all parameters other than animal orientation (Table 2.1). For the latter, scattering from each animal was averaged over 
Table 2.1 (facing) - Scattering models employed in forward calculations of volume backscattering strength expected based on MOCNESS catches. Asterisks $(*)$ indicate those models that have been validated through comparisons of model predictions to laboratory measurements of scattering from the animal of interest; elsewhere, models were deemed appropriate on the basis of what is known about the animal's physical structure, but not on experimental verifications. DWBA denotes the Distorted Wave Born Approximation. Each model involves a number of parameters, describing the animal's shape, orientation, and acoustic material properties. The latter include the ratio of the animal's density to that of the surrounding water (g) and the ratio of the speed of sound in the animal to that in the surrounding water (h). Parameter values were drawn from a number of sources. All necessary shape parameters (e.g., length:width and length:volume ratios) were measured empirically for a sub-sample of captured animals from the present study region, or for similar species from the Gulf of Maine. An average backscattering cross-section was calculated for each animal, based on a distribution of orientations. Where there was little or no information available on orientation, a normal distribution with a mean of $0^{\circ}$ and a standard deviation of $30^{\circ}$ was assumed (i.e., $\mathrm{N}(0,30)$ ), where an angle of $0^{\circ}$ indicates sound striking the animal in dorsal aspect (i.e., normal acoustic incidence). The taxa listed constituted the majority of sampled animals. Certain rare taxa $(<3 \%$ of net abundance) were excluded from forward calculations; these included thecosome Styliola-like pteropods, foraminifera, larval polychaetes, and ctenophores. Sensitivity analyses using scattering models for taxa comparable to these rare animals suggested that they were very minor contributors to overall volume backscattering (not shown).

References:

(1) Equation (5) of Stanton et al. (1998), and see Stanton and Chu (2000) and references therein.

(2) Equation given in Stanton et al. (1994), p. 507.

(3) D. Chu. Unpublished Data

(4) D. Chu. and A. Lavery, Personal Communication; Fluid-filled sphere model is derived from Anderson (1950)

(5) Derived from Anderson (1950)

(6) Chu et al. (1993)

(7) D. Chu. Personal Communication

(8) Chu and Wiebe (2005). Measurements were performed only on animals larger than $20 \mathrm{~mm}$. For animals smaller than this length (e.g., the 'small euphausiid' category), the $\mathrm{g}$ and $\mathrm{h}$ predicted by the regression equations for a $20 \mathrm{~mm}$ animal were assumed to apply.

(9) Inferred for shrimp based on model-fits to direct observations by Stanton et al. (1994), and very comparable to values measured by Chu et al.

(2000b) for the decapod shrimp Palaemonetes vulgaris. Assumed here to also apply to certain other crustacean and crustacean-like taxa.

(10) Inferred based on model-fits to empirical observations, Stanton et al. (1994)

(11) Measured by Chu et al. (2003)

(12) Based on the density and sound speed of fused silica $\left(2.2 \mathrm{~g} \mathrm{~m}^{-3}\right.$ and $5968 \mathrm{~m} \mathrm{~s}^{-1}$, respectively), and assuming the speed of sound in seawater is 1500 $\mathrm{m} \mathrm{s}^{-1}$, and the density of seawater is $1.025 \mathrm{~g} \mathrm{~m}^{-3}$.

(13) Benfield et al. (2003); based on pressure-related increases in density and thereby $g$ in depth (Medwin and Clay, 1998). $g_{\text {surface }}$ is the density contrast for carbon monoxide at the surface (1 atmospheric pressure)

(14) Measured by Chu et al. (2000b) for Gulf of Maine calanoid copepods

(15) Sound speed contrast for carbon monoxide at surface pressure of 1 atmosphere 


\begin{tabular}{|c|c|c|c|c|}
\hline \multirow[b]{2}{*}{ TAXON } & \multirow[b]{2}{*}{$\begin{array}{l}\text { SCATTERING MODEL } \\
\text { (Reference in parentheses) }\end{array}$} & \multicolumn{3}{|c|}{ PARAMETER VALUES } \\
\hline & & $\begin{array}{l}\text { Orientation } \\
\text { (Ref.) }\end{array}$ & $\begin{array}{l}\text { Density contrast (g) } \\
\text { (Ref.) }\end{array}$ & $\begin{array}{l}\text { Sound speed contrast } \\
\text { (h) (Ref.) }\end{array}$ \\
\hline Copepods* & DWBA-Based Deformed Cylinder (1) & $\mathrm{N}(0,30)$ & $1.02(7)$ & $1.058(14)$ \\
\hline $\begin{array}{l}\text { Large Euphausiids* and } \\
\text { Mysids }(>15 \mathrm{~mm})\end{array}$ & $"$ & $\begin{array}{l}\mathrm{N}(20,20) \\
\quad(6)\end{array}$ & $\begin{array}{c}\mathrm{g}=5.485 \mathrm{e}-4 \times \mathrm{L}(\mathrm{mm})+ \\
1.002(8)\end{array}$ & $\begin{array}{c}\mathrm{h}=5.942 \mathrm{e}-4 \times \mathrm{L}(\mathrm{mm})+ \\
1.004(8)\end{array}$ \\
\hline $\begin{array}{l}\text { Small Euphausiids and } \\
\text { Mysids }(<15 \mathrm{~mm})\end{array}$ & $"$ & $\begin{array}{c}\mathrm{N}(20,20) \\
(6)\end{array}$ & $\begin{array}{c}1.016 \\
(8)\end{array}$ & $\begin{array}{c}1.019 \\
(8)\end{array}$ \\
\hline Amphipods & $"$ & $\mathrm{~N}(0,30)$ & $1.058(9)$ & $1.058(9)$ \\
\hline Chaetognaths, Polychaetes & $"$ & $\mathrm{~N}(0,30)$ & $1.03(7)$ & $1.03(7)$ \\
\hline Ostracods & $"$ & $\mathrm{~N}(0,30)$ & $1.03(7)$ & $1.03(7)$ \\
\hline Fish & $"$ & $\mathrm{~N}(0,30)$ & $1.03(7)$ & $1.03(7)$ \\
\hline Salps* & $"$ & $\mathrm{~N}(0,30)$ & $1.004(10)$ & $1.004(10)$ \\
\hline Gymnosome Pteropods & $"$ & $\mathrm{~N}(0,30)$ & $1.03(7)$ & $1.03(7)$ \\
\hline Larval Crustaceans & $"$ & $\mathrm{~N}(0,30)$ & $1.058(9)$ & $1.058(9)$ \\
\hline Eggs & High-Pass Fluid Sphere (2) & - & $0.979(11)$ & $1.017(11)$ \\
\hline Thecosome Pteropods* & $"$ & - & $1.732(10)$ & $1.732(10)$ \\
\hline Radiolarians & $"$ & - & $2.147(12)$ & $3.979(12)$ \\
\hline Medusae* & $\begin{array}{l}\text { DWBA-based Model of Two Oblate } \\
\text { Spheroidal Interfaces (3) }\end{array}$ & $\begin{array}{l}\text { Broad-side } \\
\text { only }\end{array}$ & $1.02(3)$ & $1.02(3)$ \\
\hline $\begin{array}{l}\text { Siphonophore Bracts and } \\
\text { Nectophores }\end{array}$ & $\begin{array}{l}\text { Scattering proportional to an equivalent- } \\
\text { volume fluid-filled sphere (4) }\end{array}$ & - & $1.02(7)$ & $1.02(7)$ \\
\hline $\begin{array}{c}\text { Siphonophore } \\
\text { Pneumatophores* }\end{array}$ & Carbon Monoxide-filled Sphere (5) & - & $\begin{array}{l}\mathrm{g}=\mathrm{g}_{\text {surf }}(1+0.1 \text { Depth }(\mathrm{m})) \\
\quad \text { where } \mathrm{g}_{\text {surf }}=0.0012(13)\end{array}$ & $0.22(15)$ \\
\hline
\end{tabular}


some distribution of orientations, to allow for the fact that the animals are oriented at a range of angles as they move through the water.

The calculations of the net-based forward problem involved summing estimates of expected backscattering cross-sections for each $\mathrm{j}^{\text {th }}$ individual over all individuals in each $i^{\text {th }}$ taxon and then over all taxa to yield an estimate of the total expected volume backscattering strength in the volume $(V)$ sampled by each $\mathrm{k}^{\text {th }}$ net:

$$
S_{v_{k}}=10 \log _{10}\left[\frac{1}{V_{k}} \sum \sum\left\langle\sigma_{b s}\right\rangle_{i j}\right]
$$

Since the BIOMAPER-II and the MOCNESS could not be towed concurrently, comparisons of predicted volume backscattering strength could not be made to observed levels made at the identical time and location. Comparisons were thus made to acoustic observations made in the same depth interval and averaged over a spatial area within no more than $17 \mathrm{~km}$ of each of the 11 MOCNESS tows. At all but two MOCNESS tow locations, acoustic data were collected within no more than five hours of the net tow as the vessel approached or departed the station. At the mid-shelf 1 and 2 stations in winter, however, MOCNESS tows and acoustic data collection were separated in time by approximately four weeks due to problems with the instruments malfunctioning. Predictions of volume backscattering from each taxon were still calculated based on these tows, in order to shed light on the sensitivity of the predicted to observed volume backscattering comparison to temporal variation.

\subsection{RESULTS}

Volume backscattering during fall generally was enhanced within Marguerite Bay and in the southern portion of the survey area (Figure 2.2a). Large sub-surface patches of 
intensified volume backscattering that stood out markedly from background scattering levels were observed primarily in coastal regions of complex bathymetry, and at depth in the northern portion of the continental shelf. The term 'patch' is used here to denote a recognizable feature in the acoustic record, but does not imply any particular aggregative behaviour on the part of the zooplankton or micronekton comprising these features. Smaller such patches also were evident within the mixed layer across the shelf. In winter, the most striking feature was a dramatic decrease in volume backscattering relative to fall levels throughout most of the water column (Figure 2.2b); volume backscattering in winter was high only within Marguerite Bay and in the bottom scattering layer, which was present on both cruises.

\subsubsection{Environmental setting}

The continental shelf in this region is characterized by intrusions of oceanic Circumpolar Deep Water (CDW; salinity (S) 34.6 to 34.74 , potential temperature $(\theta) 1.0$ to $2.0^{\circ} \mathrm{C}$ ), pumped up onto the shelf at depth by the action of the Antarctic Circumpolar Current (see Klinck et al., (2004) and Smith et al. (1999) for further water mass definitions and descriptions of hydrography). As this warm and salty CDW interacts with cooler and fresher shelf waters, it forms a water mass that has been referred to as modifiedCircumpolar Deep Water (mCDW, sensu Hofmann and Klinck (1998); S 34.0 to 34.6, $\theta$ 1.8 to $1.5^{\circ} \mathrm{C}$ ). Such $\mathrm{mCDW}$ was the primary water mass observed through the pycnocline and below in the study area, often with CDW present at greater depths (Table 2.2). During fall, the water column at shallow depths contained Antarctic Surface Water (AASW, Table $2.2 ; \mathrm{S} 33.0$ to $33.7, \theta-1.5$ to $1.0^{\circ} \mathrm{C}$ ). In winter, AASW was mostly replaced near the surface in all blocks by Winter Water (WW; S 33.8 to 34.1, $\theta-1.8$ to $\left.1.5^{\circ} \mathrm{C}\right)$. Water properties differed between regions. The $\mathrm{mCDW}$ found during fall in the more northern blocks farther away from the continent (i.e., farther 'offshore') was generally warmer and saltier (less-modified) than elsewhere in the study area, suggesting 
Table 2.2 - Between-block comparisons of environmental properties and mean volume backscattering. Mean potential temperature and salinity are shown, with standard deviations in parentheses. Mean, median, and coefficient of variation (CV) were all calculated on the basis of the arithmetic quantity of the volume backscattering coefficient, averaged over 1-km spatial intervals, and then over the three depth layers. Means and medians are presented in decibel form. Comparisons were made of mean day (D) and night (N) volume backscattering levels (dB). In some cases, no data (N.D.) were collected during one or the other of the day/night periods in a given block. Asterisks $(*)$ indicate instances where day volume backscattering within a given depth layer and block differed significantly $(\mathrm{p}<0.05)$ from night (Mann-Whitney non-parametric t-test equivalent, with significance levels Bonferroni-corrected for multiple tests). Note that the proportion of survey time conducted during the day or night varied between blocks and seasons.

FALL

\begin{tabular}{|c|c|c|c|c|c|c|c|c|c|c|c|c|}
\hline \multirow[t]{2}{*}{ Block } & \multicolumn{3}{|c|}{$\begin{array}{c}\text { Pot. Temperature } \\
\text { (Std Deviation) } \\
\end{array}$} & \multicolumn{3}{|c|}{$\begin{array}{c}\text { Salinity } \\
\text { (Std Deviation) } \\
\end{array}$} & \multicolumn{3}{|c|}{$\begin{array}{c}\text { Mean (dB), Med. (dB), CV of } \\
\text { Volume Backscattering } \\
\end{array}$} & \multicolumn{3}{|c|}{$\begin{array}{c}\text { Day vs. Night Mean } \\
\text { Volume Backscattering (dB) }\end{array}$} \\
\hline & $\begin{array}{c}25- \\
100 \mathrm{~m}\end{array}$ & $\begin{array}{l}100- \\
300 m\end{array}$ & $\begin{array}{c}300- \\
500 \mathrm{~m}\end{array}$ & $\begin{array}{c}25- \\
100 \mathrm{~m}\end{array}$ & $\begin{array}{c}100- \\
300 \mathrm{~m}\end{array}$ & $\begin{array}{c}300- \\
500 \mathrm{~m}\end{array}$ & $25-100 \mathrm{~m}$ & $100-300 \mathrm{~m}$ & $300-500 \mathrm{~m}$ & $\begin{array}{c}25- \\
100 \mathrm{~m}\end{array}$ & $\begin{array}{l}100- \\
300 \mathrm{~m}\end{array}$ & $\begin{array}{l}300- \\
500 \mathrm{~m}\end{array}$ \\
\hline $\begin{array}{l}\text { Northern } \\
\text { Outer-Shelf }\end{array}$ & $\begin{array}{l}-0.84 \\
(0.43)\end{array}$ & $\begin{array}{c}1.02 \\
(0.65)\end{array}$ & $\begin{array}{l}1.44 \\
(0.11)\end{array}$ & $\begin{array}{l}33.95 \\
(0.21)\end{array}$ & $\begin{array}{l}34.57 \\
(0.13)\end{array}$ & $\begin{array}{l}34.71 \\
(0.01)\end{array}$ & $\begin{array}{c}\text { Mean }-76.2 \\
\text { Med }-80.1 \\
\text { CV } 3.09\end{array}$ & $\begin{array}{l}\text { Mean }-70.9 \\
\text { Med }-76.1 \\
\text { CV } 1.33\end{array}$ & $\begin{array}{l}\text { Mean } 75.8 \\
\text { Med }-78.2 \\
\text { CV } 1.29\end{array}$ & $\begin{array}{l}D-74.4 \\
N-79.2\end{array}$ & $\begin{array}{l}D-70.5 \\
N-70.7\end{array}$ & $\begin{array}{l}\text { D }-74.3 \\
\text { N }-77.9\end{array}$ \\
\hline $\begin{array}{l}\text { Northern } \\
\text { Inner-Shelf }\end{array}$ & $\begin{array}{l}-0.33 \\
(0.50)\end{array}$ & $\begin{array}{c}0.70 \\
(0.62)\end{array}$ & $\begin{array}{l}1.37 \\
(0.05)\end{array}$ & $\begin{array}{l}33.74 \\
(0.25)\end{array}$ & $\begin{array}{l}34.45 \\
(0.23)\end{array}$ & $\begin{array}{l}34.69 \\
(0.02)\end{array}$ & $\begin{array}{c}\text { Mean }-78.6 \\
\text { Med }-79.7 \\
\text { CV } 0.76\end{array}$ & $\begin{array}{c}\text { Mean }-68.6 \\
\text { Med }-72.8 \\
\text { CV } 1.49\end{array}$ & $\begin{array}{c}\text { Mean }-71.0 \\
\text { Med }-73.6 \\
\text { CV 1.53 }\end{array}$ & $\begin{array}{l}\text { D }-79.4 \\
N-78.0\end{array}$ & $\begin{array}{l}\text { D }-69.1 \\
\text { N }-68.5\end{array}$ & $\begin{array}{l}\text { D }-72.6 \\
N-70.8\end{array}$ \\
\hline $\begin{array}{l}\text { Central } \\
\text { Outer-Shelf }\end{array}$ & $\begin{array}{l}-1.02 \\
(0.26)\end{array}$ & $\begin{array}{c}0.68 \\
(0.81)\end{array}$ & $\begin{array}{l}1.47 \\
(0.08)\end{array}$ & $\begin{array}{l}33.92 \\
(0.19)\end{array}$ & $\begin{array}{l}34.51 \\
(0.16)\end{array}$ & $\begin{array}{l}34.70 \\
(0.01)\end{array}$ & $\begin{array}{c}\text { Mean }-72.2 \\
\text { Med }-73.2 \\
\text { CV } 0.88\end{array}$ & $\begin{array}{l}\text { Mean }-69.7 \\
\text { Med }-70.1 \\
\text { CV } 0.78\end{array}$ & $\begin{array}{l}\text { Mean }-67.8 \\
\text { Med }-68.4 \\
\text { CV } 0.72\end{array}$ & $\begin{array}{l}\text { D }-72.4^{*} \\
N-71.8\end{array}$ & $\begin{array}{l}\text { D }-70.1^{*} \\
N-69.4\end{array}$ & $\begin{array}{l}\text { D }-69.5^{*} \\
\text { N }-67.2\end{array}$ \\
\hline $\begin{array}{l}\text { Central } \\
\text { Inner-Shelf }\end{array}$ & $\begin{array}{l}-0.44 \\
(0.44)\end{array}$ & $\begin{array}{c}0.49 \\
(0.55)\end{array}$ & $\begin{array}{c}1.27 \\
(0.13)\end{array}$ & $\begin{array}{l}33.74 \\
(0.23)\end{array}$ & $\begin{array}{l}34.38 \\
(0.23)\end{array}$ & $\begin{array}{l}34.67 \\
(0.04)\end{array}$ & $\begin{array}{l}\text { Mean }-74.7 \\
\text { Med }-77.5 \\
\text { CV } 0.86\end{array}$ & $\begin{array}{l}\text { Mean }-64.6 \\
\text { Med }-71.2 \\
\text { CV } 4.52\end{array}$ & $\begin{array}{c}\text { Mean }-68.3 \\
\text { Med }-72.8 \\
\text { CV } 2.71\end{array}$ & $\begin{array}{l}\text { D -72.0* } \\
\text { N -76.4 }\end{array}$ & $\begin{array}{l}\text { D }-59.2^{*} \\
N-70.8\end{array}$ & $\begin{array}{l}\text { D }-65.1^{*} \\
N-71.0\end{array}$ \\
\hline $\begin{array}{l}\text { Southern } \\
\text { Outer-Shelf }\end{array}$ & $\begin{array}{l}-1.24 \\
(0.30)\end{array}$ & $\begin{array}{c}0.09 \\
(0.95)\end{array}$ & $\begin{array}{c}1.31 \\
(0.17)\end{array}$ & $\begin{array}{l}33.75 \\
(0.22)\end{array}$ & $\begin{array}{l}34.40 \\
(0.19)\end{array}$ & $\begin{array}{l}34.68 \\
(0.03)\end{array}$ & $\begin{array}{c}\text { Mean }-75.2 \\
\text { Med }-76.7 \\
\text { CV } 0.85\end{array}$ & $\begin{array}{l}\text { Mean }-69.6 \\
\text { Med }-70.6 \\
\text { CV } 0.90\end{array}$ & $\begin{array}{l}\text { Mean }-67.8 \\
\text { Med }-69.1 \\
\text { CV } 0.88\end{array}$ & $\begin{array}{l}\text { D -76.8* } \\
N-74.7\end{array}$ & $\begin{array}{l}\text { D }-70.4 \\
\text { N }-69.2\end{array}$ & $\begin{array}{l}\text { D }-68.4 \\
\text { N }-67.5\end{array}$ \\
\hline $\begin{array}{l}\text { Southern } \\
\text { Inner-Shelf }\end{array}$ & $\begin{array}{l}-0.99 \\
(0.29)\end{array}$ & $\begin{array}{l}-0.20 \\
(0.64)\end{array}$ & $\begin{array}{c}0.91 \\
(0.16)\end{array}$ & $\begin{array}{l}33.52 \\
(0.23)\end{array}$ & $\begin{array}{l}34.23 \\
(0.23)\end{array}$ & $\begin{array}{l}34.58 \\
(0.05)\end{array}$ & $\begin{array}{c}\text { Mean }-71.0 \\
\text { Med }-74.0 \\
\text { CV } 2.42\end{array}$ & $\begin{array}{l}\text { Mean }-59.9 \\
\text { Med }-63.5 \\
\text { CV } 2.03\end{array}$ & $\begin{array}{l}\text { Mean }-64.2 \\
\text { Med }-64.1 \\
\text { CV } 0.46\end{array}$ & $\begin{array}{l}\text { D -73.0 } \\
\text { N -70.3 }\end{array}$ & $\begin{array}{l}D-56.4 \\
N-62.9\end{array}$ & $\begin{array}{l}\text { D }-64.4 \\
\text { N }-64.1\end{array}$ \\
\hline $\begin{array}{l}\text { Marguerite } \\
\text { Bay }\end{array}$ & $\begin{array}{l}-0.42 \\
(0.27)\end{array}$ & $\begin{array}{c}0.38 \\
(0.44)\end{array}$ & $\begin{array}{c}1.07 \\
(0.13)\end{array}$ & $\begin{array}{l}33.48 \\
(0.09)\end{array}$ & $\begin{array}{l}34.28 \\
(0.29)\end{array}$ & $\begin{array}{l}34.61 \\
(0.04)\end{array}$ & $\begin{array}{c}\text { Mean }-71.4 \\
\text { Med }-75.1 \\
\text { CV } 1.88\end{array}$ & $\begin{array}{c}\text { Mean }-67.4 \\
\text { Med }-67.6 \\
\text { CV } 0.49\end{array}$ & $\begin{array}{l}\text { Mean }-65.4 \\
\text { Med }-65.5 \\
\text { CV } 1.31\end{array}$ & $\begin{array}{l}\text { D -77.4 } \\
\text { N -71.2 }\end{array}$ & $\begin{array}{l}D-71.4 \\
N-67.4\end{array}$ & $\begin{array}{l}\text { D N.D. } \\
\text { N }-65.3\end{array}$ \\
\hline Off-shelf & $\begin{array}{l}-1.05 \\
(0.53)\end{array}$ & $\begin{array}{c}1.11 \\
(1.03)\end{array}$ & $\begin{array}{c}1.78 \\
(0.20)\end{array}$ & $\begin{array}{l}33.92 \\
(0.19)\end{array}$ & $\begin{array}{l}34.51 \\
(0.15)\end{array}$ & $\begin{array}{l}34.69 \\
(0.02)\end{array}$ & $\begin{array}{l}\text { Mean }-78.9 \\
\text { Med }-79.2 \\
\text { CV } 0.61\end{array}$ & $\begin{array}{l}\text { Mean }-73.2 \\
\text { Med }-77.0 \\
\text { CV } 1.25\end{array}$ & $\begin{array}{c}\text { Mean }-74.9 \\
\text { Med }-77.6 \\
\text { CV } 0.46\end{array}$ & $\begin{array}{l}\text { D - } 77.7^{*} \\
N-79.8\end{array}$ & $\begin{array}{l}D-77.2 \\
N-72.3\end{array}$ & $\begin{array}{l}\text { D }-73.7 \\
N-76.0\end{array}$ \\
\hline
\end{tabular}


WINTER

\begin{tabular}{|c|c|c|c|c|c|c|c|c|c|c|c|c|}
\hline \multirow[t]{2}{*}{ Block } & \multicolumn{3}{|c|}{$\begin{array}{l}\text { Pot. Temperature } \\
\text { (Std Deviation) } \\
\end{array}$} & \multicolumn{3}{|c|}{$\begin{array}{c}\text { Salinity } \\
\text { (Std Deviation) } \\
\end{array}$} & \multicolumn{3}{|c|}{$\begin{array}{c}\text { Mean (dB), Med. (dB), and CV of } \\
\text { Volume Backscattering }\end{array}$} & \multicolumn{3}{|c|}{$\begin{array}{c}\text { Day vs. Night Mean } \\
\text { Volume Backscattering (dB) } \\
\end{array}$} \\
\hline & $\begin{array}{c}25- \\
100 \mathrm{~m}\end{array}$ & $\begin{array}{c}100- \\
300 \mathrm{~m}\end{array}$ & $\begin{array}{l}300- \\
500 \mathrm{~m}\end{array}$ & $\begin{array}{c}25- \\
100 \mathrm{~m}\end{array}$ & $\begin{array}{l}100- \\
300 \mathrm{~m}\end{array}$ & $\begin{array}{l}300- \\
500 \mathrm{~m}\end{array}$ & $25-100 \mathrm{~m}$ & $100-300 \mathrm{~m}$ & $300-500 \mathrm{~m}$ & $\begin{array}{c}25- \\
100 \mathrm{~m}\end{array}$ & $\begin{array}{l}100- \\
300 \mathrm{~m}\end{array}$ & $\begin{array}{l}300- \\
500 \mathrm{~m}\end{array}$ \\
\hline $\begin{array}{l}\text { Northern } \\
\text { Outer-Shelf }\end{array}$ & $\begin{array}{l}-1.70 \\
(0.30)\end{array}$ & $\begin{array}{c}0.90 \\
(0.79)\end{array}$ & $\begin{array}{l}1.49 \\
(0.14)\end{array}$ & $\begin{array}{l}33.96 \\
(0.07)\end{array}$ & $\begin{array}{l}34.22 \\
(0.16)\end{array}$ & $\begin{array}{l}34.71 \\
(0.02)\end{array}$ & $\begin{array}{l}\text { Mean }-79.9 \\
\text { Med }-83.5 \\
\text { CV } 2.74\end{array}$ & $\begin{array}{l}\text { Mean }-82.7 \\
\text { Med }-83.4 \\
\text { CV } 0.66\end{array}$ & $\begin{array}{l}\text { Mean }-73.9 \\
\text { Med }-77.3 \\
\text { CV } 1.39\end{array}$ & $\begin{array}{l}\text { D - }-82.9^{*} \\
\text { N }-78.8\end{array}$ & $\begin{array}{l}\text { D -83.6* } \\
N-82.3\end{array}$ & $\begin{array}{l}\text { D }-74.0 \\
N-73.7\end{array}$ \\
\hline $\begin{array}{l}\text { Northern } \\
\text { Inner-Shelf }\end{array}$ & $\begin{array}{l}-1.08 \\
(0.84)\end{array}$ & $\begin{array}{c}0.77 \\
(0.58)\end{array}$ & $\begin{array}{l}1.45 \\
(0.04)\end{array}$ & $\begin{array}{l}33.98 \\
(0.17)\end{array}$ & $\begin{array}{l}34.49 \\
(0.16)\end{array}$ & $\begin{array}{l}34.69 \\
(0.01)\end{array}$ & $\begin{array}{l}\text { Mean }-84.2 \\
\text { Med }-86.9 \\
\text { CV } 1.10\end{array}$ & $\begin{array}{l}\text { Mean }-81.5 \\
\text { Med }-85.5 \\
\text { CV } 1.64\end{array}$ & $\begin{array}{l}\text { Mean }-74.2 \\
\text { Med }-74.7 \\
\text { CV } 0.72\end{array}$ & $\begin{array}{l}\text { D }-84.3 \\
\text { N }-83.9\end{array}$ & $\begin{array}{l}\text { D }-86.2 \\
\text { N }-79.9\end{array}$ & $\begin{array}{l}\text { D }-74.9 \\
N-72.1\end{array}$ \\
\hline $\begin{array}{l}\text { Central } \\
\text { Outer-Shelf }\end{array}$ & $\begin{array}{l}-1.51 \\
(0.40)\end{array}$ & $\begin{array}{c}0.78 \\
(0.65)\end{array}$ & $\begin{array}{c}1.36 \\
(0.06)\end{array}$ & $\begin{array}{l}33.92 \\
(0.12)\end{array}$ & $\begin{array}{l}34.53 \\
(0.16)\end{array}$ & $\begin{array}{l}34.70 \\
(0.05)\end{array}$ & $\begin{array}{l}\text { Mean }-83.4 \\
\text { Med }-84.5 \\
\text { CV } 1.07\end{array}$ & $\begin{array}{l}\text { Mean }-78.6 \\
\text { Med }-79.4 \\
\text { CV } 0.68\end{array}$ & $\begin{array}{c}\text { Mean }-65.7 \\
\text { Med }-65.9 \\
\text { CV } 0.45\end{array}$ & $\begin{array}{l}\text { D -87.2* } \\
\text { N -83.0 }\end{array}$ & $\begin{array}{l}\text { D }-79.1 \\
\text { N -78.0 }\end{array}$ & $\begin{array}{l}\text { D N.D. } \\
\text { N }-65.5\end{array}$ \\
\hline $\begin{array}{l}\text { Central } \\
\text { Inner-Shelf }\end{array}$ & $\begin{array}{l}-1.50 \\
(0.39)\end{array}$ & $\begin{array}{c}0.80 \\
(0.66)\end{array}$ & $\begin{array}{l}1.38 \\
(0.04)\end{array}$ & $\begin{array}{l}33.90 \\
(0.11)\end{array}$ & $\begin{array}{l}34.52 \\
(0.17)\end{array}$ & $\begin{array}{l}34.70 \\
(0.01)\end{array}$ & $\begin{array}{c}\text { Mean -78.4 } \\
\text { Med -84.8 } \\
\text { CV } 4.66\end{array}$ & $\begin{array}{c}\text { Mean }-77.6 \\
\text { Med -80.8 } \\
\text { CV } 1.92\end{array}$ & $\begin{array}{c}\text { Mean }-74.6 \\
\text { Med -77.6 } \\
\text { CV } 0.94\end{array}$ & $\begin{array}{l}\text { D -83.5* } \\
\text { N -75.5 }\end{array}$ & $\begin{array}{l}\text { D -74.1 } \\
\text { N -79.2 }\end{array}$ & $\begin{array}{l}\text { D }-71.1 \\
\text { N }-76.9\end{array}$ \\
\hline $\begin{array}{l}\text { Southern } \\
\text { Outer-Shelf }\end{array}$ & $\begin{array}{l}-1.68 \\
(0.22)\end{array}$ & $\begin{array}{c}0.31 \\
(0.68)\end{array}$ & $\begin{array}{c}1.24 \\
(0.08)\end{array}$ & $\begin{array}{l}33.79 \\
(0.07)\end{array}$ & $\begin{array}{l}34.40 \\
(0.20)\end{array}$ & $\begin{array}{l}34.67 \\
(0.02)\end{array}$ & $\begin{array}{c}\text { Mean }-88.4 \\
\text { Med -91.5 } \\
\text { CV 1.18 }\end{array}$ & $\begin{array}{c}\text { Mean }-73.0 \\
\text { Med }-75.7 \\
\text { CV } 1.00\end{array}$ & $\begin{array}{c}\text { Mean }-61.8 \\
\text { Med }-61.2 \\
\text { CV } 0.47\end{array}$ & $\begin{array}{l}\text { D }-91.2 \\
\text { N }-85.6\end{array}$ & $\begin{array}{l}\text { D }-76.1 \\
N-69.1\end{array}$ & $\begin{array}{l}\text { D -62.3 } \\
\text { N N.D. }\end{array}$ \\
\hline $\begin{array}{l}\text { Southern } \\
\text { Inner-Shelf }\end{array}$ & $\begin{array}{l}-1.62 \\
(0.22)\end{array}$ & - & - & $\begin{array}{l}33.78 \\
(0.05)\end{array}$ & - & - & $\begin{array}{c}\text { Mean }-81.6 \\
\text { Med }-80.6 \\
\text { CV } 0.72\end{array}$ & $\begin{array}{c}\text { Mean }-71.0 \\
\text { Med }-71.1 \\
\text { CV } 0.42\end{array}$ & $\begin{array}{c}\text { Mean }-67.2 \\
\text { Med }-67.8 \\
\text { CV } 0.80\end{array}$ & $\begin{array}{l}\text { D N.D. } \\
\text { N -81.6 }\end{array}$ & $\begin{array}{l}\text { D N.D. } \\
\text { N -71.0 }\end{array}$ & $\begin{array}{l}\text { D N.D. } \\
\text { N }-67.2\end{array}$ \\
\hline $\begin{array}{l}\text { Marguerite } \\
\text { Bay }\end{array}$ & $\begin{array}{l}-1.54 \\
(0.35)\end{array}$ & $\begin{array}{c}0.53 \\
(0.58)\end{array}$ & $\begin{array}{l}1.16 \\
(0.04)\end{array}$ & $\begin{array}{l}33.70 \\
(0.12)\end{array}$ & $\begin{array}{l}34.39 \\
(0.24)\end{array}$ & $\begin{array}{l}34.64 \\
(0.01)\end{array}$ & $\begin{array}{c}\text { Mean }-78.6 \\
\text { Med }-82.5 \\
\text { CV } 1.18\end{array}$ & $\begin{array}{c}\text { Mean }-64.5 \\
\text { Med }-64.5 \\
\text { CV } 0.57\end{array}$ & $\begin{array}{c}\text { Mean }-61.3 \\
\text { Med }-61.7 \\
\text { CV } 0.59\end{array}$ & $\begin{array}{l}\text { D - } 85.7^{*} \\
\text { N }-76.9\end{array}$ & $\begin{array}{l}\text { D }-64.5 \\
\text { N }-64.2\end{array}$ & $\begin{array}{l}\text { D }-62.3 \\
\text { N }-60.5\end{array}$ \\
\hline Off-shelf & $\begin{array}{l}-1.56 \\
(0.76)\end{array}$ & $\begin{array}{c}0.77 \\
(1.15)\end{array}$ & $\begin{array}{c}1.71 \\
(0.22)\end{array}$ & $\begin{array}{l}33.97 \\
(0.12)\end{array}$ & $\begin{array}{l}34.47 \\
(0.20)\end{array}$ & $\begin{array}{l}34.69 \\
(0.04)\end{array}$ & $\begin{array}{c}\text { Mean }-83.7 \\
\text { Med }-85.2 \\
\text { CV 1.95 }\end{array}$ & $\begin{array}{c}\text { Mean }-82.6 \\
\text { Med }-82.6 \\
\text { CV } 0.45\end{array}$ & $\begin{array}{c}\text { Mean }-78.7 \\
\text { Med }-79.5 \\
\text { CV } 0.53\end{array}$ & $\begin{array}{l}\text { D -85.2* } \\
N-82.1\end{array}$ & $\begin{array}{l}\text { D -83.5* } \\
\text { N -81.8 }\end{array}$ & $\begin{array}{l}\text { D }-78.5 \\
\text { N }-80.8\end{array}$ \\
\hline
\end{tabular}


more recent intrusions of CDW onto the shelf. The more coastal regions typically had warmer and fresher AASW present at shallow depths, particularly in Marguerite Bay.

\subsubsection{Vertical distribution of volume backscattering}

Seasonal and spatial differences were observed in the vertical distribution of mean volume backscattering (Figure 2.3). In fall, volume backscattering was strongest between depths of 150 and $450 \mathrm{~m}$ in all of the inner-shelf and southern blocks. Scattering in the northern and central outer-shelf blocks was more constant with depth. A slight enhancement in volume backscattering was observed in all blocks at shallower depths (15 to $95 \mathrm{~m}$, depending on block), corresponding to the influence of episodic patches of high volume backscattering present within the mixed layer. The decrease from fall to winter was also evident in the vertical distribution of volume backscattering. Volume backscattering throughout the upper $300 \mathrm{~m}$ of the water column in winter was very low in all blocks except Marguerite Bay and the two southern blocks. Below $300 \mathrm{~m}$ depth, however, volume backscattering generally increased rapidly, and in all but one block reached levels higher than those observed at comparable depths during fall. This increase at depth was due to the influence of the deep scattering layer associated with the bottom, which was present during both surveys, but more intense in winter (Figure 2.2).

\subsubsection{Horizontal distribution of volume backscattering}

The horizontal distribution of volume backscattering was examined via comparisons between geographically-defined spatial blocks and spatial interpolations of volume backscattering data between transect lines using kriging (Chu, 2000; Figure 2.4). Since the goal of this interpolation was simply to present the data in a fashion that allowed visual identification of patterns, kriging was done on the logarithmic form of volume backscattering strength. During fall, volume backscattering in the mid-water (100 - 300 $\mathrm{m})$ and bottom (300 - $500 \mathrm{~m}$ ) depth ranges spatially averaged over 1-km intervals differed significantly between survey blocks (Kruskal-Wallis non-parametric one-way analysis of 


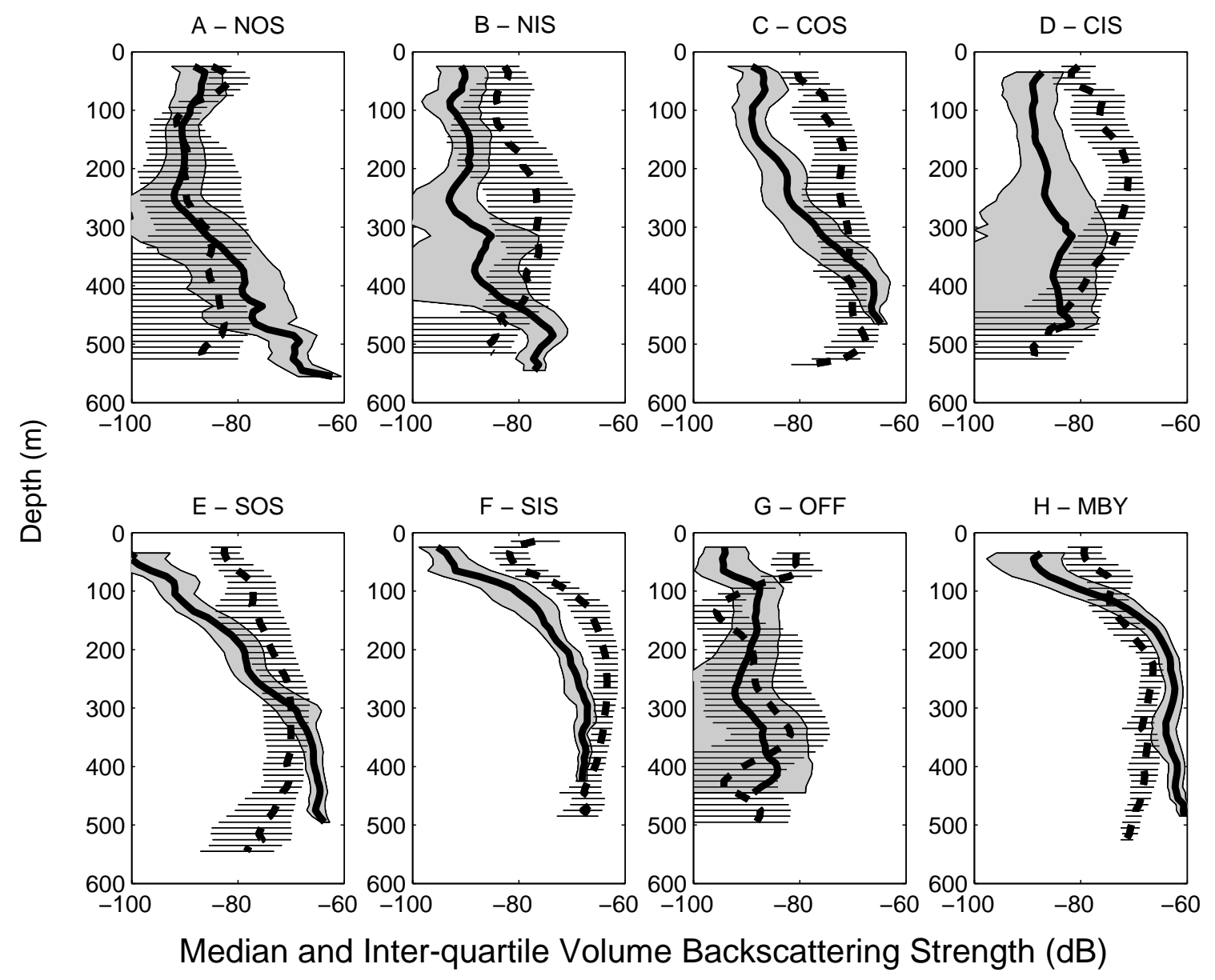

Figure 2.3 - Vertical distribution of volume backscattering strength $(\mathrm{dB})$ in each survey block, during fall (dashed line) and winter (solid line), in the (A) Northern Outer-Shelf, (B) Northern Inner-Shelf, (C) Central Outer-Shelf, (D) Central Inner-Shelf, (E) Southern Outer-Shelf, (F) Southern Inner-Shelf, (G) Off-Shelf, and (H) Marguerite Bay blocks. Block name abbreviations are as in Figure 2.1. Median and inter-quartile range (indicated by error bars) were calculated in 10-m depth intervals over all observations in each block, on the basis of the volume backscattering coefficient, and are displayed here in the logarithmic form of the volume backscattering strength. 
Figure 2.4 (facing) - Interpolated volume backscattering strength during fall and winter. Data used for interpolations are the volume backscattering levels averaged over 1-km along-track intervals; averages were performed on the arithmetic quantity of the volume backscattering coefficient.

(a,b) Interpolated volume backscattering 100-300 m. Overlain are contours of bathmetry, showing the 450 and $1000 \mathrm{~m}$ isobaths.

(c,d) Interpolated volume backscattering 300-500 m, with bathymetric contours again overlain.

(e,f) Interpolated volume backscattering 100-300 m. Overlain are contours of dynamic height (from Klinck et al., this issue) relative to $400 \mathrm{~m}$. Lows (L) and highs (H) in dynamic topography are indicated, and arrows show the direction of geostrophic flow. (g,h) Interpolated volume backscattering 25-100 m, with dynamic height contours overlain. 
FALL
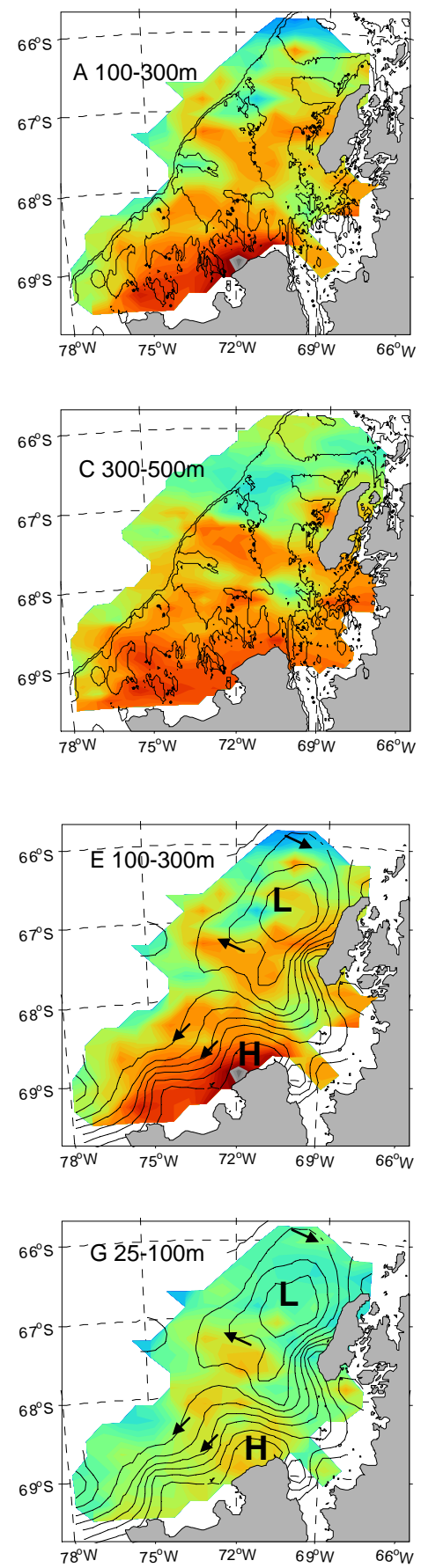

WINTER
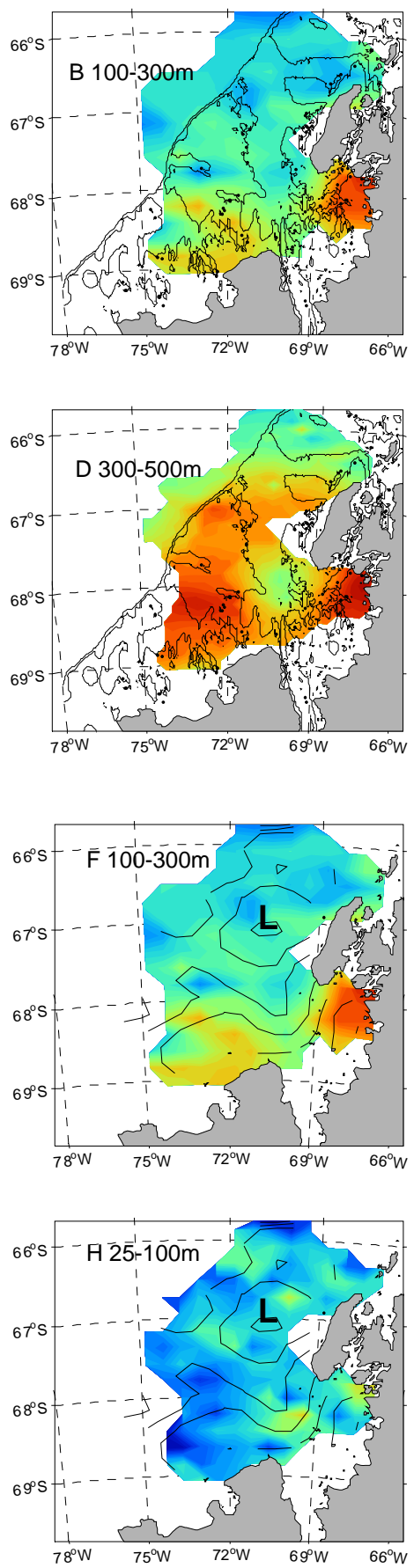

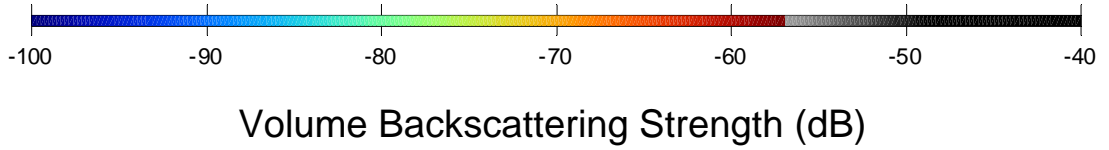


variance (Sokal and Rohlf, 2000), $\chi^{2}=809, \mathrm{p}<0.001, \mathrm{n}=1932$, and $\chi^{2}=573, \mathrm{p}<0.001$, $\mathrm{n}=1030$, respectively; Table 2.2), with highest levels in the southern inner-shelf and Marguerite Bay and lowest off-shelf (Tukey-Kramer post-hoc tests (Sokal and Rohlf, $2000), \mathrm{p}<0.05)$. Within the shallow layer $(25-100 \mathrm{~m})$, volume backscattering was reduced relative to the deeper layers, but showed similar enhancements in coastal areas, as well as significant differences between blocks $\left(\chi^{2}=367, \mathrm{p}<0.001, \mathrm{n}=1385\right)$.

Marguerite Trough is the deep trough that cuts diagonally across the continental shelf, meeting the shelf break at approximately $66.5^{\circ} \mathrm{S}$ (Figures $2.1 \mathrm{c}, \mathrm{d}$ and $2.4 \mathrm{a}, \mathrm{c}$ ); interpolations show that volume backscattering at depth was very low in the vicinity of this meeting point. A second trough meets the shelf break at approximately $67.75^{\circ} \mathrm{S}$ (Figure $2.1 \mathrm{c}, \mathrm{d}$ ). Mean volume backscattering near this point was very low in the 100 to $300 \mathrm{~m}$ depth range, and reduced relative to nearby levels in the 300 to $500 \mathrm{~m}$ range. Hydrographic observations suggest that CDW intrudes on to the shelf at these locations (Figure 9 in Klinck et al., 2004; Dinniman and Klinck, 2004); the low observed volume backscattering levels are suggestive of low zooplankton biomass in these recently intruded waters. Contours of dynamic height relative to $400 \mathrm{~m}$ calculated by Klinck et al. (2004) indicate a cyclonic gyre situated in the northern portion of the survey area, and a coastal current moving along the shelf towards the southwest (Figure 2.4e). Enhanced volume backscattering was evident in all three depth ranges at the southern end of this gyre, where water was flowing in an off-shelf direction. Scattering was also enhanced in the vicinity of the coastal current off Alexander Island.

In winter, mean volume backscattering decreased by an order of magnitude (i.e., $\sim 10 \mathrm{~dB}$ ) relative to fall levels within the shallow and middle depth layers, except in the mid-water layer of Marguerite Bay (Figure 2.4b,h and Table 2.2; Friedman non-parametric two-way analysis of variance test for the effect of season (Sokal and Rohlf, 2000), shallow layer: $\chi^{2}=8, p=0.005$, mid-water layer: $\chi^{2}=4.5, p=0.03$ ). Significantly different scattering between blocks (Kruskal-Wallis test, $\chi^{2}=510, \mathrm{p}<0.001, \mathrm{n}=748$ ) was driven primarily by high scattering in Marguerite Bay and low scattering in the northern and off-shelf 
blocks (Tukey-Kramer post-hoc tests, $\mathrm{p}<0.05)$. In the bottom layer $(300-500 \mathrm{~m}$; Figure $2.4 \mathrm{~d}$ ), volume backscattering was high over much of the continental shelf, as well as within Marguerite Bay, and did not differ between blocks (Friedman test non-significant; Table 2.2). Volume backscattering levels during winter showed less of a clear association with the deep troughs across the shelf (Figure 2.4b,d). Although there was still evidence from dynamic topography of a weakened gyre in the northern portion of the survey area and a coastal current, there was little evidence of any enhanced volume backscattering at depth associated with these features (Figure 2.4f,h).

\subsection{3.a Potential impact of vertical migrations on horizontal patterns}

In order to determine whether the observed trends in horizontal distribution were confounded by diel vertical migration of the zooplankton responsible for measured volume backscattering, mean daytime and nighttime levels in each block were compared within the shallow (25 - $100 \mathrm{~m})$, mid-water (100 - $300 \mathrm{~m})$, and deep (300 - $500 \mathrm{~m})$ layers. Day was defined as 0900 to 1500 , and night as 1700 to 0700 , with dawn and dusk excluded from analysis in order to examine solely whether day or night volume backscattering differed from one another. If the zooplankton were migrating upwards at night one might expect to see an increase in volume backscattering in the shallower depth layers from day to night, associated with decreases in the deeper strata. No such pattern consistent with diel vertical migration was observed: comparable volume backscattering levels were measured in each layer during both day and night in most blocks (Table 2.2; Mann-Whitney tests $\mathrm{p}>0.05)$.

\subsubsection{Volume backscattering relative to water masses}

The association between volume backscattering and particular water masses was explored using observations of potential temperature and salinity from CTD casts (Figure 2.5). During fall, highest volume backscattering levels (averaged in 1-km intervals) were associated with modified-CDW. Episodic high values of volume backscattering also were 

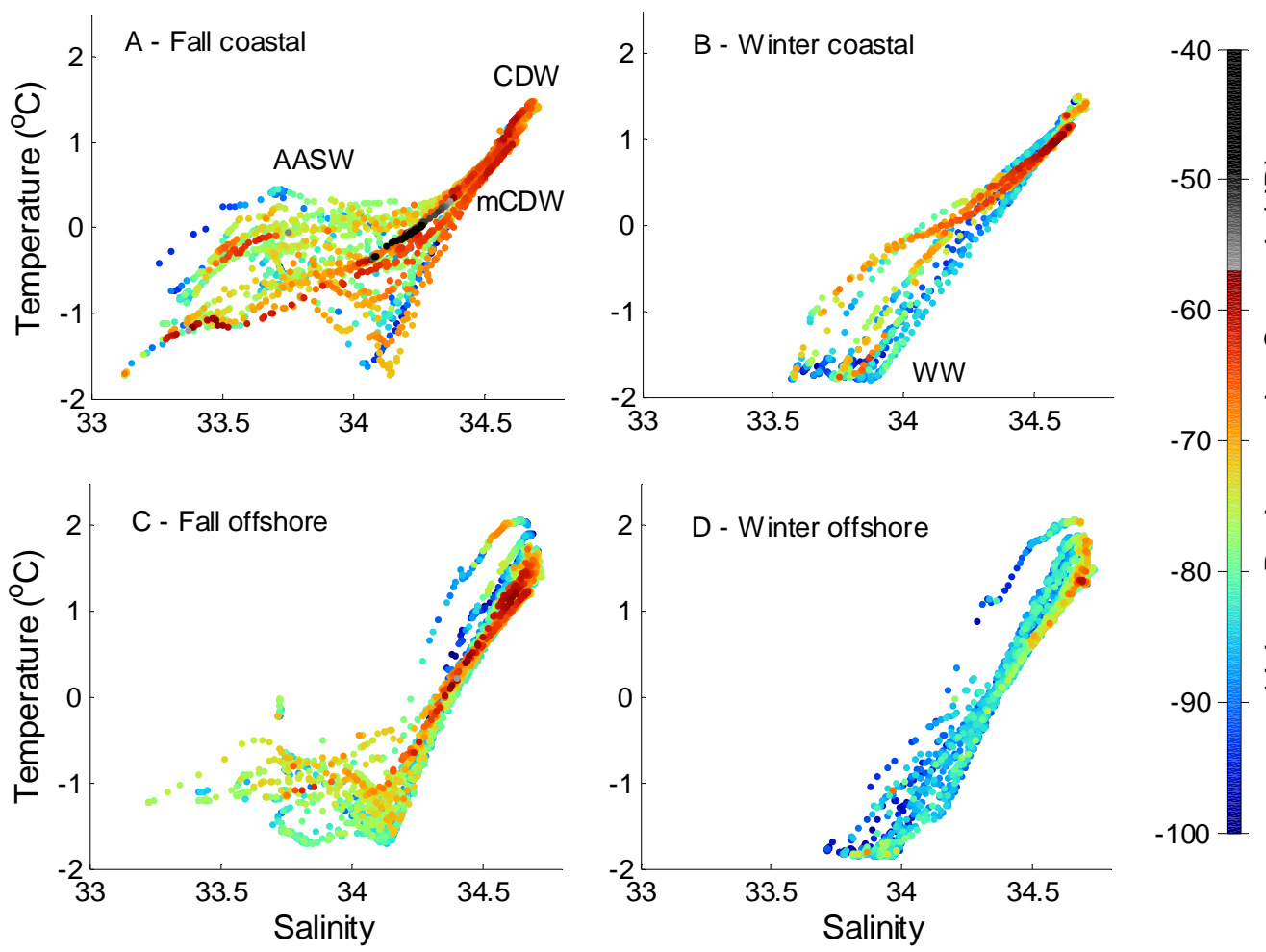

Figure 2.5 - Potential temperature-salinity diagrams, with dot color indicating volume backscattering strength (dB). Data are plotted separately for the (A) fall coastal, (B) winter coastal, (C) fall offshore, and (D) winter offshore blocks. The 'coastal' category includes the three inner-shelf blocks and Marguerite Bay, while the 'offshore' blocks include the outer- and off-shelf blocks; the term 'offshore' thus denotes regions farther away from the antarctic continent, but includes portions of the continental shelf and so must be distinguished from strictly 'off-shelf' waters. Environmental data were collected at CTD stations (see Klinck et al., this issue). Acoustic volume backscattering levels shown represent the acoustic observation (averaged over 1-km intervals via the arithmetic form of the volume backscattering coefficient) made nearest to the depth and location of each CTD measurement of temperature and salinity. Note that due to the high sample sizes (9246 in fall, and 6481 in winter), some dots were plotted on top of one another and so low values are somewhat obscured. The water masses present were Antarctic Surface Water (AASW), Circumpolar Deep Water (CDW), modified Circumpolar Deep Water (mCDW), and Winter Water (WW). 
observed in association with AASW, corresponding to the occasional presence of dense patches in surface waters. Warmer (i.e., less-modified) CDW present in areas farther offshore was typified by generally reduced volume backscattering, again suggestive of low zooplankton biomass in off-shelf waters and recent intrusions of CDW on to the continental shelf. In winter, volume backscattering was lower than in fall, particularly in the more offshore waters and in the WW and colder $\left(<0.5^{\circ} \mathrm{C}\right) \mathrm{mCDW}$ present at shallower depths (Figure 2.5). CDW and warmer mCDW present at depth showed some enhanced scattering, as would be expected from the deep scattering layer observed during the winter survey.

\subsubsection{Multi-variate analyses}

Multiple regression analysis with backward step-wise elimination of variables was used to examine how volume backscattering averaged in 1-km intervals was associated with salinity, fluorescence, transmittance, photosynthetically active radiation (PAR), bottom depth, bottom complexity, distance along-shelf, and distance across-shelf. The standard deviation of the nearest 20 measurements of bottom depth (i.e., within a horizontal distance of $\sim 400 \mathrm{~m}$ ) was used as a proxy for bottom complexity. Potential temperature, oxygen concentration, and depth were highly correlated with one another and with salinity during both cruises $(r \geq 0.8)$, and so only salinity was used in the analysis. In fall, distance along-shelf, distance across-shelf, and salinity were the most strongly associated with volume backscattering levels (standardized partial regression coefficients of $-0.53,-0.41$, and 0.31 , respectively, all p's $<0.001$ ). The former two variables had negative effects, indicating that volume backscattering increased farther in on the shelf and farther along the shelf towards the southwest. Increasing volume backscattering was associated with increasing salinity, but note that the latter's influence may be due to an association of the zooplankton with salinity itself, or due to the influence of one of its correlates, such as depth. Overall, only $34 \%$ of the variation in volume backscattering during fall was accounted for by the selected independent variables $(n=9246)$. In winter, distance along-shelf and salinity were the two most important explanatory variables 
(standardized partial regression coefficients of -0.50 and 0.46 , respectively, p's $<0.001$ ), and $41 \%$ of the total variation in volume backscattering was explained by the selected variables $(n=6481)$.

\subsubsection{Taxonomic composition}

In general, small $(<2.5 \mathrm{~mm}$ in length $)$ and large copepods $(>2.5 \mathrm{~mm})$ dominated MOCNESS catches in terms of both numbers and estimated biomass. From qualitative examinations, small copepods were dominated by Metridia gerlachei copepodites, with cyclopoids (e.g., Oithona and Oncaea spp.) also abundant at some locations. The large copepod group was composed of mostly Calanoides acutus, Calanus propinquus, Gauidius spp., adult Metridia gerlachei, Rhincalanus gigas, and Paraeuchaeta spp. (Ashjian et al., 2004).

Our silhouette method for identifying net catches was not able to identify euphausiids to the level of species. Microscopic examination of a subset of the net catches indicated that the euphausiid community consisted of Euphausia superba, E. crystallorophias, E. frigida, E. triacantha, and Thysanoessa macrura. For the remainder of this paper, we will group these species together and refer to them simply as euphausiids. Small euphausiids (all individuals $<15 \mathrm{~mm}$ in length, corresponding to larval stages) often contributed substantially to total zooplankton abundance and biomass, though less than copepods. Large ( $>15 \mathrm{~mm}$, juveniles and adults) euphausiids made important contributions to sampled biomass, but typically not to abundance. Other taxa, such as pteropods, chaetognaths, amphipods, mysids, siphonophores, other jellies, and micronektonic fishes, were proportionally important only at limited depth ranges and particular locations. Detailed analyses of MOCNESS catches were performed in a companion study (Ashjian et al., 2004), and the emphasis here is on using these catches to interpret acoustic observations. 
Calculations of expected volume backscattering strength based on net catches (i.e., 'forward calculations') showed a positive association with observed levels (Figure 2.6; results of a regression analysis for the 58 data-points indicated an $r^{2}=0.43, p<1 \times 10^{-7}$ ). Observed volume backscattering strength was generally greater than that predicted, particularly at high levels. The average deviation of observed volume backscattering from the line shown on Figure 2.6 denoting equal predicted and observed volume backscattering strengths was $6.8 \mathrm{~dB}$. These analyses excluded the mid-shelf 1 and 2 stations during winter, the two locations where net tows and acoustic data collection were separated in time by approximately a month. Interestingly, however, the predicted volume backscattering levels for the mid-shelf 1 station fell very close to the observed values. Furthermore, while the predicted volume backscattering levels for the mid-shelf 2 station were generally lower than observed levels, they were certainly not the most extreme outliers.

The ratios of the predicted volume backscattering coefficients for each of the various taxa to the total predicted level provide some insight into the possible biological sources of volume backscattering in the vicinity of each MOCNESS tow. The full set of scattering predictions for each taxon in each net and tow can be found in figure 2.7 ; here, only the more noteworthy features will be highlighted.

\subsection{6.a Sources of volume backscattering during fall}

Based on net catches made during fall and taxon-specific acoustic scattering models, large euphausiids were the predicted source of the majority of volume backscattering at only a few locations and depths: in the mid-water at the mid-shelf 1 and 2 stations (at depths of $22-240 \mathrm{~m}$, and $149-344 \mathrm{~m}$, respectively), at depths where large and diffuse patches were present (Figure 2.2a), as well as in the very high scattering and patchy 50 to $198 \mathrm{~m}$ depth range in Marguerite Bay (Figure 2.7a). Elsewhere, large euphausiids were either absent or were predicted to contribute only slightly to overall volume 


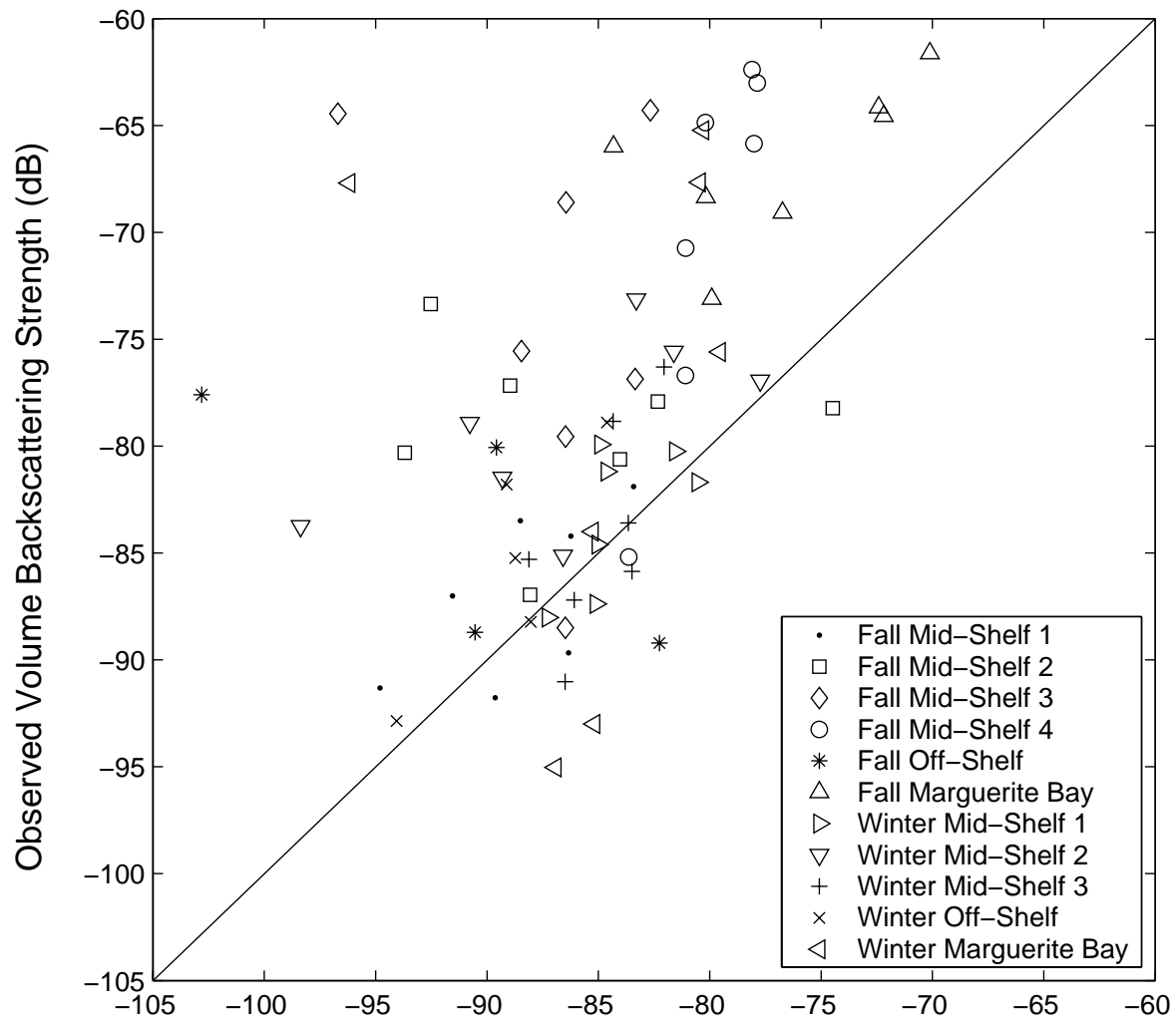

Predicted Volume Backscattering Strength (dB)

Figure 2.6 - Comparison of volume backscattering strength observed acoustically and that predicted based on the composition of the MOCNESS catches. The line where observed levels equal those predicted is shown; points falling above this line indicate cases where observed volume backscattering strength was under-predicted. Observed volume backscattering levels represent averages over depth ranges equal to those sampled by the nets, and over similar spatial extents. Individual symbols represent each MOCNESS tow. Acoustic observations were made within $17 \mathrm{~km}$ and 5 hours of the net tows. 
backscattering levels. Small euphausiids were estimated to make their most important contributions at shallow depths, ranging from 25 to $100 \mathrm{~m}$.

Aside from euphausiids, a mixture of taxa were predicted to account for the remainder of volume backscattering in fall (Figure 2.7a). Large copepods were an important predicted constituent at many stations, particularly below a depth of $100 \mathrm{~m}$. Despite their never contributing more than $11 \%$ of net-sampled biomass (Ashjian et al., 2004), pteropods were occasionally responsible for the majority of predicted volume backscattering levels (up to $69 \%$ ). This is due to the hard shell and associated strong scattering intensity of pteropods in comparison to the weakly-scattering taxa such as euphausiids or copepods (Stanton et al., 1994). Similarly, at certain depths and locations, a majority of total volume backscattering was predicted to arise from pneumatophore-bearing siphonophores. For instance, in the 99 to $145 \mathrm{~m}$ depth stratum at mid-shelf station 3, 66\% of volume backscattering was estimated to result from siphonophores, even though catch biomass in this layer was still dominated by copepods (47\%) and the contribution of siphonophores to biomass was negligible $(\sim 1 \%)$. The pneumatophore structure of siphonophores is a gas-filled sac which is an efficient scatterer of sound (Warren et al., 2001), evidently overwhelming the contribution to observed volume backscattering of the biomass-dominating copepods. Small copepods frequently dominated catches (up to $72 \%$ of biomass), but this taxon never explained more than $19 \%$ of predicted volume backscattering, due to their small size combined with their being weak scatterers (i.e., their acoustic material properties are similar to those of the surrounding seawater), and concomitant low target strength at $120 \mathrm{kHz}$.

\subsection{6.b Sources of volume backscattering during winter}

In winter, the sources of acoustic scattering predicted from net samples differed from the fall (Figure 2.7b). The dominant feature observed acoustically in winter was the deep scattering layer found close to the bottom over much of the continental shelf. Unfortunately, difficulties associated with towing the MOCNESS through the pack ice 


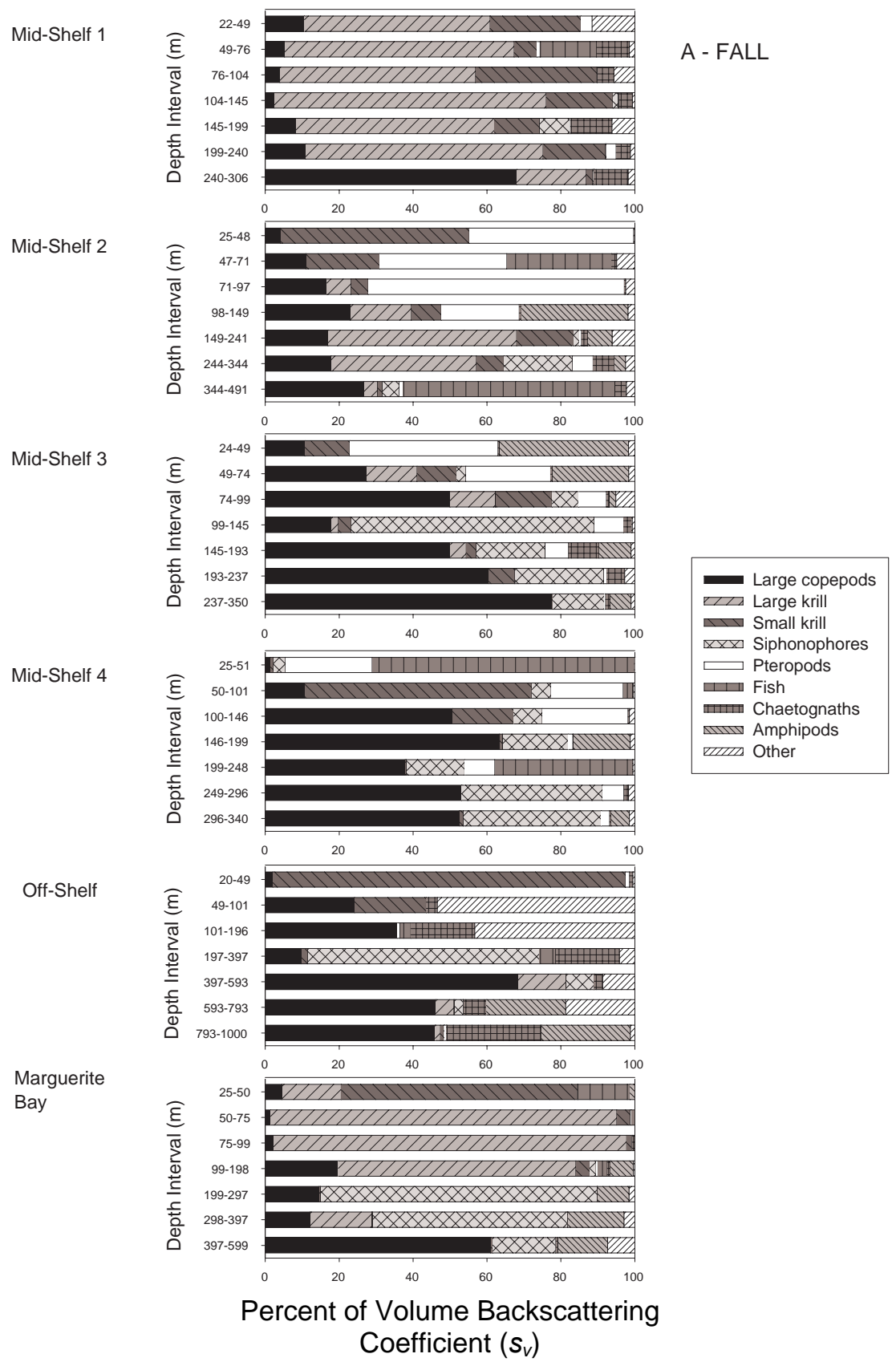

Figure 2.7 - Predictions of the sources of volume backscattering based on MOCNESS catches during (A) fall and (B) winter. The percent of total predicted volume backscattering accounted for by each taxon, calculated on the basis of the linear quantity the volume backscattering coefficient, is shown relative to the depth interval sampled by each net of each tow. The 'pteropod' category refers only to thecosomes (Limacina spp.). The 'other' category includes small $(<2.5 \mathrm{~mm})$ copepods, medusae, polychaetes, ostracods, eggs, salps, crustacean larvae, radiolarians, mysids, and gymnosome pteropods. 


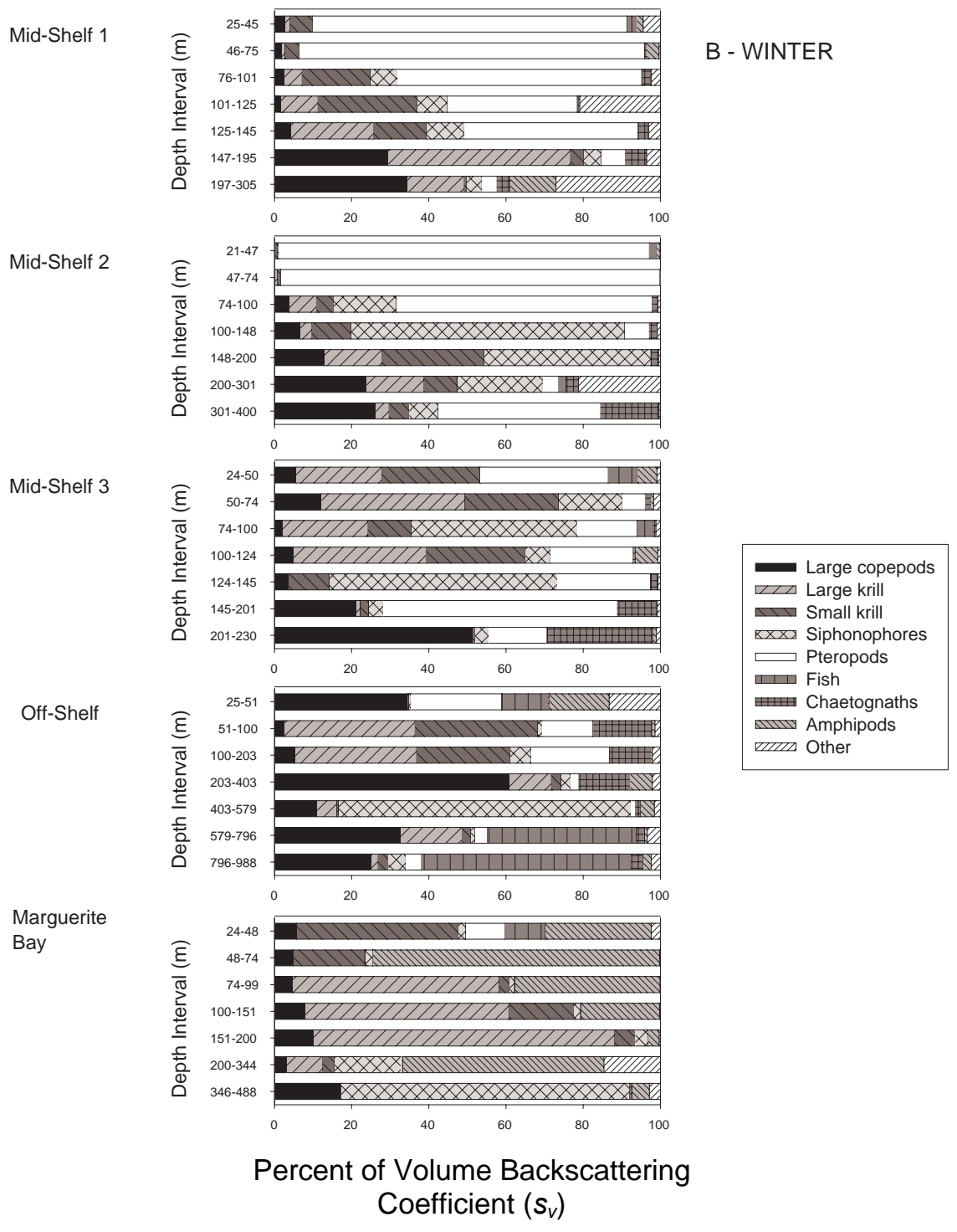

Figure 2.7 - continued 
led to problems in sampling this layer. At the mid-shelf 1 station, the deepest net sampled to within $40 \mathrm{~m}$ of the bottom. Acoustic data were collected in this region 30 days prior to the net tow, and at that time, a deep scattering layer was present extending 20 to $100 \mathrm{~m}$ above the bottom. Predictions from the catch composition in this net suggested that large copepods and radiolarians (included in the 'other category' of Figure 2.7b) were the dominant contributors to expected volume backscattering levels in the layer, with smaller contributions from amphipods and large euphausiids. At the mid-shelf 2 station, a scattering layer was present extending 100 to $150 \mathrm{~m}$ off the bottom. Predictions from the deepest net in a tow made 24 days later to within $90 \mathrm{~m}$ of the bottom indicated that expected volume backscattering in the layer was accounted for primarily by pteropods and large copepods. At the mid-shelf 3 station, the deepest net only sampled to within 95 $\mathrm{m}$ of the bottom, and therefore passed $25 \mathrm{~m}$ above the deep scattering layer observed acoustically. Volume backscattering in this sampled region immediately above the deep scattering layer was predicted to stem predominantly from copepods and chaetognaths.

Catches from shallower sampled strata suggested that the low volume backscattering observed outside the deep scattering layer stemmed from a highly complex mixture of taxa (Figure 2.7b). Where they were present, siphonophores and pteropods often accounted for most of the predicted volume backscattering. In Marguerite Bay, amphipods were the dominant scatterer in two of the sampled depth intervals, while large euphausiids dominated predicted volume backscattering in the acoustically intense 151 to $200 \mathrm{~m}$ depth range and in the less intense 74 to $151 \mathrm{~m}$ layer.

\subsection{DISCUSSION}

Distinct spatial and seasonal patterns were evident in volume backscattering across the Marguerite Bay continental shelf study area. Clear associations also were observed between volume backscattering and particular water masses and dynamic topography, which is an indicator of flow. Together with the information derived from net samples on the taxonomic composition of the zooplankton and micronekton responsible for the 
volume backscattering, these observations permit important inferences concerning the seasonal distribution, transport, and retention of zooplankton and micronekton biomass in the region.

\subsubsection{Potential limitations of the acoustic technique}

The relationship between volume backscattering at a single frequency and zooplankton biomass is highly complex, and in order to draw any conclusions about biomass on the basis of our acoustic measurements, a number of potentially confounding factors first must be taken into account. Volume backscattering depends on a number of factors, including the abundance or biomass of scatterers in the sample volume, as well as their taxonomic composition and associated differences in acoustic material properties, size, shape, and orientation (Stanton and Chu, 2000). In fisheries and zooplankton acoustics, it is commonly assumed that scattering from individual animals within the acoustic beam sums incoherently, such that the volume backscattering coefficient increases linearly with animal density. This assumption is valid provided that animal densities are not so high as to cause acoustic attenuation or multiple scattering, and targets can be assumed to be distributed randomly within the beam (MacLennan and Simmonds, 1992); this is likely to be the case here. Inasmuch as biomass increases linearly with abundance, volume backscattering therefore will also increase with biomass.

Different anatomical classes of zooplankton scatter sound with very different efficiencies, and the taxonomic composition of scatterers has a substantial impact on volume backscattering. The echo energy scattered per unit biomass of a pteropod, for example, can be 70 times greater than that from a decapod or pneumatophore-bearing siphonophore (Stanton et al., 1994). An observed increase in volume backscattering therefore could result either from an increase in the biomass of a given taxon of zooplankton, or from a shift in taxonomic composition towards stronger scatterers such as pteropods; such a shift could even be accompanied by a decrease in biomass. In the present study, predictions based on net catches of the likely relative contributions of 
different taxa to observed volume backscattering levels suggest a highly heterogeneous composition of animals (Figure 2.7; note that section 2.4.3. a below acknowledges certain limitations of these predictions). There is little evidence that changes in taxonomic composition might confound our interpretation that the major observed seasonal and spatial differences in volume backscattering are related to concomitant changes in biomass. The strong-scattering pteropods were predicted to account for more of the volume backscattering in winter than in fall, suggesting that the decrease in volume backscattering between the two seasons may be due to an even-larger decrease in biomass than if the taxonomic composition had remained the same. During fall, there was evidence of greater contributions of pneumatophore-bearing siphonophores to volume backscattering at depths below $100 \mathrm{~m}$ in the southern reaches of the survey area and in Marguerite Bay, and an increased importance of euphausiids towards the north. Although volume backscattering was lower in the north, echo energy at $200 \mathrm{kHz}$ per unit biomass has been shown to be comparable for certain sizes of siphonophores and euphausiids (Stanton et al., 1994), and this volume backscattering decrease is more likely related to a difference in biomass than to spatial patterns in community composition.

Volume backscattering generally increases with the size of the animals ensonified. Since biomass also increases with size, volume backscattering should increase with biomass irrespective of whether biomass increases are related to size or abundance. The relationship between scattering and size is not monotonically increasing, however, and there do exist size ranges for which the scattering from a given individual (i.e., its target strength) and the individual's size are negatively related, such that slightly larger (higher biomass) animals have lower target strength than smaller ones (Stanton and Chu, 2000). For single pings and individual animals, such 'dips' in the scattering vs. size relationship can be quite pronounced, and have the potential to confound the relationship between volume backscattering and biomass. In this study, however, we average volume backscattering over large depth ranges and horizontal intervals, and thereby average over a very large number of animals. When scattering is averaged over a distribution of animal lengths, the dips in target strength at particular size ranges are substantially reduced in 
magnitude, to $5 \mathrm{~dB}$ or less (Stanton et al., 1998; Stanton and Chu, 2000). Furthermore, the exact sizes of animals encountered in this study are such that the potential confounding effect of animal size on the relationship between volume backscattering and biomass is relatively small: the lengths of most of the net-sampled taxa (e.g., copepods, pteropods, siphonophores, and small euphausiids) were much smaller than the length at which the first dip in the target strength vs. size relationship occurs. Large euphausiids are the only taxon sampled by the nets whose sizes might have been expected to fall within this first dip, but examining the length distributions of this group in net catches suggests that most animals fell on either side of the requisite range of lengths (Ashjian et al., 2004).

Similarly, animal orientation can have a substantial impact on target strength for individual animals and single realizations, but this effect is also much reduced when scattering is averaged over a distribution of aspects. It is conceivable that the orientation of animals may vary spatially or seasonally, if for example, orientation changes with the animals' behavior, such as during feeding versus migrating. Too little information exists on the orientation of these various animals to explore this possibility fully. It seems unlikely, however, that the large observed spatial and seasonal patterns in volume backscattering can be explained simply by variability in the orientation of animals, as this would require complicated spatial and seasonal changes in orientation that are less plausible than differences in biomass.

Animal taxonomic composition and the associated differences in the acoustic material properties, size, shape, and orientation of scatterers certainly introduce imprecision into the relationship between volume backscattering and zooplankton and micronekton biomass, and it therefore is not possible to relate the patterns observed here in volume backscattering uniquely to patterns in overall zooplankton biomass. Nonetheless, the present analyses have revealed large spatial and temporal differences in volume backscattering strength (greater than $5 \mathrm{~dB}$ ), which should exceed any imprecision 
introduced by these confounding factors, allowing us to attribute coarsely these differences to changes in biomass.

There also exists the possibility that some of the observed volume backscattering stemmed from sources other than zooplankton or micronekton, such as nekton or nonbiological sources. It is unlikely that any animals larger than micronekton (e.g., large fishes) contributed substantially to volume backscattering measurements. Larger animals should be recognizable in the acoustic record by their very high volume backscattering levels. Very few such instances of high volume backscattering were evident, however, and volume backscattering strength seldom exceeded $-50 \mathrm{~dB}$. Aside from the artifactual scattering excised from the acoustic data collected by the up-looking transducer described above, we have little information on the possibility of scattering from non-biological sources. Work in the Gulf of Maine has demonstrated that small-scale variations in the temperature and salinity structure of the water column (i.e., microstructure) may at times scatter sound at levels comparable to that from zooplankton (Warren et al., 2003). Preliminary examinations of acoustic data collected concurrent to casts with a microstructure probe during a later cruise suggest that thin and low-intensity volume backscattering layers may be associated at times with regions of high microstructure, but such weak scattering is unlikely to contribute substantially to the averages of volume backscattering under examination in the present study.

Finally, diel vertical migrations by the animals responsible for observed volume backscattering may introduce uncertainty into our interpretations of distribution. Comparisons of mean volume backscattering within the different depth strata between day and night do not support this notion, other than perhaps in the shallow layer during winter. Even in this depth range, since the position of the ship in relation to time of day was effectively random, any diel changes in vertical position should simply introduce random error into the acoustic measurements. Diel vertical migration of some component of the zooplankton community undoubtedly does occur (e.g., Zhou and Dorland (2004) observed distinct diel vertical migrations by individual euphausiid aggregations), but it 
seems that the influence of such migrations on our large-scale analyses of overall zooplankton volume backscattering is minor.

\subsubsection{Seasonal changes in volume backscattering}

One of the most striking patterns observed in mean volume backscattering levels was the decrease in scattering from fall to winter evident in the upper $300 \mathrm{~m}$ of the water column throughout the survey area, other than in Marguerite Bay. In contrast, volume backscattering below a depth of $300 \mathrm{~m}$ remained high even in winter, and in fact increased relative to fall levels in Marguerite Bay and the northern and southern outershelf. Comparing volume backscattering levels averaged over the entire sampled depth range $(25-500 \mathrm{~m})$ suggests that volume backscattering for the water column as a whole in Marguerite Bay, the northern and southern outer-shelf areas, and off-shelf during winter was comparable to or exceeded levels observed during fall (Figure 2.8). Elsewhere, volume backscattering during winter was reduced to 18 to $46 \%$ of fall levels. Mean volume backscattering in winter averaged over the entire surveyed area and water column was $-69.6 \mathrm{~dB}$, representing a decrease of $67.5 \%$ relative to volume backscattering observed during fall (mean $-64.8 \mathrm{~dB}$ ). This is indicative of a seasonal decrease in zooplankton biomass, and correspondingly, a decrease in zooplankton biomass between the two seasons also was observed by other instruments. Biomass sampled in the MOCNESS tows described above decreased from fall to winter by approximately $60 \%$ (Ashjian et al., 2004). Analyses of zooplankton size spectra derived from an optical plankton counter (OPC) likewise suggested that particle abundance between 0.25 and 14 $\mathrm{mm}$ in equivalent spherical diameter decreased between fall and winter of 2002 by $82 \%$ (Zhou et al., 2004). The OPC generally samples a smaller fraction of the overall zooplankton and micronekton biomass than the acoustic and net systems. The greater seasonal decrease evident from the OPC may suggest greater mortality or other sources of loss for the smaller zooplankton present, or may reflect spatial differences in the locations sampled by the different instruments. 


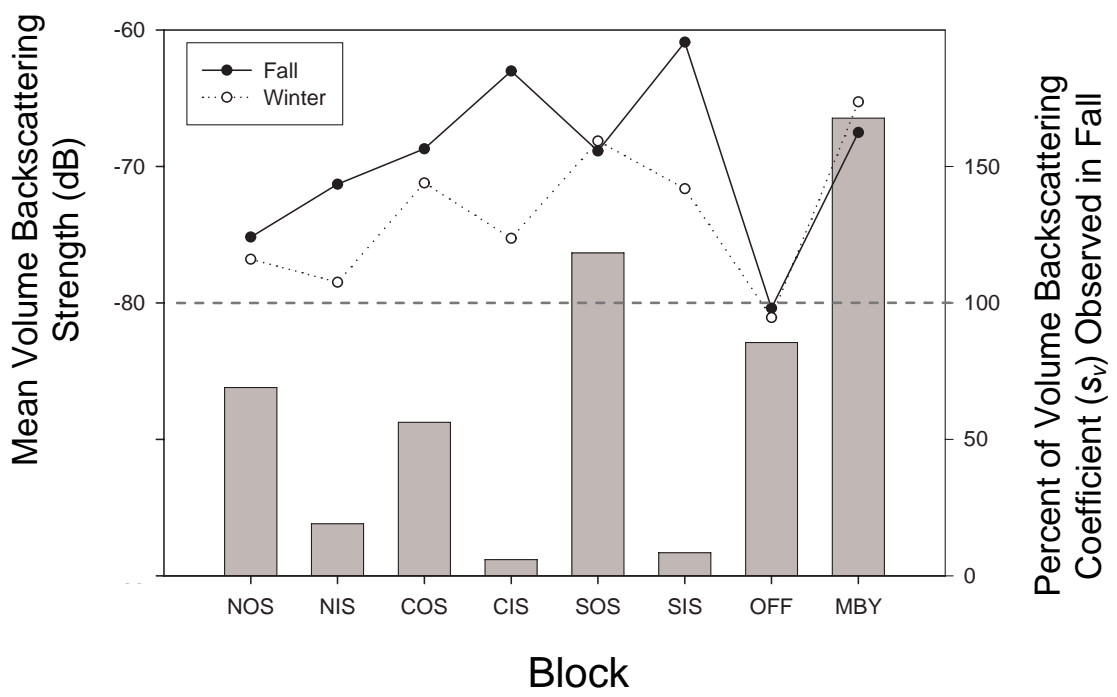

Figure 2.8 - Mean volume backscattering strength observed in the entire sampled portion of the water column $(25-500 \mathrm{~m})$ in each block, during fall and winter (left y-axis). Vertical bars indicate the percent of fall total volume backscattering in each block that can be accounted for by winter levels (right y-axis). Dashed horizontal line indicates the $100 \%$ level of equal fall and winter volume backscattering. Averages and percentages were calculated using the arithmetic quantity, the volume backscattering coefficient $\left(s_{v}\right)$, and then displayed in the logarithmic form of the volume backscattering strength $\left(S_{v}\right)$. 
Similar seasonal reductions in the biomass of zooplankton have been observed in studies of other regions of the antarctic continental shelf (e.g., copepods; Schnack-Schiel et al., 1998), and for Antarctic krill in particular (Heywood et al., 1985; Siegel 1988, 1989; Lascara et al., 1999; and see review in Siegel, 2000). A seasonal decrease in Antarctic krill biomass may not be a consistent feature across all regions, however, as South Georgia typically supports a strong krill fishery during winter (e.g., Murphy et al., 1997). In repeat surveys that overlapped during fall and summer with the northern end of the SO GLOBEC study area, and that in winter and spring covered the continental shelf farther north, Lascara et al. (1999) observed an order of magnitude decrease from spring and summer Antarctic krill biomass levels ( 32 and $95 \mathrm{~g} \mathrm{~m}^{-2}$, respectively) to fall and winter (12 and $8 \mathrm{~g} \mathrm{~m}^{-2}$, respectively). In the latter survey, mean biomass was driven primarily by one high-biomass station; biomass was zero at most other stations. These authors calculated biomass by assuming that all measurements of volume backscattering strength at $120 \mathrm{kHz}$ in excess of $-81 \mathrm{~dB}$ and above $189 \mathrm{~m}$ in depth stemmed from Antarctic krill. Although we do not make this scaling from volume backscattering to biomass, volume backscattering strength during winter in the present study frequently exceeded $-81 \mathrm{~dB}$, and so would have resulted in non-zero biomass estimates by the Lascara et al. (1999) method. However, volume backscattering strength measurements higher than $-81 \mathrm{~dB}$ typically were found below $189 \mathrm{~m}$ in depth, possibly explaining the many locations where biomass during winter was estimated to be zero in this earlier study.

There exist a number of factors that may explain the decrease in zooplankton volume backscattering from fall to winter. These include vertical and horizontal movements, mortality, and advection of the zooplankton and micronekton in question. It also must be noted in considering these explanations that here we are dealing with volume backscattering as a whole, and that different factors may explain changes in the biomass and distribution of individual taxa. 


\subsection{2.a Vertical movements}

Downwards seasonal migrations may have contributed to the decrease in overall volume backscattering levels. Certain taxa, including the large copepods Calanoides acutus and Rhincalanus gigas, are known to undergo ontogenetic migrations to deeper waters during winter (Ross et al., 1996). Migration below the depth ranges normally sampled by nets and acoustics has been hypothesized to be a possible cause of apparent seasonal changes in the biomass of Antarctic krill in the present study area (Lascara et al., 1999). Euphausiid biomass at depths below $400 \mathrm{~m}$ has typically been found to be low in all seasons (Marin et al., 1991; Ross et al., 1996; Ashjian et al., 2004). There is some evidence, however, that Antarctic krill may on occasion be associated with the bottom, from a bottom-mounted light trap in a shallow water region under fast ice (Kawaguchi et al., 1986), acoustic observations in conjunction with trawl catches (Heywood et al., 1985), and two observations made by a remote-operated vehicle (ROV) within a meter of the bottom (Gutt and Siegel, 1994).

In the present study, due to the use of a chirp pulse (Ehrenberg and Torkelson, 2000) and to the ability of the BIOMAPER-II to be towed at depths up to $300 \mathrm{~m}$, we were consistently able to sample acoustically to $500 \mathrm{~m}$, occasionally reaching as deep as 550 $\mathrm{m}$. Depending on bathymetry, this allowed us to sample all the way to the bottom over much of the continental shelf. In certain portions of the study area, volume backscattering in the deepest portions of the water column increased from fall to winter, suggestive of a downwards movement of zooplankton. Overall, however, even including volume backscattering at the deepest depths surveyed, volume backscattering during winter in the surveyed water column accounted for only $32.5 \%$ of observed fall levels. Downwards vertical movements alone therefore may not account for the seasonal decrease in volume backscattering.

Upwards migration of the zooplankton responsible for volume backscattering above the minimum sampled range of the acoustic system $(25 \mathrm{~m})$ also does not explain the fall to 
winter decrease. Analyses of MOCNESS catches do not indicate that total zooplankton biomass increased in the 0 to $25 \mathrm{~m}$ depth stratum (Ashjian et al., 2004). Concurrent ROV surveys did observe high abundances of larval euphausiids immediately under the pack ice at four of sixteen survey locations during winter, suggesting that some larval euphausiids may have migrated to the underside of the ice (Gallager et al., 2002). Since the present analyses indicate that small euphausiids are minor contributors to overall volume backscattering, such a migration is unlikely to have affected observed volume backscattering levels.

\subsection{2.b Horizontal migrations}

Horizontal migrations to preferred over-wintering habitats by zooplankton or micronekton may explain some of the decrease in volume backscattering from fall to winter. Adult Antarctic krill are capable of sustained swimming at 10 to $15 \mathrm{~cm} \mathrm{~s}^{-1}$ (Kils, 1981), and so in the eight weeks between the fall and winter surveys, could have migrated distances as far as $725 \mathrm{~km}$. Siegel (1988) hypothesized that adult Antarctic krill migrate offshore in spring, returning to coastal areas for the winter perhaps following a food gradient, and an association of zooplankton with coastal waters during winter has been observed in other shelf regions (Siegel 1988, 1989; Zhou et al., 1994; Lascara et al., 1999). In the present study, we penetrated through the ice close to shore during winter on

only limited occasions. On one of those instances, in Laubeuf Fjord at the northern end of Marguerite Bay, high volume backscattering was observed and according to our netbased predictions, much of this volume backscattering came from large euphausiids. It thus seems possible that large euphausiids may have migrated out of the surveyed area between fall and winter, into the many un-surveyed coastal fjords of Marguerite Bay and its surrounding islands. It appears unlikely, however, that a preference for a particular water mass and a change in the distribution of that water mass would be involved in such a horizontal movement. Temperature-salinity diagrams indicated that volume backscattering in fall was highest in modified CDW, and similar diagrams from data 
collected during winter indicate that abundant modified CDW was still present on the shelf.

\subsection{2.c Mortality}

Large zooplanktivorous predators are common in the Marguerite Bay region, and include whales (Thiele et al., 2004), seals (Burns et al., 2004), and birds (Chapman et al., 2004). Such predators may have been responsible for high levels of mortality. Until we gain a detailed understanding of the sources of scattering and the population dynamics of the various zooplankton taxa, the contribution of mortality to the decrease in volume backscattering remains unclear.

\subsection{2.d Transport and retention of zooplankton and micronekton}

Advection may have transported zooplankton and micronekton out of the study area, accounting for some of the observed decrease in volume backscattering between the two seasons. In fall, contours of dynamic height indicated the presence of a large gyre situated over the northern portion of the continental shelf study area; previous studies of the area and analyses of historical datasets suggest that this is a persistent feature of the region (Hofmann et al., 1996; Smith et al., 1999). The southern end of this gyre contained elevated volume backscattering, suggesting that zooplankton were being transported in an off-shelf direction. Current speeds in the gyre were on the order of 3 to $15 \mathrm{~cm} \mathrm{~s}^{-1}$ (from ADCP and dynamic height calculations, respectively; Klinck et al., 2004), and in the eight weeks between the two cruises, could have transported the zooplankton by distances between 145 and $725 \mathrm{~km}$ in a straight-line direction. Where the southern end of the gyre reached the shelf break and turned towards the north, zooplankton may either have been entrained into the fast-flowing (up to $30 \mathrm{~cm} \mathrm{~s}^{-1}$, Klinck et al., 2004) Antarctic Circumpolar Current (ACC) and transported to regions farther north, or retained within the gyre structure. 
Dynamic height estimates, ADCP measurements, and drifter tracks indicated the presence during fall of a strong coastal current moving towards the southwest along Adelaide and Alexander Islands (Beardsley et al., 2004; Klinck et al., 2004). High volume backscattering likely arising from zooplankton was associated with this physical feature. Although the coastal current passes through areas of complex bathymetry where zooplankton could potentially find refuge, it still likely transported much of the zooplankton found during fall in the southern shelf region towards the southwest and out of the study area. At ADCP-measured speeds of 10 to $25 \mathrm{~cm} \mathrm{~s}^{-1}$ (Klinck et al., 2004), this current could have transported plankton by distances of 480 to $1210 \mathrm{~km}$.

On-shelf flow also may account for some of the seasonal decrease. Hydrographic observations and modeling exercises indicate that warm oceanic CDW is pumped up onto the continental shelf primarily at points where the deep troughs bisecting the shelf meet the shelf break and where the shelf break is strongly curved (Klinck et al., 2004; Dinniman and Klinck, 2004). Maps of interpolated volume backscattering relative to bathymetry, low volume backscattering observed in the off-shelf block, analyses of the association between volume backscattering and water masses, as well as low net-sampled biomass at the off-shelf station (Ashjian et al., 2004), suggest that the oceanic waters being pumped onto the shelf were relatively low in zooplankton. The waters replacing those lost from the study area through other advective features thus may have contributed to the overall decrease in zooplankton and micronekton biomass.

Retentive processes may partially explain why water column volume backscattering in Marguerite Bay increased from fall to winter: ADCP measurements made by other SO GLOBEC investigators (Zhou et al., 2004; Klinck et al., 2004) suggest the possible existence of a small gyre in the northern end of Marguerite Bay, a notion that is supported by the dynamic height contours presented here. Such a gyre could serve to retain zooplankton in this region, keeping volume backscattering levels high in both fall and winter. 


\subsubsection{Sources of acoustic scattering}

\subsection{3.a Accuracy of forward calculations}

Any inferences about the sources of acoustic volume backscattering rely on the accuracy of our forward calculations. Forward predictions of volume backscattering strength based on net samples were generally lower than observed volume backscattering levels, particularly at high levels. A number of factors may have contributed to this discrepancy. First, MOCNESS tows and acoustic samples could not be made at exactly the same times and locations. High spatial and temporal variability in the abundance and composition of zooplankton may have resulted in the two systems sampling different communities. This is particularly true for sparsely- or patchily-distributed organisms such as euphausiids, that may have contributed to the acoustic measurements but been missed by the nets. It is pertinent that in temperate waters typified by generally higher zooplankton densities and where net and acoustic sampling were co-located, forward calculations have yielded more favorable comparisons than seen here (Wiebe et al., 1996; Bucklin et al., 2002).

Furthermore, net studies have led to the suggestion that although the absolute biomass of a particular taxon may vary dramatically in space or time, its proportional contribution to total zooplankton biomass is generally much less variable (Wiebe et al., 1992). While spatial and temporal variability thus might contribute to the discrepancy in magnitude between predicted and observed volume backscattering, the predicted relative contributions of individual taxa may be less subject to such error. Overall, however, such variability in the composition of zooplankton should only contribute to the variability in the relationship between observed and predicted volume backscattering, and does not explain the more systematic offset between the two evident at higher levels.

Second, biological characteristics such as length distribution can vary dramatically between even closely-spaced Antarctic krill swarms, and a single tow may not provide an unbiased estimate of the length distribution of krill in a given region (Watkins et al., 1986, 1990). Some degree of uncertainty thus will certainly be propagated into our 
predictions of the sources of scattering due to error in the net catch data themselves. During the surveys, it generally was not possible to conduct replicate tows in order to constrain this error quantitatively. At the Marguerite Bay station in fall, however, three separate tows were made through a series of dense euphausiids swarms over the course of 18 hours and over a spatial area of $16 \times 4.5 \mathrm{~km}$ (Wiebe et al., 2004). Analysis of the catches indicated a marginally non-significant $(p=0.065)$ difference between tows in euphausiid length.

Third, some of the animals present may have avoided the oncoming net. Larger taxa in particular might have been capable of avoidance, despite our use of a strobe light to reduce such an effect. Larger animals would also produce higher observed volume backscattering levels, and the greater offset between observed and predicted volume backscattering at higher scattering levels may support the notion that avoidance partially explains the difference between the two. Similar to the present results, Zhou et al. (1994) found that volume backscattering levels predicted from net catches of euphausiids became increasingly smaller than levels observed with an ADCP for higher observed values, which they attributed to avoidance on the part of the euphausiids.

Finally, some of the models and parameters used in making forward predictions may not have been appropriate in all instances. For most of the dominant taxa, the models of acoustic scattering used here have been experimentally validated through comparisons of model predictions to measured target strengths of actual individual organisms (Stanton et al., 1998; Table 2.1). Model parameter values (e.g., animal orientation), however, were occasionally chosen on the basis of very little information (see Table 2.1). Sensitivity analyses suggest that changing parameter values, while still keeping them within biologically-plausible ranges, could increase predicted volume backscattering strength by only one to five decibels. Uncertainty associated with model parameter values alone therefore does not appear to explain fully the difference between predicted and observed volume backscattering. 


\subsection{3.b Taxonomic composition of zooplankton and micronekton}

Given the preceding discussion, and since only five or six tows were available per cruise to describe such a large study area, any conclusions concerning the sources of observed scattering must be approached with caution. Performing the forward calculations furthermore only provides an indication of the relative contribution of each zooplankton and micronekton taxon to total volume backscattering in a given region, and does not allow the conclusion that these relative contributions have been uniquely determined. Nonetheless, these analyses do allow certain broad inferences.

Volume backscattering in the study area was found in two general forms: dense patches of elevated volume backscattering, and more elongated and homogenous layers. In fall, dense and discrete patches were observed primarily in Marguerite Bay, contributing to the high mean volume backscattering levels and enhanced coefficients of variation in volume backscattering observed in this region. Forward predictions suggest that these patches were composed of large euphausiids. Large but more diffuse patches were also observed at depth over the northern shelf. The composition of these deep patches is less certain, as we can not be certain that the fall mid-shelf 1 MOCNESS tow actually passed through one of these patches, but the catch data do suggest a high biomass of large euphausiids in this region and at the appropriate depths. Dense patches were less evident in Marguerite Bay in winter, but the MOCNESS tow suggested that large euphausiids and amphipods made up the majority of the intense scattering layer present at depths below $150 \mathrm{~m}$ in this area. Outside of these very distinct patches, the analysis of net samples indicated that the sources of scattering likely included a complex and variable mixture of taxa.

The dominant feature in winter was the dense bottom scattering layer. Copepods were predicted to be the dominant scatterer in this layer, although two of the three MOCNESS tows that sampled this layer were the two instances where net tows were separated in time from acoustic data collection by as much as 30 days. It is also possible that some 
taxa were under-sampled to a greater extent by the nets than others, leading to an apparent dominance of these other taxa (e.g., copepods in this instance). This may particularly be the case since predicted volume backscattering strength was low in comparison to measured levels in the bottom scattering layer, suggesting that some portion of the animals scattering sound may have been under-sampled. There is, however, little evidence from the current analyses to support the notion that large euphausiids formed this bottom layer present during winter.

\subsection{3.c Implications to acoustic surveys}

An important finding of the present study is that euphausiids accounted for the majority of predicted volume backscattering only at certain depths and locations within the survey area. Volume backscattering more typically was predicted to be dominated by copepods, pneumatophore-bearing siphonophores, pteropods, or a complex mixture of taxa. Where they were present, the relatively rare and low-biomass but strongly scattering pteropods and siphonophores appeared to overwhelm the contributions to volume backscattering of weakly-scattering taxa (similar to observations in the Gulf of Maine and on Georges Bank; Wiebe et al., 1996; Benfield et al., 2003). At $120 \mathrm{kHz}$, small fluid-like animals like copepods scatter near the transition between the Rayleigh and geometric scattering regions, and so in our predictions from net catches, copepod contributions to overall volume backscattering strength never exceeded $-80 \mathrm{~dB}$. Although copepod volume backscattering thus can be filtered out via thresholding if larger animals like euphausiids are of sole interest, such levels are certainly measurable and of consequence in generally low-scattering regions such as the present study site. Furthermore, copepods frequently dominate the zooplankton community in terms of abundance and biomass (Ashjian et al., 2004), and it is noteworthy that acoustic data potentially can provide information on their distribution.

Acoustic surveys in the Antarctic have employed a number of techniques in order to discriminate euphausiid scattering from that arising from other animals. Often it has been 
assumed that all measured zooplankton volume backscattering above some minimum threshold (generally ca. $-80 \mathrm{~dB}$ ) stemmed from Antarctic krill (e.g., Macaulay et al., 1984; Lascara et al. 1999; Nicol et al., 2000). This assumption would lead to overestimates of Antarctic krill biomass in the present study area, at least. In other instances, visual scrutiny and/or some degree of trawling has been employed to distinguish Antarctic krill patches from other sources of volume backscattering such as myctophid fishes (e.g., Sahrhage, 1989; Sprong and Schalk, 1992; Murray et al., 1995; Pauly et al., 2000), but this approach discards a great deal of potential information on the abundance of taxa other than krill.

Differences in mean volume backscattering strength at two or more discrete frequencies have been used with a great deal of success to identify euphausiid scattering and filter out returns from other taxa. The range of differences in scattering attributable to particular euphausiid species has been based either on analyses of patches known from net samples to be predominantly mono-specific (Madureira et al., 1993; Brierley et al., 1998; Watkins and Brierley, 2002), in one instance in conjunction with analyses of certain other patch characteristics (Woodd-Walker et al., 2003), or on theoretical predictions from target strength models (e.g., Hewitt et al., 2003). Such multi-frequency analyses are very promising, and perhaps could be expanded to account for rare, but strongly-scattering taxa such as pteropods and gas-bearing siphonophores, where they are present.

\subsection{CONCLUSIONS}

Distinct spatial and seasonal patterns were evident in zooplankton volume backscattering across the Marguerite Bay continental shelf study area. During fall, volume backscattering was highest in the southern reaches of the survey area and inside Marguerite Bay; regions also associated with high abundances of whales, seals, and birds (Thiele et al., 2004; Burns et al., 2004; Chapman et al., 2004, respectively). In winter, the dominant scattering feature was a bottom scattering layer covering much of the continental shelf. Downward vertical migrations of zooplankton into this bottom layer 
may have contributed to the observed decrease in volume backscattering from fall to winter in the mid-water, but may not account fully for the decrease evident in the water column as a whole. The latter was probably due to vertical migrations plus a combination of advection out of the survey area, mortality, and horizontal movements. Advection could have occurred either via zooplankton in the northern shelf gyre becoming entrained into the ACC or via the southwest-flowing coastal current. Although the results from the present study concerning the advection of zooplankton are equivocal, the possibility that zooplankton from the Marguerite Bay region become entrained into the ACC and transported to regions farther north is tantalizing, and would support the hypothesis that Marguerite Bay helps to sustain the large downstream euphausiid populations in the Bransfield Strait and South Georgia regions (Atkinson et al., 2001; Fach et al., 2002). Predictions based on net catches of the sources of volume backscattering suggest that euphausiids were the dominant scatterer only at very particular locations and depths. Antarctic acoustic surveys should take care to account for other scatterers, including the abundant, but weakly-scattering copepods, and the relatively rare, but strongly-scattering pteropods and gas-bearing siphonophores.

\section{ACKNOWLEDGMENTS}

We gratefully acknowledge the support of all officers and crew of the RVIB N. B. Palmer and the staff of Raytheon Polar Services. The tireless efforts of all members of the BIOMAPER-II and MOCNESS teams were greatly appreciated: P. Alatalo, M. Butler, M. Dennett, K. Fisher, A. Girard, J. Peterson, and M. Taylor. We also thank P. Alatalo, N. Copley, P. Hull, and G. Rosenwaks for lab analyses of MOCNESS catches, and E. Hofmann, J. Klinck, and all the members of the CTD group for the use of their data and dynamic height estimates. D. Chu, A. Lavery, and T. Stanton provided much appreciated assistance with acoustic models, as well as advice concerning the assumptions of the single-frequency technique. Earlier versions of the manuscript benefited substantially from the comments of Jon Watkins and an anonymous reviewer. This project was supported by NSF U.S. Antarctic Program Grant OPP-9910307 to P. Wiebe, C. Ashjian, 
C. Davis, and S. Gallager. G. Lawson was supported by a Fulbright Scholarship, a Natural Sciences and Engineering Research Council of Canada Post-Graduate Scholarship, and an Office of Naval Research Graduate Traineeship Award in Ocean Acoustics (Grant N00014-03-1-0212). This is GLOBEC contribution number 431 and Woods Hole Oceanographic Institution contribution number 11124. 


\title{
Chapter 3
}

\section{Improved Parameterization of Antarctic Krill Target Strength Models}

\author{
ABSTRACT \\ There are historical discrepancies between empirical observations of Antarctic krill target \\ strength and predictions using theoretical scattering models. These differences are \\ addressed through improved understanding of key model parameters. The scattering \\ process was modeled using the Distorted-Wave Born Approximation, representing the \\ shape of the animal as a bent and tapered cylinder. Recently published length-based \\ regressions were used to constrain the sound speed and density contrasts between the \\ animal and the surrounding seawater, rather than the earlier approach of using single \\ values for all lengths. To constrain the parameter governing the orientation of the animal \\ relative to the incident acoustic wave, direct measurements of the orientation of krill in \\ situ were made with a Video Plankton Recorder. In contrast to previous indirect and \\ aquarium-based observations, krill were observed to orient themselves mostly \\ horizontally. Averaging predicted scattering over the measured distribution of \\ orientations resulted in predictions of target strength consistent with in situ measurements \\ of target strength of large krill (mean length 40-43 mm) at four frequencies $(43-420 \mathrm{kHz})$, \\ but smaller than expected under the semi-empirical model traditionally used to estimate \\ krill target strength.
}




\subsection{INTRODUCTION}

The Antarctic krill, Euphausia superba (henceforth referred to as 'krill'), is a key species of marine zooplankton linking primary producers and higher predators in the Southern Ocean (Laws, 1985), and is also the subject of a commercial fishery (Ichii, 2000). Abundance surveys for krill stock assessments and ecological studies typically employ acoustic techniques, as acoustics offer the advantage of continuous surveying over large areas in a short period of time. In order to relate acoustic measurements of echo energy to biological quantities like absolute abundance, however, it is critical to understand the efficiency with which the krill scatter sound, expressed in terms of their target strength. The present work seeks to address certain discrepancies that have resulted between theoretical and empirical approaches to understanding krill target strength.

Most modern acoustic surveys for krill, including those conducted by the international Committee for the Conservation of Antarctic Marine Living Resources (CCAMLR; SCCAMLR, 1991), employ the semi-empirical target strength model of Greene et al. (1991). This model relates target strength at the common survey frequency of $120 \mathrm{kHz}$ linearly to the logarithm of krill length, and was derived on a theoretical basis from empirical observations at $420 \mathrm{kHz}$ of a variety of crustacean taxa in an enclosure (Greene et al., 1989; Wiebe et al., 1990). Measurements of Antarctic krill swimming freely in an enclosure (Foote et al., 1990) and in situ observations (Hewitt and Demer, 1991) have yielded estimates of krill target strength consistent with the Greene et al. (1991) model.

Substantial progress has been made in the theoretical, physics-based modeling of the target strength of fluid-like crustacean zooplankton such as krill (reviewed in Stanton and Chu, 2000). State-of-the-art models employ the Distorted-Wave Born Approximation (DWBA) to estimate the scattering using a simplified description of the shape of the animal. Such an approach accounts for the fact that scattering is a complicated function of the animal's length, shape, orientation, and acoustic material properties, as well as the frequency being used. In the case of euphausiids (the order encompassing Antarctic krill), 
the shape has typically been modeled as some kind of deformed cylinder. Scattering is integrated along the lengthwise axis of the cylinder, taking into account the phase shift arising from deformation of this axis due to curvature and variations in cross-sectional radius (Chu et al., 1993; Stanton et al., 1993; McGehee et al., 1998; Stanton et al., 1998; Demer and Conti, 2003). Lavery et al. (2002) employed the DWBA to estimate scattering as the volume integral over a fully 3-D representation of the animal derived from computerized tomography. Target strengths predicted by these theoretical models have been verified by tank observations of individual tethered animals at a variety of frequencies, animal sizes, and angles of orientation relative to the incident acoustic wave.

Although theoretical predictions are mostly consistent with tank-based measurements where the exact size, shape, and angle of orientation of the animal are known, problems have arisen in parameterizing the models in such a way that their predictions are consistent with the Greene et al. (1991) relationship, while keeping the parameters within biologically plausible ranges (Demer and Conti, 2003, 2005). In particular, the greatest uncertainty has surrounded the parameters governing the orientation of the animal and its acoustic material properties. As an individual krill goes from a horizontal to vertical orientation, its target strength as observed by a vertically aimed echosounder decreases by two or more orders of magnitude (Stanton et al., 1998, McGehee et al., 1998). Similarly, it has long been recognized that for bodies filled with fluid similar to the surrounding medium, target strength is highly sensitive to small changes in the contrasts between the sound speed and density within the body and those of the medium (i.e., the 'acoustic material properties')(Anderson, 1950; Johnson, 1977; Holliday and Pieper, 1980; Greenlaw and Johnson, 1982; Chu et al., 2000).

In order to make field-applicable predictions of target strength, it is thus highly important to constrain properly these parameters governing orientation and acoustic material properties, but very little information exists concerning their natural distribution. Chu et al. (1993) and Demer and Conti (2005) have estimated krill orientation indirectly from measurements of volume backscattering and target strength, respectively, but no direct 
and quantitative measurements exist of krill in situ orientation. Acoustic material properties are typically assumed to be uniform within the animal's body and constant with respect to animal length, although Chu and Wiebe (2005) have shown that in the Antarctic krill both the sound speed and density contrasts are significantly related to length. When McGehee et al. (1998) used the then best-available observations made by Kils (1981) of krill orientation in an aquarium and by Foote (1990) of krill acoustic material properties to parameterize a DWBA-based scattering model, their predictions of krill target strength were ca. $6 \mathrm{~dB}$ lower than predicted by the Greene et al. (1991) semiempirical relationship.

Motivated by these discrepancies between the predictions of theoretical scattering models and the Greene et al. (1991) relationship, we seek to improve model parameterization. Backscattering from individual krill is predicted using the DWBA, representing the shape of the animal as a uniformly bent and smoothly tapered cylinder. Improved parameterization is achieved by making direct observations of krill in situ orientation with a Video Plankton Recorder (VPR; Davis et al., 1992). In contrast to previous studies where single values of the acoustic material properties have been used for all lengths of krill, we also apply Chu and Wiebe's (2005) length-based regressions of krill sound speed and density contrasts. We further assess the validity of this parameterization by making in situ observations of krill target strength at four frequencies.

\subsection{METHODS}

\subsubsection{Theoretical krill scattering model}

The scattering model employed here is the DWBA-based deformed cylinder model with homogeneous acoustic material properties first used by Chu et al. (1993) and Stanton et al. (1993), and expressed more explicitly in Stanton et al. (1998). The general formulation of the DWBA gives the far-field scattering amplitude in the backscatter direction $\left(f_{\text {bs }}\right)$ for a body of finite-length as an integral over the body's volume (Morse 
and Ingard, 1968). The DWBA assumes that the contrasts between the speed of sound and density within the body and the surrounding seawater are small (i.e., weakly scattering bodies) and that the body has negligible elastic properties, thereby not supporting shear waves (i.e., fluid-like).

Under the assumption that the shape of the animal can be approximated as a deformed cylinder (elongated and circular in cross-section), Stanton et al. (1998) showed that the volume integral of the general DWBA formulation can be reduced to a line integral along the cylinder's lengthwise axis. Various kinds of cylinders have been used to represent the krill's irregular shape, ranging through a progression of complexity including straight, smoothly tapered, uniformly bent, and randomly rough cylinders, as well as the case where non-uniform variations in cross-sectional radius are used to represent appendages (Stanton and Chu, 2000). We choose to model the krill's shape as a uniformly bent and smoothly tapered cylinder. This representation only coarsely captures the actual shape of the animal; additional justification for not using a higher resolution shape description is provided in the discussion.

In the case of a uniformly bent cylinder with radius of curvature $\rho_{\mathrm{c}}$, Stanton et al. (1998) give the expression for the scattering amplitude as:

$$
f_{\text {bs }}=\frac{k_{1} \rho_{\mathrm{c}}}{4} \mathrm{e}^{\mathrm{i} 2 k_{2} \rho_{\mathrm{c}}} \int a\left(\gamma_{\kappa}-\gamma_{\rho}\right) \mathrm{e}^{-\mathrm{i} 2 k_{2} \rho_{\mathrm{c}} \cos \beta_{\text {tilt }}} \frac{J_{1}\left(2 k_{2} a \cos \beta_{\text {tilt }}\right)}{\cos \beta_{\text {tilt }}} \mathrm{d} \beta_{\text {tilt }}
$$

where $k$ is the acoustic wave number in the surrounding seawater (subscript 1) and the body (subscript 2), $a$ is the cross-sectional radius of the cylinder, $\gamma_{\kappa}$ and $\gamma_{\rho}$ are related to the compressibilities $(\kappa)$, densities $(\rho)$, and sound speeds $(c)$ of the surrounding seawater (1) and the body (2) following $\gamma_{\kappa}=\left(\kappa_{2}-\kappa_{1}\right) / \kappa_{1}, \gamma_{\rho}=\left(\rho_{2}-\rho_{1}\right) / \rho_{2}$, and $\kappa=\left(\rho c^{2}\right)^{-1}, J_{1}$ is the Bessel function of the first kind of order one, and $\beta_{\text {tilt }}$ is the angle between the incident wave $\left(\mathbf{k}_{\mathbf{i}}\right)$ and the cross-section of the cylinder at each point along its axis (Stanton et al., 1998). 
To accommodate further the actual shape of the krill, the ends of the cylinder are tapered by making the radius a function of position along the lengthwise axis $(z)$ :

$$
a(z)=a_{0} \sqrt{1-\left(\frac{z}{L / 2}\right)^{T}}
$$

where $a_{0}$ is the radius of the cylinder at its mid-point, $T$ is a parameter controlling how quickly the cylinder tapers, and $L$ is the cylinder's length with $z=0$ the animal's midpoint (Chu et al., 1993).

Approximate solutions can be found for limiting expressions of Equation 3.1 with respect to wavelength, but more typically, the cylinder is discretized into a series of thin discshaped differential elements and the integral performed numerically.

The differential backscattering cross-section $\left(\sigma_{\mathrm{bs}}\right)$ is defined as the square of the magnitude of the backscattering amplitude, and target strength (TS) is simply $\sigma_{\mathrm{bs}}$ in decibel form (dB relative to $1 \mathrm{~m}^{2}$ ):

$$
\mathrm{TS}=10 \log \sigma_{\mathrm{bs}}=10 \log \left|f_{\mathrm{bs}}\right|^{2}
$$

\subsubsection{Model parameterization}

Predictions of target strength using the above model are clearly dependent on a variety of parameters, including those governing the animal's shape $\left(L, a_{0}, T\right.$, and $\left.\rho_{\mathrm{c}}\right)$, its acoustic material properties $\left(\gamma_{\kappa}\right.$ and $\left.\gamma_{\rho}\right)$, and its orientation $\left(\beta_{\text {titt }}\right)$. As indicated above, the parameters $\gamma_{\kappa}$ and $\gamma_{\rho}$ are themselves functions of the sound speed and density contrasts between the animal and the surrounding medium $\left(h=c_{2} / c_{1}\right.$ and $g=\rho_{2} / \rho_{1}$, respectively). The emphasis here is on properly constraining the key parameters of krill orientation and acoustic material properties. 
Target strength was therefore predicted on the basis of various combinations of

orientation and sound speed and density contrast values. Predictions at a frequency of 120 $\mathrm{kHz}$ were made for cylinder lengths of 4 to $70 \mathrm{~mm}$, in $1 \mathrm{~mm}$ increments. Predictions were also made holding length constant at $43.3 \mathrm{~mm}$, for frequencies of 5 to $500 \mathrm{kHz}$, in $5 \mathrm{kHz}$ increments.

The equivalent cylinder used to represent the krill's shape was defined on the basis of the animal's average radius $\left(a_{0}\right)$ and 'acoustic' length $(L)$, defined as the distance from the anterior of the eye to the end of the sixth abdominal segment (Table 3.1), following the approach of Stanton and Chu (2000). Other than length, the shape parameters were held constant for all simulations: a slight taper parameter $T$ of 10 was used, and the crosssectional radius of the cylinder at its mid-section was related to length via $a_{0}=L / 18.4$. This constant was derived by measuring the length and average radius (averaged over 10 measurements along the animal's length) of 50 preserved krill captured with nets (see below). The radius of curvature was taken to be $\rho_{\mathrm{c}}=3 \mathrm{~L}$, based on measurements of 50 randomly-chosen krill observed with the Video Plankton Recorder, but note that backscattering cross-sections averaged over a range of angles of orientation (as is done here, see below) are mostly independent of the cylinder's bend, for $\rho_{\mathrm{c}} \geq 2 L$ (Stanton $e t$ al., 1993).

\subsection{2.a Sound speed and density contrasts}

Chu and Wiebe (2005) showed that the sound speed and density contrasts of Antarctic krill are significantly related to animal length. The $g$ and $h$ values used to parameterize the scattering model were therefore estimated from their regression equations:

$$
\begin{aligned}
& g=5.439 \times 10^{-4} L(\mathrm{~mm})+1.002 \\
& h=4.981 \times 10^{-4} L(\mathrm{~mm})+1.009
\end{aligned}
$$


Table 3.1 - Length definitions. Different lengths were required for the various purposes of the present study due to differences in how previous workers have defined krill length. Standard lengths (SL) 1 and 3 are from Mauchline (1980b). AL is the 'acoustic' length of the equivalent cylinder used to represent the krill's shape in modeling krill target strength.

\begin{tabular}{|c|c|c|c|}
\hline Name & Definition & Use in the present work & $\begin{array}{l}\text { Relation } \\
\text { to SL3 }\end{array}$ \\
\hline SL 1 & $\begin{array}{l}\text { Anterior tip of rostrum to } \\
\text { posterior end of uropods }\end{array}$ & $\begin{array}{l}\text { Length used in sound speed and density } \\
\text { contrast regression equations }\end{array}$ & $1.236 \times \mathrm{SL} 3$ \\
\hline $\mathrm{AL}$ & $\begin{array}{l}\text { Anterior of eye to end of sixth } \\
\text { abdominal segment }\end{array}$ & $\begin{array}{l}\text { Length of the equivalent cylinder used to } \\
\text { represent the krill in modeling target strength }\end{array}$ & $1.069 \times \mathrm{SL} 3$ \\
\hline SL 3 & $\begin{array}{l}\text { Posterior base of eye stalk to end } \\
\text { of sixth abdominal segment }\end{array}$ & $\begin{array}{l}\text { Length measured in silhouette analysis of } \\
\text { MOCNESS catches }\end{array}$ & - \\
\hline
\end{tabular}


where, length $(L)$ is Standard Length 1 (Table 3.1). The acoustic material properties were assumed not to vary within the animal, and so single values for each of these parameters were calculated for each krill length examined. For comparison, predictions of target strength were also made based on the length-invariant krill material property measurements of Foote $(1990)(g=1.0357, h=1.0279)$. The minimum size of animal examined by $\mathrm{Chu}$ and Wiebe (2005) was $25 \mathrm{~mm}$. Extrapolating for lengths smaller than this increasingly produced implausibly small estimates of $g$ and $h$. The material properties estimated from the regressions for a $25 \mathrm{~mm}$ long animal therefore were used for lengths smaller than $25 \mathrm{~mm}$. Note that the Chu and Wiebe (2005) measurements were made on krill collected in the same study area and at the same time of year (austral fall) as the empirical observations of krill orientation and target strength described below, but a year later (2002).

\subsection{2.b Animal orientation}

Equation 3.1 allows the scattering amplitude to be predicted for an individual animal of a given length at a single angle of orientation $(\theta)$, defined as the angle between the line joining the bent cylinder's ends and the horizontal plane. Assuming a vertically aimed echosounder, an animal oriented horizontally in the water $\left(\theta=0^{\circ}\right)$ is at normal acoustic incidence. At the cylinder's mid-point, the relationship between $\beta_{\text {tilt }}$ and $\theta$ is simply $\beta_{\text {tilt }}=$ $\theta$, while elsewhere along the cylinder's axis, it varies due to the cylinder's curvature.

In linear echo-integration theory, the echoes from individual animals within the acoustic beam are assumed to sum incoherently to yield measurements of volume backscattering. In order to simulate the averaging over ensembles of many individuals that occurs during echo-integration surveys, average scattering for each krill length investigated was calculated over a probability density function of angles of orientation $(w(\theta))$, following: 


$$
\bar{\sigma}_{\mathrm{bs}}=\int_{\theta} \sigma_{\mathrm{bs}}(\theta) w(\theta) \mathrm{d} \theta
$$

Average target strength (averaged with respect to the argument of the logarithm) was then defined as:

$$
\overline{\mathrm{TS}} \equiv 10 \log \bar{\sigma}_{\mathrm{bs}}
$$

Average scattering was calculated in this way for the observed probability density function of angles of orientation described below. An important assumption of the present work is that the distribution of orientations observed here for krill of length 3 to $15 \mathrm{~mm}$ (see results section 3.3.1) also applies to larger individuals (up to $70 \mathrm{~mm}$ ). This point will be addressed in the discussion. For comparison, average scattering was also calculated over the normal distribution of orientations observed in an aquarium by Kils (1981), $N\left(\bar{\theta}, \sigma_{\theta}\right)=N\left(45.3^{\circ}, 30.4^{\circ}\right)$, where $\bar{\theta}$ is the mean angle of orientation and $\sigma_{\theta}$ the associated standard deviation. Similarly, for some comparisons, a length-averaged predicted scattering was calculated at each length under investigation by averaging over a distribution of neighbouring animal lengths.

\subsubsection{Empirical approach}

Video, acoustic, and environmental data were collected from the RVIB N.B. Palmer in April-June of 2001, as part of the U.S. Southern Ocean GLOBal ECosystems Dynamics program (GLOBEC; Hofmann et al., 2002). The study site was a continental shelf region west of the Western Antarctic Peninsula (Figure 3.1). All data were collected with the BIo-Optical Multi-frequency Acoustical and Physical Environmental Recorder (BIOMAPER-II; Wiebe et al., 2002), a towed system consisting of a multi-frequency echosounder, a Video Plankton Recorder (VPR), and an environmental sensor package (Conductivity, Temperature, and Depth sensor; fluorometer; transmissometer). The 


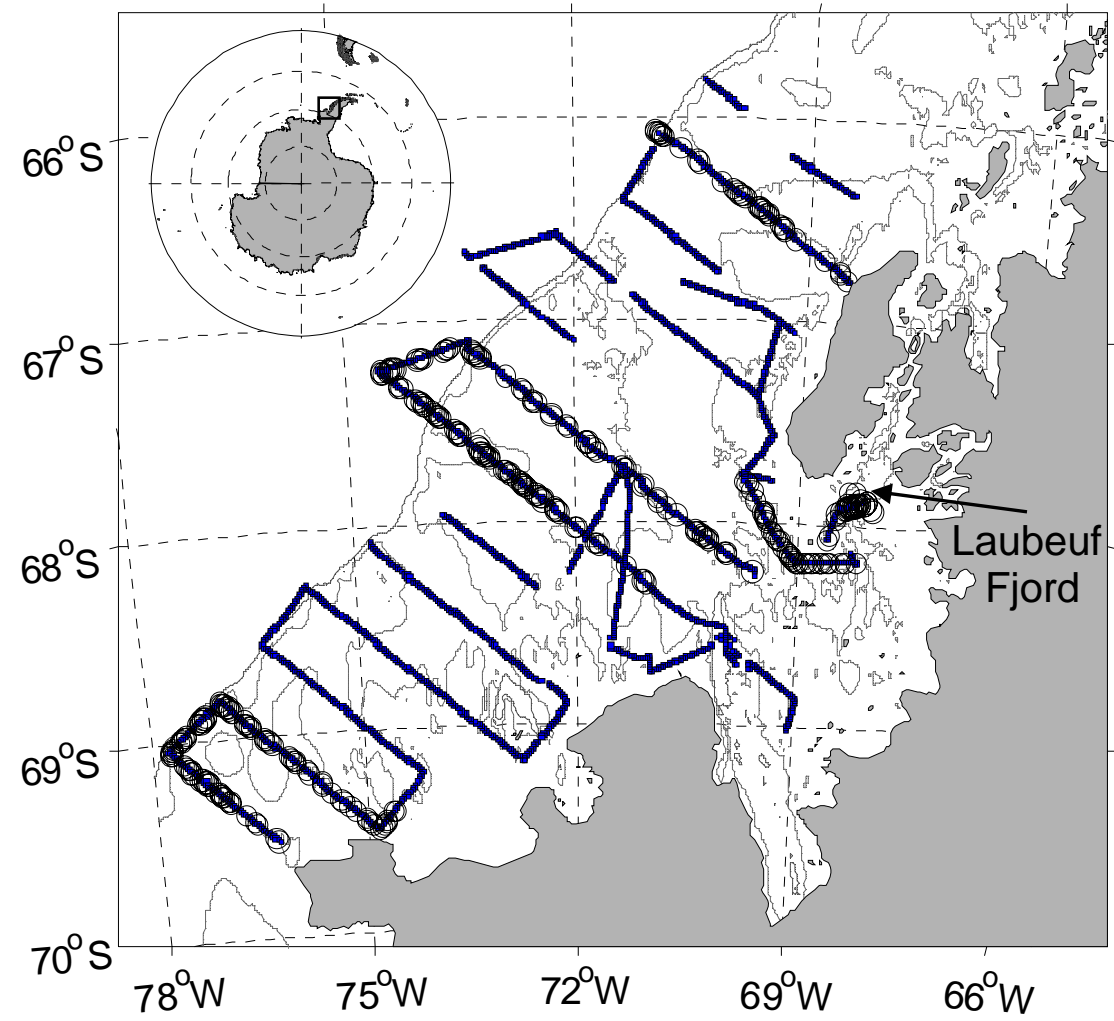

Figure 3.1 - Study site, covering a region of the continental shelf west of the Western Antarctic Peninsula. Black lines show survey transects along which acoustic, video, and environmental data were collected. Circles indicate the sub-sections of these lines where video images of krill were captured and analyzed. Contours show the 450 and $1000 \mathrm{~m}$ isobaths. Laubeuf Fjord is the region where direct measurements were made of krill target strength and where two net tows sampled acoustically-identified krill patches. 
BIOMAPER-II was 'towyoed' obliquely up and down through the water column between 20 and $300 \mathrm{~m}$ depth as the vessel proceeded along the track-line between stations at 4 to 6 knots, and surveying was conducted around the clock. Data were collected along 13 transect lines running across the continental shelf and perpendicular to the Peninsula coastline; sub-sections of these lines were selected for analysis of krill orientation (Figure $3.1)$.

\subsection{3.a Measuring the in situ orientation of krill}

Measurements of krill in situ orientation were made directly from still digital images captured from video collected with the VPR, in a similar manner to Benfield et al. (2000). The VPR consisted of a camera and $16 \mathrm{~W}$ strobe mounted on the towbody forward of the tow point, separated by $0.5 \mathrm{~m}$, and aimed towards one another and perpendicular to the direction of the body's motion. The field of view of the camera was calibrated using a translucent grid placed in the center of focus, and was found to be $31 \mathrm{x}$ $24.5 \mathrm{~mm}$ (width by height). The camera sampled at a rate of $60 \mathrm{~Hz}$, synchronized to the strobe. Video fields were time stamped and digitized at a resolution of 640 by 207 pixels. Regions of each field that were in focus were automatically extracted, and saved as Tagged Image File Format (tif) images (see Davis et al. (1996) for additional details).

These images were then visually examined and only images that were definitely krill, where the animal's whole body was in the frame, and the image was in focus, were used for further analysis. In response to vigorous disturbances, krill are known to perform a rapid tail-flip response (O'Brien, 1987). Animals performing such a tail-flip often were captured in video images (Figure 3.2a); such images were excluded from analysis.

For the remaining images, the horizontal $(d x)$ and vertical $(d y)$ excursions in pixels from the tail of each krill to its eye were measured (Figure 3.2b), and the animal's angle of orientation $(\theta)$ calculated as: 


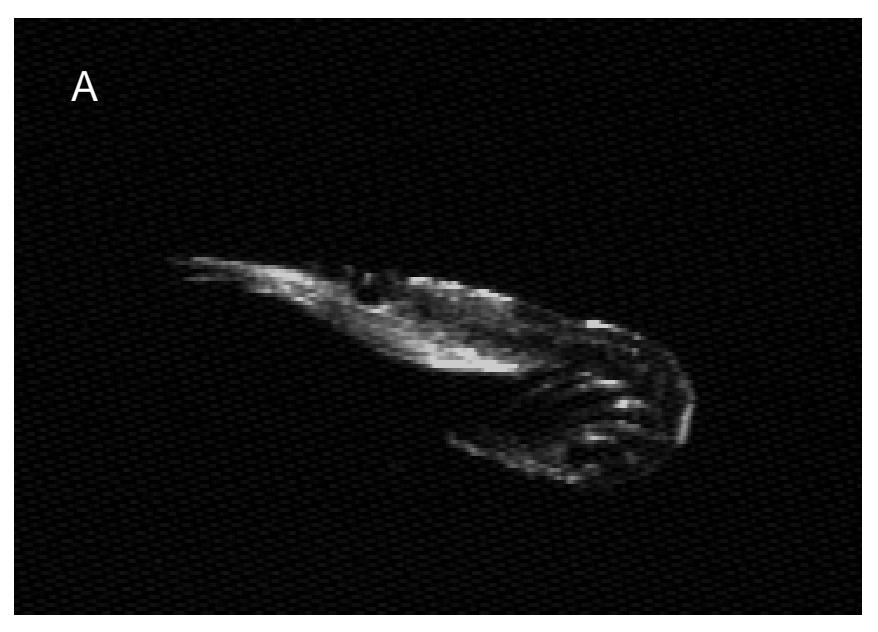

B

Figure 3.2 - Representative krill images. (A) A typical krill exhibiting the tail-flip escape response. (B) A krill of length $11.1 \mathrm{~mm}$ oriented at $-9.4^{\circ}$ relative to the horizontal. The horizontal $(d x)$ and vertical $(d y)$ excursions from the animal's tail to its eye were measured in pixels. Knowing the size of the field of view in both pixels and distance, the animal's orientation relative to horizontal $(\theta)$ and length $(L)$ were then calculated. 


$$
\theta=\tan ^{-1}\left(d y \frac{\text { fov height } \mathrm{mm}}{\text { fov height pixels }} / d x \frac{\text { fov width } \mathrm{mm}}{\text { fov width pixels }}\right)
$$

where fov denotes the field of view. Length $(L)$ was calculated via the Pythagorean theorem. An animal oriented perfectly horizontal was defined as being at an angle of $0^{\circ}$ and one oriented belly-up as $180^{\circ}$, with positive angles indicating a head upwards tilt.

In order to use the horizontal and vertical extent of the animal from the image to calculate orientation relative to the horizontal, only images where the krill was perpendicular to the direction faced by the camera, and where the animal was in side-view, were analyzed (Benfield et al., 2000). Identifying animals in side-view was done by looking for overlap of the eyes and inspecting the legs. Determining whether animals were plane to the camera was done by visually assessing the ratio of the vertical to horizontal extent of different segments of the animal.

To confirm that the detection and extraction of krill images by the VPR system were not biased against any particular angles of orientation due to insufficient illumination or focus level, segments of the raw videotapes were examined and the intensity and focus level of extracted krill images analyzed in relation to the measured angle of orientation. No such bias was evident.

These measurements of krill orientation relative to the reference frame of the camera then had to be corrected for the pitch of the towed body in order to give the orientation relative to true horizontal. Data were collected on the pitch of the BIOMAPER-II every five seconds. To capture the gross behavior of the body while reducing error associated with high frequency variability, the pitch data were subjected to a ten-point median filter. The filtered pitch observation made nearest in time to each image was then used to correct the measured angles of orientation. Corrections were also made based on interpolations of the raw and median-filtered pitch data, but the resulting distributions of orientations differed little from the previously-described correction protocol. Since the body's pitch 
was especially variable when the vessel was on station, only images collected while the vessel was moving along survey transects were considered.

\subsection{3.b Measuring the in situ target strength of krill}

Measurements of acoustic target strength were made at frequencies of 43, 120,200, and $420 \mathrm{kHz}$, for comparison with theoretical predictions. All transducers were circular and split-beam, with $3^{\circ}$ half-power beamwidths, other than the $7^{\circ}$-wide $43 \mathrm{kHz}$ transducers. Each transducer was acoustically calibrated by the manufacturer (Hydroacoustic Technologies Inc., Seattle, WA, USA) prior to the cruise for source level, receive sensitivity, electro-mechanical 'stiffness' (used to determine the position of a target within the split-beam), and transmit and receive beam patterns. An in situ calibration with a $38 \mathrm{~mm}$ tungsten carbide (6\% cobalt) standard target also was performed during a cruise later that year. A $10 \mathrm{kHz}$ bandwidth chirp pulse was used, with an effective pulse duration of $0.18 \mathrm{~ms}$, and a ping rate of 0.3 pings s$^{-1}$. The system's dynamic range allowed target strength data to be collected between -100 and $-40 \mathrm{~dB}$. Profiles of noise levels (ship's noise, ambient noise, and system noise combined) vs. depth were made in situ near the start of each cruise. Target strength measurements smaller than these noise levels were not recorded. Information on the target's location within the beam from split-beam analysis was used to remove the effects of beam-pattern. In order to reduce the likelihood that multiple targets were mistakenly accepted as individual target strengths, only measurements made at a beam pattern factor (an indicator of off-axis position) between 0 and $-3 \mathrm{~dB}$, where the length of the received acoustic pulse at half-power was within $12.5 \%$ of the transmitted pulse, and at a range of less than $13 \mathrm{~m}(8 \mathrm{~m}$ for the $43 \mathrm{kHz})$ were included for analysis. Densities in the aggregations were estimated to be ca. 5 individuals $\mathrm{m}^{-3}$, and so the selected maximum ranges limited observations to cases where on average there was less than one animal per ensonified volume.

Measurements of target strength were made continuously over the course of the survey. Due to uncertainties in associating particular target strength observations with particular 
taxa, the focus here is on measurements made in Laubeuf Fjord at the end of the cruise (Figure 3.1). Large patches of enhanced volume backscattering were present in this location (Lawson et al., 2004; Wiebe et al., 2004). Using a $1 \mathrm{~m}^{2}$ Multiple Opening/Closing Net and Environmental Sensing System (MOCNESS; Wiebe et al., 1985), 8 discrete samples were collected through these patches at depths between 50 and $100 \mathrm{~m}$, at each of two closely separated tow locations within the fjord (tow numbers M21 and M22; Wiebe et al., 2004). Both net catches and VPR observations confirmed that these acoustically-observed patches were composed almost exclusively of krill. The net catches provide an estimate of the length distribution of the krill in these patches, allowing the observations of target strength to be associated with a particular length range of krill. Krill lengths were measured for an aliquot of each net sample using the silhouette method of Davis and Wiebe (1985) as Standard Length 3, and multiplied by constant scaling factors to arrive at the lengths used for modeling target strength and estimating $g$ and $h$ (Table 3.1).

\subsection{RESULTS}

\subsubsection{In situ observations of krill orientation}

In total, the orientations of 972 individual krill were measured. The median and mean of the entire distribution of measured angles, for all lengths of krill observed combined, were $-0.5^{\circ}$ and $9.7^{\circ}$, respectively, with a standard deviation of $59.3^{\circ}$ (Figure 3.3). Defining the dominant mode as all observations between $-100^{\circ}$ and $100^{\circ}$, the median and mean of this mode were $-3.4^{\circ}$ and $0^{\circ}$, respectively, with a standard deviation of $27.3^{\circ}$ (Figure 3.3). Two smaller modes also were evident, centered near $140^{\circ}$ and $-160^{\circ}$.

Between day (0900-1500h) and night (1700-0700h), the central mode shifted from slightly above $0^{\circ}$ to slightly below ( $t$-test for day/night differences $t=6.02, p<1 \times 10^{-8}$ ). More observations were made by night (625) than by day (211), perhaps explaining why the distribution over all measurements was slightly negative. The distribution of observed 


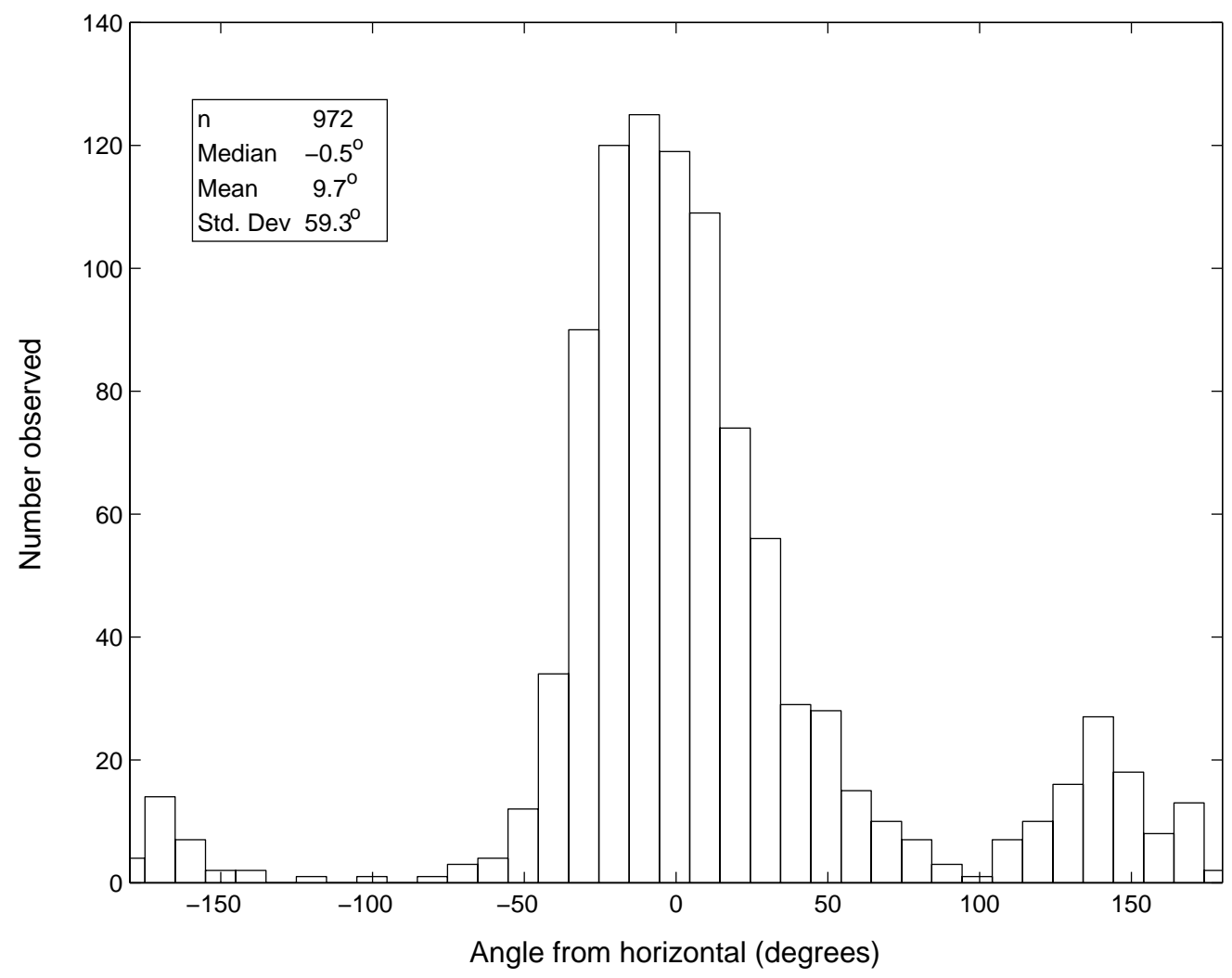

Figure 3.3 - Frequency distribution of angles of orientation for all lengths of krill combined, after correction for the pitch of the towed body. The median and mean of the entire distribution were $-0.5^{\circ}$ and $9.7^{\circ}$, respectively, with a standard deviation of $59.3^{\circ}$. Defining the central mode as all observations between $-100^{\circ}$ and $100^{\circ}$, the median and mean of this mode were $-3.4^{\circ}$ and $0^{\circ}$, respectively, with a standard deviation of $27.3^{\circ}$. 
orientations broadened with estimated krill length for lengths between 4 and $6 \mathrm{~mm}$, and then narrowed for greater lengths (Figure 3.4). At estimated lengths greater than $6 \mathrm{~mm}$, the smaller modes near $140^{\circ}$ and $-160^{\circ}$ were no longer evident.

\subsubsection{Scattering model predictions}

Averaging scattering predictions from the DWBA-based deformed cylinder model over this VPR-derived distribution of angles of orientation following Equation 3.6 resulted in higher average target strengths at $120 \mathrm{kHz}$ relative to krill length than with the Kils (1981) distribution (Figure 3.5). Although scattering is a complex function of animal length, shape, orientation, material properties, and frequency, we choose to plot target strength in relation to length (specifically the 'acoustic' length of Table 3.1) as this is the parameter most familiar to biologists and most relevant to ecological studies. These predictions were made with Foote's (1990) single values for the sound speed and density contrast parameters for all krill lengths, and with averaging only over orientation and not over length. Note also that the VPR-derived orientation distribution observed for krill of length 3-15 $\mathrm{mm}$ is being applied to a broader range of lengths $(4-70 \mathrm{~mm})$. No difference was evident in model predictions for the daytime distribution of orientations as compared to that measured at night (not shown).

When the length-based regressions of Chu and Wiebe (2005) were used to estimate the material properties for each length examined, and these parameters were used in combination with the VPR-derived distribution of orientations, modeled target strengths were smaller than with the Foote (1990) values for lengths below $43 \mathrm{~mm}$ but larger for animals above this length. To simulate further the averaging over ensembles of individuals that occurs during echo-integration surveys, length-averaged predicted scattering at each length under investigation was calculated over a normal distribution of neighbouring animal lengths with a standard deviation of $15 \%$ of the mean (corresponding to the observed length variability from net tow M22). This averaging over length was done in addition to the averaging over the observed distribution of 


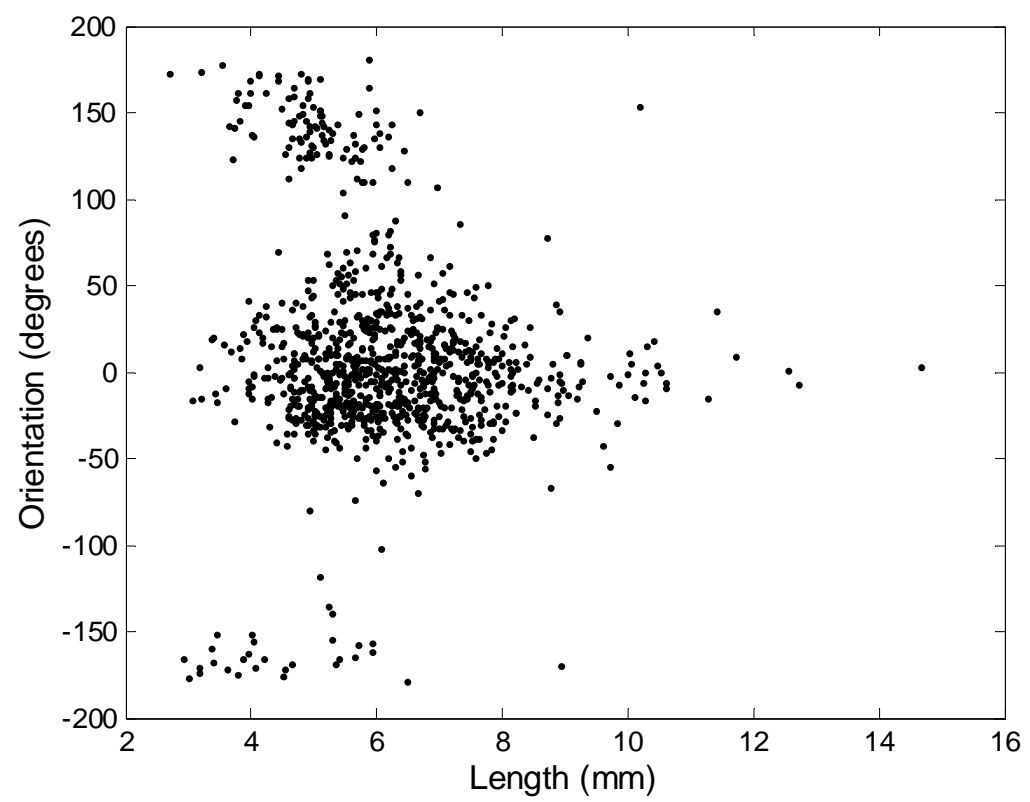

Figure 3.4 - Measured orientations in relation to krill length (mm). 


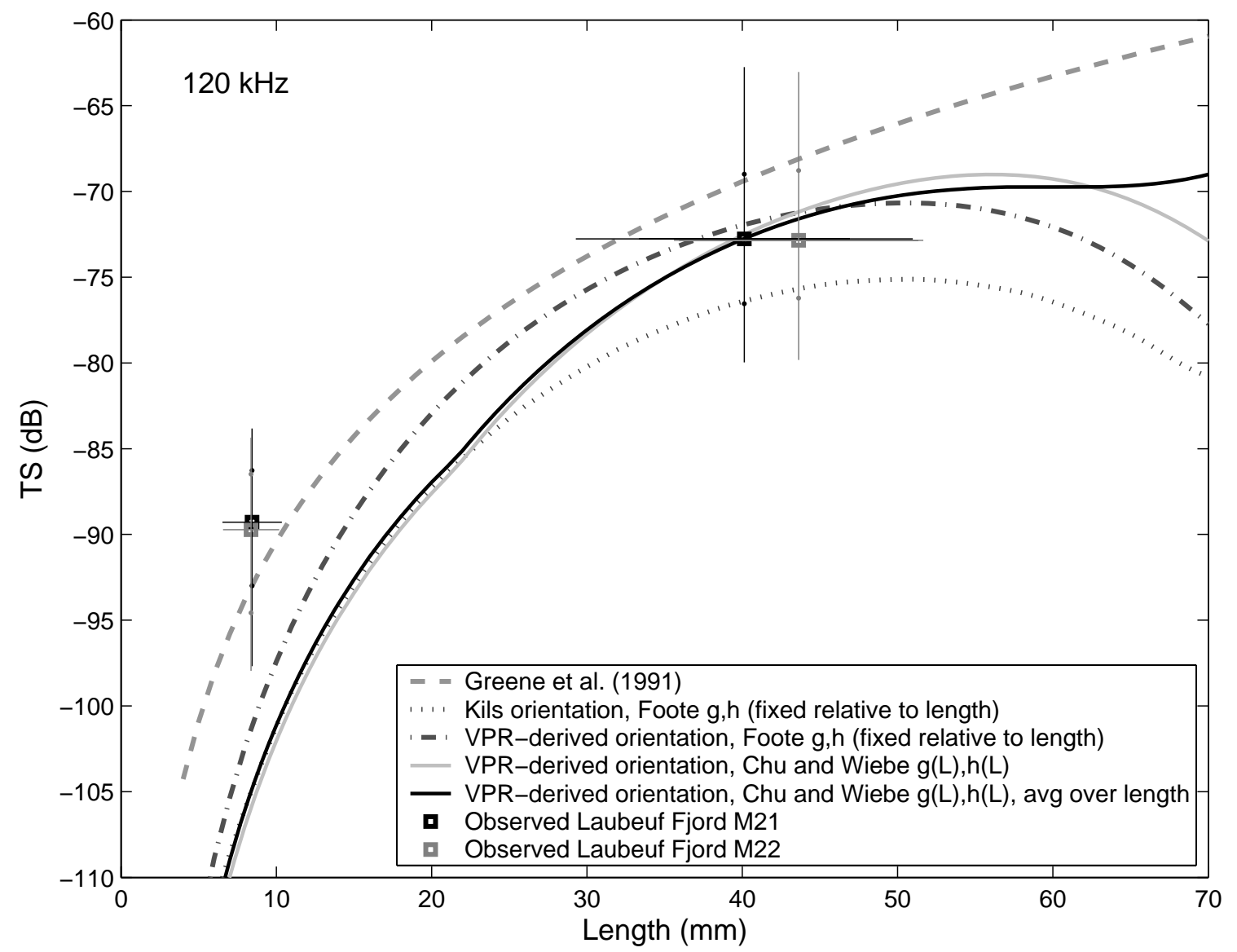

Figure 3.5 - Krill target strength ( $\overline{\mathrm{TS}}$ ) at $120 \mathrm{kHz}$ in relation to length (mm; Standard Length 2, Table 3.1), averaged over orientation. Dashed gray line shows the Greene et al. (1991) and SC-CCAMLR (1991) empirical regression line TS $=-127.45+34.85$ $\log _{10}$ (length in $\mathrm{mm}$ ), where length is Standard Length 1 . All other lines indicate different parameterizations of the theoretical DWBA-based bent cylinder model, involving various combinations of the Foote (1990) length-invariant sound speed $(h)$ and density $(g)$ contrast measurements, the Chu and Wiebe (2005) $g$ and $h$ vs. length $(L)$ regressions, Kils' (1981) aquarium observations of krill orientation, and the present VPR-derived in situ orientation measurements. Solid black line indicates predicted scattering averaged over a distribution of lengths (standard deviation $=15 \%$ of the mean). Squares show median in situ measurements of krill target strength made in Laubeuf Fjord relative to the mean length of krill sampled at the same depths and locations as the two net tows (M21 and M22 as black and gray squares, respectively). Vertical lines show $10^{\text {th }}$ and $90^{\text {th }}$ percentiles of target strength measurements, dots show the $25^{\text {th }}$ and $75^{\text {th }}$ percentiles. Horizontal lines represent one standard deviation from the mean length. 
orientations described above, and resulted in a smoothing of the null in the target strength vs. length relationship beyond $55 \mathrm{~mm}$ (Figure 3.5).

In comparison to the Greene et al. (1991) semi-empirical target strength model, the present model parameterized with Chu and Wiebe's (2005) material property relationships and the VPR-derived orientation distribution resulted in lower target strength predictions for all krill lengths, particularly for animals smaller than $25 \mathrm{~mm}$ and larger than $55 \mathrm{~mm}$.

\subsubsection{Model verification with empirical in situ target strength observations}

In situ observations of target strength within the acoustically-observed patches in the vicinity of the two net tow locations in Laubeuf Fjord were bimodal at all four frequencies employed here (Figure 3.6). The length distributions of krill sampled in the two net tows were similarly bimodal (see appendices in Wiebe et al., 2004), allowing the small and large modes of the target strength distributions to be associated with the corresponding modes evident in the length distributions. The small and large modes of the length distribution from tow M21 had means of 8.4 and $40.5 \mathrm{~mm}$, respectively, and for tow M22 were 8.4 and $43.3 \mathrm{~mm}$. For both tows, the standard deviations of length were 22 and $15 \%$ of the mean, for the small and large modes, respectively.

Determining the central tendencies for the target strength modes was less straightforward, since the left-hand tail of the smaller mode was cut of by the system's threshold of -100 $\mathrm{dB}$, while the right-hand tail of the smaller mode overlapped with the left-hand tail of the larger one (Figure 3.6). Such issues of overlap and thresholding are well appreciated (Foote et al., 1986). For simplicity, the krill target strengths were assumed to be Rayleigh distributed, even though it is known that this is often not the case (Stanton et al., 2004). A Rayleigh distribution was fit to the smaller mode and used to extrapolate the target strength distributions below the $-100 \mathrm{~dB}$ threshold and above the point where overlap began with the larger mode $(-83 \mathrm{~dB}$ at $43 \mathrm{kHz}$, and $-80 \mathrm{~dB}$ at 120,200 , and $420 \mathrm{kHz})$; the 

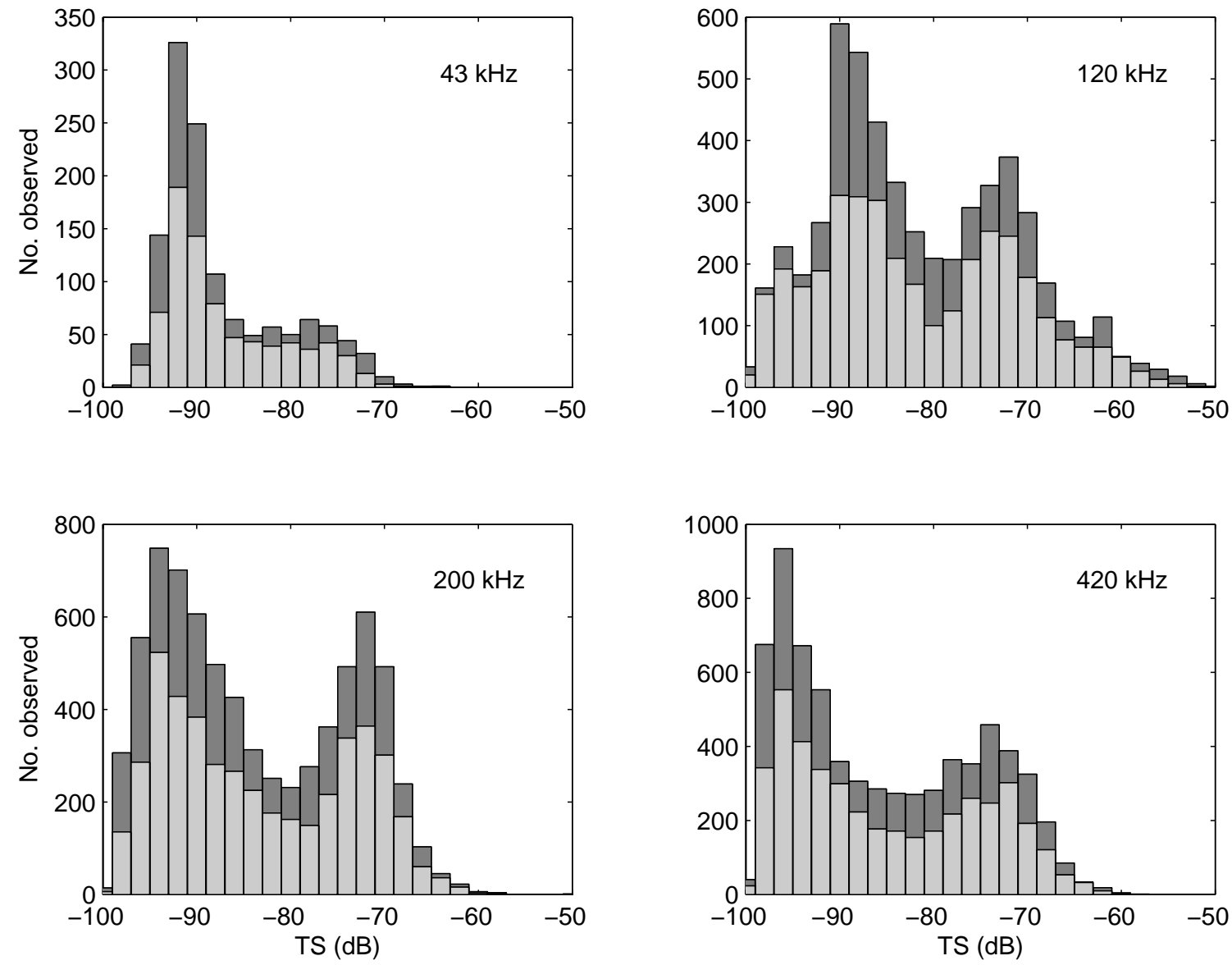

Figure 3.6 - Frequency distributions of in situ observed target strengths at 43, 120, 200, and $420 \mathrm{kHz}$ measured at the two net tow locations in Laubeuf Fjord (M21 and M22 indicated by dark and light gray bars, respectively). 
larger mode distribution was similarly extrapolated below this point of overlap.

Following extrapolation, the median of each target strength mode was calculated. The magnitude of the difference between the medians of the original truncated data and the extrapolated data never exceeded $1 \mathrm{~dB}$.

After extrapolation, the median of the larger target strength mode at $120 \mathrm{kHz}$ was found to be $-72.8 \mathrm{~dB}$ in the vicinity of both net tow locations. This median target strength for the sampled length range is consistent with our newly parameterized target strength model (Figure 3.5). We consider the median rather than the mean of the target strength distributions in order to reduce any potential bias towards higher values due to erroneous acceptance of multiple targets. The smaller mode of the $120 \mathrm{kHz}$ target strength distribution was centered at $-89.3 \mathrm{~dB}$ for tow M21 and $-89.7 \mathrm{~dB}$ for tow M22 (Figure $3.5)$.

The DWBA bent cylinder model parameterized with the VPR-derived distribution of orientations and the Chu and Wiebe (2005) material property relationships was also used to predict the target strengths at increasing frequencies for a normal distribution of animals with mean length $43.3 \mathrm{~mm}$ and a standard deviation of $15 \%$. Median target strengths after extrapolation for the larger modes of our direct measurements of target strength at all four frequencies were generally consistent with the theoretical predictions (Figure 3.7). The measurements at $200 \mathrm{kHz}$ compared less favorably to the predictions, likely due to error associated with the transducers at this frequency being calibrated less exhaustively than the others.

\subsection{DISCUSSION}

Krill observed in this study were found to orient themselves in a mostly horizontal fashion. This corresponds to normal acoustic incidence relative to a standard vertically aimed echosounder. When applied in conjunction with the length-based sound speed and density contrast relationships of Chu and Wiebe (2005), the observed distribution of 


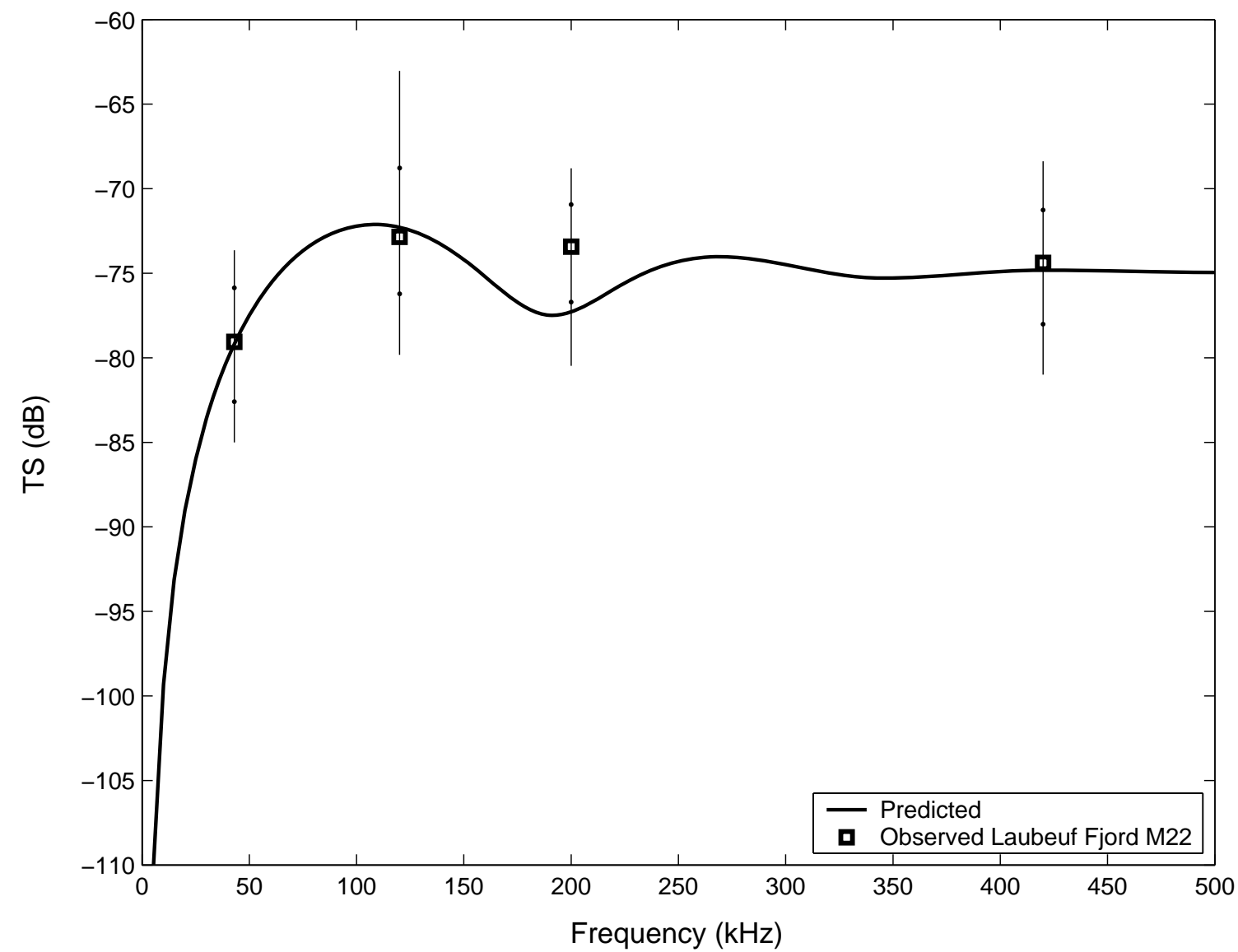

Figure 3.7 - Average target strength in relation to acoustic frequency $(\mathrm{kHz})$. Solid line shows the predictions from the DWBA bent cylinder model parameterized with the Chu and Wiebe (2005) material property relationships and the VPR-derived orientation distribution. Predicted differential backscattering cross-sections were averaged over a normal length distribution with mean $43.3 \mathrm{~mm}$ and a standard deviation $=15 \%$ of the mean, corresponding to the observed length distribution from tow M22. Squares indicate median observed target strengths at the four BIOMAPER-II frequencies $(43,120,200$, and $420 \mathrm{kHz}$ ) in the vicinity of tow M22. Vertical lines show $10^{\text {th }}$ and $90^{\text {th }}$ percentiles of observed target strength; dots show the $25^{\text {th }}$ and $75^{\text {th }}$ percentiles. 
orientations produced target strength predictions from a theoretical DWBA-based scattering model that are consistent with in situ observations of large krill target strength, but smaller than expected from the semi-empirical model of Greene et al. (1991).

Very few previous studies have examined directly the orientation of Antarctic krill or other euphausiids. Based on the qualitative observations of divers, Hamner et al. (1983) reported that schooling krill are always aligned uniformly and horizontally within aggregations, and that even when ascending or descending orient at no more than a $5^{\circ}$ to $10^{\circ}$ angle. Similar to the present study, Kristensen and Dalen (1986) used underwater photography to measure the orientation of euphausiids (Meganyctiphanes norvegica and Thysanoessa spp.) in two Norwegian fjords, and found that the mean orientation changed from slightly positive by night to slightly negative during the day. In contrast, observations made with a camera of the in situ orientation of similar euphausiid species in the Gulf of St. Lawrence revealed a shift in mean orientation from $27^{\circ}$ at 1400 to $51^{\circ}$ at 0200, albeit with fairly high variability about this trend (Sameoto, 1980).

Quantitative observations of krill in ship-board aquaria (with volumes of $0.06-0.22 \mathrm{~m}^{3}$ ) have indicated that krill hover at a mean angle of approximately $45^{\circ}$ from horizontal (Kils, 1981; Endo, 1993). Kils (1981) also calculated, however, that it is energetically more favourable for krill to swim at speeds of 3 to $10 \mathrm{~cm} \mathrm{~s}^{-1}$ than to hover, due to hydrodynamic lift. Kils (1981) further observed increasingly horizontal orientations at greater swimming speeds, with speeds of 3 to $10 \mathrm{~cm} \mathrm{~s}^{-1}$ corresponding to angles of $30^{\circ}$ to $<10^{\circ}$ (similar to observations by Miyashita et al. (1996) of E. pacifica). Our measurements of Antarctic krill orientation are thus consistent with these aquarium studies, if the wild krill are mostly swimming rather than hovering. Supporting this latter notion, observations of $M$. norvegica swimming behavior via acoustic target tracking revealed that this euphausiid swims at a modal speed of ca. $4 \mathrm{~cm} \mathrm{~s}^{-1}$, and there were virtually no observations of stationary individuals (Klevjer and Kaartvedt, 2003). 
Krill orientation has also been estimated indirectly from acoustic observations. On the basis of Foote et al.'s (1990) measurements of krill target strengths at 38 and $120 \mathrm{kHz}$ in an experimental enclosure, and using the same theoretical scattering model as employed here, Chu et al. (1993) inferred that the krill oriented on average at $20^{\circ}$ from horizontal $\left(N\left(20^{\circ}, 20^{\circ}\right)\right)$. More recently, Demer and Conti (2005) used a related theoretical scattering model to estimate an orientation distribution of $N\left(15^{\circ}, 5^{\circ}\right)$ from measurements of volume backscattering at 38 and $120 \mathrm{kHz}$ attributed to krill. These results are encouragingly similar to the present observations; the means from both studies fall within less than one standard deviation of the dominant mode of the VPR-derived measurements. In order to infer orientation from observations of volume backscattering or target strength, however, it is necessary to know that the acoustic measurements stem uniquely from krill and not from other scatterers, and all other parameters in the scattering model must be properly constrained. Discrepancies between our measurements of orientation and those from earlier indirect studies may stem from uncertainty in these factors. In the case of the Chu et al. (1993) study, the estimated distribution of orientations may also have been affected by the krill being in an enclosure where some of them may have been hovering. Our approach to measuring krill orientation is appealing as it captures directly the in situ orientation of the krill in the vicinity of a towed acoustic system. The similarity between our measurements of orientation and the estimates made by Demer and Conti (2005) from a vessel-mounted transducer may also suggest that the krill are not substantially disturbed by the passage of the survey vessel.

In using the distribution of krill orientations measured here to parameterize the theoretical krill target strength model, we make two important assumptions. First, we assume that the orientation distribution for the sizes of krill captured by the video system $(\sim 3-15 \mathrm{~mm})$ also applies to larger individuals. Krill start to exhibit schooling behavior at $10 \mathrm{~mm}$ in length, and aggregations of krill at this size display characteristics identical to those of adults, including uniform orientation and spacing (Hamner et al., 1989). In the absence of any other information, it thus seems reasonable to assume that both large and small krill possess similar aggregative behaviors and thereby similar orientations. 
Second, we assume that the orientations of the animals observed were not influenced by the presence of the towed body. Hamner and Hamner (2000) found that krill responded to a diver transport vehicle towed at $1 \mathrm{kn}$ by swimming horizontally away, but that tow speeds of 2-4 kn elicited the well-known tail-flip escape response. At a horizontal tow speed of 4-6 kn, and a vertical speed of ca. $0.2 \mathrm{kn}$, any krill able to respond to the BIOMAPER-II towed body before being captured by the video system would be expected to employ the tail-flip response. Many images of krill exhibiting such a response were indeed captured, but excluded from analysis.

Although the dominant mode of krill orientation distribution was centered at $0^{\circ}$, lesser modes were present near $140^{\circ}$ and $-160^{\circ}$. The exact behavior underlying this observation is not known, but it is worth noting that no krill larger than $6 \mathrm{~mm}$ were observed in this 'belly-up' orientation (although fewer observations were made of such larger animals). Excluding these smaller modes of angles from the orientation distribution used to parameterize the acoustic scattering model had a negligible effect on predicted target strengths. This is due to the small size of these modes and because a bent cylinder in ventral aspect scatters sound in a very similar fashion to one in dorsal aspect.

The approach to modeling krill scattering employed here represents the krill's shape as a uniformly bent and smoothly tapered cylinder, and assumes that the acoustic material properties do not vary within the animal. More sophisticated formulations employ higher resolution shape descriptions to account for appendages, and allow for variations in the sound speed and density contrasts along the animal's length (McGehee et al., 1998; Stanton et al., 1998; Stanton and Chu, 2000; Lavery et al., 2002). Similarly, the addition of a stochastic phase component to scattering models has been used to address differences evident at angles away from normal between model predictions of krill scattering and tank-based measurements (Stanton et al., 1998; Demer and Conti, 2003). When studying the single ping returns from individual animals at discrete angles of orientation (e.g., in the laboratory), the increased accuracy of these more complicated models is desirable. When examining ensembles of animals, as is the case in 
measurements of volume backscattering strength, and where predicted scattering averaged over a distribution of orientations is dominated by scattering at normal acoustic incidence, errors due to simplifications in the shape description and along-axis variations in material properties become negligible, as do the effects of random phase variability (Stanton and Chu, 2000). Since the animals here are oriented mostly horizontally, and since our interest in knowing krill target strength stems from a desire to make estimates of biologically-meaningful quantities from survey measurements of volume backscattering, there is no need to move beyond the lower resolution model, nor to include a random phase component. Higher resolution shape models require the digitization of the animal's shape in 2- or 3-D, rather than the simple measurements of length, curvature, and the ratio of length to radius required by the bent cylinder model used here. This latter model thus has the advantage of ease of application (Stanton and Chu, 2000).

Parameterizing the theoretical DWBA-based bent and tapered cylinder model with the distribution of orientations measured here and Chu and Wiebe's (2005) length-based material property regressions resulted in predictions of target strength in relation to length and frequency that for larger krill are consistent with the present in situ empirical observations of krill target strength. The congruence in theoretical predictions and empirical measurements provides support for this model parameterization for the larger animals at least. It is these larger krill that are the subject of the krill fishery and the target of most krill acoustic surveys.

In contrast, in situ observations of the target strength of smaller krill were much higher than predicted. The target strengths predicted by the DWBA-based model for such sizes of krill were approximately $-105 \mathrm{~dB}$, and so were in fact weaker than the acoustic system's minimum detectable level of $-100 \mathrm{~dB}$. The empirical measurements for the smaller length mode are thus biased upwards due to this threshold to detectability. Furthermore, although care was taken to reduce the possibility that multiple targets colocated at the same range were mistakenly accepted as single targets in the analysis of in 
situ target strength, these smaller krill were present at higher densities than the larger individuals (Wiebe et al., 2004). This increases the likelihood that multiple targets positively biased the observed target strengths for the smaller krill. It is also possible that certain of the model parameters may not be as appropriate for smaller individuals.

Foote et al. (1992) provide a comprehensive review of the then-up-to-date measurements of target strength for a variety of euphausiid species. The Antarctic krill data reviewed were of varying quality, but the measurements of krill target strength at $120 \mathrm{kHz}$ by Foote et al. (1990) and Watkins (1991) were deemed to be of high quality. Since the Foote et al. (1992) review, Hewitt and Demer (1991) and Pauly and Penrose (1998) have also reported observations of krill target strength. Most of these earlier observations lie above our newly-parameterized scattering model (Figure 3.8). This difference likely stems from two sources. First, experimental error may tend to bias the empirical observations; the Hewitt and Demer (1991) in situ measurements, for instance, are thought to be positively biased by erroneous acceptance of multiple targets as individual target strengths (Demer and Conti, 2005), and the true target strengths for the krill they observed likely fall closer to the predictions of the present model.

Second, there may have existed differences in the exact shape and nutritional status of the different krill populations under investigation, which would require different model parameter values. Our surveys were conducted during austral fall/winter when food resources are low, while previous studies were mostly of krill during summer. The stronger target strengths measured in these earlier studies may relate to the krill being fatter in summer. Properly modeling the target strengths of these summertime krill thus may require a smaller ratio of length to radius $\left(L / a_{0}\right)$ than the value of 18.4 used here. Similarly, the acoustic material properties may vary seasonally: Foote (1990) measured material properties for krill in summer that lead to larger target strength predictions for the length range of krill he examined than the material property regressions employed here. Indeed, parameterizing the present scattering model with $L / a_{0}=16$ (used previously by Chu et al. (1993) for summertime krill) and Foote's (1990) material property 


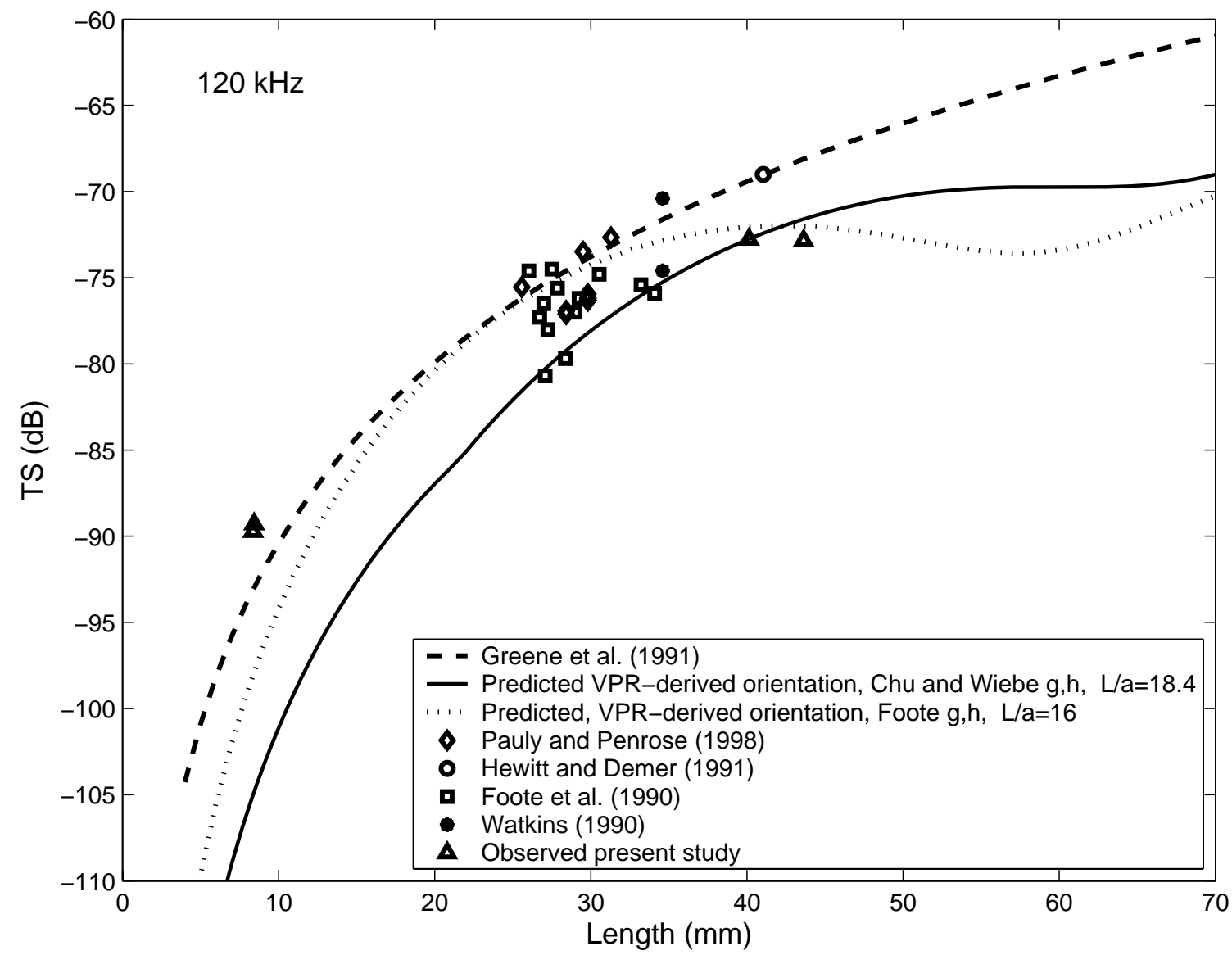

Figure 3.8 - Target strength at $120 \mathrm{kHz}$ in relation to krill length $(\mathrm{mm})$, showing the Greene et al. (1991) model; the DWBA bent cylinder model parameterized with the present VPR-derived distribution of orientations, Chu and Wiebe's (2005) $g$ and $h$ vs. length $(L)$ regressions, and an $L / a_{0}$ of 18.4 (measured for animals in the present study area); and the model parameterized with the VPR-derived distribution of orientations, Foote's (1990) $g$ and $h$ values, and an $L / a_{0}$ of 16 . Also shown are the empirical target strength observations made in the present study, as well as the measurements made by Foote et al. (1990) of krill in an enclosure, Hewitt and Demer (1991) of krill in situ, and Pauly and Penrose (1998) of krill in the laboratory, and the target strength estimates made by Watkins (1991) of krill in situ from volume backscattering measurements and photographic estimates of krill density. For the latter study, the plotted points indicate the range of estimated target strength. 
measurements results in predictions of target strength that compare more favorably to the higher values in the range of previous measurements of krill target strength (Figure 3.8). This highlights the importance of understanding and measuring wherever possible model parameters appropriate to each particular situation. In the present modeling exercises, all parameters were measured for animals in the actual study region at the time of surveying, and reasonable congruence was achieved between model predictions and empirical observations. Given the low wintertime food conditions experienced by the krill in our study, our target strength predictions should perhaps be taken as a lower bound.

The Greene et al. (1991) semi-empirical model of krill target strength at $120 \mathrm{kHz}$ as a function of length enjoys widespread use in acoustic studies of Antarctic krill. Similar to the findings of earlier studies (McGehee et al., 1998; Demer and Conti, 2003, 2005), the present predictions of krill target strength using the novel model parameterization are at least $4.4 \mathrm{~dB}$ smaller than expected under the Greene et al. (1991) relationship, for all animal lengths investigated. This divergence is particularly strong for small lengths, but Greene et al. (1991) did not intend their model to be used in the Rayleigh scattering region $(k a<1)$. Their model was derived from a linear regression of empirical target strength measurements made at $420 \mathrm{kHz}$ in relation to individual length (Greene et al., 1989; Wiebe et al., 1990). The regression line was then related to anticipated target strengths at the more typical survey frequency of $120 \mathrm{kHz}$, on the theoretical basis of a linearized version of the straight finite cylinder scattering model (Wiebe et al., 1990). This approach assumes a linear relationship between target strength and animal length, although both theoretical and empirical studies indicate that this relationship is nonlinear, due to the complicating influences of animal length, shape, orientation, and material properties. Furthermore, the target strengths of a variety of crustacean species were combined into the target strength to length regression, including the euphausiid Euphausia pacifica but not the Antarctic krill itself. Some of the taxa were of quite different body shapes to krill (e.g., decapods and copepods), and the broader body depth to length ratios of these animals may explain much of the difference between the Greene et al. (1991) line and the current model predictions for the relatively thin Antarctic krill. 
Greene et al. (1991) recognized that the linearization of the target strength to length relationship constituted a simplification of the scattering process, and proposed their model as a practical and highly useful means of estimating krill target strength "until these theoretical models are better developed." Since the Greene et al. (1991) study, DWBA-based approximate theoretical models of zooplankton scattering have progressed considerably and been extensively validated for normal acoustic incidence or averages dominated by normal incidence, especially for euphausiids (reviewed in Stanton and Chu, 2000). Modern theoretical approaches to modeling zooplankton scattering seek to capture the non-linearities in the target strength vs. length relationship, are not limited to any particular frequency (or assumptions concerning the scaling of data from one frequency to another), and include numerous parameters for animal size, shape, orientation, and material properties. These parameters can be adjusted for different taxa, animal behaviors, and body conditions, respectively, thereby providing wide applicability and substantial flexibility. The strong variability in target strength measurements evident in Figure 3.8 would suggest that such flexibility is highly desirable.

\subsection{CONCLUSIONS}

Improved understanding of key model parameters through direct observations of Antarctic krill orientation and application of recently published regressions relating sound speed and density contrasts to krill length has yielded predictions from a theoretical DWBA-based scattering model that compare favorably to in situ measurements of target strength of large krill. The congruence in theoretical predictions and empirical observations provides support for this new model parameterization, as well as further validation of the DWBA-based approach to modeling zooplankton scattering. Arguably, the semi-empirical model of Greene et al. (1991) should be replaced by the use of fully parameterized and field-validated theoretical scattering models like the one developed here, although care must be taken to constrain properly all parameters for the particular krill population at hand. Application of such models will allow more accurate estimates 
of biologically-meaningful quantities such as krill abundance and stock biomass from observations of volume backscattering.

\section{ACKNOWLEDGMENTS}

Chuck Greene provided the initial impetus for this project, when he remarked over lunch that the question of krill target strength had never been fully resolved, and he was amazed that people were still using the Greene et al. (1991) regression model 15 years later. A. Lavery, S. Kaartvedt, Y. Endo, and C. Greene provided very insightful comments on earlier manuscript drafts. We warmly acknowledge the contributions of C. Davis and S. Gallager, co-primary investigators on the zooplankton broad-scale distribution component of the Southern Ocean GLOBEC project. C. Davis and Q. Hu provided much appreciated help in assessing possible sources of error in the VPR observations. We further thank all officers and crew of the RVIB N. B. Palmer; the Raytheon Polar Services Technical Support group; the BIOMAPER-II and MOCNESS teams consisting of C. Davis, M. Dennett, K. Fisher, S. Gallager, A. Girard, E. Horgan, M. Taylor, J. Szelag, and J. Warren; as well as P. Alatalo, M.-Q. Chu, N. Copley, L. Gray, P. Hull, and G. Rosenwaks for lab analyses of net catches. This project was supported by NSF U.S. Antarctic Program Grant OPP-9910307. G. Lawson was supported by an Office of Naval

Research Graduate Traineeship Award in Ocean Acoustics (Grant N00014-03-1-0212), a Fulbright Scholarship, a Natural Sciences and Engineering Research Council of Canada Post-Graduate Scholarship, and the Woods Hole Oceanographic Institution Academic Programs Office. This is U.S. GLOBEC contribution number 259. 


\section{Chapter 4}

\section{Krill Distribution Along the Western Antarctic Peninsula and Associations With Environmental Features, Assessed Using Multi-Frequency Acoustic Techniques}

\subsection{INTRODUCTION}

The Antarctic krill (Euphausia superba) is a key prey species for many antarctic whales, birds, seals, and fishes (Laws, 1985), is the subject of an important fishery (Ichii, 2000), and contributes substantially to carbon export from the euphotic zone of the Southern Ocean (Priddle et al., 1992). Most Antarctic krill are found in highly cohesive aggregations, and like many zooplanktonic or micronektonic species, krill distribution is characterized by strong variability at a range of spatial and temporal scales (Miller and Hampton, 1989). As a characteristic feature of the antarctic marine ecosystem, such patchiness is critically important to any examination of ecosystem processes such as predator-prey interactions or carbon cycling.

Although the Antarctic krill is a well-studied species in many respects, few studies have been able to identify clear and consistent relationships between krill distribution and environmental properties (Trathan et al., 2003; Siegel 2005). Furthermore, in comparison to the well-studied time periods of austral spring and summer, when many antarctic regions are ice-free and more easily accessible to survey vessels, relatively few studies have examined krill distribution during winter (Siegel, 1989; Nordhausen, 1994; Zhou et 
al., 2004; Ross et al., 1996; Lascara et al., 1999). This is particularly true for the continental shelf region in and around Marguerite Bay, west of the Antarctic Peninsula (Lascara et al. 1999). Marguerite Bay and other locations along the Peninsula are also hypothesized to be important over-wintering grounds for krill, and may act as potential sources for down-stream populations in the Bransfield Strait and around South Georgia (Brinton, 1991; Huntley and Brinton, 1991; Atkinson et al., 2001; Fach et al., 2002). The Marguerite Bay region and the fall-winter period were chosen as the focus for the U.S. Southern Ocean GLOBal ECosystems Dynamics (SO GLOBEC) program (Figure 4.1a). A central goal of the program is to identify those factors that allow the krill to overwinter successfully, which includes understanding how krill distribution relates to physical and biological processes, and in turn affects the distribution and dynamics of higher predators (Hofmann et al., 2002).

The SO GLOBEC study area is characterized by intrusions of warm off-shelf Circumpolar Deep Water (CDW), pumped up onto the shelf at depth by the Antarctic Circumpolar Current (Figure 4.1b; Klinck et al., 2004). This CDW is enhanced in nutrients (silica in particular; Serebrinnokova and Fanning, 2004), and the intrusions are thought to be important to the annual cycle of primary productivity and the dominance of diatoms over other primary producers (Prézelin et al., 2004). The consequences of these intrusions to the krill, however, remain unclear. Analyses of krill abundance in other regions during spring and summer in relation to phytoplankton have observed both negative and positive correlations (reviewed in Weeks et al., 1995). A large and persistent gyre has also been observed over the northern portion of the study region (Figure 4.1b; Smith et al., 1999; Klinck et al., 2004), which may serve to retain planktonic organisms. Smaller gyres have been observed in more coastal reaches of the region, with similar potential effects on retention (Klinck et al., 2004; Zhou and Dorland, 2004). A coastal current flows towards the southwest, which may serve to advect zooplankton into or out of the study region (Lawson et al., 2004). In the case of krill, previous studies have suggested that abundance may be enhanced in regions of high velocity gradients such as frontal zones, meanders, and eddies (Witek et al., 1988; Ichii et 


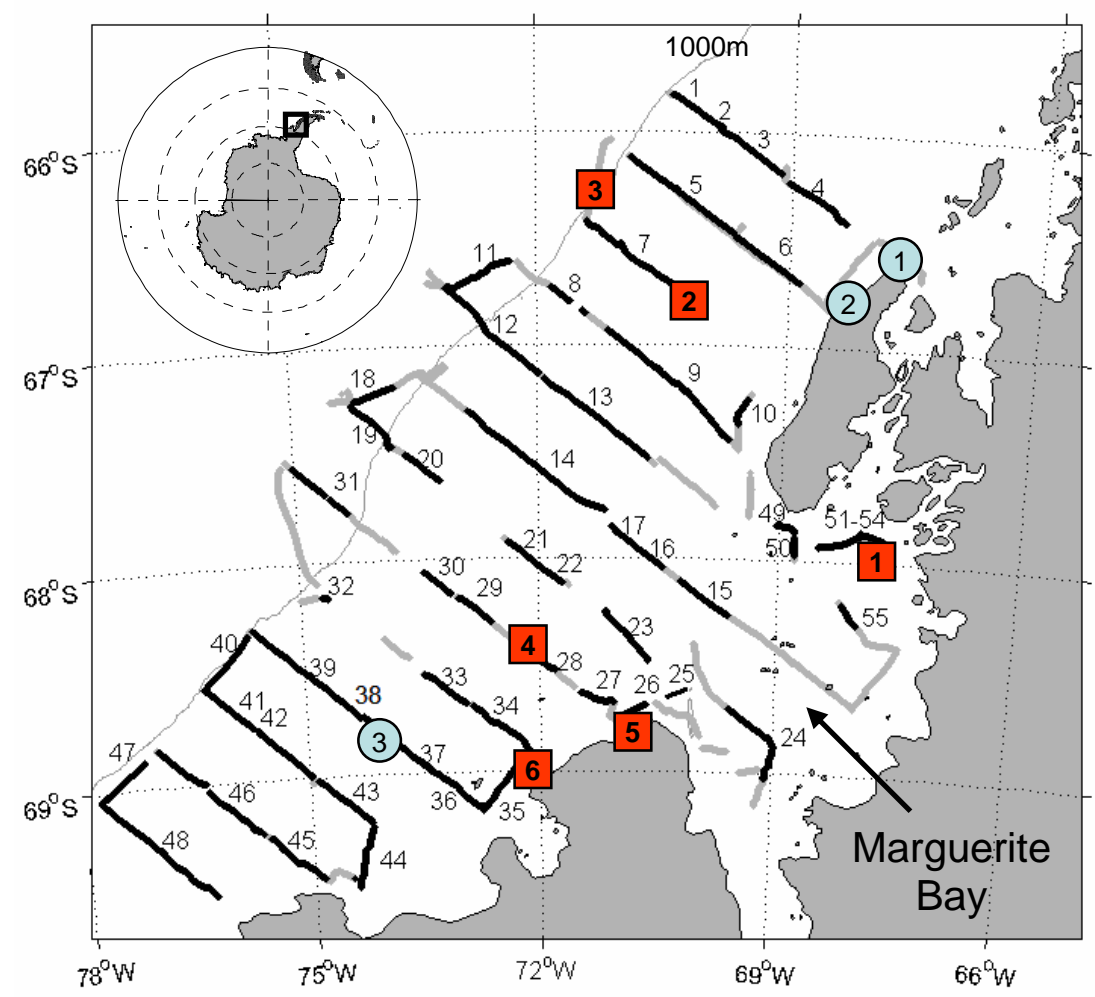

Figure 4.1a - Southern Ocean GLOBEC study region. Light grey contour shows the continental shelf break (1000 $\mathrm{m}$ isobath). Grey lines indicate where acoustic data were collected in the fall of 2002, the survey with the most comprehensive coverage, with black lines and numbers indicating shorter 'transects' used for comparing biomass estimates between surveys. Squares indicate locations selected in fall 2001 for verification of acoustic methodologies: (1) Laubeuf Fjord krill agregations, (2) 'Fish' patch area, (3) Region sampled by $10 \mathrm{~m}^{2}$ MOCNESS system (Donnelly et al., this volume), (4) Scattering layer, (5) Day 144 VPR-identified krill aggregation, (6) Day 136 VPR-identified krill aggregation. Circles indicate locations selected in fall 2002: (1) Crystal Sound krill aggregations, (2) Day 105 VPR-identified krill aggregation, (3) Day 125 VPR-identified krill aggregation. 


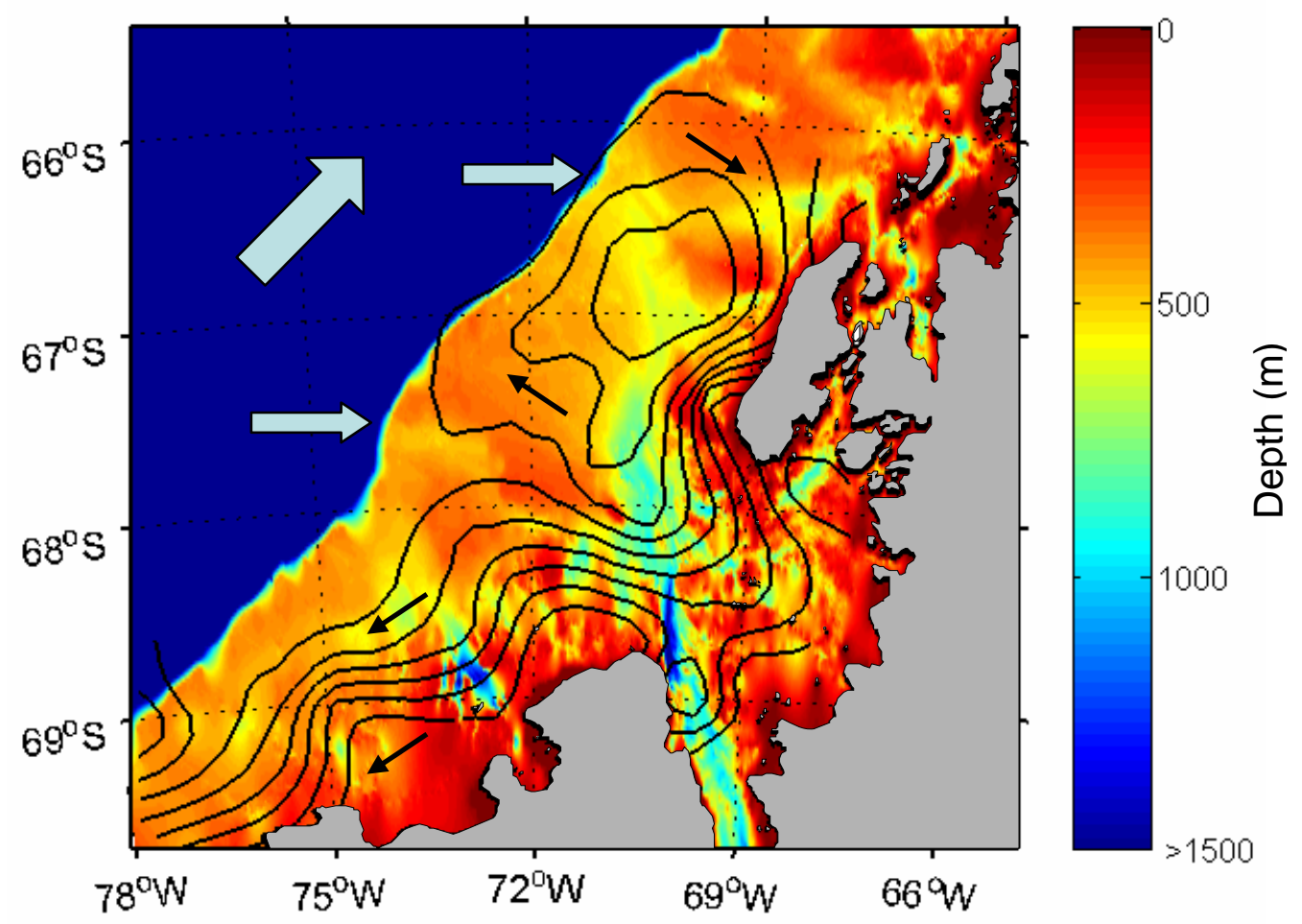

Figure 4.1b - SO GLOBEC study region bathymetry (color scale). Black lines show contours of dynamic height estimated from CTD casts in fall 2001; black arrows indicate direction of geostrophic flow. Modeling and empirical studies have suggested that offshelf circumpolar deep water is pumped up onto the shelf by the action of the Antarctic Circumpolar Current (ACC) primarily at points where the deep troughs bisecting the shelf meet the shelf break and where the shelf break is strongly curved (Dinniman and Klinck, 2004; Klinck et al., 2004); horizontal blue arrows indicate such locations. Larger blue arrow indicates the direction of flow of the ACC. 
al., 1998). A final important characteristic of the study area, typical of many antarctic regions, is that it is fully ice-covered in winter, but ice-free in summer (Perovich et al., 2004).

Ecological studies of the Antarctic krill, as well as stock assessment surveys, typically employ high-frequency acoustic techniques to estimate krill abundance, due to their ability to sample the water column to fairly great depths at high vertical and horizontal resolution (reviewed by Hewitt and Demer, 2000). Acoustic methods, however, provide only measurements of reflected or scattered sound, which are a complex function of the acoustic frequency employed, the taxonomic composition of animals present, as well as their size, shape, physical properties, and behavior. Identifying the particular animals responsible for acoustic measurements, and converting such measurements to biologically-relevant quantities such as biomass or animal length, can be challenging tasks. Methods have been developed and verified for discriminating Antarctic krill scattering from that of other animals, capitalizing on taxon-specific differences in scattering at different acoustic frequencies and on the fact that Antarctic krill form mostly mono-specific aggregations (Madureira et al., 1993; Brierley et al., 1998; Watkins and Brierley, 2002; Demer 2004). Measurements of volume backscattering strength attributed to krill are then scaled to estimates of abundance or biomass via a model of the expected level of backscattering from one animal (i.e., target strength) based on its length, combined with krill length measurements derived from nets.

Net samples for the animal body length measurements required by target strength models are always more sparsely distributed than the acoustic data, even though substantial variability in the length of member animals can exist between even closely spaced aggregations (Watkins et al., 1986). Outside of the Antarctic, a common acoustic approach is to take advantage of known size- and taxon-dependent differences in scattering at increasing acoustic frequencies to estimate zooplankton abundance in incremental length classes from multi-frequency acoustic measurements alone, without recourse to nets or other independent samples (Holliday, 1977). Such 'inversions' must 
be approached with caution, however, as the number of taxa and size classes that can be solved for is limited by the number of frequencies employed and the problem can rapidly become very complicated for heterogeneous zooplankton communities of multiple scatterer types (Lavery et al., submitted). Nonetheless, studies of particular instances of euphausiid aggregations where only a single species was present with a single length mode have been able to estimate animal length with a high degree of accuracy (e.g., Antarctic krill, Mitson et al., 1996, Azzali et al., 2004, Chu et al., submitted; Meganyctiphanes norvegica, Kristensen and Dalen, 1982, Warren et al. 2003; Greenlaw, 1979). Such studies have also produced plausible density estimates, though often higher than suggested by independent net samples. To our knowledge, such an approach has not been applied to broad-scale acoustic survey data in the Antarctic, but could provide a powerful tool for making accurate estimates of krill density.

The goals of this study are two-fold. First, we seek to build on existing methods for identifying and delineating aggregations of Antarctic krill, and estimating the length, abundance, and biomass of aggregation members, all on the basis of acoustic observations alone. We further evaluate these acoustic methods through comparisons to independent net and video samples. Second, we apply these methods to multi-frequency acoustic data collected during broad-scale surveys of the SO GLOBEC study area during the falls and winters of 2001 and 2002, in order to examine the resultant spatial and temporal patterns in the distribution of krill aggregations in relation to aspects of the physical and biological environment.

\subsection{METHODS}

\subsubsection{Study area}

The SO GLOBEC study area encompasses a generally deep continental shelf region (mostly 300-500m) in the vicinity of Marguerite Bay, to the west of the Western Antarctic Peninsula (Figure 4.1). Four broad-scale survey surveys were conducted in the 
area on the RVIB Nathaniel B. Palmer: two surveys during austral fall (acoustic data collection from April 29 to June 1, 2001 and April 14 to May 14, 2002) and two during winter (July 27 to August 24, 2001, and August 12 to September 9, 2002). Survey tracks were determined by the position of hydrographic stations distributed every $10-40 \mathrm{~km}$ along 13 transect lines spaced $40 \mathrm{~km}$ apart and running across the continental shelf, loosely perpendicular to the Peninsula coastline and shelf-break.

\subsubsection{Data collection}

Acoustic and video data were collected from the towed platform the BIo-Optical Multifrequency Acoustical and Physical Environmental Recorder (BIOMAPER-II; Wiebe et al., 2002), which includes a multi-frequency acoustic system, a Video Plankton Recorder (VPR; Davis et al., 1992), and an environmental sensing system (Conductivity, Temperature, and Depth sensor (CTD); fluorometer; transmissometer). The BIOMAPERII was towed obliquely up and down through the water column between depths of 20 and $400 \mathrm{~m}$ as the vessel proceeded along the survey transects at speeds of 4-6 knots, with surveying conducted around the clock.

\subsection{2.a Acoustic data}

Measurements of volume backscattering strength $\left(S_{v}=10 \log _{10}\left(s_{v}\right)\right.$ in units of decibels relative to $1 \mathrm{~m}^{-1}$, where $s_{v}$ is the volume backscattering coefficient) and target strength $\left(\mathrm{TS}=10 \log _{10}\left(\sigma_{\mathrm{bs}}\right)\right.$ in units of decibels relative to $1 \mathrm{~m}^{2}$, where $\sigma_{\mathrm{bs}}$ is the differential backscattering cross-section) were made continuously during surveying from pairs of upand down-facing split-beam transducers at $43,120,200$, and $420 \mathrm{kHz}$, to maximum ranges of $300,300,150$, and $100 \mathrm{~m}$, respectively. Depending on the depth of the towed body, this corresponds to maximum depths of observation between 320 and $700 \mathrm{~m}$. Acoustic data were collected with a $10 \mathrm{kHz}$ bandwidth linear frequency modulated (or 'chirp') pulse at a ping rate of 0.3 pings $\mathrm{s}^{-1}$, and the dynamic range spanned the range of 100 to $-40 \mathrm{~dB}$. The vertical resolution of the system was $1.5 \mathrm{~m}$ at 43 and $120 \mathrm{kHz}$, and 1 
$\mathrm{m}$ at 200 and $420 \mathrm{kHz}$. Volume backscattering strength is derived from echo intensities measured as squared voltages; here these measurements were integrated over time intervals corresponding to the vertical resolution $(1.035 \mathrm{~ms}$ for $1.5 \mathrm{~m}$, and $0.690 \mathrm{~ms}$ for 1 $\mathrm{m})$, and then averaged for each depth stratum over all pings collected within 12 second intervals, corresponding to a horizontal resolution of ca. $35 \mathrm{~m}$, depending on the ship's speed. For simplicity, the quantity of measured backscattered sound per unit volume will be referred to as 'volume backscattering' and we will distinguish between the arithmetic and logarithmic forms of 'volume backscattering coefficient' and 'volume backscattering strength' only when necessary.

The transducers were calibrated by the manufacturer (Hydroacoustic Technologies Inc., Seattle, WA, USA) prior to each survey year, and in situ calibrations with tungsten carbide ( $6 \%$ cobalt) spheres of diameters 38 and $21 \mathrm{~mm}$ were performed during the winter 2001 survey and both 2002 surveys. Measurements of ship's noise, ambient noise, and system noise levels combined were made in relation to depth at the start of each survey, and volume backscattering or target strength measurements smaller than these noise levels were set to zero. Additional details concerning acoustic data collection are found in Lawson et al. (2004, 2006).

\subsection{2.b Video Plankton Recorder data}

Digital images of large krill were extracted from video collected with the VPR, which consisted of two cameras and a $16 \mathrm{~W}$ strobe mounted on the BIOMAPER-II. The cameras sampled at a rate of $60 \mathrm{~Hz}$, synchronized to the strobe. Only images from the lower-resolution camera (field of view 16.5-31 mm wide by 13-24.5 mm high, depending on survey) are considered here. Regions of each field that were in focus were automatically extracted and saved as time-stamped Tagged Image File Format (tif) images (Davis et al., 1996). These files were then manually sorted to identify images of large krill, defined as individuals larger than the field of view. 


\subsection{2.c Net data}

Samples of krill for length and numerical density measurements and comparison to acoustic estimates of these quantities were made with a $1-\mathrm{m}^{2}$ Multiple Opening/Closing Net and Environmental Sensing System (MOCNESS; Wiebe et al., 1985). Each MOCNESS tow sampled eight depth strata with $335 \mu \mathrm{m}$ mesh nets. Net tows were performed at 17-24 stations per survey, of which 3-6 have been analyzed to date for each survey, chosen for their having been performed at similar locations in all surveys (Ashjian et al., 2004). Krill lengths were measured for an aliquot of each net sample following the silhouette method of Davis and Wiebe (1985). Lengths were measured from the posterior base of the eye stalk to the end of the sixth abdominal segment (i.e., 'standard length 3' as defined by Mauchline, 1980b). Of the analyzed net samples, the only ones considered here are those where particular krill aggregations observed acoustically could be associated unambiguously with the location and depths sampled by individual nets.

\subsubsection{Acoustic analyses}

The overall approach taken here was first to identify krill aggregations in the acoustic record on the basis of a threshold volume backscattering strength derived from krill visual acuity and previously-established expected differences in mean volume backscattering strength at different frequencies. Where available, this identification was confirmed on the basis of independent VPR observations and net samples. For the resulting identified aggregations, inversions of volume backscattering measurements at our four acoustic frequencies were performed to estimate the mean length and numerical density, and from these the biomass density of animals. Certain measurements of aggregation position were also made. Note that we use the word 'aggregation' to denote a non-random group of krill observed in the acoustic data, and avoid the assumptions concerning the degree of organization within the group required by the various established systems of nomenclature for krill aggregations (e.g., Mauchline, 1980c). 
The acoustic analyses that follow all employed the theory-based krill target strength model of Lawson et al. (2006). This model represents the krill's shape as an equivalent cylinder, defined on the basis of animal length measured from the anterior of the eye to the end of sixth abdominal segment. Unless otherwise indicated, all krill lengths reported below correspond to this 'acoustic' length, and wherever necessary, other length measurements (e.g., the lengths from net samples) were converted to acoustic length for analysis.

\subsection{3.a Threshold volume backscattering strength}

It is common in acoustic surveys to filter the data at some threshold volume backscattering strength, typically chosen in a somewhat arbitrary fashion as the level that visually seems to give good discrimination of 'target' from 'background' scattering (e.g., Lascara et al., 1999), or in a phenomenological fashion as the central tendency of some fixed-dimension sliding window moved through the dataset (Nero and Magnuson, 1989). Such filtering can help in separating krill volume backscattering from that of smaller and/or more sparsely distributed zooplankton. We define a threshold level on the basis of the density of animals that corresponds to the maximum sensing distance over which a given animal can maintain some association with its nearest neighbor, and thereby with the aggregation as a whole.

Estimates of euphausiid sensing distance have been made from a number of sources, including diver observations (1-2 m for E. superba; Ragulin, 1969), net avoidance (1.7$2.3 \mathrm{~m}$ for Nematoscelis megalops; Wiebe et al., 1982), and rheotactic sensing abilities (0.16-1 m for E. superba; Wiese 1996, Patria and Wiese, 2004). From such measurements of responses mostly to large objects, it is difficult to estimate at what distance a krill might be able to respond to conspecifics. Maximum sensing distances for objects of particular sizes can also be estimated, however, based on visual acuity. Visual acuity for the crustacean compound eye is typically quantified via the angle between adjacent receptor cells (i.e., the inter-ommatidal angle): objects that subtend an arc of the 
same size as this angle or larger can be detected against an otherwise homogeneous background (Land 1997). For the Antarctic krill, inter-ommatidal angles of 2.3 and 3.6 degrees have been measured for animals of length $34 \mathrm{~mm}\left(3.6^{\circ}\right), 42 \mathrm{~mm}$, and $49.6 \mathrm{~mm}$ (both $2.3^{\circ}$ )(Hiller-Adams and Case, 1984). Based on simple trigonometry, these angles would suggest that animals in an aggregation where the typical length was $40 \mathrm{~mm}$ (corresponding to the mean length of animals sampled here, see below) would be able to detect conspecifics to a maximum range of $99.6 \mathrm{~cm}$. In the absence of other information, we will use this vision-based estimate of krill sensing distance.

Given some average nearest-neighbor distance $(D)$, there are numerous ways in which animals might arrange themselves in aggregations, involving various assumptions concerning the shape of the volume inhabited by each individual and how these volumes are arranged (see Pitcher, 1973). Hamner and Carleton (1979) indicate that the most compact arrangement of animals involves isahedronic packing, where all animals are equidistant from one another and the resultant density of animals is given by $1 / 0.589 D^{3}$. For the $40 \mathrm{~mm}$ krill and setting the nearest-neighbor distance equal to the maximum visual sensing distance of $1 \mathrm{~m}$, this corresponds to a density of 1.7 individuals $\mathrm{m}^{-3}$, and for the target strength of a $40 \mathrm{~mm}$ krill predicted by the Lawson et al. (2006) model, a volume backscattering strength at $120 \mathrm{kHz}$ of $-70.5 \mathrm{~dB}$. Since both the maximum sensing distance suggested by visual acuity and target strength vary with the mean length of krill in the aggregation, but in opposing directions, the estimated threshold volume backscattering strength for krill of length $35-50 \mathrm{~mm}$ varies from only -70.9 to $-70.4 \mathrm{~dB}$. We therefore define the minimum volume backscattering strength at $120 \mathrm{kHz}$ for which a given acoustic measurement can be considered to be part of a krill aggregation as $-70 \mathrm{~dB}$. Interestingly, this agrees exactly with the threshold used by Hewitt et al. (2003) to analyze $120 \mathrm{kHz}$ single frequency survey data, defined on the basis of comparisons to acoustic measurements made when multi-frequency data were available for identifying krill. 


\subsection{3.b Distinguishing krill scattering from other sources}

Differences between the mean volume backscattering strength measured at 120 and 38 $\mathrm{kHz}$ ( $\delta \mathrm{MVBS}$ ) have been used successfully to distinguish Antarctic krill from other acoustic scatterers that may be present (e.g., salps, copepods, amphipods; Madureira et al., 1993; Brierley et al., 1998; Watkins and Brierley, 2002; Demer 2004), sometimes in combination with taxon-specific differences in aggregation structure (Woodd-Walker et al., 2003). This method capitalizes on the fact that different taxa scatter sound at increasing frequency with varying efficiency (Figure 4.2). The method has recently been thoroughly reviewed, and it appears that the approach of interpreting $\delta \mathrm{MVBS}$ values between 2 and $16 \mathrm{~dB}$ as being krill is relatively robust (Watkins and Brierley, 2002; Demer, 2004). We therefore apply these $\delta$ MVBS criteria here.

The $16 \mathrm{~dB}$ limit to the allowable $\delta \mathrm{MVBS}$ range marks scattering from krill occurring in the Rayleigh scattering region (Figure 4.2), where scattering is proportional to the fourth power of frequency. In this range, krill scattering at the lowest frequency employed here of $43 \mathrm{kHz}$ can thus be expected to be 1.6 times as large as that at the frequency of $38 \mathrm{kHz}$ used by previous studies in defining the allowable range of $\delta \mathrm{MVBS}$ values. The upper bound to the range of $\delta \mathrm{MVBS}$ attributable to krill could thus be made smaller to account for the frequencies used in the present application. We chose not to decrease the upper bound of $16 \mathrm{~dB}$, however, primarily because of issues described below (section 4.3.1.a) that emerged with the $43 \mathrm{kHz}$ measurements often appearing artificially low, likely due to problems with noise thresholds and calibration uncertainty. By applying the more generous range of 2 to $16 \mathrm{~dB}$, we increase the possibility of mistakenly accepting as krill the scattering from other small zooplankton, but allow for these sources of uncertainty associated with the measurements made at $43 \mathrm{kHz}$. Furthermore, the target strength model of Lawson et al. (2006) employed here would predict that a difference in the mean volume backscattering strength between the frequencies of 120 and $43 \mathrm{kHz}$ of $16 \mathrm{~dB}$ would correspond to a krill of length $8 \mathrm{~mm}$, and so it does not seem unreasonable to use this value as the upper bound. 


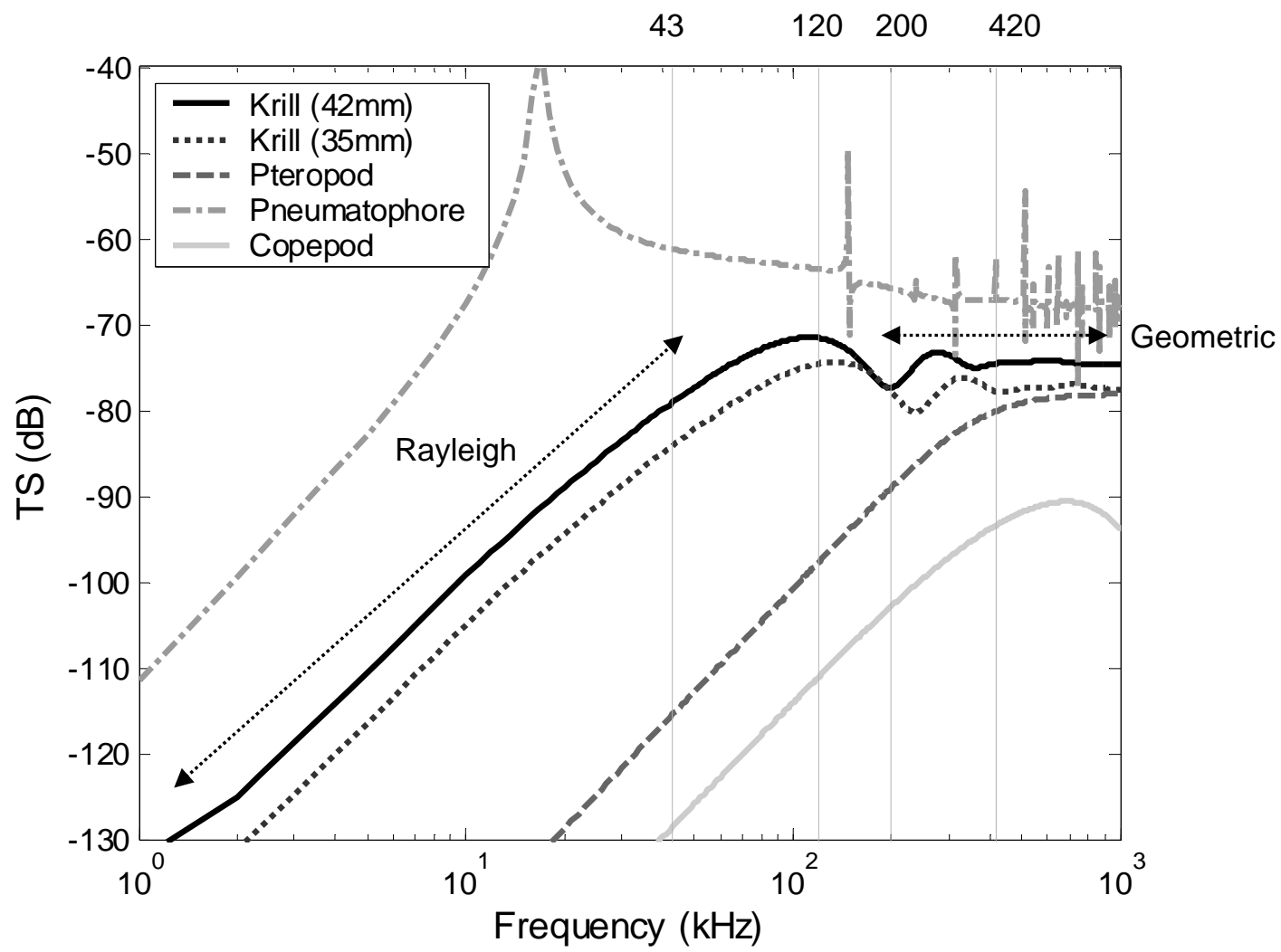

Figure 4.2 - Target strength (TS) in relation to acoustic frequency. Predictions of target strength were made using physics-based models for 35 and $42 \mathrm{~mm}$-long krill, a $1 \mathrm{~mm}$ diameter pteropod, a $1.5 \mathrm{~mm}$ diameter siphonophore pneumatophore (a gas-filled structure), and a $2 \mathrm{~mm}$-long copepod. The krill target strength model of Lawson et al., (2006) was used for krill. Models and parameter values for the other animals are the same as in Lawson et al., (2004). Arrows indicate the Rayleigh and geometric scattering regions for the krill curves. 
It is also important to note that the $\delta \mathrm{MVBS}$ method cannot distinguish between animals of very similar sizes and scattering type, and so cannot discriminate among the different species of euphausiid that may be present, including E. superba, E. crystallorophias, $E$. frigida, E. triacantha, and Thysanoessa macrura (Ross et al., 1996; Ashjian et al., 2004). Of these, E. frigida and E. triacantha are not known to form aggregations (Ross et al., 1996, and references therein), and aggregations of T. macrura that have been observed acoustically have been reported to be very diffuse and "cloud-like" (Daly and Macaulay, 1988), and so are likely excluded from our analysis by the threshold scattering level. Henceforth, we will refer to acoustically-identified aggregations as 'krill,' and do not attempt to distinguish between the two other possible euphausiid species.

\subsection{3.c Defining aggregations}

Aggregations were defined as all contiguous acoustic measurements (or acoustic 'elements') exceeding the threshold scattering level and meeting the $\delta$ MVBS criteria, where a given element was determined to be part of an aggregation if any of its eight neighboring elements also were in the aggregation (Reid and Simmonds, 1993). The minimum possible aggregation size was thus determined by the size of one element, and so had a height of $1.5 \mathrm{~m}$ and a horizontal length determined by the vessel's speed, typically approximately $35 \mathrm{~m}$.

\subsection{3.d Estimating the mean length and density of krill in identified aggregations}

The abundance of animals spanning a range of size categories can be estimated on the basis of multi-frequency acoustic data alone, following what is referred to as an 'inverse approach' (Holliday 1977, Greenlaw 1979). Similar to the $\delta$ MVBS method described previously, the inverse method capitalizes on the fact that scattering from zooplankton is both size- and frequency-dependent (Figure 4.2). In brief, for a given frequency $i$, the volume backscattering coefficient $s_{v i}$ can be assumed to be the sum over all $M$ size 
categories of the product of the expected backscattering cross-section $\left\langle\sigma_{\mathrm{bs}}\right\rangle_{i j}$ of a single animal in size category $j$, and the number of animals per unit volume in each size class $n_{j}$ :

$$
s_{v i}=\sum_{j=1}^{M}\left\langle\sigma_{\mathrm{bs}}\right\rangle_{i j} n_{j}
$$

For a given set of frequencies, this defines a set of linear equations, and with measurements of $s_{v i}$ and model-estimates of $\left\langle\sigma_{\mathrm{bs}}\right\rangle_{j j}$, one can solve for numerical density $n_{j}$.

We assume a single narrowly-distributed length mode and single scatterer type $(j=M=$ 1), and use a simple multi-frequency inversion to estimate a mean length and numerical density of krill in each acoustically-identified aggregation. These assumptions are appropriate as Antarctic krill are known to form mostly mono-specific aggregations (Miller and Hampton, 1989) of uni-modal length distributions (Watkins, 1986). We further assume that other than length, all of the parameters upon which the expected backscattering cross-section depends, such as the acoustic material properties and distribution of orientations, are constant for all aggregations. Finally, we assume that density remains constant throughout the aggregation. These assumptions reduce the problem to one where we have measurements at four frequencies, and are solving for the two unknowns of the mean length and numerical density of krill in each aggregation.

Scattering is a non-linear function of krill length, and larger individuals in the ensonified volume will contribute to total volume backscattering disproportionately relative to their numerical abundance. We account for this non-linearity by estimating the expected backscattering cross-section of Equation 4.1 as a weighted mean over an assumed normal distribution of lengths, centered at a given mean length and with a standard deviation of $15 \%$ of the mean (based on the measured lengths of krill sampled by nets during the fall of 2001 at Laubeuf Fjord; see results). The expected backscattering cross-section was also calculated as a mean over a distribution of angles of orientation (Lawson et al., 2006). It must be noted though that the estimate of krill length in each aggregation 
achieved via the inversion method is a mean that is weighted by the acoustic scattering process through the use of the krill scattering model, and is more strongly influenced by the larger krill present. The acoustically-estimated weighted mean length thus differs from the linear mean that would be calculated for a sample of krill collected by nets. This point will be revisited later in making comparisons between the krill length estimates made acoustically to those made by nets. For simplicity, this mean estimated length weighted by the acoustic scattering process henceforth will be referred to as the 'weighted mean length.'

The inversions involved theoretical predictions of volume backscattering at the four BIOMAPER-II frequencies that were generated for different combinations of weighted mean krill length and numerical density, from Equation 4.1 with $j=M=1$, for weighted mean lengths from 4 to $70 \mathrm{~mm}$ in $0.5 \mathrm{~mm}$ increments and for mean densities from 0.1 to 500 individuals $\mathrm{m}^{-3}$, in increments of 0.1 individuals $\mathrm{m}^{-3}$. By comparing the resultant theoretical predictions of $\hat{s}_{v i}$ to the average measured volume backscattering coefficient $\bar{s}_{v i}$ at the four BIOMAPER-II frequencies (averaged over all acoustic elements in a given krill aggregation), we can infer the combination of aggregation weighted mean length and density that is most likely in a least-squares sense by minimizing the error term:

$$
E_{1}=\sum_{i}^{4}\left(\hat{s}_{v i}-\bar{s}_{v i}\right)^{2}
$$

Because the acoustic observations of krill aggregations at $43 \mathrm{kHz}$ are often an order of magnitude or more lower than at the higher frequencies, this $E_{1}$ error term is most influenced by these higher frequencies and penalizes the measurement at $43 \mathrm{kHz}$. The large increase from 43 to $120 \mathrm{kHz}$ represents the transition from the Rayleigh to geometric scattering regimes, the position of which is strongly related to animal length (Figure 4.2). In order to capture the most information from this transition and make the most accurate possible estimates of length, we also developed two additional error terms, 
designed to respond more equally at all frequencies to departures in the measured data from those predicted:

$$
E_{2}=\sum_{i}^{4}\left(\log _{10} \hat{s}_{v i}-\log _{10} \bar{s}_{v i}\right)^{2}
$$

and

$$
E_{3}=\sum_{i}^{4}\left(\frac{\hat{s}_{v i}-\bar{s}_{v i}}{\hat{s}_{v i}}\right)^{2}
$$

This $E_{2}$ term is similar to an error term used by Chu et al. (1993) in an analogous fashion to estimate the most likely values for certain acoustic scattering model parameters. Unlike $E_{2}$, which is the difference between predicted and measured values of the logtransformed volume backscattering coefficient, the Chu et al. (1993) term was defined based on the backscattering cross-section, but was similarly based on the logarithmic form of this quantity (i.e., target strength).

\subsubsection{Estimation of krill biomass}

Krill biomass was examined via three related quantities: biomass density $\left(\mathrm{g} \mathrm{m}^{-3}\right)$, vertically-integrated or water-column estimates of krill biomass per unit surface area ( $\mathrm{g}$ $\mathrm{m}^{-2}$ ), and an index of total aggregation biomass ( $\mathrm{kg}$ per across-track meter; units of kilograms were used for this quantity for ease of presentation).

Estimates of krill biomass density were made by converting each measurement of the volume backscattering coefficient $s_{v}$ at $120 \mathrm{kHz}$ in each acoustically-identified krill aggregation to an estimate of krill numerical density, and then scaling these numerical density estimates to biomass density. Unlike the inversions for the weighted mean length 
and density described previously, where single values were estimated for each aggregation on the basis of mean volume backscattering averaged over all acoustic elements in each aggregation, krill biomass was estimated for each individual acoustic element in each aggregation. The derivation for the calculation of numerical density begins with the expression for the volume backscattering coefficient given in Equation 4.1 , in which the notation of $i$ to indicate frequency has been dropped since only the single frequency of $120 \mathrm{kHz}$ was considered:

$$
S_{v}=\sum_{j=1}^{M}\left\langle\sigma_{\mathrm{bs}}\right\rangle_{j} n_{j}
$$

where the expected value of the acoustic backscattering cross-section for length class $j$, $\left\langle\sigma_{\mathrm{bs}}\right\rangle$, has been calculated as an average over a distribution of angles of orientation (Lawson et al., 2006). Defining the total numerical density of krill $\left(N\right.$, individuals $\left.\mathrm{m}^{-3}\right)$ as the sum over all $M$ length classes of the density of krill in each length class $\left(n_{j}\right.$, individuals $\mathrm{m}^{-3}$ ):

$$
N=\sum_{j=1}^{M} n_{j}
$$

and

$$
n_{j}=N p_{j}
$$

where $p_{j}$ is a dimensionless quantity giving the fraction of all krill in length class $j$, and is defined such that $\sum_{j=1}^{M} p_{j}=1$, Equation 4.5 becomes:

$$
s_{v}=N \sum_{j=1}^{M}\left\langle\sigma_{\mathrm{bs}}\right\rangle_{j} p_{j}
$$


For a continuous distribution of lengths, the summation over discrete length classes in Equation 4.8 can then be replaced by the continuous form of an integral over length $(L)$ :

$$
S_{v}=N \int_{L}\left\langle\sigma_{\mathrm{bs}}(L)\right\rangle w(L) \mathrm{d} L
$$

where the acoustic backscattering cross-sections for the discrete length categories have been replaced by a continuous function over length, $\sigma_{\mathrm{bs}}(L)$, and the fractions $p_{j}$ of krill in each category have been replaced by a probability density function of lengths in the aggregation, $w(L)$. Rearranging terms in Equation 4.9 gives the total density of krill of all lengths as:

$$
N=\frac{S_{v}}{\int_{L}\left\langle\sigma_{\mathrm{bs}}(L)\right\rangle w(L) \mathrm{d} L}
$$

Similar to how total numerical density was considered to be the sum of contributions from a series of discrete length classes, krill biomass density $\left(\rho, \mathrm{g} \mathrm{m}^{-3}\right)$ can be considered to be the summation over $M$ size classes of the product of the wet weight biomass of one individual in length class $j\left(W W_{j}, \mathrm{~g}\right)$ and the numerical density of krill in that length class $\left(n_{j}\right.$, individuals $\left.\mathrm{m}^{-3}\right)$ :

$$
\rho=\sum_{j=1}^{M} W W_{j} n_{j}
$$

or, using Equation 4.7:

$$
\rho=N \sum_{j=1}^{M} W W_{j} p_{j}
$$

The summation over discrete length categories can again be replaced by an integral: 


$$
\rho=N \int_{L} W W(L) w(L) \mathrm{d} L
$$

where wet-weight biomass, $W W(L)$, is now a continuous function of length. Combining Equations 4.10 and 4.12, biomass density for an arbitrary distribution of lengths is given by:

$$
\rho=S_{v} \frac{\int_{L}^{L} W W(L) w(L) \mathrm{d} L}{\int_{L}\left\langle\sigma_{\mathrm{bs}}(L)\right\rangle w(L) \mathrm{d} L}
$$

It is perhaps instructive to note that in the limiting case of a krill length distribution consisting of only a single length $L_{0}$, the probability density function $w(L)$ becomes a delta function, and the integrals in Equation 4.13 reduce significantly to give the simple expression:

$$
\rho=s_{v} \frac{W W\left(L_{0}\right)}{\left\langle\sigma_{\mathrm{bs}}\left(L_{0}\right)\right\rangle}
$$

In essence, the calculations of Equations 4.10 and 4.12 involve scaling the measured volume backscattering coefficient by a predicted mean expected backscattering crosssection to estimate the density of individual krill, and then by a predicted mean biomass per individual to estimate the density of biomass. In both cases, these are weighted means, calculated via the integrals over the length probability density function to account for the fact that both wet weight and the backscattering cross-section are non-linear functions of length. The approach of estimating total biomass density in a single species situation on the basis of a mean backscattering cross-section and mean biomass per individual calculated in this way over a distribution of lengths is common in the field of fisheries acoustics (MacLennan and Simmonds, 1992). 
Equation 4.13 is valid for any length probability density function, $w(L)$, provided that the size classes encompassed by the length distribution are detectable by the acoustic system. For each krill aggregation examined here, the exact length distribution was not known. Like for the calculations of the expected backscattering cross-section used in the inversion protocol described above, a normal distribution was therefore assumed, centered at the weighted mean length estimated by the acoustic inversion, with a standard deviation of $15 \%$ of the mean. This again assumes that a single acoustically-dominant length mode was present in each aggregation. As noted earlier, the acoustic inversion estimates a mean krill length that is weighted by the scattering process via the krill scattering model. Although the exact way in which this weighted mean relates to the linear mean of all krill lengths actually present in the aggregation is complicated, it is at least self-consistent to use the weighted mean length derived from the inversion to estimate a mean target strength for krill present in the aggregation, since both are assuming the same normal distribution of krill lengths and accounting for the non-linear nature of the relationship between scattering and krill length in the same way.

The weight to length relationship employed here was drawn from Wiebe et al. (2004):

$$
W W(L)=5.5 \times 10^{-6} \times L^{3.2059}
$$

This relationship was derived from measurements of krill sampled in the present study region and gives the wet-weight in grams based on length $(L)$ in millimeters, measured as standard length 3 as defined by Mauchline (1980b). An estimate of biomass density was calculated following Equations 4.13 and 4.15 for each acoustic element within each acoustically-identified aggregation.

In cases where the inverse method could not be applied, target strength was estimated based on the mean length of krill in the nearest aggregation found within a $10 \mathrm{~km}$ horizontal radius, $50 \mathrm{~m}$ vertically, and with mean volume backscattering strength at 120 
$\mathrm{kHz}$ within $10 \mathrm{~dB}$ of that of the aggregation of interest. If no such aggregation was present, the median over all inversion-estimated lengths for that survey was used. In winter, no estimates of length could be made using the inverse method, due to malfunctions in the $43 \mathrm{kHz}$ system described below (section 4.3.1.a). For these surveys, the median length for the corresponding fall survey was employed to estimate single target strength values that were then applied to all observed aggregations (37.5 and 37 $\mathrm{mm}$ in 2001 and 2002, respectively). The biomass estimates made for the winter surveys should thus be approached with greater caution than those made in fall, but as will be explained in the discussion, the error introduced into the biomass estimates due to uncertainty in krill length estimates is relatively minor.

Estimates of vertically-integrated, or water-column, biomass were calculated by first integrating the estimates of biomass density over depth ranges of 1-100 m, 1-600 m, and 101-600 m. Note, however, that this maximum depth of $600 \mathrm{~m}$ was attained only inconsistently because of the undulating position of the BIOMAPER-II. The resulting vertically-integrated estimates of biomass per unit of surface area $\left(\mathrm{g} \mathrm{m}^{-2}\right)$ were then averaged in 1-km along-track intervals. This transect length was chosen to reduce spatial auto-correlation in krill biomass estimates. Such estimates will be referred to as 'vertically-integrated' biomass, to distinguish them from the biomass density estimates described in the previous paragraphs and the index of total biomass made on a byaggregation basis described next.

An index was also developed for the total biomass of krill in each acoustically-identified aggregation. This index was derived by multiplying each estimate of biomass density by the depth and along-track distance represented by that acoustic element, and then summing over all elements within the aggregation. Since the across-track extent of the aggregation is not known, it is not possible to calculate absolute biomass, and so the index of total biomass is left here in units of kilograms per across-track meter. 
A variety of additional measurements were made for each krill aggregation identified in the acoustic record. The position of each aggregation was defined on the basis of its centroid, or the mean depth and mean horizontal coordinates of all acoustic measurements made in the aggregation. The depth of the top and bottom of each aggregation was also measured, based on the shallowest and deepest measurements, as was the altitude of the centroid and bottom of the aggregation from the seafloor. The distance to the nearest neighboring aggregation was calculated on the basis of centroid positions (Nero and Magnuson, 1989).

\subsubsection{Analysis of krill distribution in relation to environmental features}

\subsection{5.a Environmental data}

Environmental measurements were available from a variety of sources. Physical properties included temperature and salinity data recorded by the BIOMAPER-II concurrent to acoustic data collection, to the maximum depth reached by the tow-body (maximally $400 \mathrm{~m}$, more typically $250 \mathrm{~m}$ ). Deeper than this, temperature and salinity data were spatially interpolated from CTD casts at hydrographic stations positioned nominally every $20 \mathrm{~km}$ along the survey lines (Klinck et al., 2004). CTD casts were also used to determine the temperature maximum below $200 \mathrm{~m}$ depth (Tmax); these data were then interpolated to estimate Tmax at the midpoint of each 1-km interval over which krill vertically-integrated biomass was averaged. Bottom depth estimates were drawn from the high-resolution dataset of Bolmer et al. (2004). Bathymetric slope was calculated as the difference in these depth estimates between the locations of successive measurements by the BIOMAPER-II acoustic system, divided by the distance between measurements, and averaged within each 1-km interval. Interpolations were also made of observations of along-track ice concentration in tenths made every six hours in fall and nearly every hour in winter (C. Fritsen, unpublished data; see U.S. SO GLOBEC, 2001b and 2002b). These data were supplemented by observations made by bird observers during daylight survey periods (Ribic et al., submitted). Distance to nearest land was calculated from the 
midpoint of each 1-km krill biomass interval. A $150 \mathrm{kHz}$ Acoustic Doppler Current Profiler (ADCP) measured velocity measurements in 8-m depth bins from a depth of 31 $\mathrm{m}$ to a maximum of 300 or $350 \mathrm{~m}$, averaged in 1 hour along-track intervals (Klinck et al., 2004). Assuming an isotropic flow field, the magnitude of horizontal shear at depth $j$ was estimated from the East-West and North-South velocity components ( $u$ and $v$, respectively) measured nearest to a given 1-km interval (position $i$ ) and the previous set of measurements (position $i-1$ ), and the distance between the two locations $(\Delta s)$ following:

$$
\left|\frac{\partial \vec{u}}{\partial s}\right|=\sqrt{\left(\frac{u_{i, j}-u_{i-1, j}}{\Delta s}\right)^{2}+\left(\frac{v_{i, j}-v_{i-1, j}}{\Delta s}\right)^{2}}
$$

Chlorophyll $a$ (chl- $a$, in $\mathrm{mg} \mathrm{m}^{-2}$ ) measured from bottle samples at hydrographic stations and integrated to a depth of $30 \mathrm{~m}$, was interpolated to the location of each $1-\mathrm{km}$ vertically-integrated biomass estimate, and used as an index of food availability (M. Vernet, unpublished data; see U.S. SO GLOBEC, 2001a and 2002a). All interpolations were done linearly on the basis of latitude and longitude.

\subsection{5.b Statistical analysis}

Empirical statistical models, specifically Generalized Additive Models (GAM; Hastie and Tibshirani 1990), were used to examine the association of krill vertically-integrated biomass averaged in 1-km along-track intervals with these properties of the physical and biological environment. GAM is a regression method where the assumption made in linear regression modeling of a Gaussian error structure is generalized to any distribution from the exponential family, providing greater flexibility in modeling non-normally distributed data. Furthermore, GAMs proceed by fitting smoothing functions to the relationship between the response and each predictor variable, and thereby allow for nonlinear relationships (Hastie and Tibshirani 1990). The use of GAMs to examine 
associations between the results of acoustic surveys and environmental features has been employed previously for krill (Trathan et al., 2003), allowing interesting ecological insight.

Three hypotheses in particular were addressed: 1 . Krill biomass increases in regions of high food availability, as indicated by chl- $a$ concentrations. 2. Higher krill biomass is associated with regions where recent intrusions of Circumpolar Deep Water (CDW) are present at depth. This is the water mass suggested by Prézelin et al. (2004) to be an important driver of primary productivity on the continental shelf, and can be tracked via the temperature maximum below a depth of $200 \mathrm{~m}$ (Tmax; Prézelin et al., 2004; Klinck et al., 2004). This hypothesis can thus be tested by determining whether krill biomass is positively associated with Tmax. 3. Krill biomass is higher in regions where currents and horizontal current shear are weak, in order to avoid advection out of the area and having aggregations being pulled apart by shear, respectively.

It is possible that other measured properties of the environment may also influence krill distribution, and so in addition to these four variables, multi-variate GAM analyses included distance to land, depth, bathymetric slope, and ice concentration. All of these variables were examined together in order to assess their relative importance. By virtue of including a number of variables where no prior expectation existed for a relationship with krill biomass, these analyses are more exploratory than they are tests of hypotheses.

The distribution of krill vertically-integrated biomass proved to be strongly dominated by an absence of krill (e.g., 2151 observations of zero $\mathrm{g} \mathrm{m}^{-2}$ out of 2685 total measurements in fall of 2002), making the application of standard error distributions for GAM analysis (e.g., Gaussian, Gamma) inappropriate. We therefore followed the approach recommended by Barry and Welsh (2002) for such 'zero-inflated' observations, and modeled the data in two steps. First, a model was developed with the presence or absence of krill as the response variable in relation to the various environmental predictors, assuming a binomial error distribution and employing a logit link function (i.e., a logistic 
regression model). Then a second model was fit to log-transformed krill verticallyintegrated biomass, but only where it exceeded zero, employing a Gaussian error structure. Essentially, this allows the separate but related questions of 'what determines krill habitat?' and 'within krill habitat, what factors favor increased biomass?' to be addressed.

Analysis began with a model for the response variable of either presence/absence or krill vertically-integrated biomass where non-zero, in relation to all predictor variables: chl- $a$, Tmax, distance to land, depth, bathymetric slope, ice concentration, current magnitude at the depth of $150 \mathrm{~m}$, and horizontal current shear at $150 \mathrm{~m}$. The depth of $150 \mathrm{~m}$ was chosen as it proved to be the depth of maximal krill biomass density, and as such gave an indication of currents experienced by the greater part of the krill. Furthermore, the patterns described below concerning the association of krill biomass with currents and shear at $150 \mathrm{~m}$ were highly similar to the unreported associations of biomass with currents and shear at shallower depths where currents were stronger. Each survey was considered separately. In the fall of 2001, virtually no sea ice was present, and ice concentration was not included in analysis. Similarly, sufficient noise-free ADCP-derived current data were not available for analysis in the winter surveys. Each variable was checked for co-linearity (defined as $r>0.7$ ) with other predictors; due to co-linearity with chl- $a$, measurements made by the BIOMAPER-II of temperature and salinity were not included in any analyses. For the initial model, the relationships between the dependent variable and each environmental predictor were fit with spline smoother functions constrained to 3 degrees of freedom, in order to allow for potential non-linearities, but restrict unrealistic features in the shape of the resulting functions (Hastie et al., 2005).

Variable selection then proceeded following a semi-formal approach consistent with the recommendations of Hastie and Tibshirani (1990). The effect of removing each environmental variable in turn was examined and tested for significance via a chi-square test on the deviance explained by the full model versus that with the variable removed. The variable whose removal resulted in the smallest non-significant reduction in deviance 
explained was then dropped. This was repeated until any possible removal resulted in a significant decrease in deviance explained. The goal was to arrive at the most parsimonious model with the fewest independent predictor variables, while simultaneously maximizing deviance explained. Similarly, each time a variable was dropped from the model, it was determined whether a linear or smoothing function $(\mathrm{df}=$ 3) best described the relationship between the response variable and each remaining predictor. Again in order to err on the side of parsimony, if the confidence interval about the smoothed function did not exclude the possibility of a linear relationship, then a linear function was adopted. The fraction of deviance explained ([null deviance-residual deviance]/null deviance) was used to assess the explanatory power of each final model. All analyses were done using the GAM package in R (R Development Core Team, 2006).

\subsection{RESULTS}

\subsubsection{Application and verification of acoustic methodologies}

\subsection{1.a Krill identification}

Verification of the method for identifying krill in the acoustic data can be provided by examining $\delta$ MVBS levels for regions and depths where krill were known to be present via independent lines of evidence. The two instances where net samples can be associated with particular acoustically-observed krill aggregations with the least ambiguity are Laubeuf Fjord in fall of 2001 and Crystal Sound in fall of 2002 (Figure 4.1a). In these two locations, on the basis of net catches, krill were predicted to account for $>95 \%$ of scattering levels at $120 \mathrm{kHz}$ for the depth ranges where large aggregations of enhanced volume backscattering were evident (calculations explained in Lawson et al., 2004). Numerous VPR images of 'large' krill (defined as individuals larger than the width of the field of view of 16.5-31 mm) were also collected in these aggregations (Figure 4.3a). $\delta$ MVBS levels observed for the krill aggregations at the same depths and within a distance of $400 \mathrm{~m}$ horizontally of these net tows were 10 to $14 \mathrm{~dB}$, and thus were within the allowable 'krill' range (Table 4.1). Similarly, in other instances elsewhere in the 


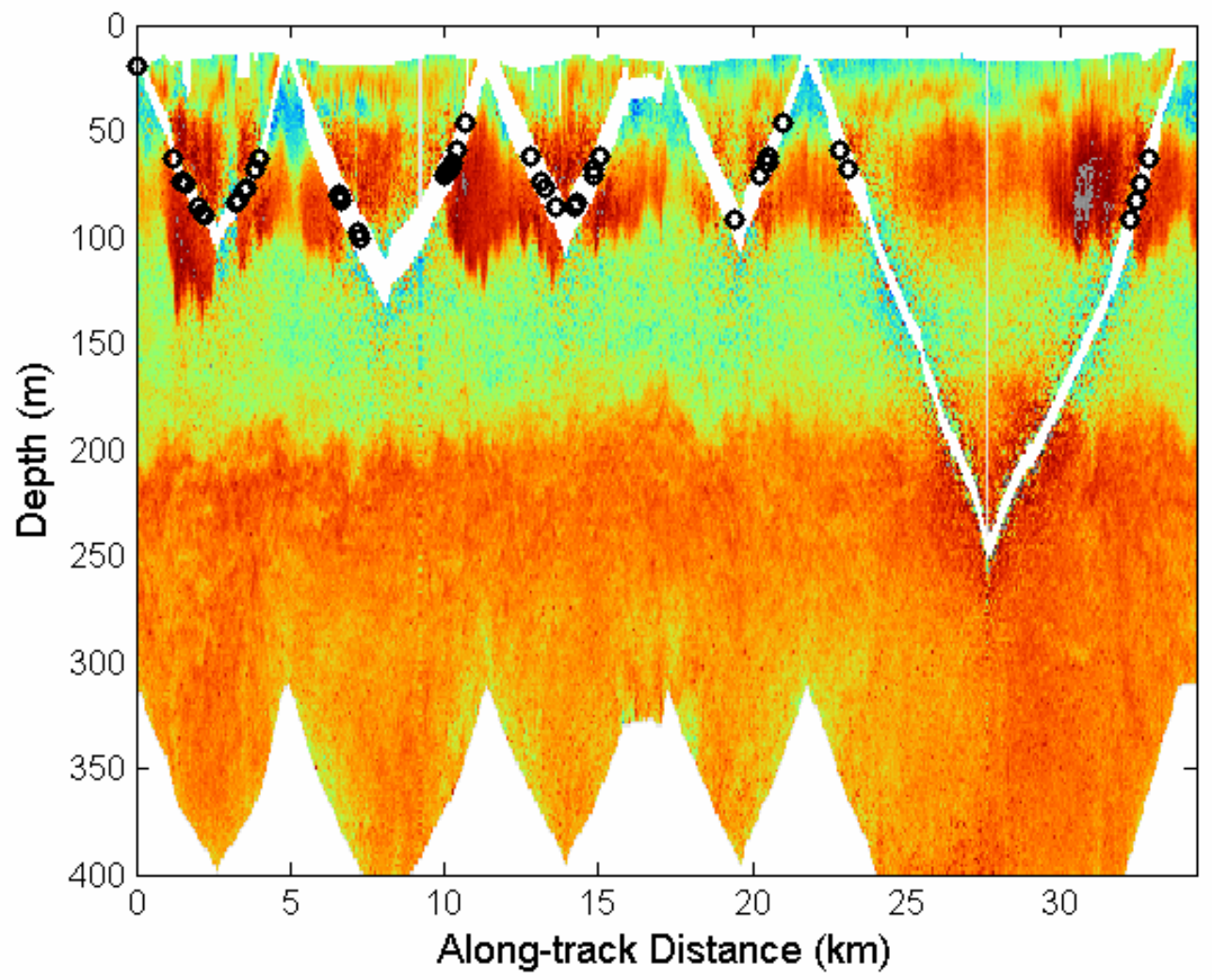

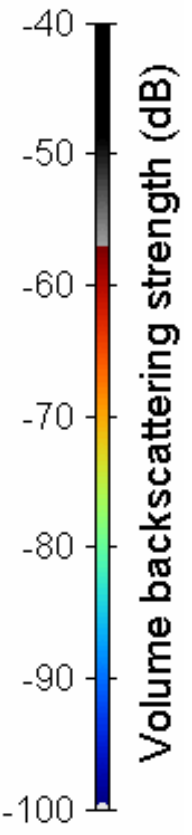

Figure 4.3a - Echogram of volume backscattering strength at $120 \mathrm{kHz}$, showing a krill aggregation observed acoustically between depths of 50 and $100 \mathrm{~m}$ in Laubeuf Fjord during the fall 2001 cruise. Repeat net samples also were made in this region. Black circles indicate locations where large krill were observed with the VPR. The deeper layer below a depth of $200 \mathrm{~m}$ is likely composed of a mixture of copepods, siphonophores, and other zooplankton or micronekton (Lawson et al., 2004). 


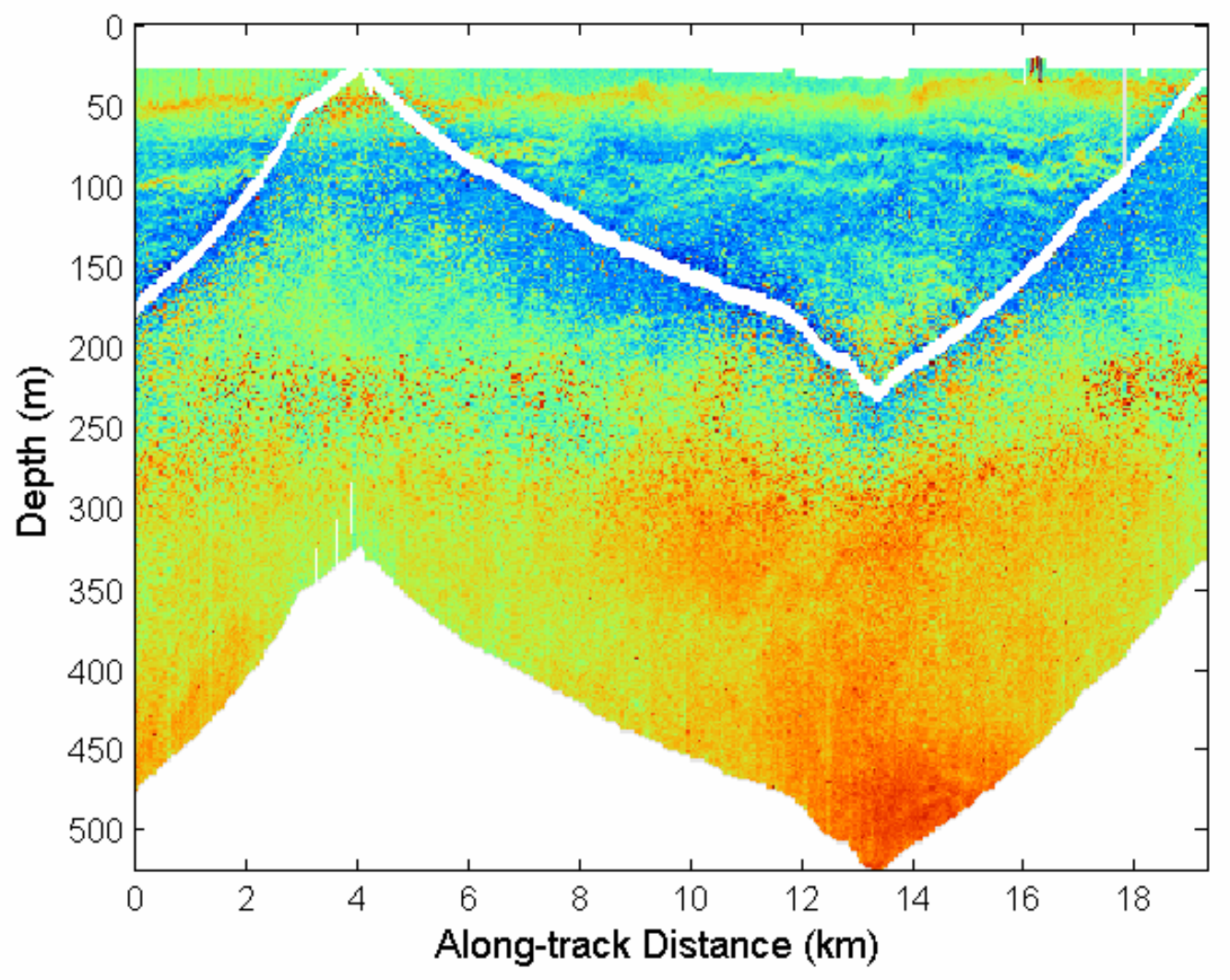

Figure 4.3b - Typical homogeneous scattering layer observed in the northern mid-shelf during the fall 2002 survey. Such layers were present over much of the shelf region during both falls, and are thought to be composed of a mixed-zooplankton community and not aggregating euphausiids. 


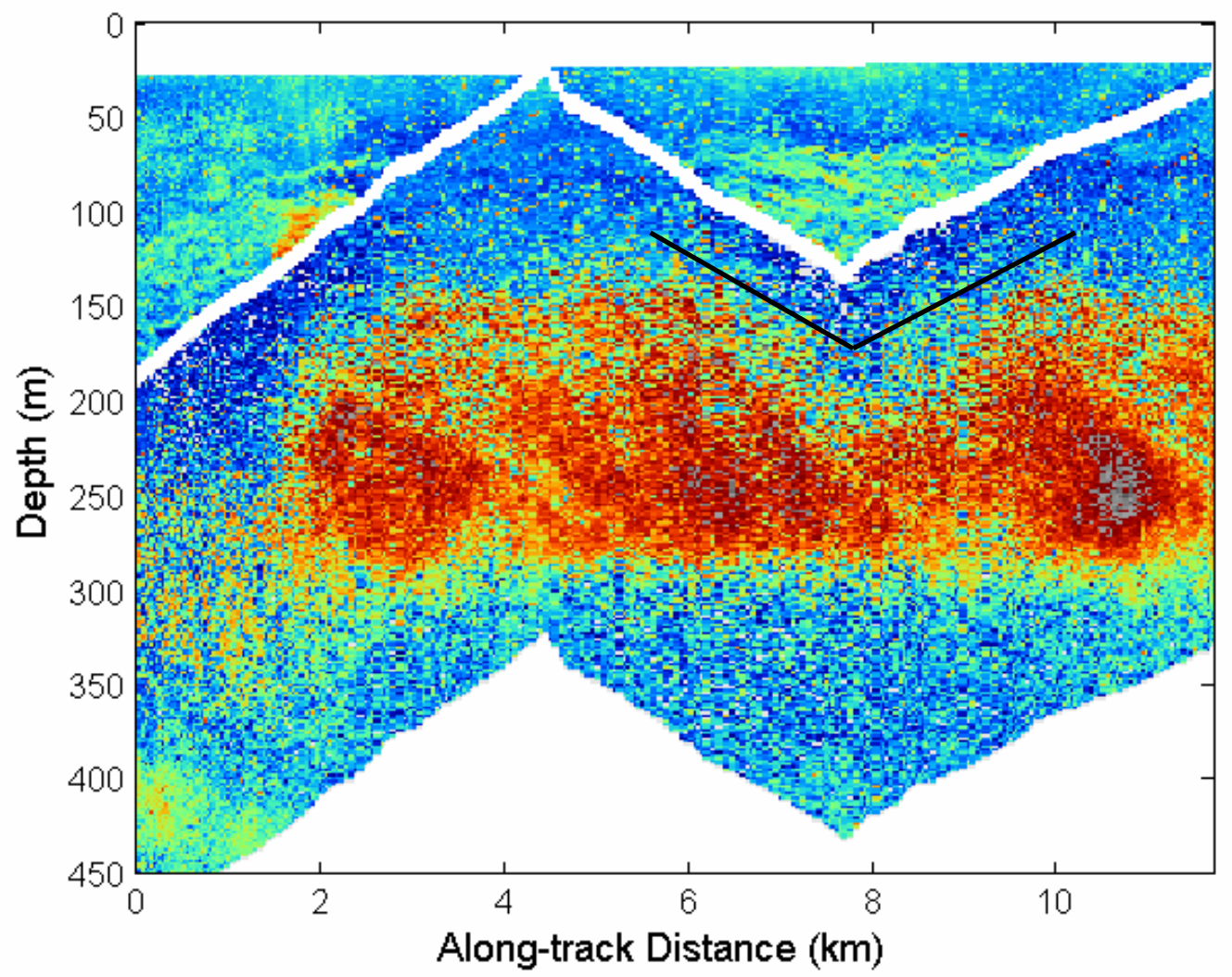

Figure 4.3c - Typical layer or patch of enhanced but variable ('speckled') volume backscattering believed to be composed primarily of swimbladder-less fishes rather than zooplankton. Such patches were present over much of the northern outer shelf region during fall 2001 (Lawson et al., 2004), and near the shelf break during fall 2002. White trace indicates the path of the towed body; black lines indicate portions of the aggregation suggestive of avoidance of the body. 
survey area when the BIOMAPER-II bisected a krill aggregation and the VPR was able to make observations of large krill, $\delta \mathrm{MVBS}$ was always within the allowable range (Table 4.1).

In general, portions of the acoustic record meeting both the threshold scattering level and SMVBS criteria had the very typical appearance of krill aggregations (Figure 4.3a, 50$100 \mathrm{~m}$ depth range). There were, however, three types of acoustic feature where some acoustic elements met both criteria, but where nets, VPR observations, and other lines of evidence do not support the presence of krill (Figure 4.3b,c). These include the pervasive, homogeneous scattering layers present over the mid-shelf region during both fall surveys (Figure 4.3b,> $150 \mathrm{~m}$ depth), observed for distances as long as $100 \mathrm{~km}$, and extending from between the surface and a depth of $150 \mathrm{~m}$ to the bottom. Net samples (Ashjian et al., 2004; Lawson et al. 2004) and analyses of VPR data (C. Ashjian, unpublished data) suggest these layers were composed of a mixture of copepods, gas-bearing siphonophores, and other zooplankton, rather than krill. Furthermore, averaging over these layers in their entirety, $\delta$ MVBS was typically greater than $20 \mathrm{~dB}$, and it was only some elements or groups of elements where $\delta$ MVBS was $<16$ and which might therefore be confused with krill. These few elements likely represent the occasional presence of larger, stronger scattering animals, such as siphonophores, fish, or non-aggregated euphausiid species. All elements that passed the krill identification criteria, but which were visually determined to be within a layer, therefore were excised from further analysis.

The second such feature type involved large patches or layers of enhanced, but variable ('speckled'), volume backscattering extending horizontally as much as tens of kilometers at depths of 150 to $350 \mathrm{~m}$ (Figure 4.3c), where mean $\delta$ MVBS was typically 4-6 dB. Although this falls within the allowable range for krill, it is suggestive of mean krill lengths around $50 \mathrm{~mm}$, which is larger than was typically observed in the region with nets (Ashjian et al., 2004). Three additional lines of evidence suggest that these layers were not comprised of krill, but rather were made up of swimbladder-less fishes. First, the 
TABLE 4.1 (facing) - Krill length and numerical density in acoustically-observed aggregations, measured by nets and estimated on the basis of the multi-frequency inversion method. Laubeuf Fjord (fall 2001) and Crystal Sound (fall 2002) were the two locations where nets and acoustics definitely sampled the same krill aggregations. 'Net range' refers to inversions of mean volume backscattering levels observed at the same depths and in overlapping spatial intervals as sampled by the net system, although at a different time (since the net and acoustic systems could not be deployed at the same time). 'Near nets' refers to all aggregations identified in the spatial interval sampled by the nets, irrespective of depth, while 'in region' refers to all aggregations identified in the overall vicinity of the net tows. The lengths sampled by nets were described in three ways: the linear mean and the root-mean-square ('RMS') of the larger length mode of captured krill lengths (see text and Figure 4.6), and a mean of the lengths from both the small and large length modes, weighted by the predicted scattering of each length ('Wted'; see text). TS inverse refers to estimates of mean krill length based on inversions of observed target strengths in the depth range and spatial area sampled by net tows. For the inversion on target strength, only an $E_{2}$-like error term was applied (i.e., an error term defined on the basis of target strength in logarithmic form). $s_{v} / \sigma_{\text {bs }}$ refers to the case where the mean volume backscattering coefficient $\left(s_{v}\right)$ averaged over all measurements made in the depth range and spatial region sampled by net tows 21 and 22 was scaled by the mean measured target strength in linear form $\left(\sigma_{\mathrm{bs}}\right)$ to yield an estimate of krill density. On yeardays 136 and 144 of the fall 2001 survey and 105 and 125 in fall of 2002, repeat observations were made by the VPR of large krill in acoustically-identified aggregations. Lengths and densities estimated by the inversion method for these aggregations are presented, although no net samples were available. 


\begin{tabular}{|c|c|c|c|c|c|c|c|c|c|c|c|c|c|c|c|c|c|}
\hline \multirow[b]{3}{*}{ Row } & \multirow[b]{3}{*}{ Location } & \multirow[b]{3}{*}{ Tow } & \multirow[b]{3}{*}{ Depth } & \multirow[b]{3}{*}{ VPR } & \multicolumn{2}{|c|}{$\begin{array}{l}\text { Acoustic vs. } \\
\text { Net Uncertainty }\end{array}$} & \multicolumn{4}{|c|}{ Net-derived } & \multicolumn{7}{|c|}{ Acoustically-derived } \\
\hline & & & & & \multirow{2}{*}{$\begin{array}{l}\text { Max. } \\
\text { Dist. }\end{array}$} & \multirow{2}{*}{$\begin{array}{l}\text { Max. } \\
\text { Time } \\
\end{array}$} & \multicolumn{3}{|c|}{ Length (mm) } & \multirow{2}{*}{$\begin{array}{c}\text { Dens. } \\
\left(\# \mathrm{~m}^{-3}\right) \\
\end{array}$} & \multicolumn{3}{|c|}{ Length (mm) } & \multicolumn{3}{|c|}{ Density $\left(\# \mathrm{~m}^{-3}\right)$} & \multirow{2}{*}{$\begin{array}{c}\delta \mathrm{MVBS} \\
(\mathrm{dB}) \\
\end{array}$} \\
\hline & & & & & & & Mean & RMS & Wted & & E1 & E2 & E3 & E1 & $\mathrm{E} 2$ & E3 & \\
\hline & $\begin{array}{l}\text { FALL } 2001 \\
\text { Laubeuf Fjd }\end{array}$ & & & & & & & & & & & & & & & & \\
\hline 1 & Net range & 21 & $50-100 \mathrm{~m}$ & Yes & $365 \mathrm{~m}$ & $7.5 \mathrm{hrs}$ & 40.1 & 40.5 & 41.7 & 0.8 & 39 & 35.5 & 37.5 & 9.8 & 9.6 & 9.5 & 13.3 \\
\hline 2 & Net range & 22 & $50-90 \mathrm{~m}$ & Yes & $373 \mathrm{~m}$ & $6 \mathrm{hrs}$ & 43.6 & 44.0 & 44.9 & 1.5 & 39 & 38.5 & 38.5 & 12.6 & 6.7 & 10.8 & 13.7 \\
\hline 3 & Net range & 24 & $25-50 \mathrm{~m}$ & Yes & $1254 \mathrm{~m}$ & $10 \mathrm{hrs}$ & 8.3 & 8.5 & 10.1 & 1.7 & 39 & 16.5 & 40.5 & 2.6 & 33 & 2.1 & 23.1 \\
\hline 4 & Near nets & 21 & $41-128 m$ & Some & $365 \mathrm{~m}$ & $7.5 \mathrm{hrs}$ & 40.1 & 40.5 & 41.7 & 0.8 & 39 & 37 & 38 & 7.6 & 5.9 & 6.7 & 13.3 \\
\hline 5 & Near nets & 22 & $12-112 \mathrm{~m}$ & Some & $373 \mathrm{~m}$ & $6 \mathrm{hrs}$ & 43.6 & 44.0 & 44.9 & 1.5 & 39 & 39 & 38.5 & 10.5 & 5.9 & 8.9 & 12.8 \\
\hline 6 & In region & 21,22 & $12-188 \mathrm{~m}$ & Some & $14 \mathrm{~km}$ & $22.3 \mathrm{hrs}$ & - & - & - & - & 39.1 & 38.4 & 38.4 & 5.6 & 3.2 & 5.9 & 13.7 \\
\hline 7 & TS inverse & 21 & $50-100 \mathrm{~m}$ & Yes & $365 \mathrm{~m}$ & $7.5 \mathrm{hrs}$ & 40.1 & 40.5 & 41.7 & 0.8 & - & 40.5 & - & - & - & - & 13.3 \\
\hline 8 & TS inverse & 22 & $50-90 \mathrm{~m}$ & Yes & $373 \mathrm{~m}$ & $6 \mathrm{hrs}$ & 43.6 & 44.0 & 44.9 & 1.5 & - & 40.5 & - & - & - & - & 13.7 \\
\hline 9 & $s_{v} / \sigma_{\mathrm{bs}}$ & 21 & $50-100 \mathrm{~m}$ & Yes & $365 \mathrm{~m}$ & $7.5 \mathrm{hrs}$ & 40.1 & 40.5 & 41.7 & 0.8 & - & - & - & 7.0 & 4.3 & 7.7 & 13.3 \\
\hline 10 & $s_{v} / \sigma_{\mathrm{bs}}$ & 22 & $50-90 \mathrm{~m}$ & Yes & $373 \mathrm{~m}$ & $6 \mathrm{hrs}$ & 43.6 & 44.0 & 44.9 & 1.5 & - & - & - & 8.4 & 4.3 & 11.4 & 13.7 \\
\hline 11 & Day 136 & - & $84 \mathrm{~m}$ & Yes & - & - & - & - & - & - & 39.5 & 40 & 39 & 105.3 & 67.8 & 89.6 & 11.0 \\
\hline 12 & Day 144 & - & $163 \mathrm{~m}$ & Yes & - & - & - & - & - & - & 39 & 36.5 & 37 & 14.7 & 15.6 & 15.8 & 11.2 \\
\hline & $\begin{array}{l}\text { FALL } 2002 \\
\text { Crystal Sd. }\end{array}$ & & & & & & & & & & & & & & & & \\
\hline 13 & Net range & 24 & $103-125 \mathrm{~m}$ & Yes & $109 \mathrm{~m}$ & $10.5 \mathrm{hrs}$ & 39.9 & 40.5 & 41.9 & 0.2 & 38.5 & 37.5 & 37.5 & 24.2 & 23.7 & 24.1 & 9.9 \\
\hline 14 & Near nets & 24 & $62-178 \mathrm{~m}$ & Some & $109 \mathrm{~m}$ & $10.5 \mathrm{hrs}$ & 39.9 & 40.5 & 41.9 & 0.2 & 38.5 & 38.3 & 37.8 & 5.2 & 3.5 & 4.5 & 11.7 \\
\hline 15 & In region & 24 & $14-258 m$ & Some & $2 \mathrm{~km}$ & $21 \mathrm{hrs}$ & 39.9 & 40.5 & 41.9 & 0.2 & 38.0 & 37.5 & 36.0 & 2.4 & 1.5 & 2.4 & 12.5 \\
\hline 16 & Day 105 & - & $99 \mathrm{~m}$ & Yes & - & - & - & - & - & - & 38.5 & 38 & 38.5 & 44.3 & 25.8 & 37.2 & 12.4 \\
\hline 17 & Day 125 & - & $136 \mathrm{~m}$ & Yes & - & - & - & - & - & - & 38 & 34.5 & 37.5 & 25.4 & 19.9 & 22.1 & 15.0 \\
\hline
\end{tabular}


layers were observed to avoid the BIOMAPER-II at ranges of up to $50 \mathrm{~m}$ (Figure 4.3c). Such large avoidance distances exceed those previously reported for the Antarctic krill (10 m, Everson and Bone, 1986), but have been observed in mesopelagic fish (e.g., 130 $\mathrm{m}$ for orange roughy; Koslow et al., 1995). Second, median target strengths at $43 \mathrm{kHz}$ observed in these layers were approximately $-47 \mathrm{~dB}$ (Figure 4.4), much stronger than would be expected from krill (-78 to $-70 \mathrm{~dB}$ for krill of length 43 to $50 \mathrm{~mm}$, Lawson et al., 2006).

Finally, although catches of fish made with the $1-\mathrm{m}^{2}$ mouth opening MOCNESS employed in the present broad-scale surveys were low (Ashjian et al., 2004; Lawson et al., 2004), catches made with a $10-\mathrm{m}^{2}$ MOCNESS by a companion SO GLOBEC project (J. Donnelly, unpublished data), suggest fish densities near these features of 0.6 to $2.2 \mathrm{x}$ $10^{-3}$ individuals $\mathrm{m}^{-3}$, of size 40 to $150 \mathrm{~mm}$. At present there is no target strength model for Antarctic myctophids, but if we follow the approach of Filin et al. (1990) and use a target strength model for swimbladder-less North Atlantic myctophids (Mamylov, 1988), these sizes would predict target strengths levels of -60 to $-45 \mathrm{~dB}$ at $38 \mathrm{kHz}$, quite close to the levels observed at $43 \mathrm{kHz}$ (Figure 4.4). Based on these estimates of target strength and fish density, we would expect volume backscattering strengths of -78 to $-88 \mathrm{~dB}$. These are one to two orders of magnitude smaller than mean volume backscattering strengths observed in these features, perhaps due to the avoidance by the animals in these patches of the oncoming towed body described above and to the nets integrating over large volumes of water of variable fish density. Although the evidence is thus consistent with these features being comprised of fish, we also can't exclude the possible presence of other animals, such as squid, whose avoidance capabilities and target strengths might likewise be consistent with those observed, but which might be strong enough avoiders that they are also under-sampled by the 10- $\mathrm{m}^{2}$ MOCNESS. In either case, these 'fish patches' were highly recognizable in the acoustic record (Figure 4.3c), and so were excised on the basis of visual scrutiny. A similar approach for avoiding the inclusion of fish scattering based on a combination of net data and visual assessment has been taken in previous krill surveys (Pauly et al, 2000). 


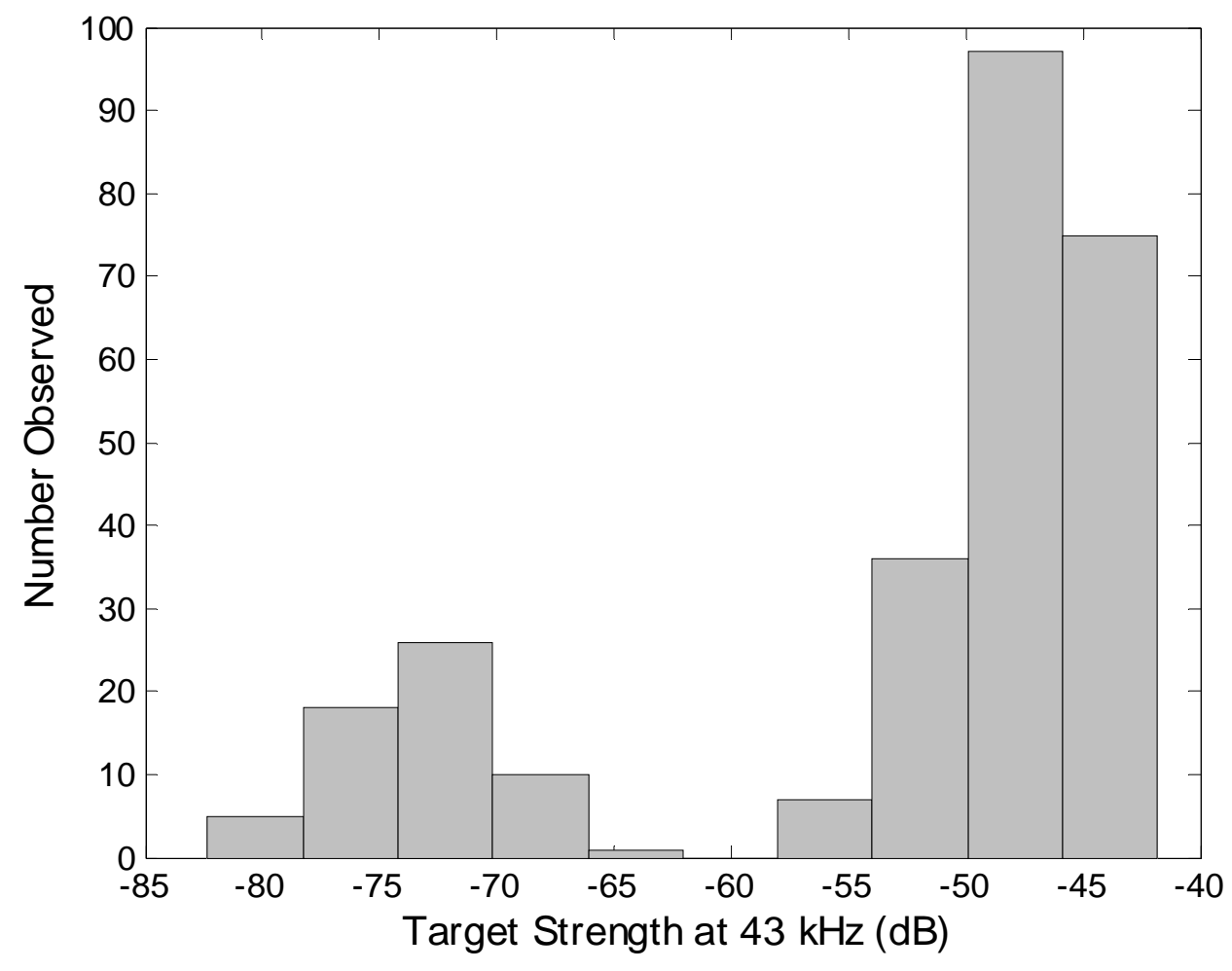

Figure 4.4 - Target strengths measured at $43 \mathrm{kHz}$ in a 'fish patch.' Note that the system's dynamic range was set to -100 to $-40 \mathrm{~dB}$ to optimize measurements of target strength for zooplankton, resulting in the right-hand tail of the distribution being cut off here due to system saturation. In order to reduce the likelihood that multiple targets were mistakenly accepted as individual target strengths, only measurements made at a beam pattern factor (an indicator of off-axis position) between 0 and $-3 \mathrm{~dB}$ and where the length of the received acoustic pulse at half-power was within $12.5 \%$ of the transmitted pulse were accepted for analysis. Target strengths were also lower both above and below the patch, suggesting that the high target strengths within the patch were not solely due to increased acceptance of multiple targets with increased range. 
During the fall 2002 survey, the $43 \mathrm{kHz}$ transducers operated properly and most aggregations that passed the threshold volume backscattering strength at $120 \mathrm{kHz}$ also fell within the krill range of $\delta$ MVBS (Figure 4.5). In contrast, during the fall 2001 survey, there were numerous aggregations that exceeded the threshold scattering level but did not meet the $\delta$ MVBS criterion (Figure 4.5), despite having the appearance of krill aggregations, rather than fish patches or mixed-zooplankton layers. The $43 \mathrm{kHz}$ data during the fall of 2001 were affected by a sensitivity issue, likely related to the noise thresholds applied during this survey, which were higher than in the 2002 survey. In general, the data at this frequency were appropriately strong in features near to the transducers where volume backscattering was also high at the higher frequencies, but set to zero by the noise thresholds at greater ranges. Given the similarity in volume backscattering strength at $120 \mathrm{kHz}$ for the fall of 2001 and 2002 aggregations (Figure 4.5), and given that most aggregations passing the $120 \mathrm{kHz}$ threshold in fall of 2002 also passed the $\delta$ MVBS test, we assume that all fall 2001 aggregations that did not have the appearance of layers or fish patches and where $\delta \mathrm{MVBS}>2 \mathrm{~dB}$ were krill.

In the winter of 2001, most of the $43 \mathrm{kHz}$ data were unusable due to strong noise associated with ice-breaking, while during the winter of 2002, both $43 \mathrm{kHz}$ transducers malfunctioned. During the wintertime surveys, krill aggregations were therefore identified solely on the basis of the threshold volume backscattering strength at $120 \mathrm{kHz}$ and on the basis of visual comparison to known krill aggregations from the surveys conducted in fall. This led to the exclusion of a deep scattering layer present during winter in association with the bottom (see figures in Lawson et al., 2004). This layer was present over much of the continental shelf, extending upwards from the bottom by distances as much as $100 \mathrm{~m}$ or more. In the few cases where noise-free measurements were made at $43 \mathrm{kHz}$ in this layer during the winter of 2001, the measured $\delta \mathrm{MVBS}$ exceeded $17 \mathrm{~dB}$. Limited net samples also suggest that scattering in this layer was primarily due to copepods and pteropods, and not krill, but we cannot reject the possibility that it was in part made up of krill (see discussion in Lawson et al. (2004)). 

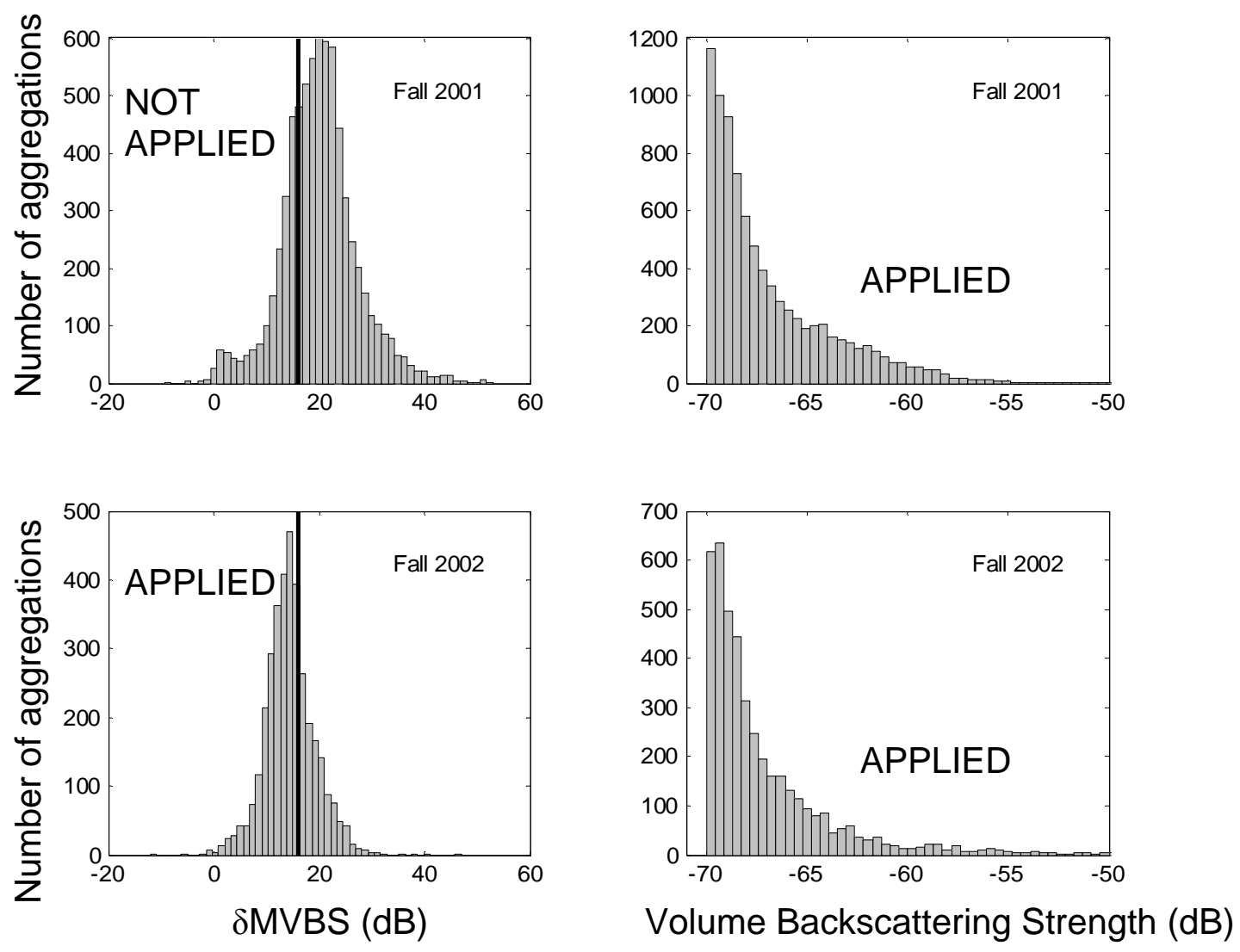

Figure 4.5 - Left-hand plots show differences in mean volume backscattering strength between 120 and $43 \mathrm{kHz}$ ( $\delta \mathrm{MVBS}$ ), for all aggregations observed during the fall 2001 and 2002 surveys that also passed the threshold volume backscattering strength at 120 $\mathrm{kHz}$ criterion. Black vertical line indicates the maximum $\delta \mathrm{MVBS}$ for krill of $16 \mathrm{~dB}$. Right-hand plots show mean volume backscattering strength at $120 \mathrm{kHz}$ for these same aggregations. Due to issues associated with the functioning of the $43 \mathrm{kHz}$ system in fall of 2001, the $\delta$ MVBS criterion was only applied to aggregations detected in the fall 2002 survey. The threshold volume backscattering strength criterion was applied in both falls (as well as both winter surveys) 


\subsection{1.b Estimating krill length and density}

Verification of the inverse method for estimating the weighted mean length and density of krill in aggregations identified acoustically following the methods examined above was achieved by first applying it to aggregations observed in the two locations where nets and acoustics were most likely to have sampled the same aggregations, and where VPR observations provided further confirmation of the presence of large krill (Laubeuf Fjord in the fall of 2001 and Crystal Sound in fall of 2002; Figure 4.1a). Comparisons of acoustically-estimated lengths and densities to net samples at these two test-locations were also used to determine which of the three error terms $\left(E_{1}-E_{3}\right)$ was most suitable for application to the full acoustic dataset, a necessary step in making the biomass estimates examined in the biological analyses that follow in section 4.3.2.

Acoustic estimates of weighted mean length (where the weighting is by the acoustic scattering process via the scattering model) were encouragingly similar to the linear mean of krill lengths measured in net samples, although consistently slightly smaller than the net estimates. In Laubeuf Fjord, applying the inverse method to volume backscattering meeting the threshold scattering and $\delta$ MVBS criteria and measured at the same depth and spatial region as the net samples, separated in time by no more than 5 hours, resulted in weighted mean estimated lengths of 35.5 to $40.5 \mathrm{~mm}$. These compare favorably to measurements of the mean lengths of large krill (>20 mm) in net samples of 40.1 to 43.6 mm (rows 1-2 in Table 4.1, and see Wiebe et al., 2004). In Crystal Sound, the acoustic estimates ranged from 37.5 to $38.5 \mathrm{~mm}$ (depending on which error term was used), again very similar to the net-estimated mean length of $39.9 \mathrm{~mm}$ (row 13 in Table 4.1).

The distribution of lengths sampled at both locations was in fact bimodal, with one mode of small animals ( $<20 \mathrm{~mm}$ ) and one of larger individuals ( $>20 \mathrm{~mm}$; Figure 4.6). The contribution to total measured volume backscattering from these krill of size less than 20 $\mathrm{mm}$, however, will be overwhelmed by the scattering from the larger animals. Using the Lawson et al. (2006) scattering model, predictions of expected volume backscattering 

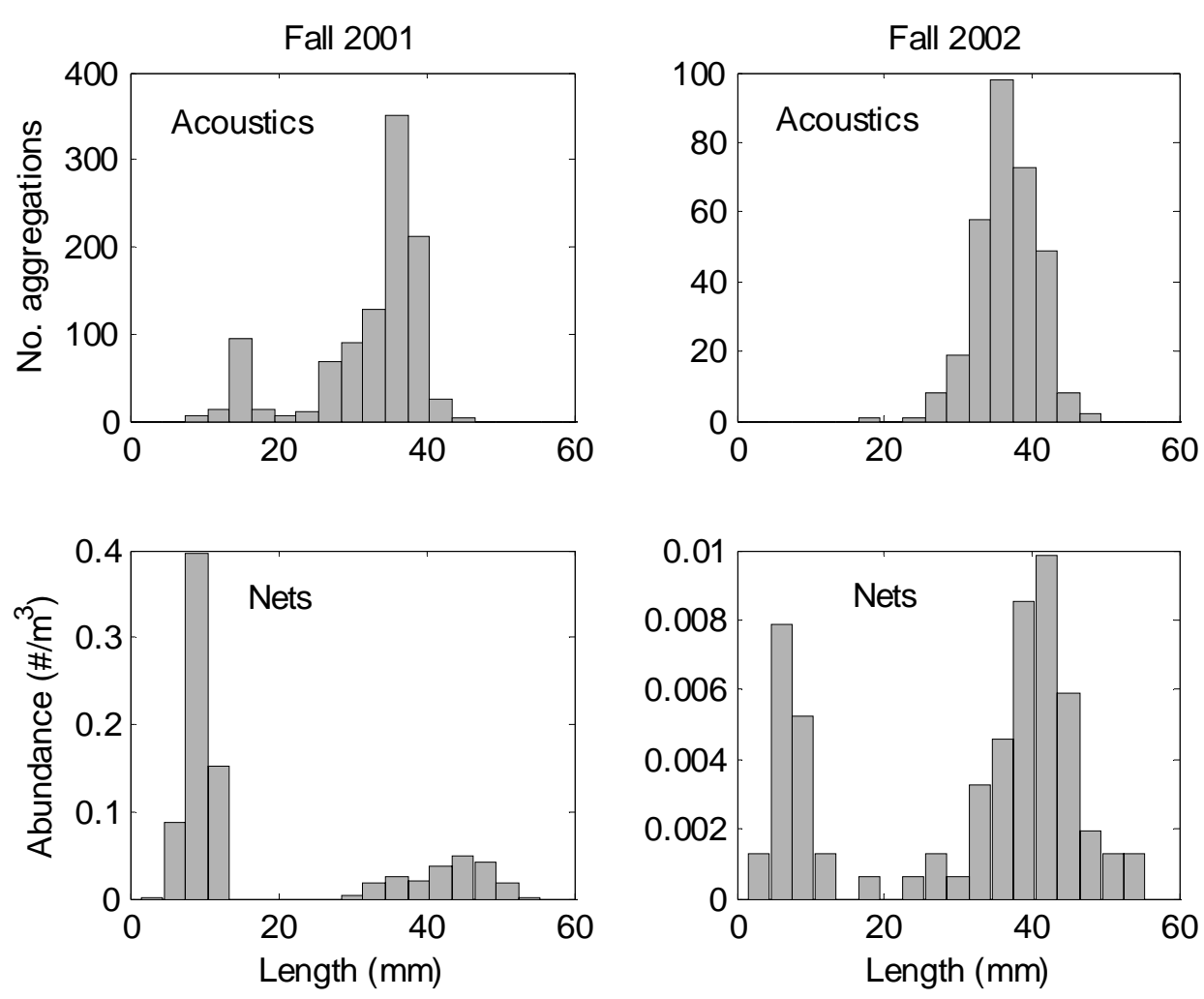

Figure 4.6 - Distribution of krill lengths estimated with acoustics and nets for the two locations in the fall 2001 and 2002 surveys where nets and acoustics could be unambiguously associated with one another: Laubeuf Fjord in fall 2001, and Crystal Sound in fall 2002. For the acoustics, the weighted mean lengths estimated by the inverse method using the $E_{2}$ error term for all aggregations observed in the overall vicinity of the net tow are shown (see Table 4.1 for additional details); frequency distributions show the number of aggregations for which the mean length represented by each length bin was estimated. For the nets, frequency distributions show the number of individuals per $\mathrm{m}^{3}$ in each length bin, based on measured samples and volumes of water filtered, for tows \#24 (fall 2001) and \#24 (fall 2002). 
strength based on net catches for the larger krill alone versus predictions based on both the large and small length modes differ at 43 and $120 \mathrm{kHz}$ by no more than $0.1 \mathrm{~dB}$ and at 200 and $420 \mathrm{kHz}$ by no more than $0.3 \mathrm{~dB}$ (see Lawson et al. (2004) for an explanation of the calculations involved). The contribution of the smaller length mode to the volume backscattering measurements used to estimate length should thus be minor, and the acoustic estimates of length can be taken as representing only the larger length mode of the two modes actually present.

As noted earlier, scattering is a non-linear function of length and the estimates of krill length arrived at acoustically are weighted by the scattering process. It is thus not entirely appropriate to compare weighted mean length estimates to the linear mean of the lengths for the larger krill sampled by nets. Scattering from the larger krill at the frequencies other than $43 \mathrm{kHz}$ will be mostly in the geometric range, where scattering is proportional to the square of length. The root-mean-square (RMS) of net-sampled lengths might therefore be a more appropriate basis for comparison of the acoustically-estimated lengths; estimates of the RMS length from net samples were somewhat larger than the linear means, but still compared favorably to the acoustic estimates (Table 4.1). Perhaps more rigorously, the nature of scattering from krill of varying length can be accounted for by calculating a mean length where the length of each sampled krill (both small and large) is weighted by its expected backscattering cross-section at $120 \mathrm{kHz}$ (i.e., target strength in linear form, again based on the Lawson et al. (2006) model). The central tendency of the net-sampled lengths calculated in this way was also slightly higher than the linear mean, but again compared favorably to the estimates yielded by the acoustic inversion (Table 4.1).

Net samples in the 50-100 m depth range in Laubeuf Fjord were dominated by large krill, and for inversions of acoustic data collected in this depth range, all three error terms produced similar length estimates (rows 1-2 in Table 4.1). For a shallower net-sampled depth range $(25-50 \mathrm{~m})$ dominated by small krill (mean $8.3 \mathrm{~mm}$ ), however, only the $E_{2}$ estimated a small weighted mean length (row 3 in Table 4.1). Even that estimate was 
much larger than evident in the nets, perhaps due to the influence of much less abundant but strongly scattering larger krill co-located with these smaller animals. The $E_{1}$ error term produced the largest length estimates and the closest to those observed in the nets, but also estimated the same mean length for regions where the two net tows (nos. 21 and 22) suggested differing mean sizes. In contrast, $E_{2}$ and $E_{2}$ produced less accurate length estimates, but their results did vary between these two regions, increasing as the net estimates did (rows 1-2 in Table 4.1).

Expanding beyond just the depth ranges sampled by the nets and examining all aggregations identified in the overall vicinity of these net tows, the distribution of weighted mean lengths estimated from the acoustic inversion was somewhat smaller, but still overlapped substantially with the larger mode in the distribution of net lengths (rows 4-6 and 14-15 in Table 4.1; Figure 4.6). Although numerous small krill ( $<20 \mathrm{~mm}$; Figure 4.6) were sampled by the nets, the weighted mean lengths of animals in acousticallyidentified aggregations estimated by the inverse method were much less often smaller than $20 \mathrm{~mm}$. This is again due to the fact that mean aggregation volume backscattering strength will be dominated by the scattering from any large krill present, even for aggregations with numerically abundant small krill.

Further verification of the inverse method's estimates of krill length at the Laubeuf Fjord test site can be provided by fitting in situ observations of target strength at the four BIOMAPER-II frequencies to theoretical predictions from the Lawson et al. (2006) target strength model (similar to the process of fitting observations to predictions of volume backscattering described by Equations 4.2 - 4.4). Doing this for target strengths measured in the same depths and similar spatial areas as sampled by net tows 21 and 22 produced length estimates of $40.5 \mathrm{~mm}$, again similar to those derived from nets (rows 7-8 in Table 4.1).

Density estimates derived from the acoustic data were an order of magnitude larger than those made with nets in Laubeuf Fjord and two orders of magnitude larger in Crystal 
Sound, with $E_{1}$ producing the largest discrepancy at both locations (Table 4.1). This discrepancy likely relates primarily to krill avoiding the nets, and will be addressed in the discussion. Important support for the inverse method can also be achieved by rearranging Equation 4.1, and scaling measurements of volume backscattering made in these same regions sampled by the nets by concurrent measurements of target strength to yield estimates of density. In contrast to the inversion, this approach is free of any assumptions concerning the mathematics of the inversion and most of the assumptions of the target strength model, since measured volume backscattering and measured target strength are used. Applying such an approach results in density estimates of 4.3 to 11.4 individuals $\mathrm{m}^{-3}$, very similar to the inverse method, although still higher than seen in the nets (rows 9-10 in Table 4.1).

Aside from these two locations, there were net tows whose catches have been analyzed where krill were sampled, but not at densities where we can be certain that the nets passed through acoustically-observed aggregations (Ashjian et al. 2004). Due to uncertainties in associating particular net samples with particular aggregations, it is thus not possible to ground-truth the acoustic estimates of length and density at any other location. We can, however, examine particular locations where the aggregations observed acoustically are known with certainty from VPR observations to be krill, and assess whether the resulting length and density estimates seem plausible. The aggregations at all such locations produce comparable acoustic density estimates to those observed at the net tow sites (rows 11-12 and 16-17 in Table 4.1), and acoustic length estimates quite similar to those measured at other locations in the survey area, consistent with the notion of a single length cohort of adult krill being present in the region.

In comparing the three proposed error terms to be minimized in estimating the weighted mean krill length and density in acoustically-identified aggregations, it is evident that for instances where large krill were present, all three methods produced similar length estimates. For cases where small krill dominated, the volume backscattering levels at 43 $\mathrm{kHz}$ were much lower than the higher frequencies, and both $E_{1}$ and $E_{3}$ were less apt than 
$E_{2}$ to produce length estimates as small as expected based on nets. In the case of the $E_{1}$ error term, at least, this is because it is most strongly influenced by the strong scattering levels at the higher frequencies, and is less sensitive to the lower (but highly informative) scattering at $43 \mathrm{kHz}$ that characterizes scattering by the smaller krill. All of the error terms yielded density estimates much larger than observed in nets, again likely due to avoidance behavior (see discussion), but density estimates made with $E_{1}$ were the most different from net measurements. Again this is due to this term being defined on the basis of the difference between observed and predicted scattering levels in arithmetic form. Since scattering at the different frequencies often varied by an order of magnitude or more, the resulting $E_{1}$ fitted curves were driven primarily by the frequency where scattering was highest (typically $120 \mathrm{kHz}$ here; Figure 4.7), and so produced higher density estimates than the other error terms, which are more equally influenced by all four frequencies. For the analyses of all acoustically-identified aggregations that follow, we applied the $E_{2}$ error term, due to its ability to produce smaller or larger estimates of lengths in accordance with whether the nets sampled smaller or larger krill, and due its typically producing the smallest, and thus most conservative, density estimates of the three approaches.

Applying the inverse method with the $E_{2}$ error term more broadly to estimate the weighted mean length in each krill aggregation identified acoustically during the entire survey conducted in the fall of 2001 resulted in a bimodal distribution of length estimates (Figure 4.8), consistent with the results of net tows (Ashjian et al., 2004) and indicative of two cohorts of krill, one larval and one adult (or perhaps juvenile). Recall that in the fall of 2001, aggregations that did not fall within the allowable $\delta$ MVBS for krill were still retained as 'likely' krill; the inverse method was not applied to such aggregations due to their overly low volume backscattering levels at $43 \mathrm{kHz}$ and the associated likelihood of estimating overly small mean lengths of krill. Moreover, the low sensitivity at $43 \mathrm{kHz}$ often affected acoustic elements differently within a given aggregation (e.g., as the BIOMAPER-II moved shallower or deeper in its towpath and away from the aggregation). For this 2001 survey, only those individual elements where the difference 

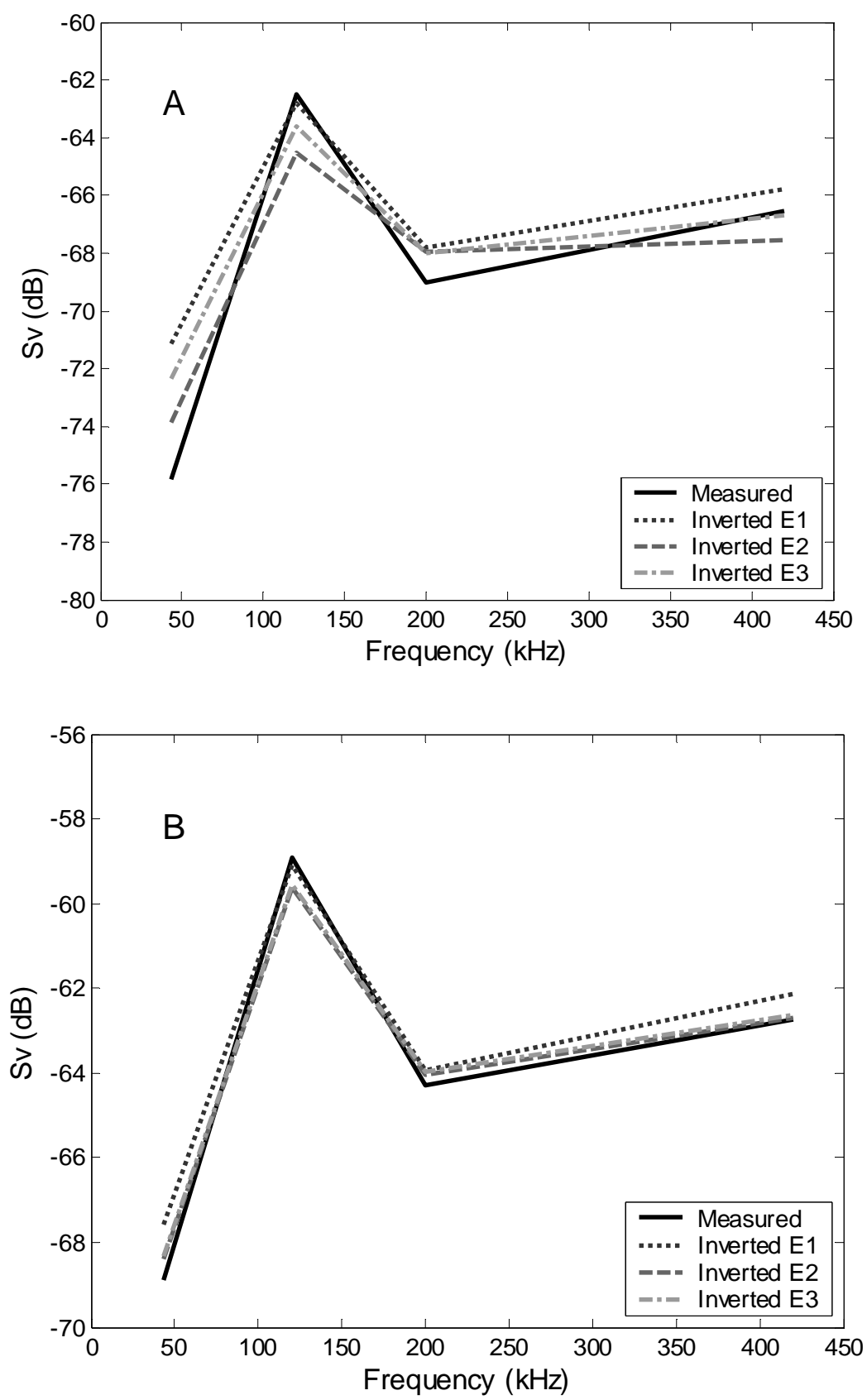

Figure 4.7 - Mean volume backscattering strength $\left(S_{v}\right)$ measured at the four BIOMAPER-II acoustic frequencies in (A) Laubeuf Fjord fall 2001, for the same depths and spatial region sampled by nets during tow \#21, and (B) Crystal Sound, fall 2002, for the same depths and region as tow \#24. Also shown are the best-fit predicted curves based on the three different error terms $\left(E_{1}-E_{3}\right)$. The length and density of krill used to generate these best-fit predicted curves are taken as the most likely mean length and density of animals in the observed aggregations. 

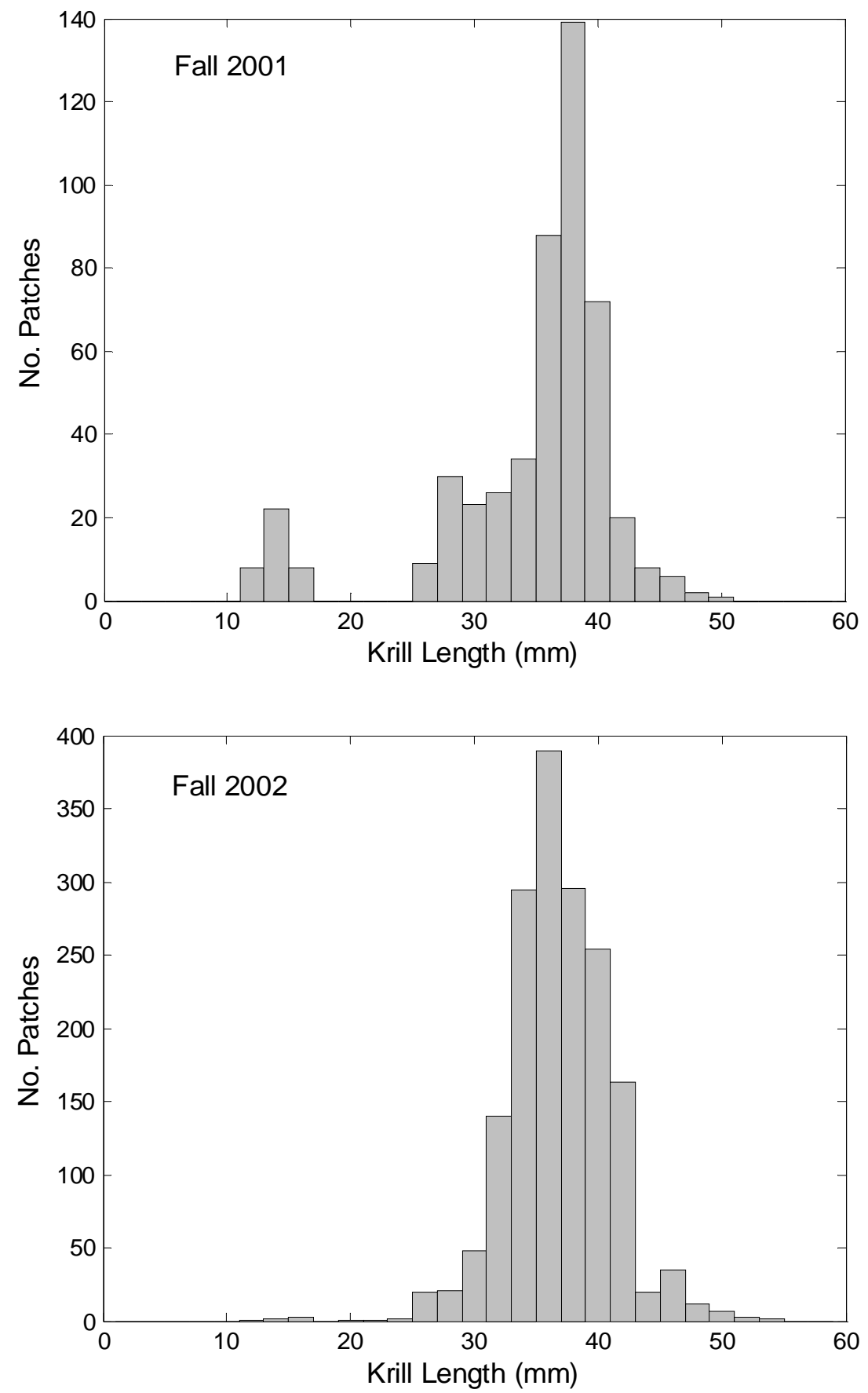

Figure 4.8 - Distribution of weighted mean krill lengths estimated acoustically using the $E_{2}$ error term for all aggregations observed in the falls of (A) 2001 and (B) 2002.

Frequency distributions show the number of aggregations for which the mean length represented by each length bin was estimated. 
in volume backscattering strength between 120 and $43 \mathrm{kHz}$ was within the allowable 2$16 \mathrm{~dB}$ range thus were used in calculating the mean volume backscattering strength values used in the assessment of the overall $\delta \mathrm{MVBS}$ for each aggregation and subsequent estimation of a weighted mean krill length. During the fall of 2002, a similar distribution of weighted mean aggregation animal lengths was observed as in 2001, suggesting that the uncertainty associated with the $43 \mathrm{kHz}$ measurements in the fall of 2001 did not substantially affect the length estimates, in aggregate.

Note that the inverse method was only applied to instances where valid volume backscattering measurements were made at all four frequencies, and so were limited to observations made within $100 \mathrm{~m}$ of the BIOMAPER-II (i.e., the maximum range of the $420 \mathrm{kHz}$ system). The inverse method also was not applied to aggregations observed during winter, due to the malfunctions at $43 \mathrm{kHz}$ described above (section 4.3.1.a).

Full attention will be devoted in the discussion to reconciling the discrepancies evident between net and acoustic estimates of krill length, and density in particular, which should provide confidence in the biological patterns that emerged based on the application of the acoustic methods and that are described in the following section.

\subsubsection{Krill distribution}

\subsection{2.a Horizontal distribution}

Application of these various acoustic methods resulted in the detection of between 531 and 8303 krill aggregations in each survey (Table 4.2). Of these, the majority (78-86\%) were the minimum measurable size set by the resolution of the acoustic system. We are less certain for these very small aggregations that they were indeed composed of krill, due to their often being immediately adjacent to scattering features of very similar appearance but which did not meet the threshold scattering criterion. Furthermore, during fall of 2001 in particular, these smallest aggregations were more likely not to have the 
TABLE 4.2 - Total number of aggregations observed during each cruise and the sum of their total biomass indices (kg per across-track meter), for all aggregations, small aggregations $\left(<100 \mathrm{~kg} \mathrm{~m}^{-1}\right)$, and large aggregations $\left(>100 \mathrm{~kg} \mathrm{~m}^{-1}\right)$. Percentages in parentheses indicate the percent of the total over all aggregations accounted for by the small or large aggregations. Columns 1 and 2 represent all acoustically-identified aggregations. Columns 3 and 4 indicate the number and total biomass indices of only those aggregations larger than the minimum detectable size (see text). Note that these biomass indices summed over all aggregations are presented for the purpose of assessing the contribution of large vs. small aggregations to overall biomass levels, and are not intended as regional biomass estimates.

\begin{tabular}{|c|c|c|c|c|}
\hline & $\begin{array}{c}\text { Number of } \\
\text { Aggregations }\end{array}$ & $\begin{array}{l}\text { Total biomass } \\
\text { index }\left(\mathrm{kg} \mathrm{m}^{-1}\right)\end{array}$ & $\begin{array}{l}\text { Number larger } \\
\text { than minimum }\end{array}$ & $\begin{array}{l}\text { Biomass larger } \\
\text { than minimum }\end{array}$ \\
\hline \multicolumn{5}{|l|}{ FALL 2001} \\
\hline Total & 8303 & $3.58 \times 10^{5}$ & 1147 & $3.55 \times 10^{5}$ \\
\hline Sm. aggregations & $8221(99 \%)$ & $1.13 \times 10^{4}(3 \%)$ & $1066(93 \%)$ & $8.40 \times 10^{3}(2 \%)$ \\
\hline Lg. aggregations & $82(1 \%)$ & $3.47 \times 10^{5}(97 \%)$ & $81(7 \%)$ & $3.47 \times 10^{5}(98 \%)$ \\
\hline \multicolumn{5}{|l|}{ WINTER 2001} \\
\hline Total & 531 & 1796.8 & 117 & 1560.4 \\
\hline Sm. aggregations & $528(99 \%)$ & $1100.5(61 \%)$ & $114(97 \%)$ & $864.1(55 \%)$ \\
\hline Lg. aggregations & $3(1 \%)$ & $696.4(39 \%)$ & $3(3 \%)$ & $696.4(45 \%)$ \\
\hline \multicolumn{5}{|l|}{ FALL 2002} \\
\hline Total & 2597 & $1.86 \times 10^{5}$ & 500 & $1.85 \times 10^{5}$ \\
\hline Sm. aggregations & $2490(96 \%)$ & $7.33 \times 10^{3}(4 \%)$ & $393(79 \%)$ & $5.80 \times 10^{3}(3 \%)$ \\
\hline Lg. aggregations & $107(4 \%)$ & $1.79 \times 10^{5}(96 \%)$ & $107(21 \%)$ & $1.79 \times 10^{5}(97 \%)$ \\
\hline \multicolumn{5}{|l|}{ WINTER 2002} \\
\hline Total & 2585 & $1.03 \times 10^{5}$ & 566 & $1.01 \times 10^{5}$ \\
\hline Sm. aggregations & $2487(96 \%)$ & $7.80 \times 10^{3}(8 \%)$ & $468(83 \%)$ & $6.34 \times 10^{3}(6 \%)$ \\
\hline Lg. aggregations & $98(4 \%)$ & $9.51 \times 10^{4}(92 \%)$ & $98(17 \%)$ & $9.51 \times 10^{4}(94 \%)$ \\
\hline
\end{tabular}


measurements at $43 \mathrm{kHz}$ necessary in applying the $\delta$ MVBS criteria for identifying krill, due to the malfunctions at this frequency described previously. While these aggregations were numerically dominant, they only accounted for $0.8-13 \%$ of the summed total biomass indices (Table 4.2). As such, excluding them from the spatial analysis of the along-track distribution of krill vertically-integrated biomass has a negligible impact. All of the analyses that follow were performed with and without these smallest aggregations of less certain composition included, but only the with-smallest results will be reported, except for those cases where the results of these two approaches differed.

During both falls, estimates of krill biomass integrated over the sampled portion of the water column and averaged in 1-km along-track intervals (i.e., 'vertically-integrated' biomass) were highest in areas on the continental shelf close to the coast, and decreased farther out on the shelf and beyond the shelf-break (Figure 4.9). Due to the presence of pack ice covering the entire study area, only certain portions of the survey grid could be reached in the winter of 2001. Krill vertically-integrated biomass was low throughout the surveyed area, with the only observations of reasonably high vertically-integrated biomass made immediately north of Alexander Island, and at the mouth of Marguerite Bay (Figure 4.9). During the winter of 2002, the ice was even thicker and surveying over the southern portion of the study area was limited and did not follow the intended regular survey lines. Nonetheless, krill vertically-integrated biomass was high everywhere surveyed, other than along the northernmost transect (Figure 4.9).

The distribution of the indices of total aggregation biomass $\left(\mathrm{kg} \mathrm{m}^{-1}\right)$ was strongly skewed towards small values (Figure 4.10). In all surveys, only 1-4\% of all aggregations by number were estimated to have total biomass indices greater than $100 \mathrm{~kg} \mathrm{~m}^{-1}$, but those few large aggregations accounted for $39-97 \%$ of the summed total biomass indices observed during each survey (Table 4.2).

The horizontal distribution of aggregations was also assessed via the distance from each aggregation to neighboring aggregations. The majority of aggregations (92-99\%) during 

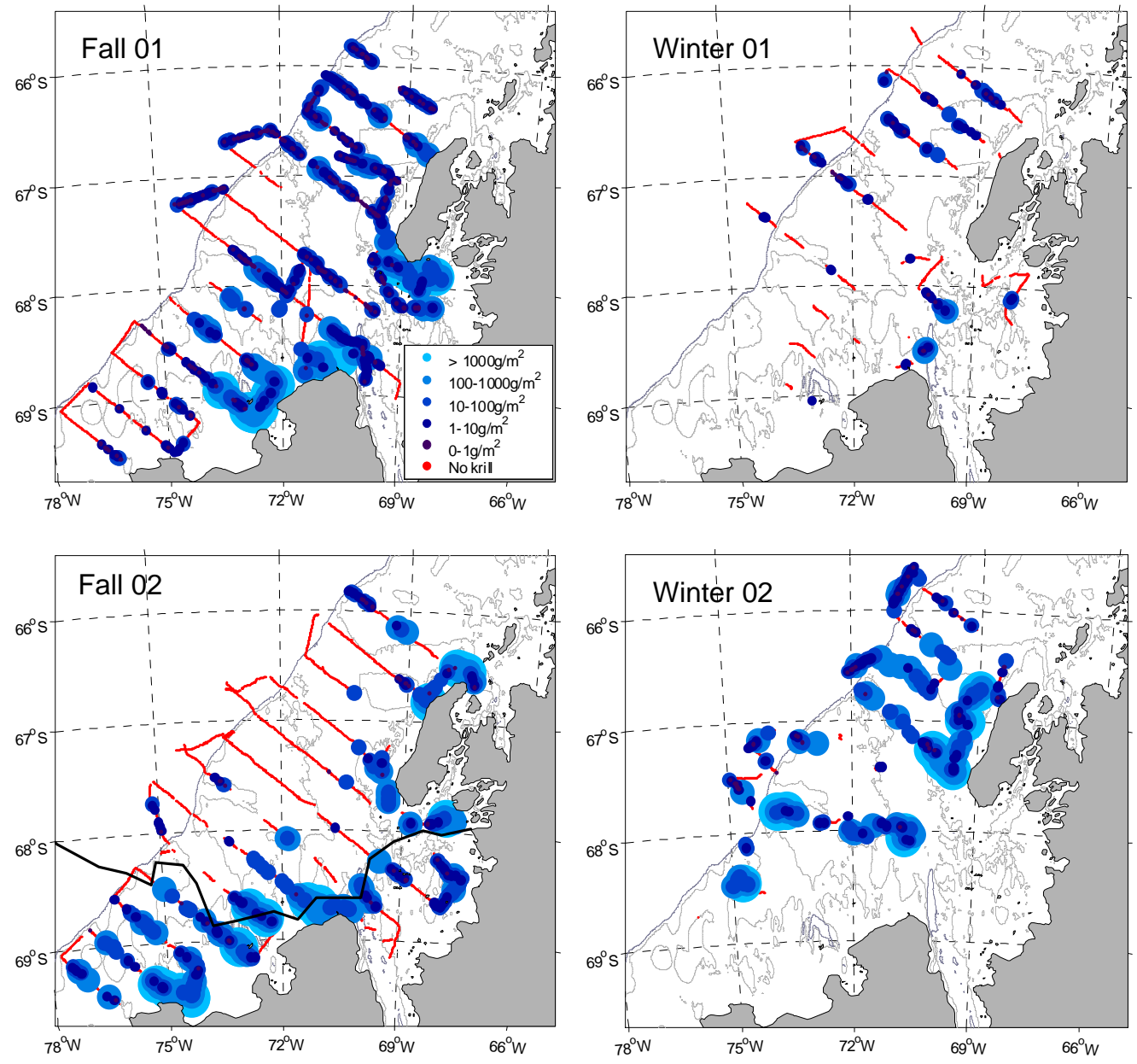

Figure 4.9 - Estimates of krill vertically-integrated biomass $\left(\mathrm{g} \mathrm{m}^{-2}\right)$, averaged in 1-km along-track intervals. A composite ice edge for the whole cruise is shown for fall 2002 (black line). In fall 2001, sea ice was not encountered during acoustic surveying. During both winters the entire region was ice-covered. 


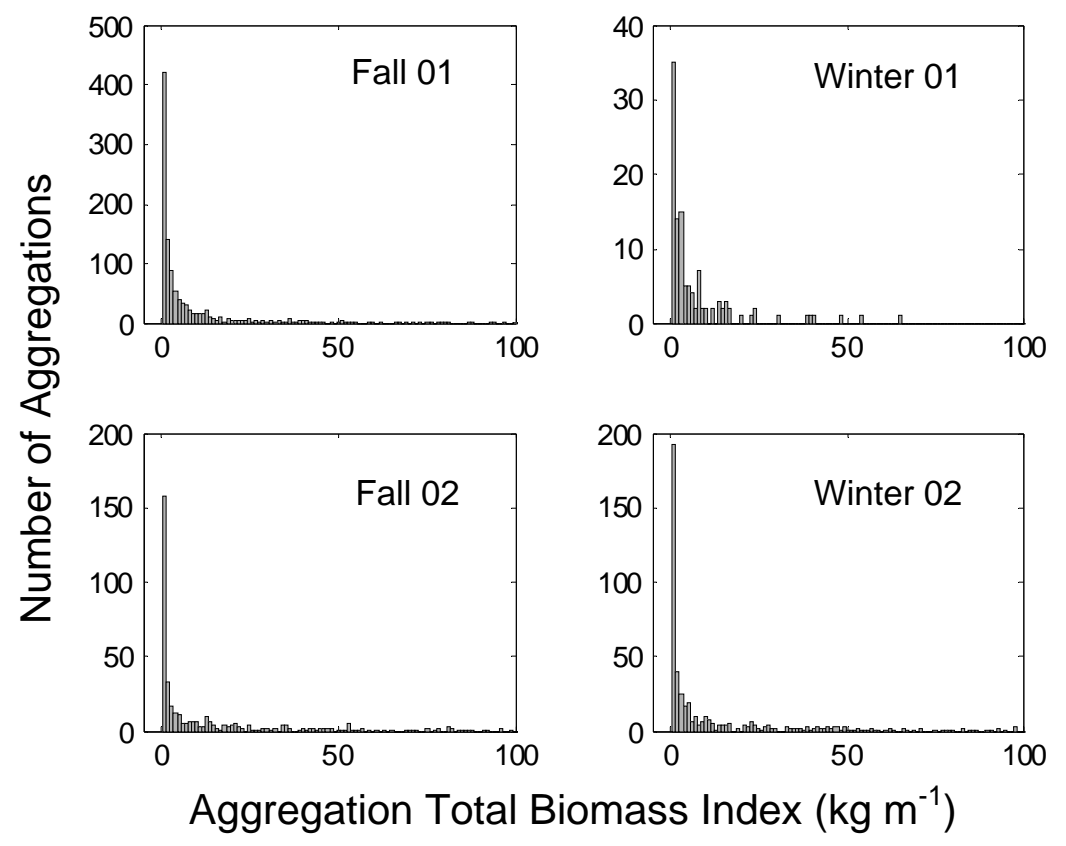

Figure 4.10 - Distribution of the total biomass indices $\left(\mathrm{kg} \mathrm{m}^{-1}\right)$ for acoustically-identified aggregations. In each cruise, the right-hand tail of the distribution continued well past $100 \mathrm{~kg} \mathrm{~m}^{-1}$, to a maximum of $6 \times 10^{4}$, but was completely flat and so is not shown. The very small aggregations equivalent to the minimum size detectable by the system have not been included in these histograms; such aggregations were all of very small biomass, and were excluded to allow the right-hand tail of the distribution to be more easily visualized. 
all surveys were found within a distance of $1 \mathrm{~km}$ of another aggregation, and $79-90 \%$ were found within distances of $100 \mathrm{~m}$ of another aggregation (Figure 4.11). The distribution of nearest neighbor distances showed modes near 1.5, 35, and $65 \mathrm{~m}$ followed by a long tail extending towards large distances. These modes correspond to aggregations with centroids positioned at the same measurement point but a different depth as the given aggregation, separated by one measurement, and by two measurements, respectively.

As described above (section 4.3.1.b), a mean krill length (weighted by the scattering process via the scattering model) was estimated for a subset of all aggregations observed during the fall surveys (Figure 4.8). In the fall of 2001, no obvious pattern was evident in the distribution of these estimated lengths (Figure 4.12). In the fall of 2002, however, most aggregations with estimated weighted mean krill lengths less than $35 \mathrm{~mm}$ were found in coastal areas, while aggregations with larger estimated krill sizes were more broadly distributed across the shelf.

\subsection{2.b Vertical distribution}

The number of krill aggregations was greatest during all survey periods at depths less than $100 \mathrm{~m}$ (Figure 4.13). Mean krill biomass density $\left(\mathrm{g} \mathrm{m}^{-3}\right)$, in contrast, was greatest below a depth of $100 \mathrm{~m}$ during the fall 2001 and both 2002 surveys. In the winter of 2001, mean biomass density was greatest shallower than $100 \mathrm{~m}$, but overall, estimates of biomass were much lower than in the other three surveys (Figure 4.13). During both 2002 surveys, a lesser peak in mean biomass density was evident at shallow depths $(<100 \mathrm{~m})$, and the larger peak in biomass density shifted slightly deeper between fall and winter of that year. These depth distributions were reflected in the altitude of aggregations (water depth - aggregation depth; Figure 4.14): by number the majority of aggregations in all surveys other than the fall of 2002 were positioned away from the bottom $(>150 \mathrm{~m}$ depth), but the majority of biomass was found in closer association with the bottom 


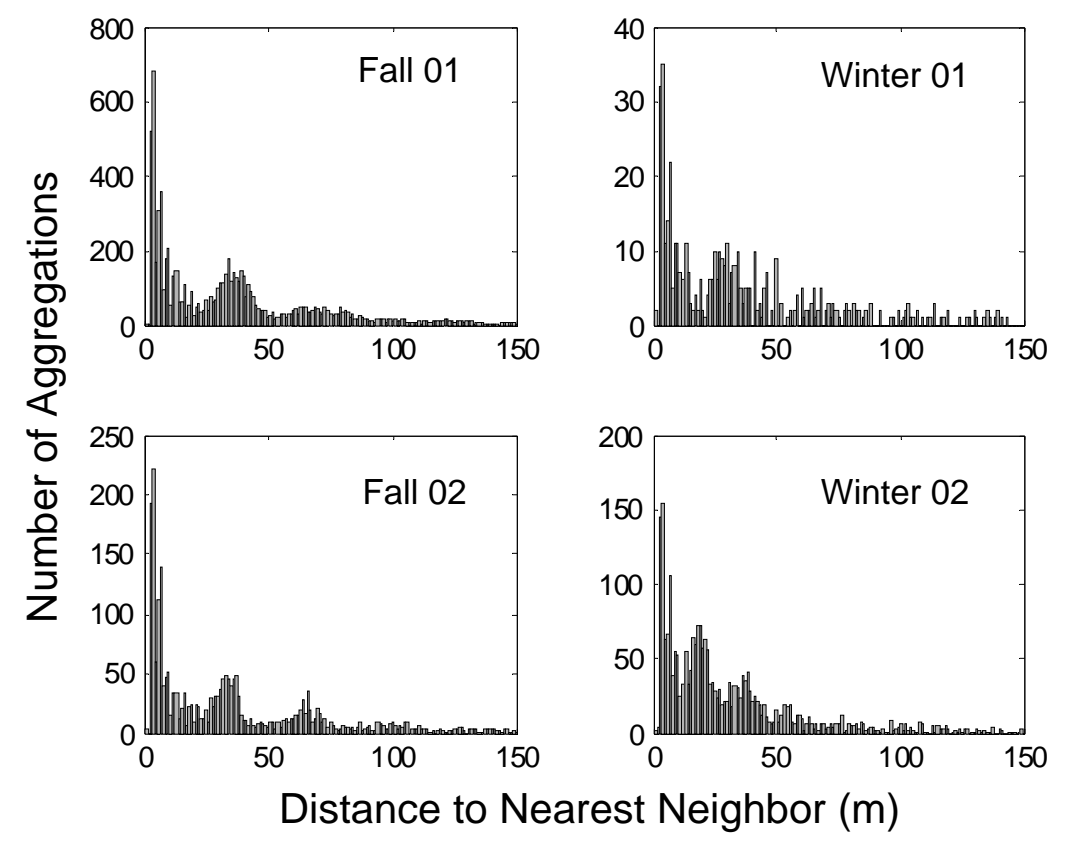

Figure 4.11 - Distribution of distances to nearest neighboring aggregations. In each cruise there was also a long and flat right-hand tail to the distribution of these distances, with $612,67,253$, and 210 aggregations having the nearest neighbor beyond $150 \mathrm{~m}$ in the fall 2001, winter 2001, fall 2002, and winter 2002 cruises, respectively. Plots show all aggregations, but distributions for only those aggregations larger than the minimum observable size showed identical shapes. 

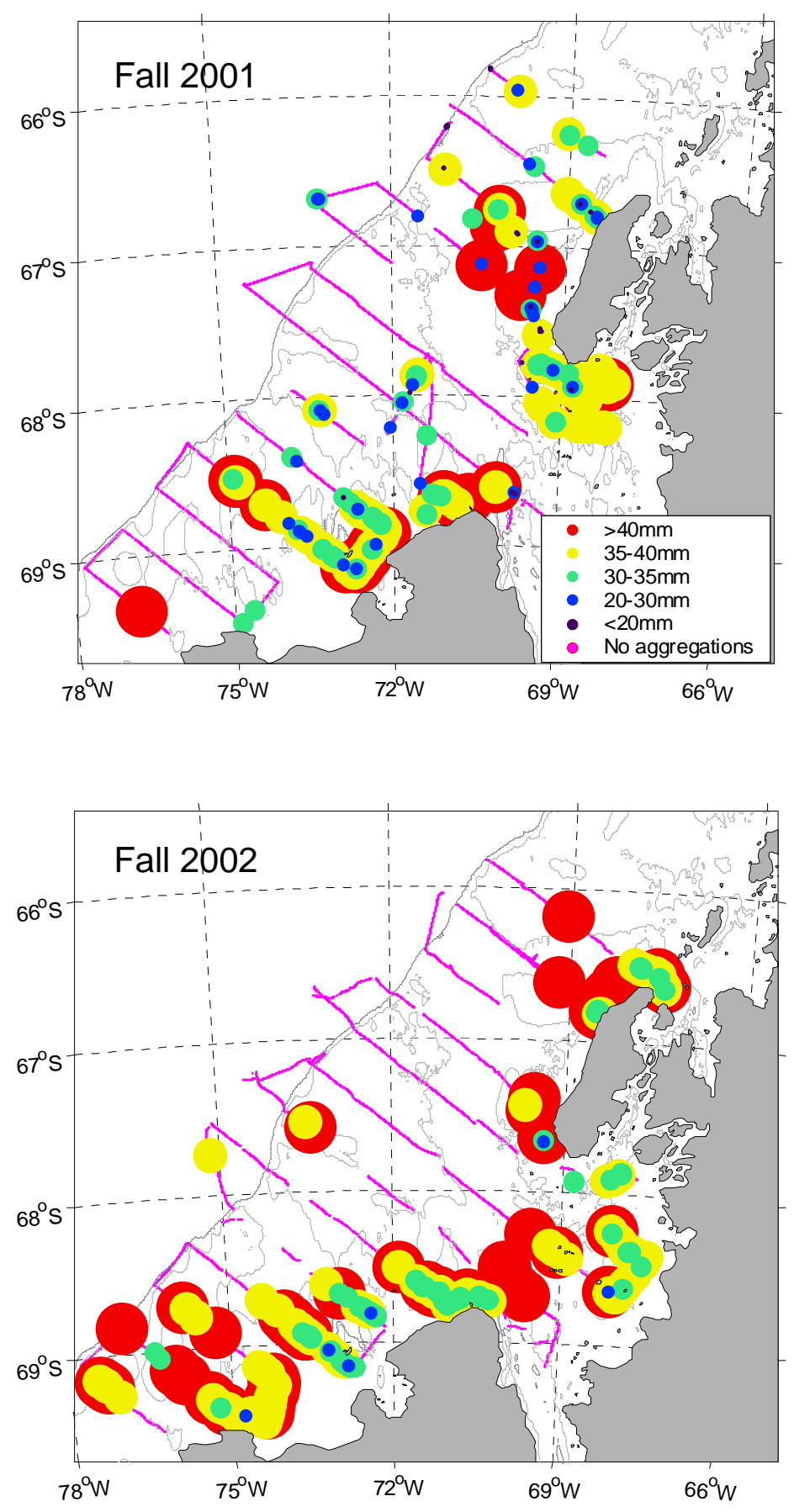

Figure 4.12 - Spatial distribution of the weighted mean krill length in each acousticallyidentified aggregation, estimated via the acoustic inversion protocol using the $E_{2}$ error term. Dot color indicates estimated length, with larger dots also indicating larger lengths, to allow dots to be plotted on top of one another. 

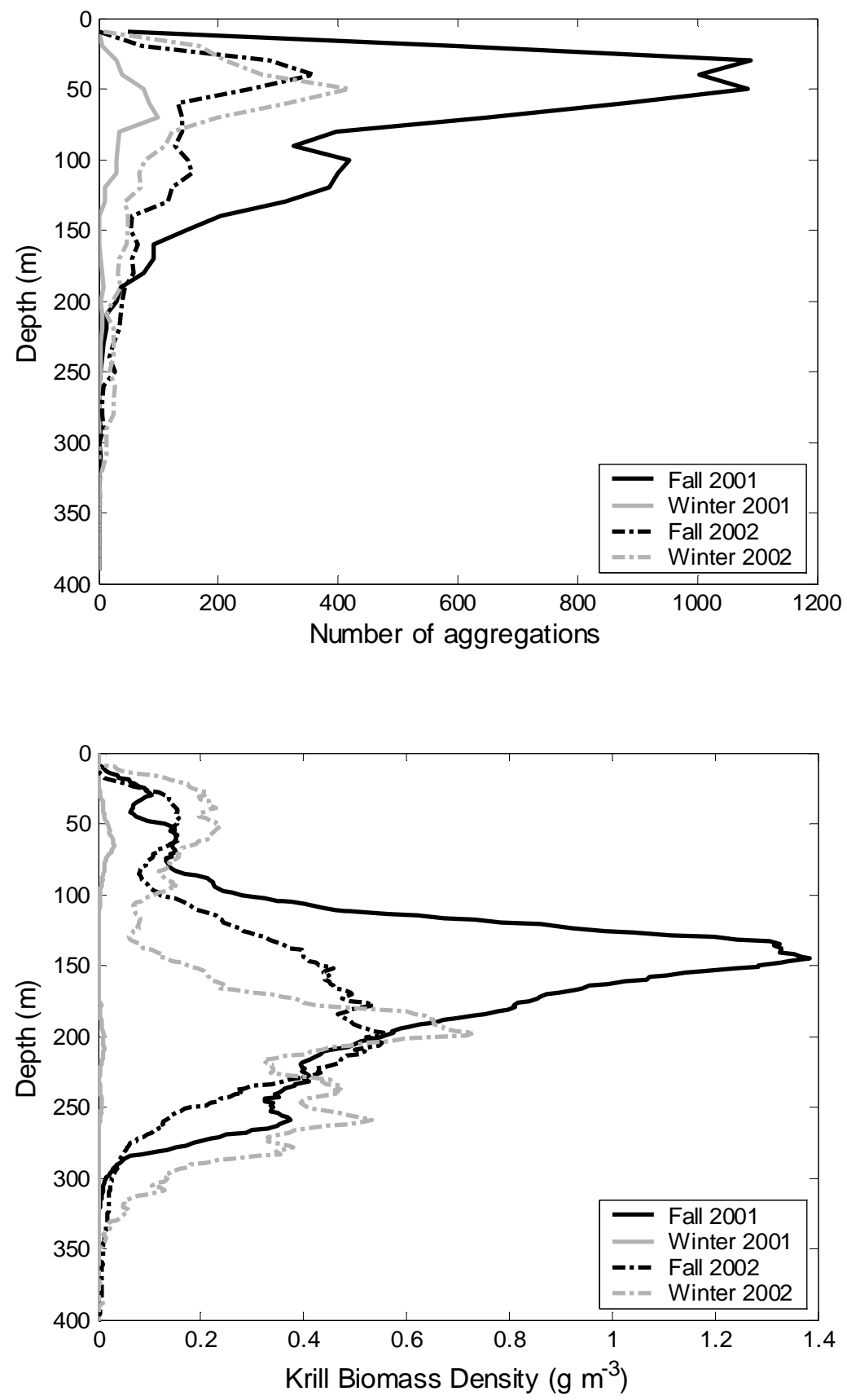

Figure 4.13 - Vertical distribution by total number of aggregations (top plot) and mean biomass density (lower plot), in 10-m bins. 

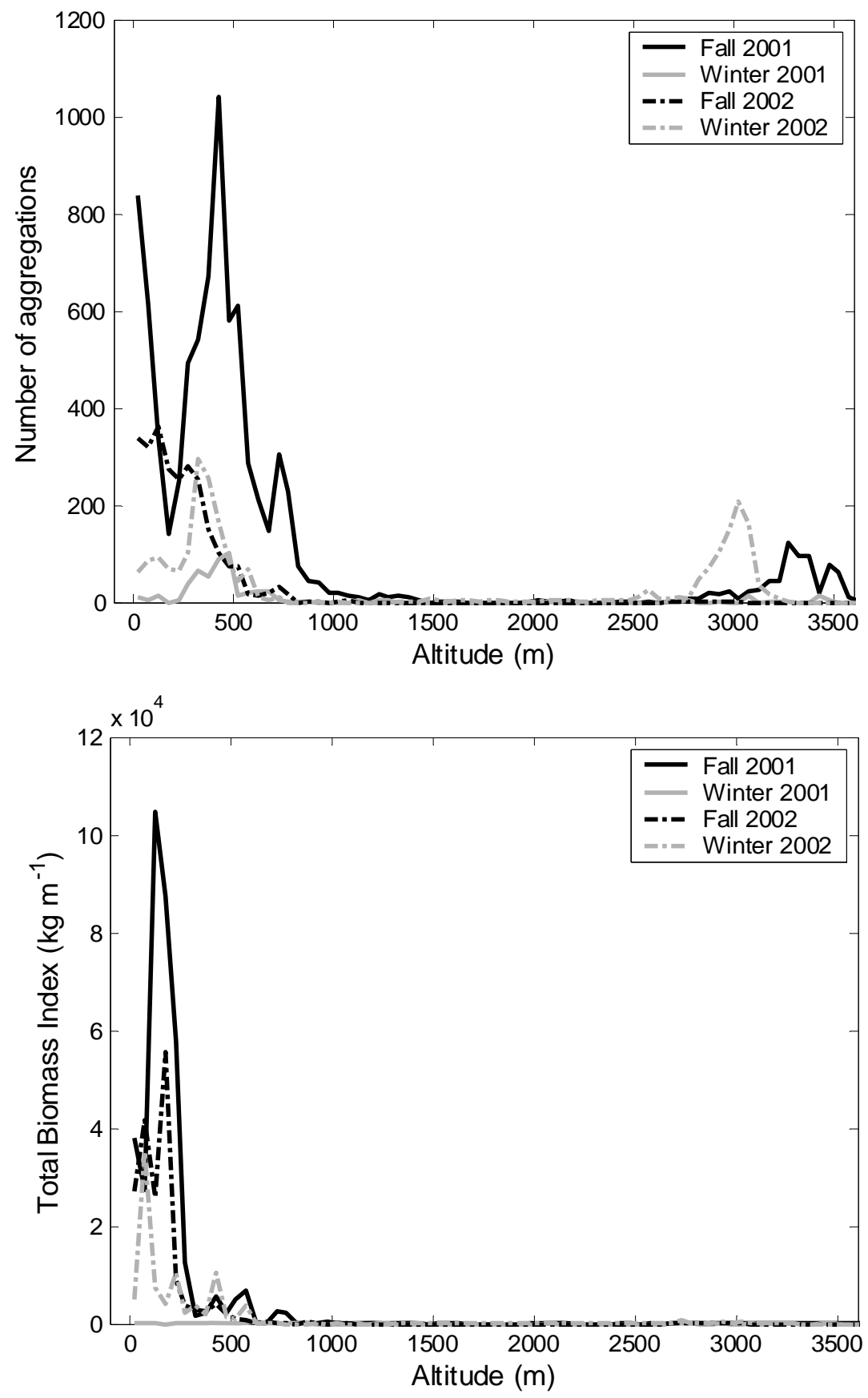

Figure 4.14 - Distance from bottom (i.e., altitude) by total number of aggregations (top plot) and total biomass index (lower plot), in 50-m bins. 
$(<150 \mathrm{~m})$. The spatial distribution of depths and altitudes occupied by krill aggregations showed no obvious patterns (not shown).

No attempt was made to account or correct for the potential impact of diel vertical migration on estimates of vertically-integrated biomass, although summertime estimates of krill biomass around Elephant Island have been estimated to be biased by as much as $49.5 \%$ due to upwards migration of krill at night outside of the acoustic survey window (Demer and Hewitt, 1995). Examining mean estimated krill vertically-integrated biomass relative to time of day in hourly intervals, however, does not show the decrease during the night and increase by day that might be expected if diel vertical migration were biasing the estimates (Figure 4.15). Vertically-integrated biomass estimates were consistently highest between 1500 and 2000h (local time). The timing of sunset varied substantially over the course of each survey, but fell between 1347 and $1719 \mathrm{~h}$ in fall and 1516 and $1803 \mathrm{~h}$ in winter; maximal vertically-integrated biomass thus was not observed during the day.

\subsection{2.c Distribution in relation to environmental features during fall}

Contrary to our hypothesis, vertically-integrated biomass in both falls showed a generally negative association with chlorophyll $a$ (Figure 4.16). Somewhat more consistent with our expectations, highest biomass was found in regions of lowest current magnitude and horizontal current shear, but otherwise, little trend was evident between verticallyintegrated biomass and currents (Figure 4.17). Krill vertically-integrated biomass in both falls was mostly low in the northern half of the surveyed shelf region, in the vicinity of the persistent cyclonic gyre identified by previous studies (see Figures $4.1 \mathrm{~b}$ and 4.9 ).

Krill aggregations also showed associations with particular water masses, defined on the basis of their characteristic salinity and potential temperature values. During both falls, the dominant water mass at shallow depths was Antarctic Surface Water (Figure 4.18; salinity (S) 33.0 to 33.7 , potential temperature $(\theta)-1.5$ to $1.0^{\circ} \mathrm{C}$; see Klinck et al., 2004 


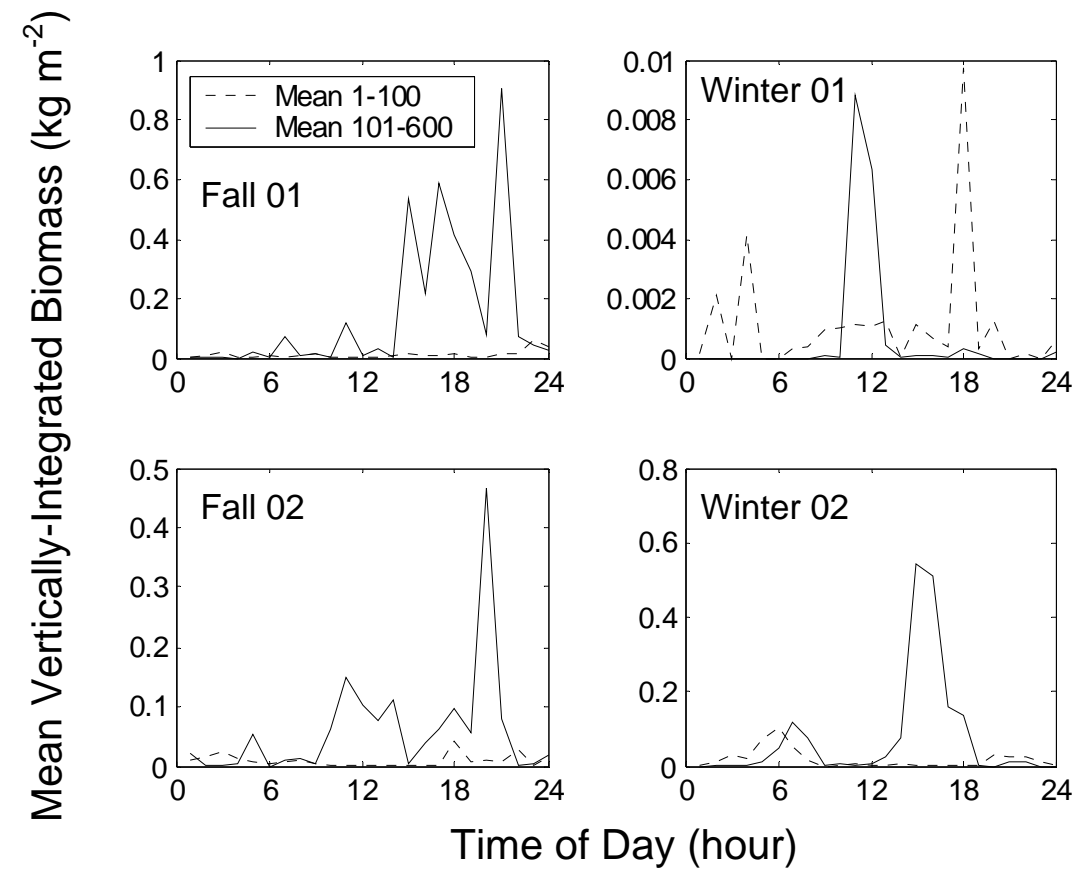

Figure 4.15 - Mean along-track krill biomass (vertically integrated over the whole sampled water column, $\mathrm{kg} \mathrm{m}^{-2}$ ), averaged over hourly intervals. 

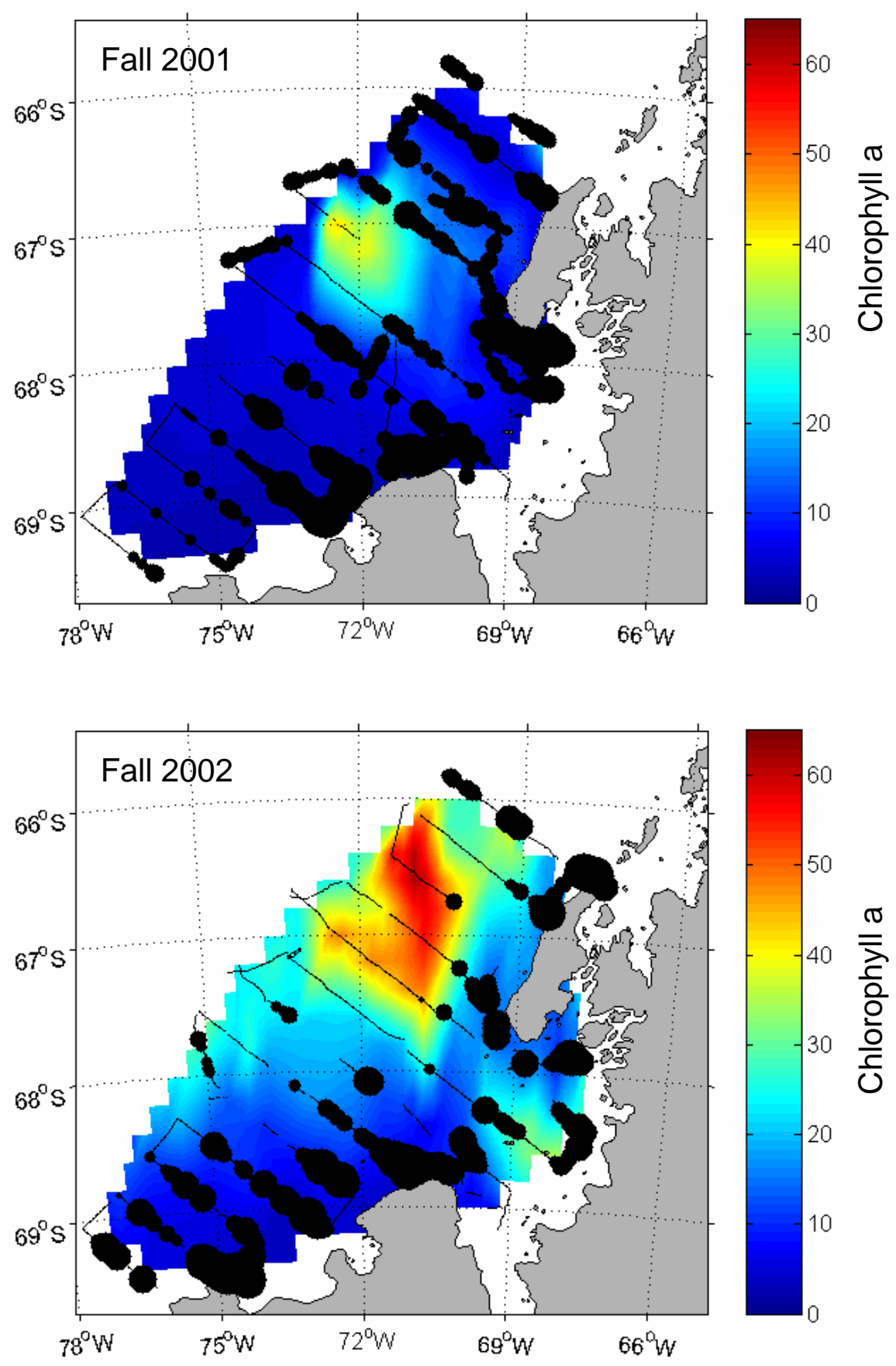

Figure 4.16 - Distribution of chlorophyll a integrated to a depth of $30 \mathrm{~m}\left(\mathrm{mg} \mathrm{m}^{-2}\right)$ during fall 2001 (top plot) and 2002 (lower plot). Black dots indicate krill vertically-integrated biomass $\left(\mathrm{g} \mathrm{m}^{-2}\right)$, with larger dots denoting larger biomass (see Figure 4.9). Smallest black dots indicate no krill present. 

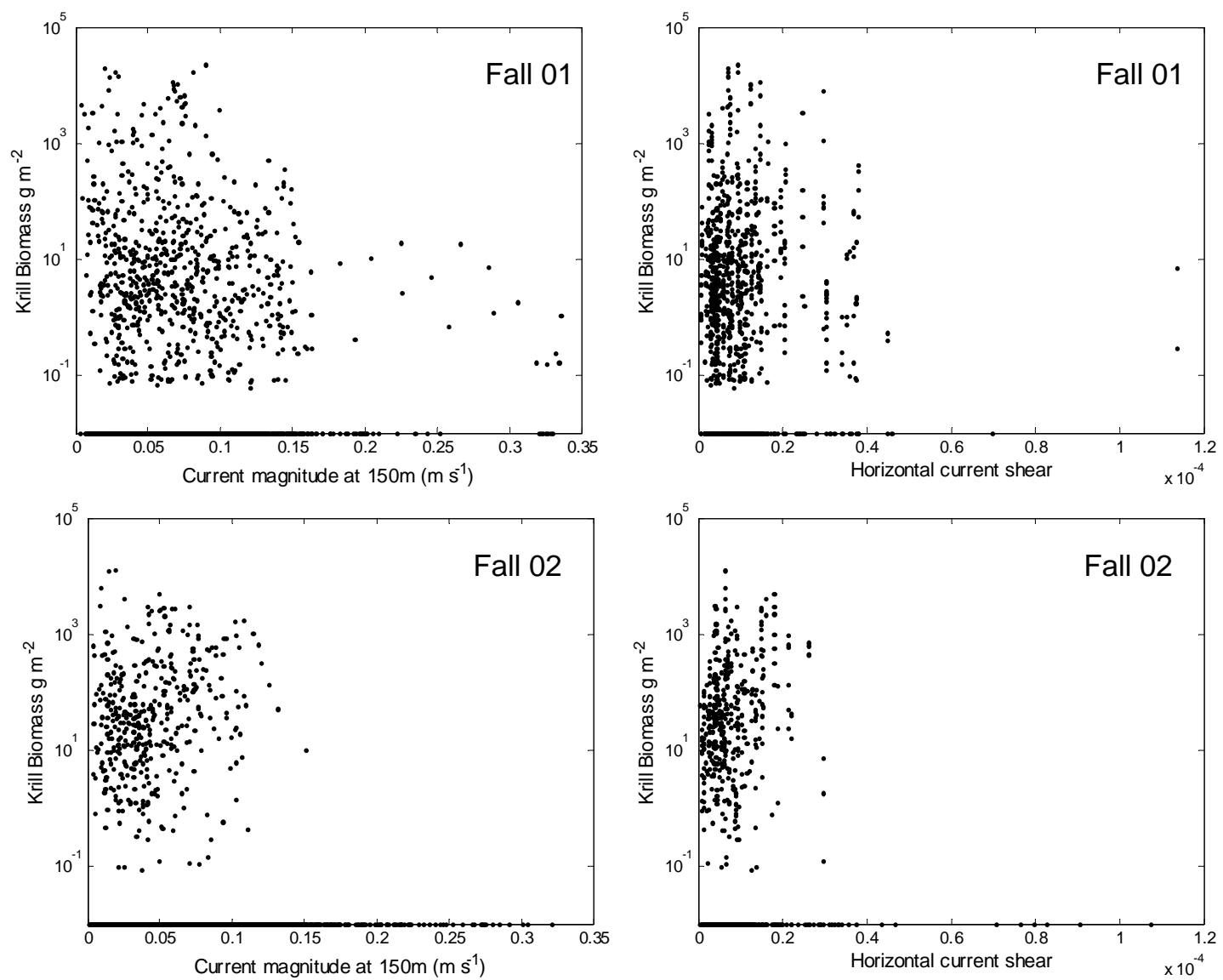

Figure 4.17 - Krill biomass $\left(\mathrm{g} \mathrm{m}^{-2}, \log _{10}\right.$ scale) during fall averaged in 1-km along-track intervals and integrated over the sampled water column $(1-600 \mathrm{~m})$, in relation to ADCPmeasured current magnitude at $150 \mathrm{~m}$ depth ( $\mathrm{m} \mathrm{s}^{-1}$; left-hand plots) and estimated

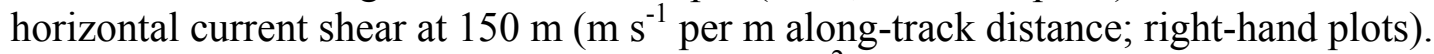
Zero values for krill biomass have been set to $10^{-2}$. 

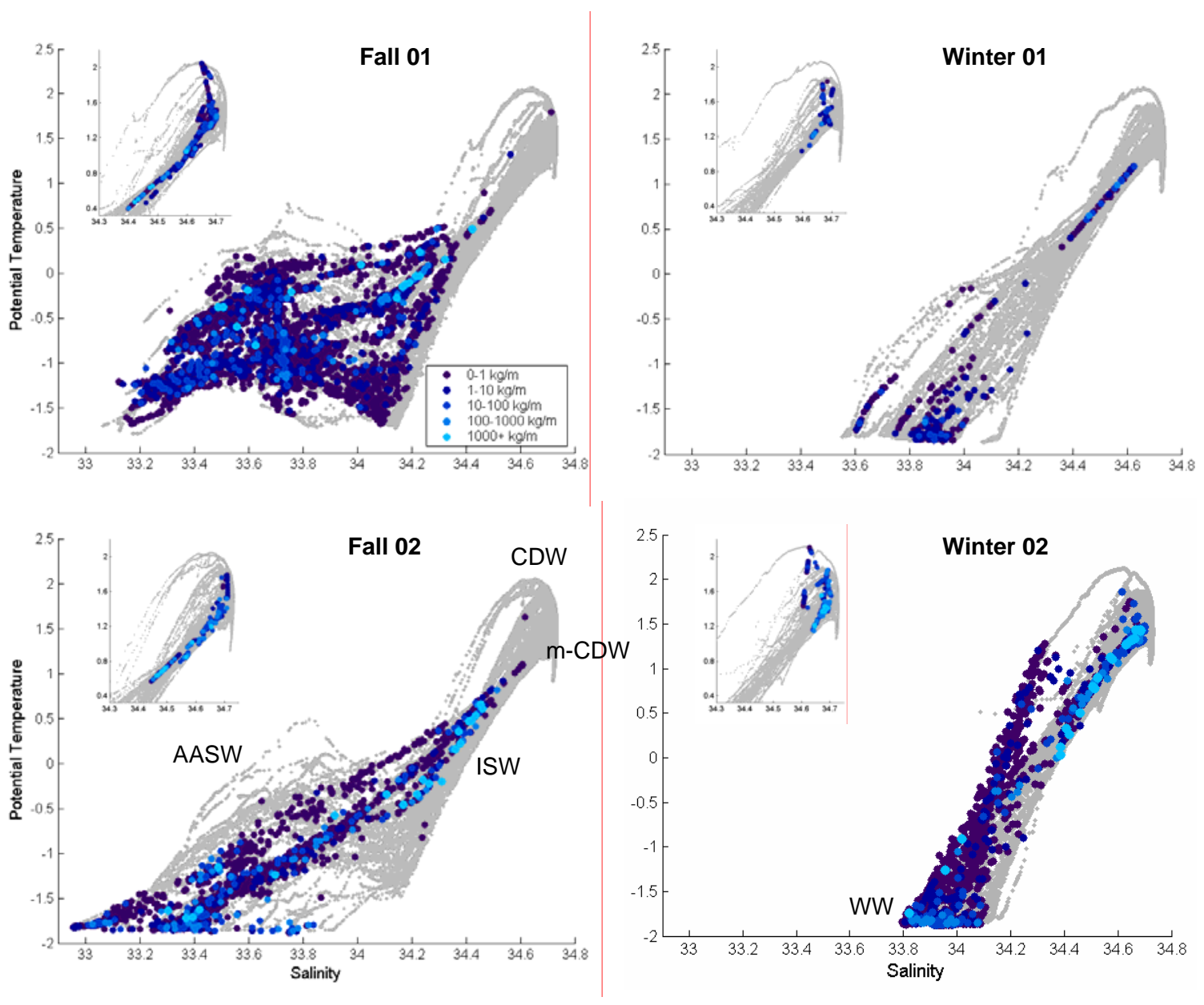

Figure 4.18 - Potential temperature and salinity associated with each acousticallyidentified krill aggregation, interpolated from measurements made by the BIOMAPER-II, or from CTD cast data for aggregations present at greater depths than sampled by the BIOMAPER-II. Dot color indicates aggregation total biomass index $\left(\mathrm{kg} \mathrm{m}^{-1}\right)$. Grey indicates temperature-salinity values measured during CTD casts at all hydrographic stations combined for each survey, and thus shows conditions available to the krill across the survey area as a whole. Water masses are $\mathrm{CDW}=$ Circumpolar Deep Water, $\mathrm{m}-\mathrm{CDW}=$ modified-CDW, AASW=Antarctic Surface Water, ISW=Inner Shelf Water, and $\mathrm{WW}=$ Winter Water. Inset are plots showing the temperature and salinity conditions present below aggregations at $300 \mathrm{~m}$ depth. 
for further water mass definitions and explanations). The primary water masses at depth in the region were modified-Circumpolar Deep Water (mCDW; S 34.0 to 34.6, $\theta 1.0$ to $1.5^{\circ} \mathrm{C}$ ), formed by the mixing of oceanic Circumpolar Deep Water (S 34.6 to 34.74, $\theta 1.0$ to $\left.2.0^{\circ} \mathrm{C}\right)$ with cooler and fresher shelf waters, and colder $\left(<1.3^{\circ} \mathrm{C}\right)$ water that has been referred to as 'Inner Shelf Water' (Prezelin et al., 2004) (Figure 4.18).

Many shallow aggregations in fall were associated with Antarctic Surface Water, some of quite high total biomass indices (Figure 4.18). The majority of high-biomass aggregations, however, were found at depth, in association with Inner Shelf Water. Contrary to our hypothesis, no aggregations of substantial biomass were found in association with off-shelf or recently intruded Circumpolar Deep Water. Examining the temperature-salinity characteristics at a depth of $300 \mathrm{~m}$ in the waters underlying observed krill aggregations, indicates that the aggregations of highest total biomass indices were present in regions where cooler and fresher Inner Shelf Water was present at depth, rather than modified- or recently intruded-Circumpolar Deep Water (inset in Figure 4.18). Similarly, highest vertically-integrated biomass was found in regions of cooler maximum temperature below $200 \mathrm{~m}$ in depth, which can be used as an indicator of the presence of Circumpolar Deep Water (Figure 4.19).

Generalized Additive Modeling provided further insight into the association of krill with environmental features. The exact shape of the predictor-response curves varied somewhat between analyses, but in general, both presence/absence and verticallyintegrated biomass where it was non-zero were significantly and negatively associated with Tmax and distance from land, during both falls (Table 4.3, Figures 4.20 and 4.21). In fall 2001, the presence/absence of krill also exhibited an increasing then decreasing relationship with chl- $a$, while during fall 2002 , krill presence/absence showed a mostly flat relationship with chl- $a$, decreasing only at high concentrations. In the fall of 2002, both the presence/absence of krill and krill vertically-integrated biomass where it exceeded zero were additionally associated with water depth in a decreasing fashion, and with ice concentration following a dome-shaped functional form, peaking at ice 

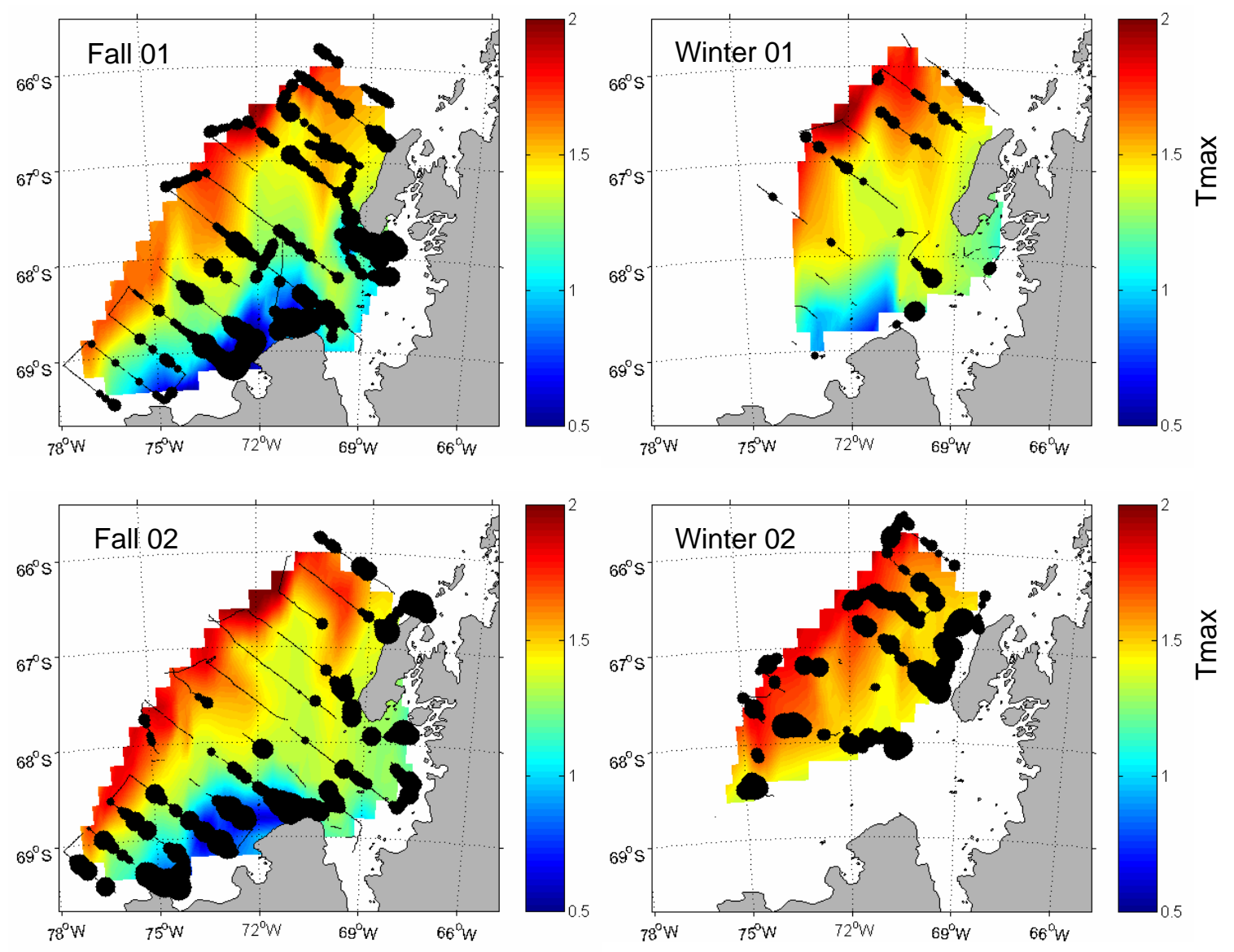

Figure 4.19 - Distribution of the temperature maximum below a depth of $200 \mathrm{~m}$ (Tmax; $\left.{ }^{\circ} \mathrm{C}\right)$ during each survey. Black dots indicate krill vertically-integrated biomass $\left(\mathrm{g} \mathrm{m}^{-2}\right)$, with larger dots denoting larger biomass (see Figure 4.9). Smallest black dots indicate no krill present. 
TABLE 4.3 - Generalized Additive Modeling results for the fall surveys. Analyses were conducted separately first for the dependent variable of krill presence or absence, and then for krill vertically-integrated biomass $\left(\mathrm{g} \mathrm{m}^{-2}\right)$ averaged in 1-km along-track intervals where it exceeded zero. Analyses began with a larger set of environmental variables, and only those remaining after variable selection are shown (see methods section 4.2.5.b). For each GAM, the null deviance (ND), residual deviance (RD), and percent of deviance explained (\%Dev.) are shown. $\mathrm{s}($ ) indicates dependent variables whose relationship with the response variable was described by smoothed functions. Otherwise, this relationship was taken to be linear, and the coefficient of the linear relationship is shown. The significance of each environmental variable was tested for significance via a chi-square test on the deviance explained by the full model versus that with the variable removed; the drop in deviance between the two and associated $p$-value are shown.

\begin{tabular}{llll}
\hline & Drop in & \\
Coefficient & deviance & $p$ \\
\hline \hline
\end{tabular}

FALL 2001

Presence/absence

(ND 1070.0, RD 777.4, \%Dev. 27.4)

$\begin{array}{rccc}\mathrm{s}(\text { Chl- }-a) & - & 123.0 & <1 \mathrm{e}-25 \\ \mathrm{~s}(\text { Tmax }) & - & 72.5 & <1 \mathrm{e}-14 \\ \text { Distance to land } & -0.020 & 41.7 & <1 \mathrm{e}-9\end{array}$

Vertically-integrated biomass $>\mathbf{0}$

(ND 473.7, RD 273.0, \%Dev. 42.4)

$\begin{array}{rlll}\mathrm{s}(\text { Tmax }) & - & 54.5 & <1 \mathrm{e}-12 \\ \mathrm{~s}(\text { Distance to land ) } & - & 34.3 & <1 \mathrm{e}-7\end{array}$

FALL 2002

Presence/absence

(ND 1196.9, RD 717.2, \%Dev. 40.1)

$\begin{array}{rccc}\text { s( Chl- } a \text { ) } & - & 40.4 & <1 \mathrm{e}-8 \\ \text { s( Tmax ) } & - & 71.2 & <1 \mathrm{e}-14 \\ \text { s( Distance to land ) } & - & 57.5 & <1 \mathrm{e}-11 \\ \text { s( Ice ) } & - & 31.2 & <1 \mathrm{e}-6 \\ \text { Current magnitude } & -16.78 & 34.4 & <1 \mathrm{e}-8 \\ \text { Depth } & -1.5 \mathrm{e}-3 & 18.8 & <1 \mathrm{e}-4\end{array}$

Vertically-integrated biomass $>\mathbf{0}$

(ND 222.8, RD 113.5, \%Dev. 49.1)

\begin{tabular}{rccc} 
s( Tmax ) & - & 8.6 & 0.001 \\
s( Ice ) & - & 9.8 & 0.001 \\
Chl- $a$ & -0.037 & 10.5 & $<1 \mathrm{e}-5$ \\
ro land & $-5.8 \mathrm{e}-3$ & 3.6 & 0.008 \\
Depth & $-1.4 \mathrm{e}-3$ & 10.4 & $<1 \mathrm{e}-5$ \\
\hline
\end{tabular}



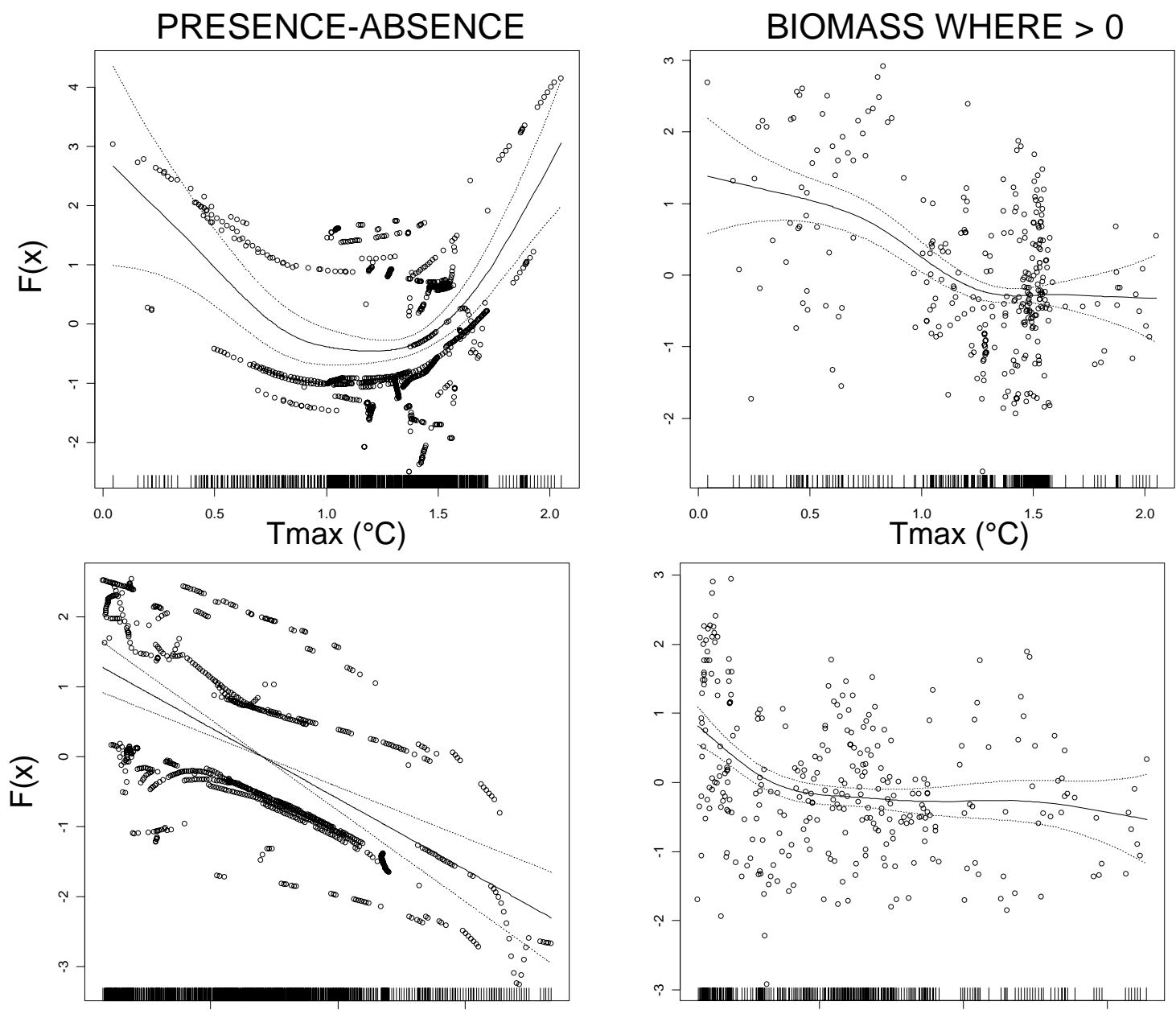

100

Distance to Land (km)

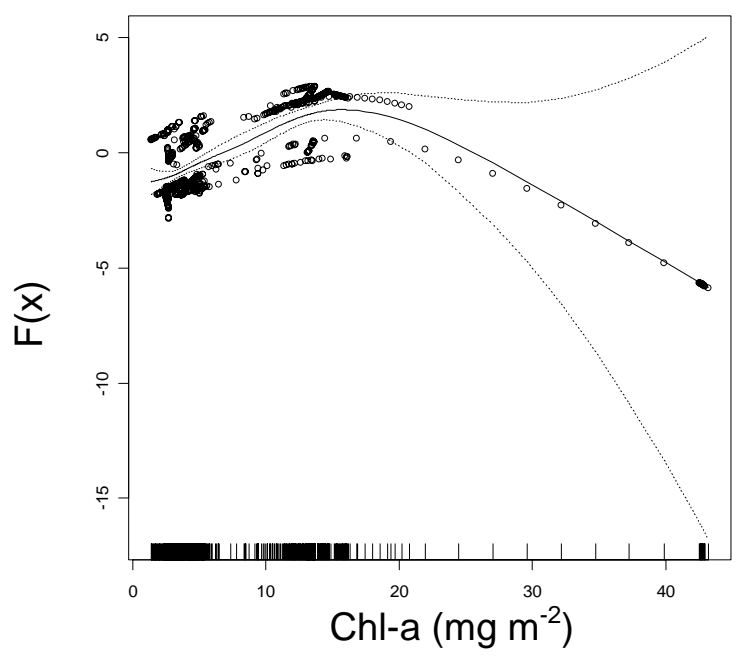

Figure 4.20.- Generalized Additive Modeling results for fall 2001. Solid lines indicate the linear or smoothing function, $\mathrm{F}(\mathrm{x})$, relating each environmental predictor to the dependent variables of either krill presence or absence (left-hand plots) or krill biomass where it was not zero (right-hand plots). Dotted lines denote the $95 \%$ confidence interval. Ticks along the $\mathrm{x}$-axis indicate sampled values. Open circles show residuals. 

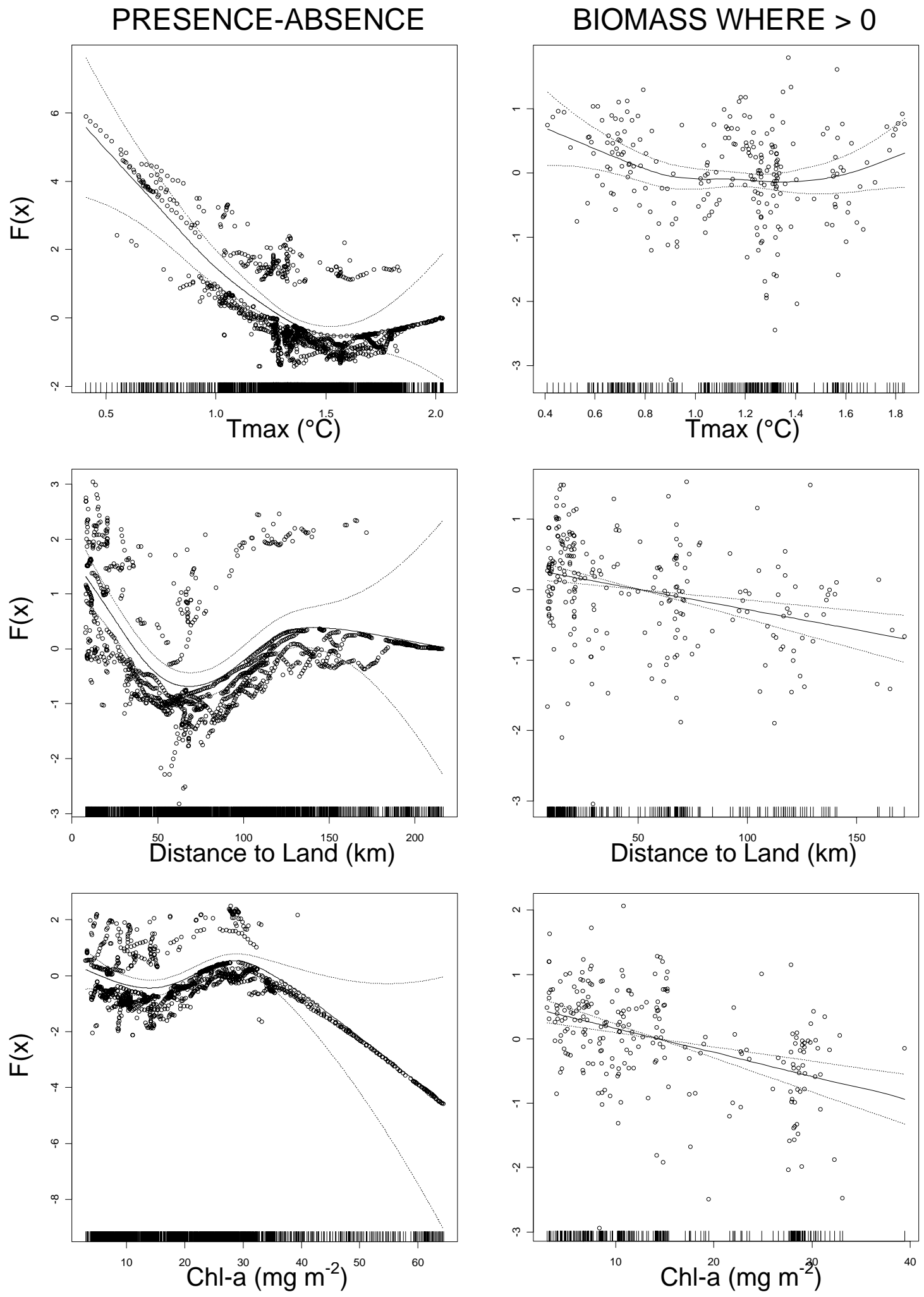

Figure 4.21 - Generalized Additive Modeling results for fall 2002. Solid lines indicate the linear or smoothing function, $\mathrm{F}(\mathrm{x})$, relating each environmental predictor to the dependent variables of either krill presence or absence (left-hand plots) or krill biomass where it was not zero (right-hand plots). Dotted lines denote the $95 \%$ confidence interval. Ticks along the $\mathrm{x}$-axis indicate sampled values. 

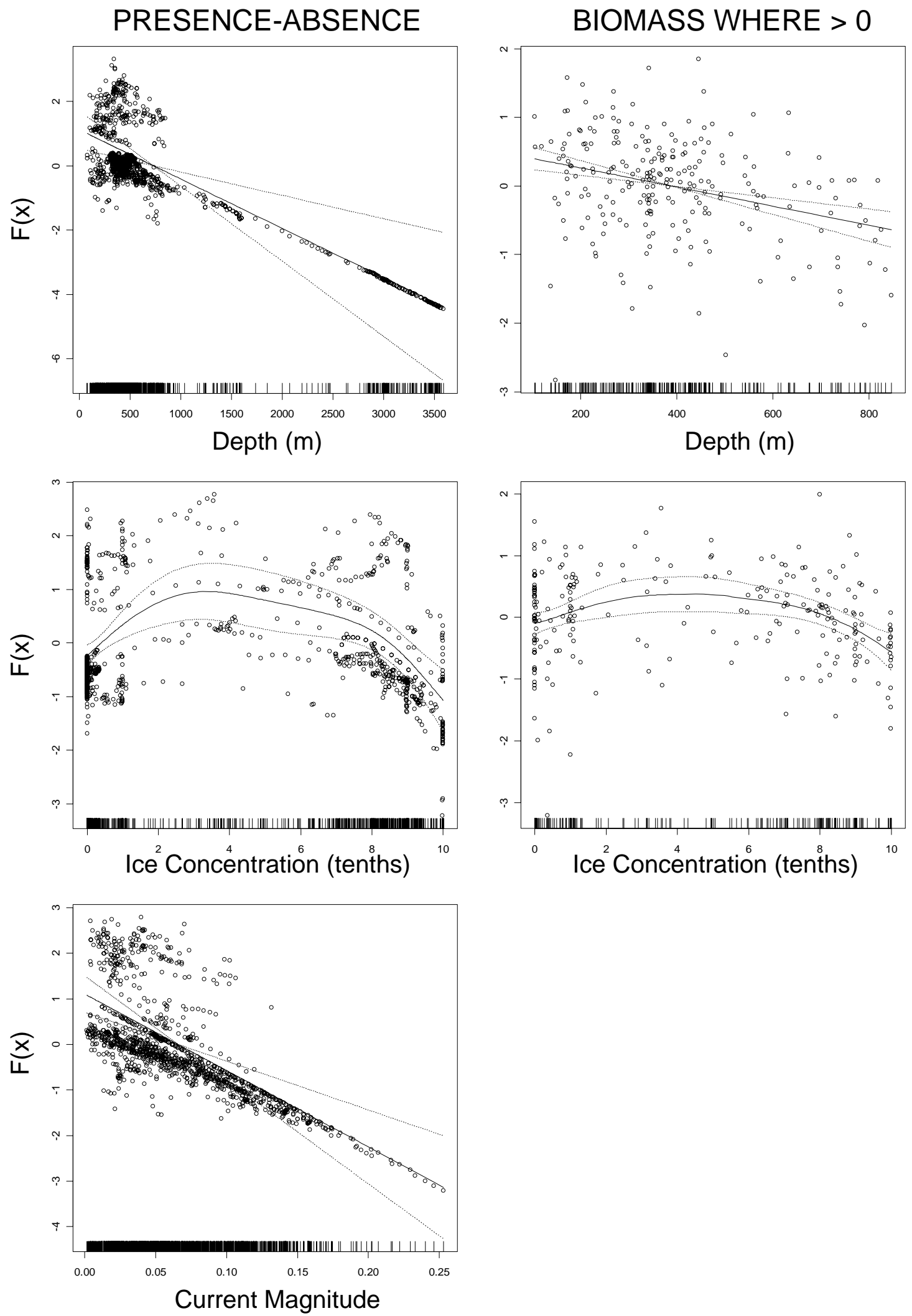

Figure 4.21, continued. 
concentrations of 3-6 tenths (Table 4.3, Figure 4.21). Krill presence/absence also decreased with current magnitude for that survey. Overall, more of the variability in krill vertically-integrated biomass where it was non-zero was explained by these various environmental predictors (42.4 and 49.1\% in the falls of 2001 and 2002, respectively) than krill presence/absence (27.4 and 40.1\%). For both dependent variables, much variability remained unexplained (Table 4.3, and see residual variability in Figures 4.20 and 4.21).

\subsection{2.d Distribution in relation to environmental features during winter}

During the winter of 2001, too little biomass was observed to make firm interpretations, but in 2002, highest biomass was no longer restricted to coastal areas, and instead was broadly distributed across the shelf and beyond the shelf break (Figure 4.9). Shallow depths in both winters were characterized by Winter Water (S 33.8 to 34.1, $\theta-1.8$ to $1.5^{\circ} \mathrm{C}$ ). The high total biomass index aggregations of 2002 were mostly associated either with shallow Winter Water, or with deeper Inner Shelf Water and modified Circumpolar Deep Water (Figure 4.18). The entire region was ice-covered, and the highest verticallyintegrated biomass estimates were found more than $300 \mathrm{~km}$ inwards from the ice edge. Chl- $a$ never exceeded $3 \mathrm{mg} \mathrm{m}^{-2}$ in either winter.

The results of the GAM analysis for the winter surveys were much less conclusive than in fall; only $6.2-7.8 \%$ of the deviance in presence/absence was explained by the available environmental variables, and $23.8-30.0 \%$ of deviance in vertically-integrated biomass where it was greater than zero (Table 4.4, Figures 4.22 and 4.23). The results from the winter of 2001 in particular should be approached with caution, due to the very low and few krill biomass observations made, and low explanatory power. During that survey, krill presence/absence increased with temperature and decreased with chl- $a$, although chl$a$ levels were so low it is difficult to know whether krill were actually responding to chl$a$, or to some covariate. Water depth was the only environmental variable to show a significant association with krill vertically-integrated biomass where it exceeded zero 
TABLE 4.4 - Generalized Additive Modeling results for the winter surveys. Analyses were conducted separately first for the dependent variable of krill presence or absence, and then for krill vertically-integrated biomass where it exceeded zero. Analyses began with a larger set of environmental variables, and only those remaining after variable selection are shown (see methods section 4.2.5.b). For each GAM, the null deviance (ND), residual deviance (RD), and percent of deviance explained (\%Dev.) are shown. s( ) indicates dependent variables whose relationship with the response variable was described by smoothed functions. Otherwise, this relationship was taken to be linear, and the coefficient of the linear relationship is shown. The significance of each environmental variable was tested for significance via a chi-square test on the deviance explained by the full model versus that with the variable removed; the drop in deviance between the two and associated $p$-value are shown.

\begin{tabular}{|c|c|c|c|}
\hline & Coefficient & $\begin{array}{c}\text { Drop in } \\
\text { deviance }\end{array}$ & $p$ \\
\hline WINTER 2001 & & & \\
\hline $\begin{array}{l}\text { Presence/absence } \\
\text { (ND 412.8, RD 380.7, \%Dev. 7.8) } \\
\text { s( Tmax ) } \\
\text { Chl- } a\end{array}$ & $\begin{array}{c}- \\
-2.87\end{array}$ & $\begin{array}{l}31.6 \\
16.4\end{array}$ & $\begin{array}{l}<1 \mathrm{e}-6 \\
<1 \mathrm{e}-4\end{array}$ \\
\hline $\begin{array}{l}\text { Vertically-integrated biomass }>\mathbf{0} \\
\text { (ND 43.6, RD 33.2, \%Dev. 23.8) } \\
\text { s( Depth ) }\end{array}$ & - & 10.4 & $<1 \mathrm{e}-4$ \\
\hline $\begin{array}{l}\text { WINTER } 2002 \\
\text { Presence/absence } \\
\text { (ND 773.9, RD 726.3, \%Dev. 6.2) } \\
\text { s( Tmax ) }\end{array}$ & - & 43.7 & $<1 \mathrm{e}-9$ \\
\hline $\begin{array}{l}\text { Vertically-integrated biomass }>\mathbf{0} \\
\text { (ND 237.9, RD 166.6, \%Dev. } 30.0) \\
\mathrm{s}(\mathrm{Tmax})\end{array}$ & - & 71.3 & $<1 \mathrm{e}-17$ \\
\hline
\end{tabular}



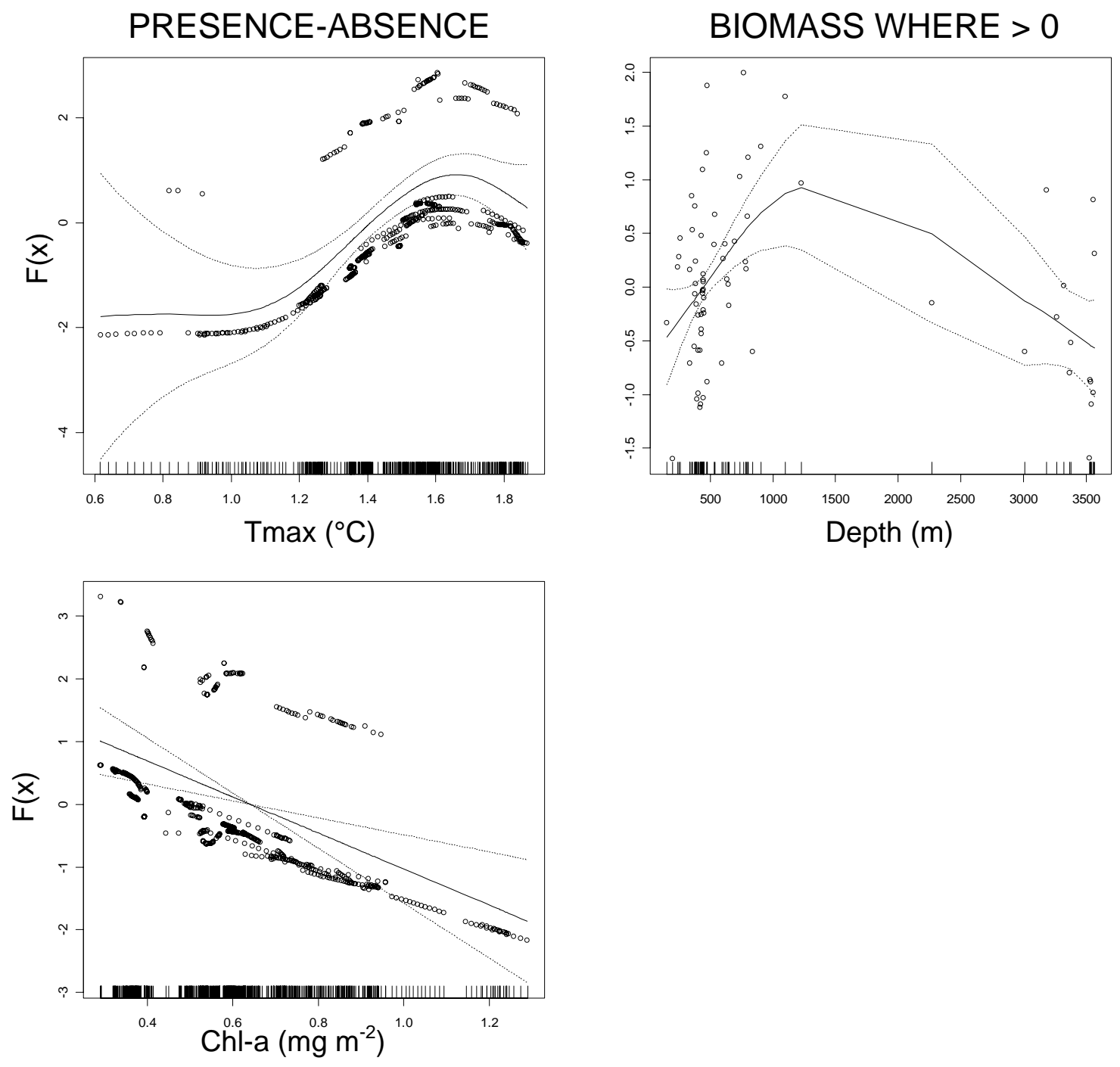

Figure 4.22 - Generalized Additive Modeling results for winter 2001. Solid lines indicate the linear or smoothing function, $\mathrm{F}(\mathrm{x})$, relating each environmental predictor to the dependent variables of either krill presence or absence (left-hand plots) or krill biomass where it was not zero (right-hand plots). Dotted lines denote the 95\% confidence interval. Ticks along the $\mathrm{x}$-axis indicate sampled values. Open circles show residuals. 

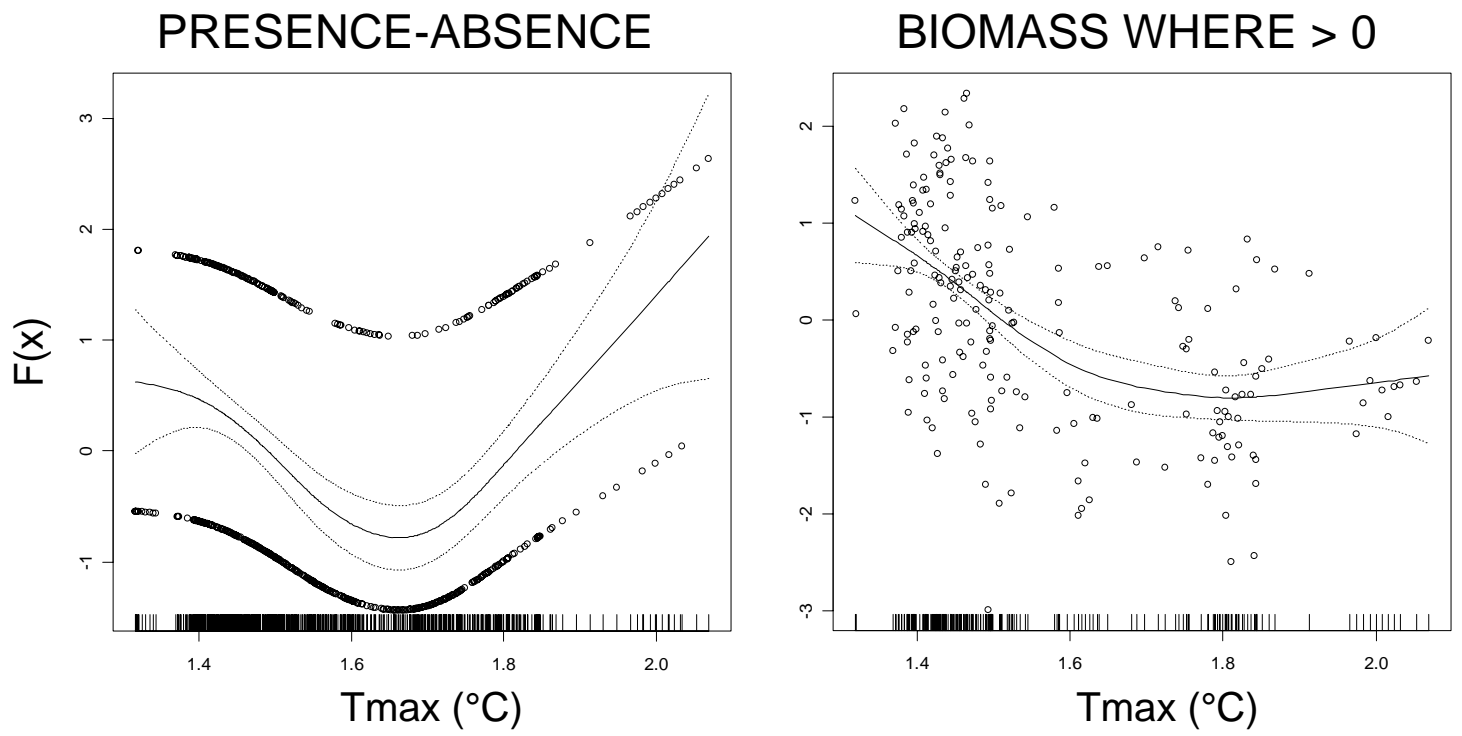

Figure 4.23 - Generalized Additive Modeling results for winter 2002. Solid lines indicate the linear or smoothing function, $\mathrm{F}(\mathrm{x})$, relating each environmental predictor to the dependent variables of either krill presence or absence (left-hand plots) or krill biomass where it was not zero (right-hand plots). Dotted lines denote the 95\% confidence interval. Ticks along the $\mathrm{x}$-axis indicate sampled values. Open circles show residuals. 
(Table 4.4, Figure 4.22). During the winter of 2002, Tmax was the only variable associated with either krill presence/absence or vertically-integrated biomass where it was non-zero, with functional relationships of very similar shape to the fall of 2001. Unlike in fall, however, when krill vertically-integrated biomass was maximal at Tmax levels $<1{ }^{\circ} \mathrm{C}$, during the winter of 2002, peak biomass was associated with temperatures between 1.4 and $1.6{ }^{\circ} \mathrm{C}$ (Figure 4.23). Note also that the initial model for the winter of 2002 before variable selection did not include chl- $a$, distance to the land, or water depth, as these were highly correlated $(r>0.7)$ with Tmax. The apparent association of krill with Tmax in that survey could thus also be due to the effects of one of these covariates.

\subsection{2.e Seasonal and inter-annual changes in biomass}

Comparison of biomass between the seasons and years under study is complicated by the variable coverage of the different surveys. Restricting analysis to only overlapping segments of the survey lines, however, it is evident that mean krill vertically-integrated biomass along such 'transects' decreased substantially between the fall and winter of 2001 (Table 4.5, and see Figure 4.1a for transect locations). In contrast, krill biomass estimates were quite comparable during the falls of 2001 and 2002. In the northern portion of the survey area, mean vertically-integrated biomass was greater in the fall of 2001 for most transects, but was greater in the fall of 2002 towards the southern portion of the shelf. Averaging over all transects for each survey, weighting each transect by its length following the methods of Jolly and Hampton (1990), mean vertically-integrated biomass for the region was greatest in the fall of 2001, followed by winter 2002, then fall 2002 (but note the high variability about these estimates; Table 4.5). Mean regional vertically-integrated biomass in the winter of 2001 was an order of magnitude lower than during other surveys. Comparing biomass estimates from the winter of 2002 to other time periods is particularly problematic. The northern portion of the survey area was quite well covered, however, and restricting comparison to this region indicated that mean 
TABLE 4.5 - Mean vertically-integrated biomass estimates $\left(\mathrm{g} \mathrm{m}^{-2}\right)$ for transects (Tr.) of overlapping survey coverage (Figure 4.1a). Standard deviation shown in parentheses. Asterisks indicate transects that were particularly short due to only very limited data being available during the winter 2002 survey.

\begin{tabular}{|c|c|c|c|c|c|c|c|c|c|}
\hline Region & Tr. & Fall 01 & $\begin{array}{c}\text { Winter } \\
01 \\
1-100 \mathrm{~m}\end{array}$ & Fall 02 & $\begin{array}{c}\text { Winter } \\
02 \\
1-100 \mathrm{~m}\end{array}$ & $\begin{array}{c}101- \\
600 \mathrm{~m} \\
\end{array}$ & $\begin{array}{c}\text { Winter } \\
01 \\
101- \\
600 \mathrm{~m} \\
\end{array}$ & $\begin{array}{c}101- \\
600 \mathrm{~m} \\
\end{array}$ & $\begin{array}{c}\text { Winter } \\
02 \\
101- \\
600 \mathrm{~m} \\
\end{array}$ \\
\hline North & 1 & $\begin{array}{c}2.03 \\
(7.38)\end{array}$ & - & $\begin{array}{c}2.33 \\
(10.76)\end{array}$ & $\begin{array}{c}0.04 \\
(0.90)\end{array}$ & $\begin{array}{c}2.50 \\
(22.44)\end{array}$ & - & $\begin{array}{c}0.16 \\
(3.63)\end{array}$ & $\begin{array}{c}0.00 \\
(0.00)\end{array}$ \\
\hline North & 2 & $\begin{array}{c}4.99 \\
(12.56)\end{array}$ & $\begin{array}{c}0.00 \\
(0.00)\end{array}$ & $\begin{array}{l}1.23 \\
(9.06)\end{array}$ & $\begin{array}{c}0.71 \\
(9.06)\end{array}$ & $\begin{array}{c}0.82 \\
(2.83)\end{array}$ & $\begin{array}{c}0.00 \\
(0.00)\end{array}$ & $\begin{array}{c}0.00 \\
(0.00)\end{array}$ & $\begin{array}{c}0.00 \\
(0.00)\end{array}$ \\
\hline North & 3 & $\begin{array}{l}- \\
-\end{array}$ & $\begin{array}{c}0.03 \\
(0.65)\end{array}$ & $\begin{array}{c}5.43 \\
(70.24)\end{array}$ & $\begin{array}{c}1.31 \\
(33.82)\end{array}$ & - & $\begin{array}{c}0.00 \\
(0.00)\end{array}$ & $\begin{array}{c}0.00 \\
(0.00)\end{array}$ & $\begin{array}{c}0.00 \\
(0.00)\end{array}$ \\
\hline North & 4 & $\begin{array}{c}7.00 \\
(29.78)\end{array}$ & $\begin{array}{c}2.49 \\
(12.03)\end{array}$ & $\begin{array}{c}0.00 \\
(0.00)\end{array}$ & - & $\begin{array}{c}0.03 \\
(0.28)\end{array}$ & $\begin{array}{c}0.00 \\
(0.06)\end{array}$ & $\begin{array}{c}0.00 \\
(0.00)\end{array}$ & $\begin{array}{l}- \\
-\end{array}$ \\
\hline North & 5 & $\begin{array}{c}5.10 \\
(24.43)\end{array}$ & $\begin{array}{c}0.87 \\
(8.45)\end{array}$ & $\begin{array}{c}0.00 \\
(0.00)\end{array}$ & $\begin{array}{c}5.37 \\
(100.52)\end{array}$ & $\begin{array}{c}0.00 \\
(0.00)\end{array}$ & $\begin{array}{c}0.04 \\
(1.04)\end{array}$ & $\begin{array}{c}0.00 \\
(0.00)\end{array}$ & $\begin{array}{c}0.00 \\
(0.00)\end{array}$ \\
\hline North & 6 & $\begin{array}{c}0.65 \\
(5.52)\end{array}$ & $\begin{array}{c}0.94 \\
(5.23)\end{array}$ & $\begin{array}{c}0.00 \\
(0.00)\end{array}$ & - & $\begin{array}{c}0.00 \\
(0.00)\end{array}$ & $\begin{array}{c}0.00 \\
(0.00)\end{array}$ & $\begin{array}{c}0.00 \\
(0.00)\end{array}$ & - \\
\hline North & 7 & $\begin{array}{c}6.49 \\
(65.17)\end{array}$ & $\begin{array}{c}1.33 \\
(10.24)\end{array}$ & $\begin{array}{c}0.70 \\
(16.52)\end{array}$ & $\begin{array}{c}20.40 \\
(247.98)\end{array}$ & $\begin{array}{c}0.00 \\
(0.00)\end{array}$ & $\begin{array}{c}0.00 \\
(0.00)\end{array}$ & $\begin{array}{c}0.00 \\
(0.00)\end{array}$ & $\begin{array}{c}0.00 \\
(0.00)\end{array}$ \\
\hline North & 8 & $\begin{array}{c}4.02 \\
(11.80)\end{array}$ & $\begin{array}{c}0.00 \\
(0.00)\end{array}$ & $\begin{array}{c}0.00 \\
(0.00)\end{array}$ & $\begin{array}{c}9.90 \\
(161.82)\end{array}$ & $\begin{array}{c}0.00 \\
(0.00)\end{array}$ & $\begin{array}{c}0.00 \\
(0.00)\end{array}$ & $\begin{array}{c}0.00 \\
(0.00)\end{array}$ & $\begin{array}{c}3.38 \\
(39.66)\end{array}$ \\
\hline North & 9 & $\begin{array}{c}6.92 \\
(40.95)\end{array}$ & - & $\begin{array}{c}3.97 \\
(81.14)\end{array}$ & $\begin{array}{c}3.76 \\
(83.41)\end{array}$ & $\begin{array}{c}0.02 \\
(0.63)\end{array}$ & - & $\begin{array}{c}0.00 \\
(0.00)\end{array}$ & $\begin{array}{c}292.27 \\
(943.13)\end{array}$ \\
\hline North & 10 & $\begin{array}{c}5.52 \\
(20.57)\end{array}$ & - & $\begin{array}{c}2.09 \\
(27.77)\end{array}$ & $\begin{array}{l}1.02 \\
(5.55)\end{array}$ & $\begin{array}{c}0.00 \\
(0.00)\end{array}$ & - & $\begin{array}{c}0.00 \\
(0.00)\end{array}$ & $\begin{array}{c}59.88 \\
(185.10)\end{array}$ \\
\hline North & 11 & $\begin{array}{c}1.26 \\
(4.40)\end{array}$ & $\begin{array}{c}0.00 \\
(0.00)\end{array}$ & $\begin{array}{c}0.00 \\
(0.00)\end{array}$ & - & $\begin{array}{c}0.00 \\
(0.00)\end{array}$ & $\begin{array}{c}0.00 \\
(0.00)\end{array}$ & $\begin{array}{c}0.00 \\
(0.00)\end{array}$ & - \\
\hline Central & 12 & $\begin{array}{c}0.00 \\
(0.00)\end{array}$ & $\begin{array}{l}1.17 \\
(9.00)\end{array}$ & $\begin{array}{c}0.00 \\
(0.00)\end{array}$ & - & $\begin{array}{c}0.00 \\
(0.00)\end{array}$ & $\begin{array}{c}0.04 \\
(0.56)\end{array}$ & $\begin{array}{c}0.00 \\
(0.00)\end{array}$ & - \\
\hline Central & 13 & - & $\begin{array}{c}0.10 \\
(1.28)\end{array}$ & $\begin{array}{c}0.01 \\
(0.22)\end{array}$ & - & - & $\begin{array}{c}0.00 \\
(0.00)\end{array}$ & $\begin{array}{c}0.00 \\
(0.00)\end{array}$ & - \\
\hline Central & 14 & $\begin{array}{c}1.05 \\
(6.12)\end{array}$ & - & $\begin{array}{c}0.00 \\
(0.00)\end{array}$ & - & $\begin{array}{c}0.00 \\
(0.00)\end{array}$ & - & $\begin{array}{c}0.00 \\
(0.00)\end{array}$ & - \\
\hline Central & 15 & $\begin{array}{c}0.89 \\
(3.65)\end{array}$ & $\begin{array}{c}8.13 \\
(51.48)\end{array}$ & $\begin{array}{c}0.00 \\
(0.00)\end{array}$ & - & $\begin{array}{c}0.00 \\
(0.00)\end{array}$ & $\begin{array}{c}0.09 \\
(1.58)\end{array}$ & $\begin{array}{c}0.00 \\
(0.00)\end{array}$ & - \\
\hline Central & $16^{*}$ & $\begin{array}{c}5.83 \\
(25.51)\end{array}$ & - & $\begin{array}{c}0.00 \\
(0.00)\end{array}$ & $\begin{array}{c}0.00 \\
(0.00)\end{array}$ & $\begin{array}{c}0.00 \\
(0.00)\end{array}$ & - & $\begin{array}{c}0.00 \\
(0.00)\end{array}$ & $\begin{array}{c}128.72 \\
(435.80)\end{array}$ \\
\hline Central & 17 & $\begin{array}{c}4.86 \\
(17.98)\end{array}$ & $\begin{array}{l}- \\
-\end{array}$ & $\begin{array}{c}0.06 \\
(0.97)\end{array}$ & $\begin{array}{c}131.82 \\
(331.96)\end{array}$ & $\begin{array}{c}0.00 \\
(0.05)\end{array}$ & - & $\begin{array}{c}0.00 \\
(0.00)\end{array}$ & $\begin{array}{c}11.91 \\
(50.03)\end{array}$ \\
\hline Central & 18 & $\begin{array}{c}2.66 \\
(6.22)\end{array}$ & $\begin{array}{l}- \\
-\end{array}$ & $\begin{array}{c}0.00 \\
(0.00)\end{array}$ & $\begin{array}{c}0.00 \\
(0.00)\end{array}$ & $\begin{array}{c}0.00 \\
(0.00)\end{array}$ & - & $\begin{array}{c}0.00 \\
(0.00)\end{array}$ & $\begin{array}{c}1.25 \\
(30.37)\end{array}$ \\
\hline Central & 19 & $\begin{array}{c}0.00 \\
(0.00)\end{array}$ & $\begin{array}{c}0.18 \\
(1.20)\end{array}$ & $\begin{array}{c}0.00 \\
(0.00)\end{array}$ & $\begin{array}{c}0.01 \\
(0.27)\end{array}$ & $\begin{array}{c}0.00 \\
(0.00)\end{array}$ & $\begin{array}{c}0.07 \\
(0.71)\end{array}$ & $\begin{array}{c}0.00 \\
(0.00)\end{array}$ & $\begin{array}{c}0.48 \\
(6.99)\end{array}$ \\
\hline Central & 20 & $\begin{array}{c}0.00 \\
(0.00)\end{array}$ & $\begin{array}{c}0.00 \\
(0.00)\end{array}$ & $\begin{array}{c}0.55 \\
(2.48)\end{array}$ & - & $\begin{array}{c}0.00 \\
(0.00)\end{array}$ & $\begin{array}{c}0.00 \\
(0.00)\end{array}$ & $\begin{array}{c}0.00 \\
(0.00)\end{array}$ & $\begin{array}{l}- \\
-\end{array}$ \\
\hline Central & 21 & $\begin{array}{c}5.47 \\
(16.94)\end{array}$ & $\begin{array}{c}0.00 \\
(0.00)\end{array}$ & $\begin{array}{c}0.00 \\
(0.00)\end{array}$ & $\begin{array}{c}0.07 \\
(2.41)\end{array}$ & $\begin{array}{c}0.00 \\
(0.00)\end{array}$ & $\begin{array}{c}0.00 \\
(0.00)\end{array}$ & $\begin{array}{c}0.00 \\
(0.00)\end{array}$ & $\begin{array}{c}7.13 \\
(84.88)\end{array}$ \\
\hline Central & 22 & $\begin{array}{c}0.11 \\
(0.76)\end{array}$ & $\begin{array}{c}0.00 \\
(0.00)\end{array}$ & $\begin{array}{c}29.94 \\
(121.70)\end{array}$ & $\begin{array}{c}0.00 \\
(0.00)\end{array}$ & $\begin{array}{c}0.00 \\
(0.00)\end{array}$ & $\begin{array}{c}0.00 \\
(0.00)\end{array}$ & $\begin{array}{c}0.00 \\
(0.00)\end{array}$ & $\begin{array}{c}14.05 \\
(109.18)\end{array}$ \\
\hline S Mbay & 23 & $\begin{array}{c}10.61 \\
(65.07)\end{array}$ & $\begin{array}{l}- \\
-\end{array}$ & $\begin{array}{c}0.00 \\
(0.00)\end{array}$ & - & $\begin{array}{c}0.00 \\
(0.00)\end{array}$ & - & $\begin{array}{c}0.00 \\
(0.00)\end{array}$ & $\begin{array}{l}- \\
-\end{array}$ \\
\hline S Mbay & 24 & $\begin{array}{c}0.09 \\
(1.34)\end{array}$ & - & $\begin{array}{c}0.00 \\
(0.00)\end{array}$ & - & $\begin{array}{c}0.00 \\
(0.00)\end{array}$ & - & $\begin{array}{c}0.00 \\
(0.00)\end{array}$ & - \\
\hline S Mbay & 25 & $\begin{array}{c}12.82 \\
(110.09)\end{array}$ & $\begin{array}{c}0.00 \\
(0.00)\end{array}$ & - & - & $\begin{array}{c}7.36 \\
(85.82)\end{array}$ & $\begin{array}{c}32.06 \\
(154.30)\end{array}$ & - & - \\
\hline S Mbay & 26 & $\begin{array}{l}1.10 \\
(5.02)\end{array}$ & $\begin{array}{c}0.07 \\
(1.03)\end{array}$ & $\begin{array}{c}26.32 \\
(39.70)\end{array}$ & - & $\begin{array}{l}2284.40 \\
(2392.7)\end{array}$ & $\begin{array}{c}0.38 \\
(2.88)\end{array}$ & $\begin{array}{c}135.86 \\
(151.52)\end{array}$ & - \\
\hline S Mbay & 27 & $\begin{array}{c}19.78 \\
(58.90)\end{array}$ & - & $\begin{array}{c}0.72 \\
(2.43)\end{array}$ & - & $\begin{array}{c}77.36 \\
(354.78)\end{array}$ & - & $\begin{array}{c}803.37 \\
(1121.2)\end{array}$ & - \\
\hline
\end{tabular}




\begin{tabular}{|c|c|c|c|c|c|c|c|c|c|}
\hline Region & Tr. & $\begin{array}{l}\text { Fall } 01 \\
1-100 \mathrm{~m}\end{array}$ & $\begin{array}{l}\text { Wint } 01 \\
1-100 \mathrm{~m}\end{array}$ & $\begin{array}{l}\text { Fall } 02 \\
1-100 \mathrm{~m}\end{array}$ & $\begin{array}{l}\text { Wint } 02 \\
1-100 \mathrm{~m}\end{array}$ & $\begin{array}{c}\text { Fall } 01 \\
101- \\
600 \mathrm{~m} \\
\end{array}$ & $\begin{array}{c}\text { Wint } 01 \\
101- \\
600 \mathrm{~m} \\
\end{array}$ & $\begin{array}{c}\text { Fall } 02 \\
101- \\
600 \mathrm{~m} \\
\end{array}$ & $\begin{array}{c}\text { Wint } 02 \\
101- \\
600 \mathrm{~m} \\
\end{array}$ \\
\hline "South & 28 & $\begin{array}{l}- \\
-\end{array}$ & $\begin{array}{c}0.00 \\
(0.00)\end{array}$ & $\begin{array}{c}0.00 \\
(0.00)\end{array}$ & $\begin{array}{l}- \\
-\end{array}$ & $\begin{array}{l}- \\
-\end{array}$ & $\begin{array}{c}0.00 \\
(0.00)\end{array}$ & $\begin{array}{c}9.31 \\
(60.91)\end{array}$ & - \\
\hline South & 29 & $\begin{array}{c}3.52 \\
(21.38)\end{array}$ & $\begin{array}{c}0.00 \\
(0.00)\end{array}$ & $\begin{array}{c}5.79 \\
(49.20)\end{array}$ & $\begin{array}{l}- \\
-\end{array}$ & $\begin{array}{c}0.00 \\
(0.00)\end{array}$ & $\begin{array}{c}0.00 \\
(0.00)\end{array}$ & $\begin{array}{c}0.00 \\
(0.00)\end{array}$ & - \\
\hline South & 30 & $\begin{array}{c}11.03 \\
(43.15)\end{array}$ & - & $\begin{array}{c}0.24 \\
(1.11)\end{array}$ & $\begin{array}{l}- \\
-\end{array}$ & $\begin{array}{c}0.00 \\
(0.00)\end{array}$ & - & $\begin{array}{c}0.00 \\
(0.00)\end{array}$ & - \\
\hline South & 31 & - & - & $\begin{array}{c}0.00 \\
(0.00)\end{array}$ & $\begin{array}{c}2.04 \\
(38.30)\end{array}$ & - & - & $\begin{array}{c}0.00 \\
(0.00)\end{array}$ & $\begin{array}{c}0.13 \\
(3.40)\end{array}$ \\
\hline South & $32^{*}$ & $\begin{array}{c}0.00 \\
(0.00)\end{array}$ & - & $\begin{array}{c}0.00 \\
(0.00)\end{array}$ & $\begin{array}{c}6.31 \\
(34.69)\end{array}$ & $\begin{array}{c}0.00 \\
(0.00)\end{array}$ & $\begin{array}{l}- \\
-\end{array}$ & $\begin{array}{c}0.00 \\
(0.00)\end{array}$ & $\begin{array}{c}0.29 \\
(2.86)\end{array}$ \\
\hline South & 33 & $\begin{array}{c}0.90 \\
(10.00)\end{array}$ & $\begin{array}{c}0.00 \\
(0.00)\end{array}$ & $\begin{array}{c}6.38 \\
(53.65)\end{array}$ & $\begin{array}{l}- \\
-\end{array}$ & $\begin{array}{c}0.00 \\
(0.00)\end{array}$ & $\begin{array}{c}0.00 \\
(0.00)\end{array}$ & $\begin{array}{c}0.43 \\
(7.60)\end{array}$ & - \\
\hline South & 34 & $\begin{array}{c}17.29 \\
(63.50)\end{array}$ & - & $\begin{array}{c}26.75 \\
(119.05)\end{array}$ & - & $\begin{array}{c}279.83 \\
(833.12)\end{array}$ & - & $\begin{array}{c}70.85 \\
(240.85)\end{array}$ & - \\
\hline South & 35 & $\begin{array}{c}23.78 \\
(119.48)\end{array}$ & - & $\begin{array}{c}0.07 \\
(1.64)\end{array}$ & - & $\begin{array}{l}1683.80 \\
(2987.7)\end{array}$ & - & $\begin{array}{c}0.00 \\
(0.00)\end{array}$ & - \\
\hline South & 36 & $\begin{array}{c}112.78 \\
(243.76)\end{array}$ & - & $\begin{array}{c}30.87 \\
(191.81)\end{array}$ & - & $\begin{array}{c}88.64 \\
(236.47)\end{array}$ & - & $\begin{array}{c}264.40 \\
(655.49)\end{array}$ & - \\
\hline South & 37 & $\begin{array}{c}5.69 \\
(12.86)\end{array}$ & $\begin{array}{c}0.00 \\
(0.00)\end{array}$ & $\begin{array}{c}11.60 \\
(23.09)\end{array}$ & - & $\begin{array}{c}43.80 \\
(153.23)\end{array}$ & $\begin{array}{c}0.00 \\
(0.00)\end{array}$ & $\begin{array}{c}49.25 \\
(76.81)\end{array}$ & - \\
\hline South & 38 & $\begin{array}{c}0.61 \\
(3.50)\end{array}$ & $\begin{array}{l}- \\
-\end{array}$ & $\begin{array}{c}3.36 \\
(23.85)\end{array}$ & - & $\begin{array}{c}0.00 \\
(0.00)\end{array}$ & - & $\begin{array}{c}6.03 \\
(154.19)\end{array}$ & - \\
\hline South & $39 *$ & $\begin{array}{c}0.00 \\
(0.00)\end{array}$ & - & $\begin{array}{c}0.00 \\
(0.00)\end{array}$ & $\begin{array}{c}234.16 \\
(273.12)\end{array}$ & $\begin{array}{c}0.00 \\
(0.00)\end{array}$ & - & $\begin{array}{c}187.15 \\
(844.29)\end{array}$ & $\begin{array}{c}0.00 \\
(0.00)\end{array}$ \\
\hline South & 40 & $\begin{array}{c}0.00 \\
(0.00)\end{array}$ & - & $\begin{array}{c}0.00 \\
(0.00)\end{array}$ & $\begin{array}{l}- \\
-\end{array}$ & $\begin{array}{c}0.00 \\
(0.00)\end{array}$ & - & $\begin{array}{c}0.00 \\
(0.00)\end{array}$ & - \\
\hline South & 41 & $\begin{array}{c}0.24 \\
(2.19)\end{array}$ & - & $\begin{array}{c}6.89 \\
(70.46)\end{array}$ & - & $\begin{array}{c}0.00 \\
(0.00)\end{array}$ & - & $\begin{array}{c}0.00 \\
(0.00)\end{array}$ & - \\
\hline South & $42^{*}$ & $\begin{array}{c}0.00 \\
(0.00)\end{array}$ & - & $\begin{array}{c}1.99 \\
(18.31)\end{array}$ & $\begin{array}{c}9.64 \\
(25.70)\end{array}$ & $\begin{array}{c}0.00 \\
(0.00)\end{array}$ & - & $\begin{array}{c}0.00 \\
(0.00)\end{array}$ & $\begin{array}{c}10.97 \\
(25.20)\end{array}$ \\
\hline South & 43 & $\begin{array}{l}1.49 \\
(9.27)\end{array}$ & - & $\begin{array}{c}6.14 \\
(43.34)\end{array}$ & $\begin{array}{l}- \\
-\end{array}$ & $\begin{array}{c}0.00 \\
(0.00)\end{array}$ & - & $\begin{array}{c}0.00 \\
(0.00)\end{array}$ & $\begin{array}{l}- \\
-\end{array}$ \\
\hline South & 44 & $\begin{array}{c}0.00 \\
(0.00)\end{array}$ & - & $\begin{array}{c}42.06 \\
(98.10)\end{array}$ & - & $\begin{array}{c}0.00 \\
(0.00)\end{array}$ & - & $\begin{array}{c}279.24 \\
(733.41)\end{array}$ & - \\
\hline South & 45 & $\begin{array}{c}0.30 \\
(2.34)\end{array}$ & - & $\begin{array}{c}54.21 \\
(178.74)\end{array}$ & - & $\begin{array}{c}0.00 \\
(0.00)\end{array}$ & - & $\begin{array}{c}172.83 \\
(430.70)\end{array}$ & - \\
\hline South & 46 & $\begin{array}{l}0.03 \\
(0.49)\end{array}$ & - & $\begin{array}{c}5.18 \\
(47.79)\end{array}$ & - & $\begin{array}{c}0.00 \\
(0.00)\end{array}$ & - & $\begin{array}{c}0.00 \\
(0.00)\end{array}$ & - \\
\hline South & 47 & $\begin{array}{c}0.00 \\
(0.00)\end{array}$ & - & $\begin{array}{c}0.00 \\
(0.00)\end{array}$ & - & $\begin{array}{c}0.00 \\
(0.00)\end{array}$ & - & $\begin{array}{c}0.00 \\
(0.00)\end{array}$ & - \\
\hline South & 48 & $\begin{array}{c}0.50 \\
(3.32)\end{array}$ & $\begin{array}{l}- \\
-\end{array}$ & $\begin{array}{c}8.22 \\
(63.05)\end{array}$ & - & $\begin{array}{c}0.00 \\
(0.00)\end{array}$ & $\begin{array}{l}- \\
-\end{array}$ & $\begin{array}{c}0.00 \\
(0.00)\end{array}$ & - \\
\hline N Mbay & 49 & $\begin{array}{c}2.27 \\
(15.94)\end{array}$ & - & $\begin{array}{c}0.00 \\
(0.00)\end{array}$ & - & $\begin{array}{c}292.84 \\
(673.59)\end{array}$ & - & $\begin{array}{c}0.00 \\
(0.00)\end{array}$ & - \\
\hline N Mbay & 50 & $\begin{array}{c}6.16 \\
(26.33)\end{array}$ & $\begin{array}{c}0.00 \\
(0.00)\end{array}$ & $\begin{array}{c}10.68 \\
(57.40)\end{array}$ & - & $\begin{array}{c}4.40 \\
(18.81)\end{array}$ & $\begin{array}{c}0.00 \\
(0.00)\end{array}$ & $\begin{array}{c}0.00 \\
(0.00)\end{array}$ & - \\
\hline N Mbay & 51 & $\begin{array}{c}83.42 \\
(110.29)\end{array}$ & $\begin{array}{c}0.00 \\
(0.00)\end{array}$ & $\begin{array}{c}0.58 \\
(2.66)\end{array}$ & - & $\begin{array}{c}4.22 \\
(15.93)\end{array}$ & $\begin{array}{c}0.00 \\
(0.00)\end{array}$ & $\begin{array}{c}0.00 \\
(0.00)\end{array}$ & - \\
\hline N Mbay & 52 & $\begin{array}{c}0.00 \\
(0.00)\end{array}$ & $\begin{array}{l}- \\
-\end{array}$ & $\begin{array}{c}16.44 \\
(20.06)\end{array}$ & $\begin{array}{l}- \\
-\end{array}$ & $\begin{array}{c}0.00 \\
(0.00)\end{array}$ & - & $\begin{array}{c}0.00 \\
(0.00)\end{array}$ & - \\
\hline N Mbay & 53 & $\begin{array}{c}0.00 \\
(0.00)\end{array}$ & $\begin{array}{c}0.00 \\
(0.00)\end{array}$ & $\begin{array}{c}64.45 \\
(53.82)\end{array}$ & - & $\begin{array}{c}0.00 \\
(0.00)\end{array}$ & $\begin{array}{c}0.00 \\
(0.00)\end{array}$ & $\begin{array}{c}2.66 \\
(4.93)\end{array}$ & - \\
\hline N Mbay & 54 & - & $\begin{array}{c}0.00 \\
(0.00)\end{array}$ & $\begin{array}{c}11.49 \\
(25.45)\end{array}$ & - & - & $\begin{array}{c}0.00 \\
(0.00)\end{array}$ & $\begin{array}{c}280.09 \\
(251.50)\end{array}$ & - \\
\hline N Mbay & 55 & $\begin{array}{l}- \\
-\end{array}$ & $\begin{array}{c}0.00 \\
(0.00)\end{array}$ & $\begin{array}{l}1.38 \\
(4.54)\end{array}$ & $\begin{array}{l}- \\
-\end{array}$ & - & $\begin{array}{c}0.00 \\
(0.00)\end{array}$ & $\begin{array}{c}0.00 \\
(0.00)\end{array}$ & - \\
\hline \multicolumn{2}{|c|}{$\begin{array}{l}\text { NORTHERN } \\
\text { REGION } \\
\text { OVERALL }\end{array}$} & $\begin{array}{c}4.20 \\
(1.00) \\
7.36 \\
(2.96) \\
\end{array}$ & $\begin{array}{c}0.81 \\
(0.24) \\
0.82 \\
(0.37) \\
\end{array}$ & $\begin{array}{c}1.13 \\
(0.59) \\
5.72 \\
(1.51) \\
\end{array}$ & $\begin{array}{l}7.25 \\
(3.25) \\
12.44 \\
(7.26) \\
\end{array}$ & $\begin{array}{c}0.12 \\
(0.11) \\
70.38 \\
(44.37) \\
\end{array}$ & $\begin{array}{c}0.01 \\
(0.01) \\
0.51 \\
(0.50) \\
\end{array}$ & $\begin{array}{c}0.005 \\
(0.005) \\
29.82 \\
(11.90) \\
\end{array}$ & $\begin{array}{c}83.11 \\
(67.62) \\
50.59 \\
(41.03) \\
\end{array}$ \\
\hline
\end{tabular}


vertically-integrated biomass estimates during the winter of 2002 were mostly higher than in the other surveys (Table 4.5).

\subsection{DISCUSSION}

Application of the acoustic methods developed and refined here to broad-scale survey data has revealed distinct patterns in the vertical and horizontal distribution of krill, as well as interesting associations with the physical and biological environment, and seasonal and inter-annual changes. Before making firm ecological interpretations, however, attention must be devoted to reconciling the differences evident between acoustic and net-derived estimates of krill length and abundance.

\subsubsection{Acoustic methodologies}

For those cases where independent confirmation of the presence of krill was available from net samples or Video Plankton Recorder observations, and data at $43 \mathrm{kHz}$ were available, measurements of $\delta$ MVBS fell within the range previously ascribed to krill (Watkins and Brierley, 2002; Demer 2004). The $\delta$ MVBS values observed here mostly fell towards the high end of this range, perhaps due in part to calibration uncertainty. This uncertainty was the reason for applying the full 2 to $16 \mathrm{~dB} \delta \mathrm{MVBS}$ range, despite our lowest frequency being $43 \mathrm{kHz}$, rather than the $38 \mathrm{kHz}$ in more common use and upon which the $\delta$ MVBS criteria were developed. Despite such uncertainty, the $\delta$ MVBS method appears sufficiently robust to identify the krill aggregations in this region. Issues associated with noise contamination and the sensitivity and proper functioning of the 43 $\mathrm{kHz}$ system, however, made application of this method impossible for much of the fall 2001 survey, and all of both winter surveys. In these cases, krill aggregations were identified on the basis of the threshold scattering criterion and visual scrutiny to remove the 'mixed-zooplankton layers' and 'fish patches.' This approach resulted in the extraction of krill datasets that qualitatively resemble the data from the fall of 2002 when the $\delta$ MVBS method could be applied. Estimates of along-track vertically-integrated 
biomass and an index of total aggregation biomass from the fall of 2002 were also highly comparable to the other surveys. Other studies have similarly assumed that all volume backscattering exceeding some threshold level corresponded to krill (e.g., Lascara et al., 1999; Hewitt et al., 2003). Nonetheless, our estimates of biomass for the fall of 2001 and both winters must be approached with greater caution.

At the two locations where net samples provided a basis for comparison, length estimates for the larger krill size mode from all three error terms defined here were encouragingly similar to mean values from net measurements, within a margin of error of $3-12 \%$. This congruence in acoustic and net estimates of krill length agrees with the results of previous studies that have attempted to invert multi-frequency acoustic observations of euphausiid aggregations and compare these to independent estimates of animal length available from other sources (e.g., Antarctic krill, Mitson et al., 1996, Azzali et al., 2004, Chu et al., submitted; Meganyctiphanes norvegica, Kristensen and Dalen, 1982, Warren et al., 2003; Greenlaw, 1979). The consistently accurate estimation of animal length in the present work and these various earlier studies may relate in part to the shape of the scattering versus frequency relationship and particularly the transition from the Rayleigh to geometric scattering ranges which impart so much information in estimating length being less sensitive to uncertainty associated with calibrations, noise, and the exact scattering model employed.

As pointed out earlier, due to the nature of the scattering versus size relationship, there is some ambiguity associated with exactly how the acoustically-estimated length relates to the true linear mean of krill lengths in each aggregation. It is perhaps most appropriate to think of the acoustically-estimated mean length as having been weighted by the scattering process through the use of the krill scattering model, or in more tangible terms as a rootmean-square. In either case, however, the relative information provided by the length estimates made acoustically should not be affected by this uncertainty: aggregations where larger lengths are estimated should have larger true mean lengths. Furthermore, as is explained further below, the error introduced into estimates of krill biomass by 
uncertainty associated with acoustic estimates of the mean length of animals in each aggregation is likely to be small. The fact that acoustically-estimated lengths were consistently smaller than those sampled by nets may relate to the influence of the smaller krill length mode that was present in the test locations; although the scattering from such small krill will be overwhelmed by that of the larger krill when the latter are present (as discussed in more detail in section 4.3.1.b of the results), for some of the acoustic measurements over which the mean volume backscattering used for the inversions was averaged, small krill may have been the dominant scatterer. Such instances would tend to bias the shape of the measured backscattering versus frequency relationship towards the shape of smaller animals. This finding may also relate to calibration uncertainty with the $43 \mathrm{kHz}$ system: if measurements at that frequency were artificially low, the estimated lengths would be made smaller. Note that the net estimates of length are not themselves thought to be affected by avoidance (Wiebe et al., 2004).

In contrast to the length estimates, much greater discrepancies were evident between the net and acoustic estimates of krill density. Again, this is consistent with previous acoustic studies of euphausiids, where density estimates from acoustic systems have exceeded those from nets by one to three orders of magnitude (e.g., in the Antarctic, Zhou et al., 1994; in the Irish Sea, Mitson et al., 1996; in the Gulf of Maine, Warren et al., 2003). The exception to this pattern is the comparable acoustic and net estimates of density made by Mitson et al., (1996) for various euphausiid species in the Gulf of Lawrence and in the Antarctic. In the present study, at the Laubeuf Fjord site, density estimates from the model-based inversion protocol and from direct scaling of observed volume backscattering by observed target strength were highly comparable, but both were an order of magnitude larger than net estimates of density. In Crystal Sound, acousticallyestimated density estimates were as much as two orders of magnitude higher than those from nets. Although there is uncertainty associated with the inversion method and the target strength model employed that might affect estimated density, such concerns do not apply to the approach of directly scaling in situ measured volume backscattering by measured target strength. This latter approach does still assume that the distribution of 
orientations of the krill at the short ranges from the towed body over which unbiased target strengths could be measured (see Lawson et al., 2006) was the same as for the krill at greater ranges that were responsible for the volume backscattering measurements. Too little evidence exists to verify this assumption, but in either case, the congruence in density estimated by the two acoustic approaches suggests that the offset in density from acoustics and nets relates more to factors other than the target strength model and inversion method.

Uncertainty does exist in the acoustic measurements themselves. Scattering is a stochastic process, and the mean volume backscattering measurements inverted here will have large confidence intervals in cases where the averages were over small aggregations with only limited numbers of acoustic observations (Greenlaw and Johnson, 1983). Similarly, the inversion method assumes that that total scattering is simply the sum of the contributions from each individual scattering organism, which requires that scatterers are randomly distributed within the ensonified volume (Greenlaw and Johnson, 1983). For low densities of animals or short ranges where the ensonified volume is particularly small, in combination with our short integration intervals (4 pings), this assumption may be suspect. Noise also introduces uncertainty into the acoustic measurements, but at the maximum range considered here for inversions $(100 \mathrm{~m})$, based on measured average noise profiles, the signal-to-noise ratio at all frequencies should exceed $10 \mathrm{~dB}$. Nonetheless, while all of these concerns introduce error into the acoustic estimates of length and numerical density, it is not obvious that they would introduce any bias, and certainly are unlikely to account for the order of magnitude offset between net and acoustic estimates of density.

Some of the difference between the net and acoustic estimates of density relates to the acoustic inversion estimating a smaller mean length of animal than was sampled by the nets. If we assume the length sampled by the net samples and use the inversion to solve for only the abundance of krill in Laubeuf Fjord, we arrive at density estimates of 4.0-8.9 individuals $\mathrm{m}^{-3}$, rather than the 6.7-12.6 individuals $\mathrm{m}^{-3}$ estimated when solving for both 
length and abundance simultaneously. Like previous investigators studying the use of acoustics for measuring krill abundance (e.g., Zhou et al., 1994), we attribute the remaining difference between the two sampling methods to spatial and temporal differences in acoustic and net data collection, and to avoidance by the krill. Such avoidance is consistent with known sensory capabilities and swimming speeds for krill: Wiebe et al., (2004) calculated that a $40 \mathrm{~mm}$ krill swimming at speeds of 8-11 body lengths $\mathrm{s}^{-1}$ (known to be possible from work by Kils 1981) would need to commence avoiding the oncoming MOCNESS at a distance of $2 \mathrm{~m}$ to avoid capture. In fact, krill have been observed to avoid a net system at least $10 \mathrm{~m}$ away (Everson and Bone, 1986). Sameoto et al. (1993) caught 10-20 times more of the euphausiid Meganyctiphanes norvegica when using lights on a net system than without, suggestive of strong avoidance capabilities on the part of that smaller krill species. During the present net tows, a strobe light was used to reduce avoidance (shown by Wiebe et al, 2004 to increase catches of large krill by a factor of approximately two). Despite the use of the strobe, avoidance by the strongly swimming krill of this slowly moving net system (ca. 2 knots) may explain much of the difference between net and acoustic estimates of abundance.

The offset in data collection between the net and acoustic systems may also play a role in explaining some of the difference in density estimates. The nets integrated over large volumes of water (281-636 $\left.\mathrm{m}^{3}\right)$ at different times and locations to the acoustic sampling. We compare the resulting net estimates of density to acoustic samples taken within the heart of large acoustically-observed krill aggregations, but due to the offset in space and time, we can't be certain whether the nets sampled exclusively within these krill aggregations or whether they also sampled empty water. In this context, it is interesting that density estimates averaged over all aggregations identified acoustically in the overall vicinity of where the net system sampled were much closer to net estimates than was the case when we examined only volume backscattering in the exact depth interval and as close as possible to the spatial area sampled by the nets. Furthermore, although the acoustic estimates of krill density exceeded those from the nets, they fell within the range 
of estimates made with nets elsewhere (nets 0.2-348.3 individuals $\mathrm{m}^{-3}$; Siegel, 2000), but below those estimated visually by divers (20,000-60,000 individuals $\mathrm{m}^{-3}$; Watkins, 2000).

Some previous studies employing inverse methods to estimate krill length and density have modeled the scattering from individual krill as that from a fluid-filled sphere of equivalent radius (Greenlaw, 1979, Mitson et al., 1996, Azzali et al., 2004), an approach that has been superceded by more sophisticated acoustic models with more realistic representations of the animal's shape (e.g., Stanton et al., 1998). We used the physicsbased target strength model of Lawson et al., (2006), which models the shape of the animal as a uniformly bent cylinder. In solving for animal length and abundance, we assumed that all of the other parameters upon which scattering depends (e.g., orientation, acoustic material properties, shape, etc.) are known. Chu et al. (submitted) have also proposed a non-linear inversion method by which both scattering model parameters (specifically, orientation and size) and animal abundance can be estimated simultaneously. We chose to take the simpler approach described here because other than length, all necessary scattering model parameters were measured or observed in situ for krill from the actual survey area and study period, and then validated with direct in situ observations of krill target strength (Lawson et al., 2006). The non-linear method also requires a great deal of computer-processing time, and our goal was to apply the method to all acoustically-identified krill aggregations. Furthermore, the Chu et al. (submitted) method has been tested on the same acoustic aggregation in Crystal Sound examined here, estimating a mean length of $38.4 \mathrm{~mm}$ and an abundance of 25 individuals $\mathrm{m}^{-3}$, highly comparable to the results of our simpler approach (length $37.5-38.5 \mathrm{~mm}$, abundance 23.7-24.2 individuals $\mathrm{m}^{-3}$ ).

The central quantity of interest here in terms of assessing the distribution of krill, however, is biomass. Biomass density was estimated on the basis of volume backscattering measured at $120 \mathrm{kHz}$, the mean krill length in each aggregation estimated from the inversion, the target strength model of Lawson et al., (2006), and the weight-tolength relationship measured by Wiebe et al. (2004). As demonstrated by Hewitt and 
Demer (1993), acoustic estimates of krill biomass density are much less sensitive to error associated with the assumed mean length than are estimates of numerical density, since the increase in expected scattering from one krill with length is offset by the decrease in the number of krill required to make up one kilogram of biomass with length. The difference in the target strength per kilogram of krill biomass for a mean krill length of 30 $\mathrm{mm}$ versus $45 \mathrm{~mm}$ is thus only $1.2 \mathrm{~dB}$, or a factor of $32 \%$ in biomass density estimates. The potential error introduced into biomass density estimates by applying the estimated length from a nearby aggregation for aggregations where the inverse method could not be applied, or by applying the mean length observed in fall to the survey data collected during the winter, should thus be relatively minor. Similarly, any uncertainty propagated into biomass density estimates due to the use of the $E_{2}$ error term in estimating mean krill length rather than the other two terms considered should be small.

The biomass density estimates made here, and the estimates of vertically-integrated biomass per unit surface area and the index of total aggregation biomass derived from biomass density, are also subject to other uncertainty introduced at the various stages of the acoustic analyses. Although thresholding the $120 \mathrm{kHz}$ data at $-70 \mathrm{~dB}$ decreases the likelihood of mistakenly accepting scattering from animals with smaller target strengths than krill or occurring at lower densities, it may also exclude some scattering from krill present at low densities. Antarctic krill are not thought to occur often or at large abundances outside of aggregations (Watkins, 1986), however. Furthermore, the majority of observed biomass was accounted for by a minority of very large and dense aggregations that easily passed the threshold criterion, and so the impact on overall biomass of any krill excluded by the threshold should be small. Visually excluding scattering found in the 'fish' patches and mixed-zooplankton layers also introduces uncertainty and subjectivity into our biomass estimates. As described in the results, however, the evidence supporting the exclusion of these features is compelling, and the resulting biomass estimates are at least conservative. Finally, as described above, all necessary parameters for the krill target strength model were measured for animals sampled in the study region, but the assumption is made that these parameters did not 
vary spatially or temporally. There is little reason to expect that parameters like krill orientation would vary across the study region or between survey periods, but insufficient evidence exists to address this concern directly, and so it must be acknowledged that this assumption may introduce some further uncertainty into the present results.

\subsubsection{Krill distribution}

Krill vertically-integrated biomass in the study region was high in all survey periods

other than the winter of 2001, with average biomass falling between 36 and $78 \mathrm{~g} \mathrm{~m}^{-2}$. These estimates are consistent with estimates of mean regional biomass per unit survey area made for Antarctic krill in other parts of the Southern Ocean using both nets (0.03$31.2 \mathrm{~g} \mathrm{~m}^{-2}$ ) and acoustics (1.87-187.7 $\mathrm{g} \mathrm{m}^{-2}$ ) (Siegel, 2000), giving us some confidence in our methodologies. Moreover, the present vertically-integrated biomass estimates are comparable to other high-krill areas such as the South Shetland Islands (1-60 $\mathrm{g} \mathrm{m}^{-2}$, Hewitt et al., 2003) and South Georgia (1.87-40.57 $\mathrm{g} \mathrm{m}^{-2}$, Brierley et al., 1997); this confirms the notion of the Marguerite Bay environs as a region rich in krill.

The overall pattern in the distribution of aggregations was one of many small aggregations closely spaced relative to one another, punctuated by much more episodic aggregations of very large size and biomass. As has been observed previously in this region and elsewhere, the size distribution of krill aggregations was strongly dominated by many small, low-biomass aggregations (Lascara et al., 1999; Pauly et al., 2000). The majority of overall biomass, however, was accounted for by the small number of very large aggregations. Nearest neighbor distances indicated that most aggregations were found in close proximity to one another $(<100 \mathrm{~m}$ in distance), suggesting that aggregations occur in clusters. In part, these small distances may also reflect artifacts of our sampling protocols: aggregations might be curved or exhibit holes, such that they appear discontinuous in our acoustic record, but are continuous in un-sampled waters alongside the vessel's track. Our imposition of a threshold scattering level may also 
artificially break up into separate aggregations features that are in fact continuous from the perspective of the krill, although at densities below the threshold.

\subsection{2.a Fall}

Vertically-integrated biomass in the two fall survey periods was comparable, though slightly higher overall in 2001, and with very high variance about the means. During both years, biomass during fall was highest in coastal regions, decreased over the shelf, and was particularly low in the surveyed off-shelf waters. Portions of the shelf were unoccupied by krill during both falls; the specific portions differed between years. In an acoustic survey conducted during fall of overlapping portions of the continental shelf to the present study region, Lascara et al., (1999) estimated biomass along transects of length $1-2 \mathrm{~km}$ ranging from 0 to $101 \mathrm{~g} \mathrm{~m}^{-2}$, for a regional average of $12 \mathrm{~g} \mathrm{~m}^{-2}$. These estimates are encouragingly similar to our own, although direct comparison is made difficult by that study's assumption that all measurements of volume backscattering originated from krill (likely not to be true in this region, Lawson et al., 2004), their only sampling to $189 \mathrm{~m}$ in depth, and their use of the Greene et al. (1991) target strength model now thought to produce overly large target strength predictions and thus overly small abundance estimates (Demer and Conti, 2005; Lawson et al., 2006). Our verticallyintegrated biomass estimates during fall are generally larger than those made by Lascara et al., (1999), perhaps due to these methodological differences, or perhaps due to interannual variability.

Mean biomass density during fall in the present surveys was maximal below a depth 100 $\mathrm{m}$, and was found in quite close association with the bottom (mostly within $150 \mathrm{~m}$ ). This is in contrast to Lascara et al., (1999), who observed greatest biomass in fall at shallow depths $(<75 \mathrm{~m})$. Again, this may be due in part to spatial differences in the exact areas surveyed, and to their only sampling to $189 \mathrm{~m}$ in depth. The present observations of vertical distribution during fall also contrast the general consensus from spring and 
summer surveys of krill being limited to the upper 100 or $150 \mathrm{~m}$ of the water column (Miller and Hampton, 1989).

The frequency distributions of acoustically-estimated lengths from the two fall surveys indicate that the patterns examined here in acoustically-estimated biomass relate predominantly to adult krill. The distributions of larval stages are best assessed by other methods (e.g., Video Plankton Recorder, nets), and for the SO GLOBEC region are the subject of companion studies (Ashjian et al., 2004; Daly 2004). In addition, the pulse of recruiting juvenile krill (15-30 mm total length, ca. 12.6-25 $\mathrm{mm}$ in terms of the 'acoustic' length considered here) observed in the region between 2001 and 2002 by Daly (2004) is not evident in our results. This may be due to these juvenile krill being mostly excluded by our methods for identifying krill aggregations, or to Daly (2004) having focused on a few particular 'process study' sites within the overall SO GLOBEC region.

The spatial distribution of estimated krill lengths in the fall of 2001 did not reveal any obvious patterns; this may relate either to a lack of any size-segregation on the part of the krill, or to error associated with the acoustic measurements in that survey. In contrast, during the fall of 2002, the acoustic system was performing optimally and small weighted mean lengths were only estimated for aggregations relatively close to the coast, while larger lengths were more broadly distributed across both coastal and shelf regions. A pattern of smaller Antarctic krill distributed more coastally has also been observed based on net samples in spring through fall by Lascara et al. (1999) in this same general area, and by Ichii et al. (1998) during summer near the South Shetland Islands. It is also important to recall that our acoustic methods do not distinguish between the different species of aggregating euphausiid that may be present; the aggregations with smaller estimated lengths may be composed of Euphausia crystallorophias, which attains smaller maximum lengths (ca. $30 \mathrm{~mm}$ observed in this region, K. Daly personal communication) and is generally thought to have a more neritic distribution than the Antarctic krill, Euphausia superba (Nordhausen, 1994; Ross et al., 1996). 


\subsection{2.b Winter}

Evidence concerning the distribution of adult krill in winter has been equivocal, due in part to a paucity of surveys during this season. Possible hypotheses include the notions that during winter krill 1) are associated with the environment immediately under the ice; 2) migrate to neritic regions; or 3) migrate to the bottom. Based on qualitative observations made with an ROV in the Weddell Sea, Marschall (1988) suggested that both adult and larval krill spend the winter in close association with the under-ice environment in order to feed on ice-associated algae. In contrast, ROV and diver surveys in the Bransfield Strait during winter have only seldom observed adult krill in association with the under-ice environment (Quetin et al. 1996), and wintertime net surveys in the Gerlache Strait found maximal euphausiid abundance between 15 and $50 \mathrm{~m}$ depth (Nordhausen, 1994; Zhou et al., 1994). Quetin et al. (1996) suggested that small krill are able to exploit the under-ice environment as they are less susceptible to predation by shallow feeding predators such as penguins, while larger krill occupy mostly deeper depths since they are more robust and able survive long periods of little food.

A competing hypothesis is that after migrating to spawn along the continental shelf-break and spending the summer broadly distributed over shelf and oceanic waters, krill migrate during fall to over-winter in inshore regions (Siegel, 1988). This hypothesis was proposed based on high net catches during winter of post-larval krill in coastal waters and low catches in the waters beyond the continental slope where krill were abundant during spring and summer (Siegel 1989). It was further supported by the seasonal acoustic surveys conducted by Lascara et al. (1999), and by the observations made acoustically by Zhou et al. (1994) and with nets by Nordhausen (1994) of high krill biomass in association with the coastal bays and islands of the Gerlache Strait. Siegel (2005) and Lascara et al. (1999) also recognized the alternate possibility, however, that the apparent seasonal decrease in krill abundance from spring/summer to fall/winter may stem from krill migrating to deeper portions of the water column, beyond the reach of standard survey depths $(200 \mathrm{~m})$. In support of this latter view, some studies have suggested that 
krill may take on a bentho-pelagic existence during winter, based on light trap catches under fast ice in waters shallower than $50 \mathrm{~m}$ in depth (Kawaguchi et al., 1986) and acoustic observations supplemented by occasional net samples of krill layers from the bottom to $20 \mathrm{~m}$ above near South Georgia (Heywood et al., 1985). Benthic diatom species have also been observed in stomach content analyses of krill collected in winter in Peninsula waters (Ligowski, 2000). The Nordhausen (1994) and Zhou et al. (1994) studies, however, sampled to 290 and $400 \mathrm{~m}$, respectively, and so would have been less likely to miss the krill due to their being distributed at greater depths during winter.

In the present study, while few krill were observed in the winter of 2001, numerous aggregations were observed in winter 2002, broadly distributed over the survey area. Overall vertically-integrated biomass in the winter of 2002 was two orders of magnitude larger than in 2001. Although we cannot assess the abundance of krill immediately under the ice due to the upper limit of the acoustic system, we can say that within the surveyed portion of the water column, the majority of krill biomass was found below a depth of $100 \mathrm{~m}$, and deeper in winter 2002 than the fall of that year. Furthermore, like the Nordhausen (1994) and Quetin et al. (1996) studies, companion SO GLOBEC surveys conducted with an ROV (S. Gallager, unpublished data, and see U.S. SO GLOBEC, $2002 b$ ) and diver observations (K. Daly, personal communication) observed only few post-larval krill under the ice. We thus find very little support for the hypothesis that adult krill inhabit only the environment immediately under the ice during winter in this region. Note that as indicated above, the present acoustic estimates of biomass are dominated by larger krill, and the acoustic system is not suited to sampling larval stages; the present results thus do not allow us to address the question of how larval krill were distributed and whether they were associated with the under-ice environment during winter.

The previous wintertime surveys upon which the hypothesis of a seasonal migration to coastal regions was based were limited in depth to $189 \mathrm{~m}$ (the acoustic survey of Lascara et al., 1999) and $200 \mathrm{~m}$ (the net survey of Siegel 1989). In the present study, due to the 
use of a chirp pulse (Ehrenberg and Torkelson, 2000) and to the ability of the BIOMAPER-II to be towed at depths up to $400 \mathrm{~m}$, we were consistently able to sample acoustically to $500 \mathrm{~m}$, often reaching even greater depths. This allowed us to sample to the bottom over much of the survey region. Despite this ability, krill biomass observed in the winter of 2001 was much lower than the fall of that year. Similar to the winter survey of Lascara et al. (1999), vertically-integrated biomass was zero or negligible along all but a few of the survey transects. Also similar to the surveys conducted during winter by Nordhausen (1994) and Zhou et al. (1994) using nets and acoustics, respectively, krill biomass was maximal vertically at depths less than $100 \mathrm{~m}$, and horizontally was greatest in regions close to shore. The high biomass observed in the winter of 2002, however, confuses matters substantially. Krill during this period were broadly distributed across the shelf and also found in off-shelf waters. Vertically, the greatest biomass was found at depths greater than $150 \mathrm{~m}$. The fact that the krill were not restricted to the most coastal areas surveyed does not appear consistent with an obligate migration to over-winter in the inner-most reaches of the shelf. Much of the observed biomass was found at depths unattainable by the Lascara et al. (1999) and Siegel (1989) survey protocols, consistent with the notion that krill did over-winter deeper in the water column. Such depths were still surveyed in the winter of 2001, and were likewise sampled by the winter surveys of Nordhausen (1994) and Zhou et al. (1994). This raises the question of why the results from the winter of 2002 differed so drastically from those of 2001, and from those of previous krill surveys conducted during the winter season.

The two winter surveys overlapped spatially less than in fall, but given the broad distribution observed in 2002, if krill had been similarly distributed in the winter of 2001 it seems unlikely that they would have gone undetected. The difference between the two winters also does not seem likely to relate to inter-annual fluctuations in total population abundance or recruitment, since estimated biomass was highly comparable in the two falls. Furthermore, during both winters the area was entirely covered by ice, and the water masses occupied by large krill aggregations in the winter of 2002 were also present 
in 2001. In all apparent respects, similar habitat to that occupied in the winter of 2002 was thus available (and surveyed) in the winter of 2001.

One substantial difference between the two years was an earlier arrival of the seasonal advance of the ice sheet in 2002 (Perovich et al., 2004). If as ice forms the krill move along the shelf towards the northeast following the advance of the pack ice, migrating to depth in late fall and winter based on internal or external cues that do not vary between years (e.g., day length), then their distribution in winter would be expected to be more southerly in 2001 than 2002. It is possible that such inter-annual differences in alongshelf movements may have resulted in the near absence of krill in the study region during the winter of 2001; such migrations could also be related to factors other than ice. We also cannot exclude the possibility that predation pressure during fall and winter may relate to ice cover, with less predation mortality in the winter of 2002 when the ice arrived earlier and was thicker with fewer leads.

Alternately, along-shelf advection may play an important role in determining krill abundance in the region. The present surveys did not cover the entire likely range of these krill populations, and high abundances are known to be present north of our study region (Lascara et al., 1999; and see our observation of high vertically-integrated biomass in Crystal Sound in the fall of 2002, Figure 4.9). These more northerly krill might be transported southwards into the region by the coastal current. Inter-annual variability in such advection or in krill production at upstream sources could explain the presence or absence of high krill biomass during our snapshot winter surveys. Similarly, during the fall of 2001, biomass was low over the southern outer shelf region, and krill were mostly absent that winter. This contrasts the fall of 2002, where abundant krill were abundant over the southern surveyed shelf region; if flow is generally towards the northeast over the outer shelf then the krill present towards the south in fall 2002 may have been advected along the shelf, where they were later captured by our winter survey. 


\subsection{2.c Environmental associations}

Highest krill vertically-integrated biomass during both of the fall surveys was associated with regions close to land, where temperatures at depth were cooler than what was available on the shelf as a whole. GAM analyses suggested that the maximum temperature below a depth of $200 \mathrm{~m}$ (Tmax) was consistently the best predictor of krill presence vs. absence and vertically-integrated biomass where it exceeded zero in our study region, although in a negative direction, and thus opposite to that predicted under the hypothesis that krill are associated with Circumpolar Deep Water (CDW). Statistical analysis of environmental influences on krill distribution also revealed a consistent negative association with the distance to nearest land. Lascara et al. (1999) similarly observed a general pattern of higher biomass during fall closer to the coast. Trathan et al. (2003) demonstrated a similar negative association of summertime krill abundance at South Georgia with temperature in broad-scale GAM analyses of acoustic data averaged over $80 \mathrm{~km}$-long transects. They attributed this pattern to variation in the position of the southern Antarctic Circumpolar Current front, however, and it is unlikely that such largescale processes are responsible for the relationships of krill biomass with temperature observed here.

At the finer scales of $0.5 \mathrm{~km}$ acoustic integration intervals, Trathan et al. (2003) found no consistent effect of temperature, and instead bathymetry was the only consistent predictor of abundance, with abundance greatest near the shelf-break (similar to the qualitative summertime observations of Ichii et al., 1998 and Pauly et al., 2000). Krill in summer may be associated with the shelf break in order to be positioned above CDW, due to the latter being favorable to successful spawning (Hofmann et al., 1992). Krill during our post-spawning season surveys, however, showed no association with CDW, nor with the shelf break. Intrusions of nutrient-rich CDW have also been linked to enhanced primary production in this region (Prezelin et al., 2004), and were evident during our surveys (Klinck et al., 2004), but also were not associated with enhanced krill biomass. Visual examination of the relationship between chlorophyll $a$ concentration and krill vertically- 
integrated biomass in fall suggested a mostly inverse relationship, and statistical analysis confirmed this for the fall of 2002.

The relationship of krill with phytoplankton may be scale-dependent, and our choice of 1$\mathrm{km}$ along-track intervals for examining environmental influences on krill biomass may have influenced the results of the statistical analysis. Visual examination of the association of krill biomass with chlorophyll $a$, however, indicated large regions of zero krill biomass coincident with high concentrations of chlorophyll $a$. During 2002 in particular, this region of high chlorophyll and zero krill biomass occupied an area of approximately $120 \mathrm{~km}$ along-shelf by at least $50 \mathrm{~km}$ across-shelf. Whether we had examined a smaller scale, such as the scale of individual krill aggregations, or some interval larger than $1-\mathrm{km}$, the overall pattern of zero biomass in the central portion of the shelf where chlorophyll $a$ levels were highest would still stand. This negative association of krill biomass with chlorophyll $a$ may relate to the krill having depleted phytoplankton stocks in the regions they inhabited; to predators removing krill from certain regions, allowing phytoplankton to achieve higher concentrations; or to a fall bloom occurring in an area simply not inhabited by krill. It is also possible that the high chlorophyll levels were due to algal mats or some other form of phytoplankton that might be too large or otherwise unpalatable to the krill. High abundances of algal mats were observed with the VPR in the vicinity of the region of elevated chlorophyll during the fall of 2002 (C. Ashjian, unpublished data), providing some support for this hypothesis.

Qualitative examinations of krill abundance in relation to dynamic topography have previously led to the suggestion that high krill abundance may be associated with regions of high velocity gradients and the sluggish currents associated with eddies and meanders (Witek et al., 1988; Brinton, 1991; Ichii et al., 1998), and that retention may contribute to the formation of regions of enhanced krill abundance. The main known retentive feature in the present study region is a large and persistent gyre situated over the northern shelf, where krill biomass was low in fall. Although the gyre appears to weaken in winter (Klinck et al., 2004), high krill biomass was found in its vicinity during the winter of 
2002. Currents in the gyre were on the order of 3 to $15 \mathrm{~cm} \mathrm{~s}^{-1}$ (from ADCP and dynamic height calculations, respectively; Klinck et al., 2004), while krill are capable of sustained swimming speeds of 10 to $15 \mathrm{~cm} \mathrm{~s}^{-1}$ (Kils, 1981). It is thus not clear to what degree the gyre may serve to retain krill. There was also a certain indication from statistical analyses of the data from the fall of 2002 that krill were associated with regions of low currents. This provides some very limited support for our hypothesis that krill biomass select habitats where currents and horizontal current shear are weak, in order to avoid advection out of the area and having aggregations being pulled apart by shear, respectively. The lack of a clear and consistent relationship between krill biomass and currents over all surveys may either be due to currents not exerting a strong influence on krill distribution, or to the scales chosen for the present analysis (currents averaged over hourly intervals and krill biomass over distances of $1 \mathrm{~km}$ ) not being appropriate to the detection of any relationship.

It is not immediately obvious why these coastal regions where cooler waters were present at depth and the abundance of phytoplankton prey was low were most favorable during fall as krill habitat, but it is perhaps appropriate to speculate on potential explanations. One possibility may relate to the strong coastal current flowing in a generally southwards direction through the study region (Figure 4.1b; Klinck et al., 2004). This current may serve to bring zooplankton prey to the omnivorous krill during this period when phytoplankton prey are so low. It is also possible that the canyons and regions of variable bathymetry present in these coastal regions provide a refuge from currents that otherwise would advect the krill from the region. Meso-scale eddies were present in these coastal waters during both years (Klinck et al., 2004; Zhou and Dorland 2004), potentially enhancing retention of krill or its planktonic prey. Alternately, contrary to the general understanding that krill spawn along and beyond the continental shelf break (reviewed in Siegel, 2005), Brinton (1991) suggested on the basis of patterns in the distribution of larval krill in the western Bransfield Strait that some krill, particularly small adults, may spawn in the deep basins in coastal reaches of the continental shelf. It is thus possible that the krill observed in coastal regions during fall in the present study were occupying these 
waters in preparation for coastal spawning in the following spring and summer. This does not seem fully consistent, however, with the observation during the winter of 2002 that krill biomass was high over most of the shelf, and that unlike the fall of that year, high biomass was no longer restricted to the coastal regions of deep canyons. Finally, the present surveys also only represent a brief window in time, and the krill may have been responding to unmeasured environmental conditions that preceded the survey periods.

\subsection{CONCLUSIONS}

This study addressed the paired goals of developing acoustic methodologies for making estimates of ecologically-relevant quantities from multi-frequency acoustic data, and then employing these estimates to examine variability in the distribution of krill in the Marguerite Bay region during the falls and winters of 2001 and 2002. A biologicallybased threshold level of volume backscattering strength for identifying krill aggregations was developed using published measurements of krill visual acuity. Additional verification was provided of the robust nature of established multi-frequency methods for discriminating krill aggregations from other sources of scattering (reviewed in Watkins and Brierley, 2002). Mean volume backscattering strength in these acoustically-identified aggregations was then used to estimate simultaneously the weighted mean length and density of krill in each aggregation, and on the basis of these, krill biomass. The potential for multi-frequency data and mathematical inverse techniques to be used for the simultaneous and quantitative estimation of zooplankton abundance and size has been known since Holliday (1977), but to the best of our knowledge, this study marks the first time that such methods have been applied to broad-scale data from Antarctic krill surveys. Comparison of the results of the acoustic analysis to net samples were favorable in the case of estimated krill length, but acoustic estimates of krill density exceeded those from nets by one to two orders of magnitude, likely due primarily to avoidance and differences in the volumes sampled by the two systems. 
Strong variability was evident in the distribution of krill biomass both in a spatial, seasonal, and inter-annual sense. Very high krill biomass was observed at depth over the continental shelf region in the winter of 2002. This differed from the results of the survey conducted during the winter of 2001, and from the results of the few winter surveys conducted previously for krill, where krill biomass observed has been shallowlydistributed and very low (Lascara et al., 1999) or mostly restricted to coastal bays and islands (Nordhausen, 1994; Zhou et al., 1994). The exact reasons behind this difference are not known, but generally demonstrate the highly variable nature of krill distribution.

Few previous studies have demonstrated clear and consistent relationships between krill abundance and environmental properties (Siegel 2005). In part, this has been due to data on krill abundance and environmental features being collected at disparate scales, leading to uncertainty in making statistical inferences (Weber et al., 1986). In the present study, environmental data were collected at highly similar scales to the 1-km intervals chosen for examining krill vertically-integrated biomass. Several consistent and interesting patterns emerged that provide a certain predictive capability concerning krill distribution. They do not, however, allow any firm conclusions regarding the impetus behind krill distribution: the reasons why krill inhabit the coastal regions of cooler and fresher waters, or are brought to them, remain unclear. Since these coastal regions were also characterized by high abundances of predators, especially seals (Burns et al., 2004), further investigation of this question is warranted to provide a comprehensive understanding of the links between physical processes, the Antarctic krill, and its predators.

\section{ACKNOWLEDGMENTS}

We warmly acknowledge the contributions of C. Davis and S. Gallager, co-primary investigators on the zooplankton broad-scale distribution component of the Southern Ocean GLOBEC project. Mark Baumgartner and Andy Solow provided muchappreciated statistical advice, while Dezhang Chu and Andone Lavery provided excellent 
advice during the development of the acoustic methodologies. Maria Vernet provided data on chlorophyll $a$ concentrations; ice observations were provided by Chris Fritsen, Christine Ribic, and Alice Doyle; Joe Donnelly and Jose Torres provided data on fish catches; Carlos Moffat and Jason Hyatt provided assistance and code for processing satellite ice data. All of these collaborators are thanked for their generosity in sharing these data. We further thank all officers and crew of the RVIB N. B. Palmer; the Raytheon Polar Services Technical Support group; the BIOMAPER-II and MOCNESS teams consisting of M. Butler, C. Davis, M. Dennett, K. Fisher, S. Gallager, A. Girard, E. Horgan, M. Taylor, J. Szelag, and J. Warren; as well as P. Alatalo, M.-Q. Chu, N. Copley, L. Gray, P. Hull, and G. Rosenwaks for lab analyses of net catches. This project was supported by NSF U.S. Antarctic Program Grant OPP-9910307. G. Lawson was supported by an Office of Naval Research Graduate Traineeship Award in Ocean Acoustics (Grant N00014-03-1-0212), a Fulbright Scholarship, a Natural Sciences and Engineering Research Council of Canada Post-Graduate Scholarship, and the Woods Hole Oceanographic Institution Academic Programs Office. 


\section{Chapter 5}

\section{Krill Aggregation Structure and Vertical Migration in Relation to Features of the Physical and Biological Environment}

\subsection{INTRODUCTION}

Patchiness in the distribution of zooplankton can occur due to a variety of mechanisms. Fully planktonic animals will tend to be distributed passively according to physical processes, while larger animals capable of overcoming prevailing currents (i.e., micronekton) are able to aggregate actively. Such aggregations may form due to enhanced foraging efficiency in aggregations (Antezana and Ray, 1984), energetic advantages such as hydrodynamic gains (Ritz, 1994), social factors such as greater success at locating mates, or reduced exposure to predators either through confusion, dilution, or evasion (Folt and Burns, 1999). Trade-offs likely exist as well, since the benefits of aggregating must be balanced against increased intra-specific competition.

Most euphausiids aggregate to some extent (Mauchline, 1980a), but the Antarctic krill (Euphausia superba) is notable for its consistent formation of strikingly cohesive aggregations, ranging in horizontal extent from meters to several kilometers, and vertically from 1 to $250 \mathrm{~m}$ (Watkins, 2000). Krill aggregative behavior is not restricted to

adults, but is also seen in larval forms (Marr, 1962; Hamner et al., 1989). The persistent occurrence of krill in such aggregations has led many authors to suggest that the krill swarm constitutes the basic ecological unit of the species (Watkins, 1986). These 
aggregations are highly recognizable with hydroacoustic instruments, making the krill a model species for the in situ study of zooplankton aggregation. The formation of dense aggregations susceptible to capture by nets also makes the Antarctic krill attractive for commercial exploitation, and the krill fishery is one of the largest crustacean fisheries in the world (Ichii, 2000).

Aggregation in the Antarctic krill is thought to represent a balance between the benefits of predator avoidance and possibly an enhanced ability to locate patchily-distributed food resources (Antezana and Ray, 1984), and the disadvantage of increased intra-specific competition once food patches are located (Daly and Macaulay, 1991). Physical processes may also play a role, however, and Zhou and Dorland (2004) suggest that horizontal current shear and strain limit the horizontal extent of krill aggregations. Most studies examining the relationship of krill and higher predators have concentrated on the question of how the distribution and population size of land-based and diving predators relates to that of the krill (Alonzo and Mangel, 2001). The role of predators in driving krill aggregation has rarely been examined directly (Daly and Macaulay, 1991; Zhou and Dorland, 2004), even though the different diving depths, spatial ranges, and feeding mechanisms of the various predators may have important consequences to the predation pressure experienced by krill at different spatial and temporal scales.

Although it has often been studied separately from aggregation, diel vertical migration by zooplankton is similarly thought to relate to feeding and avoiding predators (Ritz, 1994). For krill, the typical pattern observed in spring and summer is one of a diurnal migration from deeper depths inhabited during the day, where predation pressure from visual predators may be lower, towards the surface at night, presumably to feed (Godlewska, 1996). Sometimes this upwards migration is associated with dispersal of the animals into more loosely-associated aggregations during night (Demer and Hewitt, 1995). Wintertime studies of the vertical position of krill aggregations have observed no evidence of diel vertical migrations (Ross et al., 1996), although Taki et al. (2005) inferred from Japanese krill fishery catch data that migrations do occur in winter, and at 
greater depths and with greater amplitude than in summer. Godlewska (1996) suggests that the amplitude of summertime vertical migrations varies with the availability of food, with larger migratory extents under good feeding conditions. The potentially modulating effect of the presence of predators has not been examined directly for Antarctic krill, but Onsrud and Kaartvedt (1998) found that upwards migrations at night by the related euphausiid Meganyctiphanes norvegica were restricted when planktivorous fish were abundant in surface waters.

Since the advent of modern acoustic sensors and their application in the Antarctic, analysis of the characteristics of individual acoustically-detected aggregations has typified the study of Antarctic krill aggregative and vertical migratory behavior. In the absence of an ability to conduct experimental studies, identifying associations between characteristics of aggregations observed acoustically and external or internal factors allows inferences to be made concerning the forces driving the aggregative behavior of the animals involved (Nero et al., 1990). This approach has revealed that aggregation size, density, and position in the water column can vary between seasons (Ross et al., 1996; Lascara et al., 1999), geographic locations (Miller et al., 1993), and in ice-covered versus open waters (Sprong and Schalk, 1992; Zhou and Dorland, 2004). Net studies have demonstrated that biological characteristics, such as the length distribution and maturity stage of constituent members, are generally quite similar within krill aggregations, but differ substantially between even close neighboring aggregations (Watkins, 1986). The only study to examine whether such internal biological properties such as animal length are related to any morphological or positional features of the aggregations identified via acoustics, however, found no associations for the 30 aggregations analyzed (Ricketts et al., 1992).

In this study we examine the morphology, internal composition, and vertical position of individual krill aggregations observed during broad-scale acoustic surveys of the Western Antarctic Peninsula continental shelf in fall and winter, in relation to a variety of concurrently-measured features of the physical and biological environment. These 
include time of day, food availability, ice cover, vertical and horizontal current shear, and the occurrence of predators including whales, seals, and penguins. More specifically, we seek to address the following inter-related questions:

1. Do the krill in fall and winter exhibit diel vertical migration or other diel changes in aggregation structure, and are such patterns modified by the presence of food, ice cover, or predators? Are any other aggregation characteristics influenced by these environmental properties?

2. Is the size of aggregations affected by current shear?

3. Is there any evidence of size-related changes in aggregative behavior, as indicated by comparisons of aggregation characteristics to acoustic estimates of mean animal length? Following on the previous point, as animals become larger and have greater swimming capabilities, are they better equipped to overcome currents, and so do their aggregations become larger?

4. Are there seasonal or inter-annual changes in the above-described relationships, indicative of changes in the impetus or nature of aggregative and vertical migratory behavior?

Finally, we select certain large and high-biomass aggregations for more detailed examination of intra-aggregation variation in krill length and density. Ultimately, the aim of this work is to assess the relative factors driving krill aggregative and vertical migratory behavior.

\subsection{METHODS}

\subsubsection{Study area}

This study was conducted as part of the U.S. Southern Ocean GLOBal ECosystems Dynamics program (GLOBEC; Hofmann et al., 2002), which has as its primary study site 
the continental shelf region in and around Marguerite Bay, west of the Western Antarctic Peninsula (see Figure 4.1 in Chapter 4). Four surveys were conducted of the region by the RVIB Nathaniel B. Palmer: two surveys in austral fall (acoustic data collection from April 29 to June 1, 2001 and April 14 to May 14, 2002) and two in winter (July 27 to August 24, 2001, and August 12 to September 9, 2002). Survey tracks were determined by the position of hydrographic stations positioned nominally every $10-40 \mathrm{~km}$ along 13 transect lines spaced $40 \mathrm{~km}$ apart and running across the continental shelf, loosely perpendicular to the Peninsula coastline and shelf-break.

\subsubsection{Data collection}

Observations of krill aggregations were derived from acoustic data collected using the BIo-Optical Multi-frequency Acoustical and Physical Environmental Recorder (BIOMAPER-II; Wiebe et al., 2002), a towed system consisting of a multi-frequency echosounder, a Video Plankton Recorder (VPR), and an environmental sensing system (Conductivity, Temperature, and Depth sensor (CTD); fluorometer; transmissometer). Full details concerning acoustic data collection are found in Lawson et al. (2004, 2006), and only a summary will be provided here. The BIOMAPER-II was towed obliquely up and down through the water column between depths of 20 and $400 \mathrm{~m}$ as the vessel proceeded between stations at speeds of 4 to 6 knots. Surveying was conducted irrespective of time of day, but was interrupted by on-station activities, resulting in variable coverage of each 24 hour period.

Measurements of acoustic volume backscattering strength, or $S_{v}\left(S_{v}=10 \log _{10}\left(S_{v}\right)\right.$ in units of decibels relative to $1 \mathrm{~m}^{-1}$, where $s_{v}$ is the volume backscattering coefficient), were made with the BIOMAPER-II from pairs of up- and down-looking transducers at frequencies of 43, 120,200, and $420 \mathrm{kHz}$, to maximal ranges of 300,300, 150, and 100 $\mathrm{m}$, respectively. Maximum depths of observation thus varied between 320 and $700 \mathrm{~m}$, depending on the position of the towed body in the water column. Acoustic data were collected with a vertical resolution of $1.5 \mathrm{~m}(43$ and $120 \mathrm{kHz})$ or $1 \mathrm{~m}(200$ and $420 \mathrm{kHz})$, 
at a ping rate of 0.3 pings $\mathrm{s}^{-1}$. The measurements of squared voltage from which volume backscattering strength is derived were integrated over time intervals corresponding to the vertical resolution and then averaged for each depth stratum over all pings collected within 12 second intervals, corresponding to a horizontal resolution of approximately 35 $\mathrm{m}$, depending on the ship's speed. All transducers were calibrated by the manufacturer prior to each survey year, and in situ calibrations with tungsten carbide ( $6 \%$ cobalt) spheres of diameters 38 and $21 \mathrm{~mm}$ were performed during the winter of 2001 and both surveys in 2002. Noise profiles (ship's, ambient, and system noise combined) were measured at the start of each survey, and used as thresholds for volume backscattering strength measurements.

\subsubsection{Acoustic data analysis}

The methods developed and verified in Chapter 4 were used to identify krill aggregations in the acoustic record and then estimate the weighted mean length, numerical density, and biomass density of constituent animals. In brief, measurements of volume backscattering strength attributable to krill were distinguished from those due to other zooplankton or micronekton first on the basis of a threshold volume backscattering strength level of -70 $\mathrm{dB}$, derived from the minimum sensing distance over which a given animal can be expected to maintain an association with its nearest neighbor based on physiological measurements of krill visual acuity (Hiller-Adams and Case, 1984). Aggregations were defined as all vertically or horizontally contiguous sets of super-threshold volume backscattering strength measurements (or acoustic 'elements'). Differences in mean volume backscattering strength at 120 and $43 \mathrm{kHz}$ were then calculated for these putative krill aggregations, and aggregations where this difference fell between 2 and $16 \mathrm{~dB}$ were accepted as krill (Watkins and Brierley, 2002; Demer, 2004).

Sensitivity and noise problems in the channel that operated at $43 \mathrm{kHz}$ during the fall of 2001 survey led to numerous cases where this mean volume backscattering strengthdifference method could not be applied; malfunctions at $43 \mathrm{kHz}$ during the entireties of 
both winter surveys similarly precluded its application. In such instances, krill aggregations were identified on the basis of the threshold volume backscattering strength criterion alone. Certain acoustic features more likely composed of other animals, such as myctophid fishes, were also excluded on the basis of visual scrutiny. Comparisons to survey results from the fall 2002 survey when the $43 \mathrm{kHz}$ system functioned properly suggest that this approach did not result in a substantially different description of krill aggregations, but see Chapter 4 for a discussion of the potential uncertainty introduced by these decisions. It is also important to note that these methods do not distinguish between animals of very similar sizes and scattering type, and so cannot discriminate among the different species of aggregating euphausiids that may be present (notably Euphausia superba and E. crystallorophias, but potentially also Thysanoessa macrura; see discussion and Ross et al., 1996).

The mean length and numerical density of krill in each aggregation were next estimated on the basis of inversions of the four-frequency acoustic data (similar to Greenlaw 1979; Warren et al., 2003). Aggregations were assumed to be composed of krill with a unimodal and narrowly-distributed length distribution (Watkins et al., 1986), and theoretical predictions were made of expected volume backscattering coefficients at each frequency for varying combinations of krill length and density, using the target strength model of Lawson et al. (2006). The most likely mean krill length and numerical density were then inferred on the basis of the best fit between these predictions and mean measured volume backscattering coefficients in each aggregation, minimizing an error term defined as the sum of the squared difference between observed and predicted log-transformed volume backscattering coefficients at each frequency (calculations explained in detail in Chapter 4). This method was only applied to aggregations meeting both the threshold volume backscattering strength and mean volume backscattering strength-difference criteria, and was verified at certain locations where net and Video Plankton Recorder observations provided independent bases for comparison (see Chapter 4). The calculations also require volume backscattering measurements at all four acoustic frequencies, and so length could only be estimated for aggregations found within a distance of $100 \mathrm{~m}$ (the range of the 420 
$\mathrm{kHz}$ system) of the towed body. Similarly, because data at all four frequencies were not available during the winter surveys, length and density were only estimated for aggregations observed in fall.

The estimate of krill length in each aggregation achieved via the inversion method is a mean that is weighted by the acoustic scattering process through the use of the krill scattering model. Scattering is a non-linear function of length, and so the acoustic estimate of length is more strongly influenced by the larger krill present, and differs from the linear mean that would be calculated for a sample of krill collected by nets. A more comprehensive discussion of this point and its consequences is found in Chapter 4. Irrespective of exactly how the acoustically-estimated weighted mean length relates to the linear mean of actual krill lengths present in the acoustically-observed aggregations, the acoustic estimates should still be informative in a relative sense: a larger acousticallyestimated length should indicate a larger true length of animal. Fortunately, it is such relative information that is important to the analyses here, which examine how aggregation features vary in relation to changes in the acoustic estimates of krill length, and so are not contingent on having absolute information on krill length. For simplicity, this mean estimated length weighted by the acoustic scattering process henceforth will be referred to as the 'weighted mean length.'

Krill biomass was assessed in two ways: via mean aggregation biomass density and via an index of total aggregation biomass. Mean krill biomass density $\left(\mathrm{g} \mathrm{m}^{-3}\right)$ in each acoustically-identified aggregation was estimated on the basis of mean volume backscattering at $120 \mathrm{kHz}$ (averaged over all measurements in the aggregation via the linear quantity of the volume backscattering coefficient), the target strength model of Lawson et al., (2006), the wet weight to length relationship of Wiebe et al., (2004), and the weighted mean length estimated by the multi-frequency inversion (see Chapter 4 for a full derivation of the calculations involved). Where animal length could not be estimated acoustically, the length used in biomass density estimation was taken as the length estimated for the nearest neighboring aggregation within a distance of $50 \mathrm{~m}$ vertically and 
$10 \mathrm{~km}$ horizontally, and with mean $120 \mathrm{kHz}$ volume backscattering strength within $10 \mathrm{~dB}$ of the aggregation of interest, and otherwise as the median length for all aggregations observed during that particular survey. In winter, length was never estimated acoustically and was taken as the median over all acoustically-estimated weighted mean lengths from the survey conducted in the previous fall. Likewise, although numerical density was estimated by the acoustic inversion for some aggregations, in order to have estimates for all observed aggregations, mean density (individuals $\mathrm{m}^{-3}$ ) was calculated from mean volume backscattering at $120 \mathrm{kHz}$ and a target strength per individual derived from the Lawson et al. (2006) target strength model combined with estimated krill length.

An index of total aggregation biomass was also derived by first converting each volume backscattering element in each aggregation to an estimate of biomass density, similar to the calculations for mean biomass density described above. The size of the volume represented by each element in terms of depth and along-track distance is known, so each element's estimate of biomass density was multiplied by its cross-sectional area and summed over all elements to yield an estimate of aggregation biomass per across-track meter. Since the across-track extent of the aggregation is not known, it is not possible to calculate absolute biomass, and so this quantity of biomass per across-track meter $\left(\mathrm{kg} \mathrm{m}^{-1}\right)$ is used as an index of total aggregation biomass.

In some previous studies of other fish and zooplankton species, various morphological operators (e.g., dilations and erosions) have been applied to the acoustic data in order to help define bounded objects and discriminate aggregations of the target organisms from other features such as the bottom or other scatterers (e.g., Reid and Simmonds 1993). These operators treat the acoustic data like pixels, and have the effect of filling holes and small gaps between neighboring groups of pixels and filtering out very small aggregations. Such operators were not applied here, because the krill aggregations here were already very distinct from background scattering and because as is described below, the smallest aggregations (of the minimum detectable size set by the resolution of the acoustic data) were not considered in the analyses that follow. Furthermore, the holes and 
gaps evident in the acoustic representations of the schools are at least the size of one acoustic integration interval $(\sim 35 \mathrm{~m})$, and so are substantially larger than the krill's sensing distance.

\subsubsection{Measurements of aggregation features}

A variety of additional measurements were made for each acoustically-identified aggregation, based on the $120 \mathrm{kHz}$ acoustic volume backscattering data measurements and knowledge of the location of each measurement from GPS, following accepted methodologies (Reid, 2000). The position of each aggregation was defined on the basis of the time and geographic location of its centroid, or the mean depth and mean horizontal coordinates of all acoustic elements in the aggregation (Figure 5.1). Aggregation depth was taken as centroid depth, although the depths of the shallowest and deepest acoustic elements were also measured.

Aggregation length was calculated based on the distance between the location of the first and last observation within the aggregation (Figure 5.1). The mean inter-element distance was added to this calculated length to account for the distance traversed during the first half of the first element and second half of the last. Algorithms based on simulated fish schools are proposed in Reid (2000) for correcting such length estimates for the distorting effects of the acoustic beam width. For the present data, however, each measurement is an ensemble average over four pings and a 12 second interval (ca. $35 \mathrm{~m}$ along-track), and it is not obvious that the corrections suggested in Reid (2000) are appropriate in the case of such coarse horizontal resolution. We therefore calculated for each aggregation what these corrections would be, and examined for all statistical analyses the effect of making and not making the corrections. No effect was evident, and so only the uncorrected lengths are reported.

Height was calculated as the difference between the shallowest and deepest elements in the aggregation, multiplied by the vertical bin size (1.5 m; Figure 5.1). Often height 


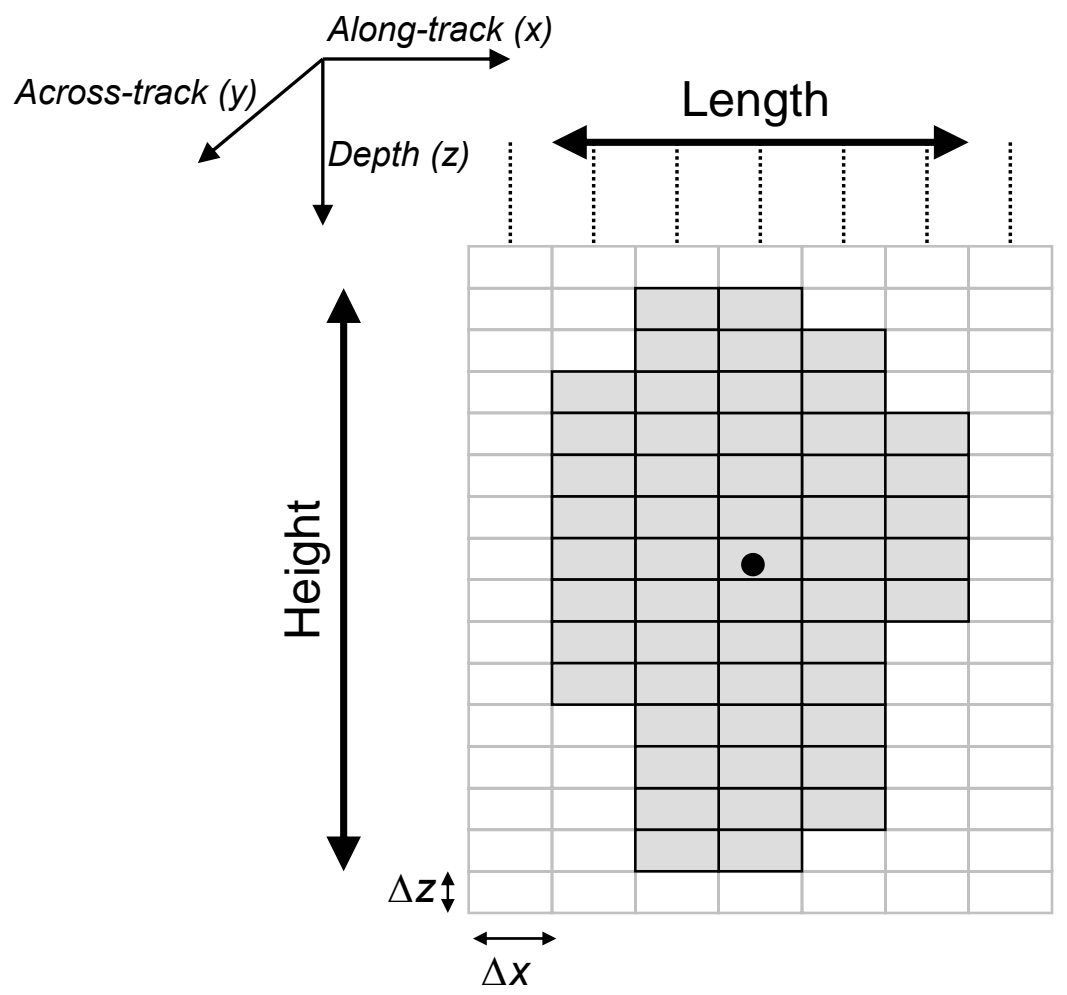

Figure 5.1 - Schematic illustration of the acoustic representation of a krill aggregation. Measurements are made in depth $(z)$ and along-track distance $(x)$; the extent of aggregations in the across-track dimension $(y)$ remains unknown. Each measurement, or 'acoustic element,' was taken to represent an area defined by the vertical resolution of the data $(\Delta z)$ of $1.5 \mathrm{~m}$, and the horizontal distance between successive measurements $(\Delta x)$ of approximately $35 \mathrm{~m}$, varying with the ship's speed. Acoustic elements indicated here by boxes. Aggregations were defined as groups of contiguous elements exceeding the threshold scattering level; grey boxes represent a typical aggregation. The GPS position associated with each measurement (indicated schematically by dashed lines) was assumed to represent that measurement's center. Aggregation height was the difference between the deepest and shallowest elements within the aggregation, multiplied by the vertical resolution. Aggregation length was the distance between the position of the first and last elements within the aggregation, with the mean inter-measurement distance added to account for the distance traveled during the first half of the first ping and the second half of the last. The area represented by each element was calculated as $\Delta x \mathrm{x} \Delta z$ and summed over all elements to yield total aggregation area. The vertical and horizontal position of each aggregation was defined on the basis of the position of its centroid, or the mean depth and horizontal position of all elements in the aggregation (represented by black dot). 
estimated in this way is corrected by one-half of a pulse length $(13.5 \mathrm{~cm}$ in this case; Reid, 2000), but given the small size of this correction relative to the vertical resolution of our measurements, no correction was made here. Finally, the size of each acoustic element was determined on the basis of vertical bin size and the distance to the next element, and then summed over all elements to estimate aggregation cross-sectional area (in depth and along-track distance; Figure 5.1).

It is important to note that while these calculations of aggregation morphology treat each acoustic element as representing simple box-shaped volumes of size defined by the vertical and along-track resolution of the data, they are in fact quite complex. The acoustic beam is conical, sampling volumes that are larger in horizontal extent at greater ranges from the towed body. Samples were taken every 3.3 seconds, resulting in sample volumes that overlapped between successive measurements at larger ranges, with the exact range at which overlap began varying with the ship's speed. These samples were then integrated over 12-second along-track intervals, resulting in the horizontal resolution of approximately $35 \mathrm{~m}$. Some uncertainty may enter the resultant measurements of volume backscattering strength due to coverage of the box-shaped volume assumed to be represented by each measurement varying with range and with the vessel's speed.

\subsubsection{Measurements of environmental properties}

Aggregations were considered in relation to various aspects of the physical and biological environment, including time of day, ice cover, vertical and horizontal current shear, food availability, and the occurrence of certain predators (whales, seals, and penguins).

Estimates of ice concentration at the location of each aggregation were made via linear interpolations to the location of each aggregation based on latitude and longitude of along-track ice observations made every six hours in fall and nominally every hour in winter (C. Fritsen, unpublished data; see US SO GLOBEC, 2001b and 2002b). Where available, these ice observations were supplemented by records made by bird observers whenever ice conditions changed during daytime survey periods (Ribic et al., submitted). 
Chlorophyll $a\left(\mathrm{mg} \mathrm{m}^{-2}\right)$ concentrations, measured from bottle samples at hydrographic stations and integrated vertically to a depth of $30 \mathrm{~m}$, were similarly interpolated to the location of each aggregation and used as an index of food availability (M. Vernet, unpublished data; see U.S. SO GLOBEC, 2001a and 2002a).

Measurements of current velocity were made with a $150 \mathrm{kHz}$ Acoustic Doppler Current Profiler (ADCP) in 8-m depth bins from a depth of $31 \mathrm{~m}$ to a maximum of 300 or $350 \mathrm{~m}$, and averaged in 1-hour along-track intervals (Klinck et al., 2004). Assuming an isotropic flow field, the magnitude of horizontal shear was estimated from the East-West and North-South velocity components ( $u$ and $v$, respectively) measured nearest to a given aggregation (position $i$ ) and the previous set of measurements (position $i-1$ ), and the distance between the two locations ( $\Delta s$ ) following (Figure 5.2):

$$
\left|\frac{\partial \vec{u}}{\partial s}\right|=\sqrt{\left(\frac{u_{i, j}-u_{i-1, j}}{\Delta s}\right)^{2}+\left(\frac{v_{i, j}-v_{i-1, j}}{\Delta s}\right)^{2}}
$$

These calculations were done for the 8-m depth bin $(j)$ nearest to each aggregation, and so give an estimate of horizontal shear at the aggregation's depth. Vertical shear was similarly calculated based on the East-West and North-South velocity components measured at depths $j$ and $j+1$ separated by the vertical resolution $(\Delta z)$ of $8 \mathrm{~m}$ following (Figure 5.2):

$$
\left|\frac{\partial \vec{u}}{\partial z}\right|=\sqrt{\left(\frac{u_{i, j+1}-u_{i, j}}{\Delta z}\right)^{2}+\left(\frac{v_{i, j+1}-v_{i, j}}{\Delta z}\right)^{2}}
$$

Vertical shear was estimated in this way from the current measurements made nearest to the aggregation (position $i$ ), and averaged over as many depth bins $(j$ ) as were available within the depth range occupied by the aggregation (i.e., over the vertical scale of the aggregation). Strong noise associated with ice-breaking led to many fewer reliable ADCP 

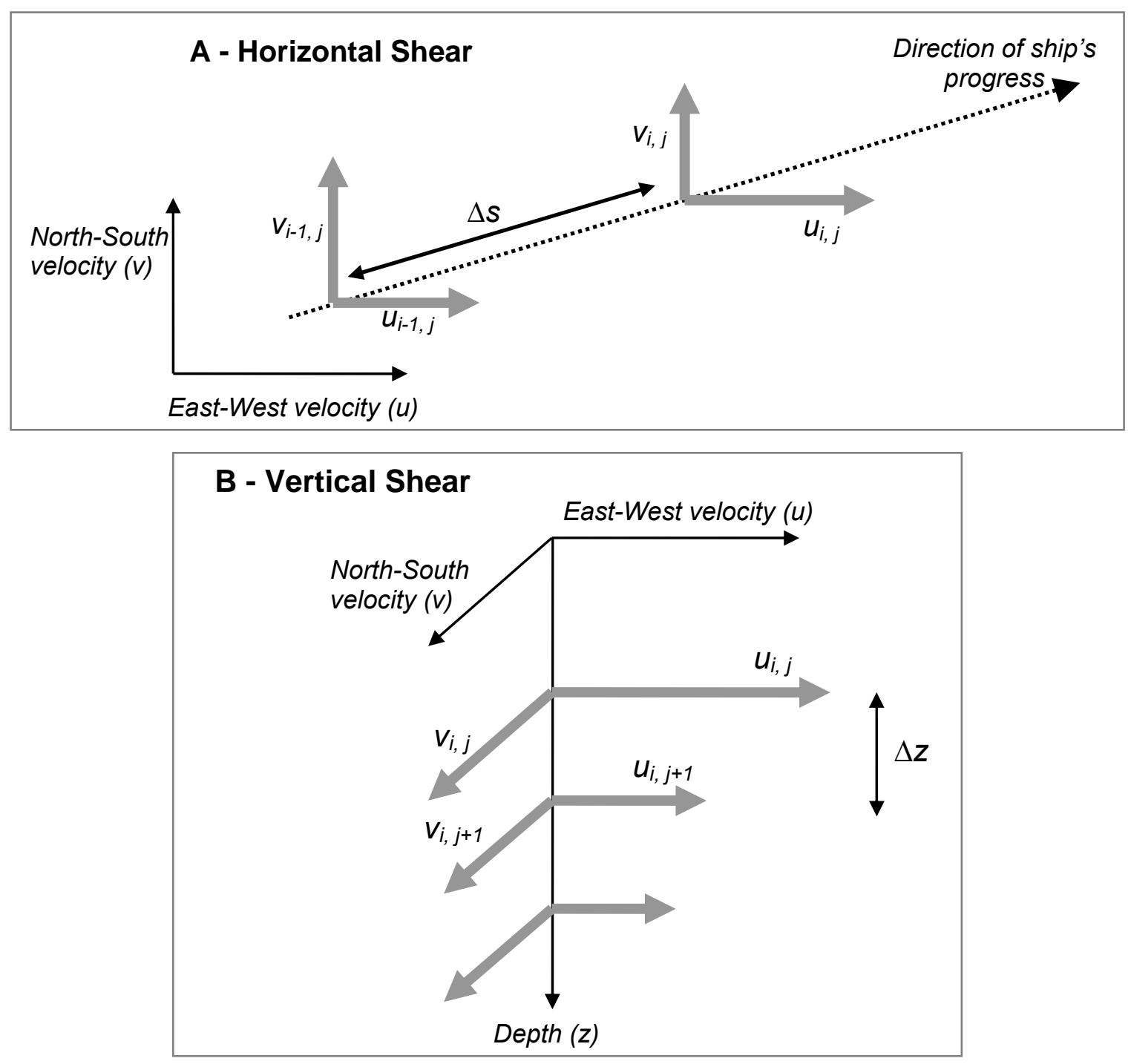

Figure 5.2 - Schematic illustration of ADCP current measurements (large grey arrows) used in estimating horizontal and vertical shear. Measurements of the East-West and North-South velocity components made at along-track position $i$ and depth $j$ are designated as $u_{i j}$ and $v_{i j}$, respectively. Equations for shear given in text. (A) Measurements used in estimating horizontal shear. Shown is a plan view of the East-West $(u)$ and North-South $(v)$ velocity components measured at successive positions $i$ and $i-1$ (the position of measurements made nearest to a given aggregation, and the previous set of measurements, respectively), separated by an along-track distance of $\Delta s$, corresponding to the distance traveled by the vessel during the 1 hour between measurements. Estimates of horizontal shear were calculated at depth $j$ corresponding to the depth of the centroid a given krill aggregation. (B) Measurements used in estimating vertical shear. The calculations used measurements of the East-West and North-South velocity components made at the horizontal position nearest to each krill aggregation $(i)$, at successive depths $j$ and $j+1$ separated by a vertical distance $(\Delta \mathrm{z})$ of $8 \mathrm{~m}$. 
measurements in winter, and so currents and shear were not examined during that season for either year.

During most daylight hours when the vessel was in transit, visual surveys for whales, seals, and penguins were conducted concurrent to acoustic surveying. Surveys were conducted by trained observers following standard strip-transect protocols (full methodological details are found in Chapman et al., (2004) and Ribic et al., (submitted) for birds and seals, and Thiele et al. (2004) and Friedlaender et al. (in press) for whales). Rather than calculate along-track estimates of density for these patchily-distributed predators, we chose simply to examine whether each type of predator was present or absent. Presence was defined as at least one individual observed within a range of $10 \mathrm{~km}$ of a given krill aggregation, where the aggregation had to have been observed during a period of predator surveying. Other ranges were considered, but for much smaller ranges, too few aggregations were associated with predators to allow meaningful comparisons. At larger ranges, similar patterns were evident to those described below, but it becomes increasingly less certain whether predators at large distances were in fact influencing given aggregations. Predator categories were whales, including minke (Balaenoptera acutorostrata) and humpback (Megaptera novaeangliae); crabeater seals (Lobodon carcinophagus); and penguins, including mostly Adelie penguins (Pygoscelis adeliae) and rarely Emperor penguins (Aptenodytes forsteri).

\subsubsection{Statistical analyses}

\subsection{6.a Diel vertical migration}

Following the recommendations of Godlewska (1996), diel changes in the vertical position of krill aggregations were assessed via the mean depth of the center of aggregation biomass, averaging over all aggregations observed in each survey in 2-hour time intervals over the 24 hour cycle. The center of biomass $(H)$ in each interval was calculated by weighting each aggregation's depth by its total biomass index in taking the 
averages. On the basis of visual examination of the data, a 24 hour period $(T)$ was assumed, and a sinusoidal model of biomass vertical distribution fit to the observed data, employing the function proposed by Godlewska and Klusek (1987):

$$
H(t)=A+B \cos (2 \pi(t+\phi) / T)
$$

This equation describes the situation where the mean center of biomass varies sinusoidally in time $(t)$ about some mean depth $A$ with amplitude $B$ and a phase shift in hours of $\varnothing$, where $\varnothing=0$ is the case where depth is shallowest at exactly midnight. The various parameters were estimated from observations of center of biomass depths from each survey via nonlinear least-squares regression. The reduction in residual deviance relative to the null model $H(t)=A$ was used to assess model fit.

\subsubsection{Analysis of individual aggregations}

In addition to the analyses described above, which considered collectively all aggregations identified acoustically within each survey, certain individual aggregations of very large size encountered during the fall surveys were selected for more detailed study. Unlike the acoustic analyses described above where inversions for weighted mean krill length and density were performed on volume backscattering coefficients averaged over all acoustic elements in each aggregation, for these case-study aggregations, the measured volume backscattering coefficients at the four frequencies were used to estimate length and numerical density for each element. This allowed an examination of whether and how length and density varied within the aggregations.

\subsection{RESULTS}

Between 531 and 8303 krill aggregations were observed in each survey (see Table 4.2 in Chapter 4). A large number of these aggregations (78-86\%) were the minimum size detectable by the system (i.e., one acoustic element $1.5 \mathrm{~m}$ high by $\sim 35 \mathrm{~m}$ along-track). As 
described in Chapter 4, it is less certain that these small aggregations were composed of krill. For the purposes here of inferring behavior from acoustic observations of aggregation structure, knowing with certainty that the aggregations were indeed composed of krill is highly important, and so the analyses that follow examined only those aggregations larger than the minimum detectable size. Limited analyses that will not be reported were also performed on the dataset including all aggregations, however, with results highly comparable to those that follow.

The size distribution of aggregations in all survey periods was dominated by small sizes as assessed by either aggregation length or height, with decreasing numbers of aggregations at larger sizes (Figures 5.3 and 5.4). Very large aggregations (height $>100$ $\mathrm{m}$, length $>1 \mathrm{~km}$ ) were absent in the winter of 2001, but otherwise, the distributions were highly comparable between survey periods. In both falls and the winter of 2001, the distributions of aggregation density (either by number or biomass of animals), were also dominated by low densities, with long tails extending towards higher values (Figures 5.5 and 5.6). During the winter of 2002, in contrast, in addition to the mode at small values, the distribution showed a second mode at higher densities (Figures 5.5 and 5.6). Within each survey, aggregation density assessed by the number of animals and by biomass showed similar distributions (Figures 5.5 and 5.6). Although numerical density is perhaps the more relevant quantity to the behavioral investigations that follow, biomass density is much less subject to error associated with the estimates of krill length used in calculating target strength (see Chapter 4). This is particularly relevant in making comparisons between the fall and winter survey periods, due to a single length being assumed to apply to all aggregations during winter. All subsequent analyses therefore examined biomass density only.

By plotting the number of aggregations larger than a given size relative to aggregation size, it is possible to assess whether the distribution of sizes is fractal (i.e., scaleinvariant), or more specifically, self-similar. A linear relationship when the distribution is plotted in this way with both axes scaled logarithmically is diagnostic of self-similarity 

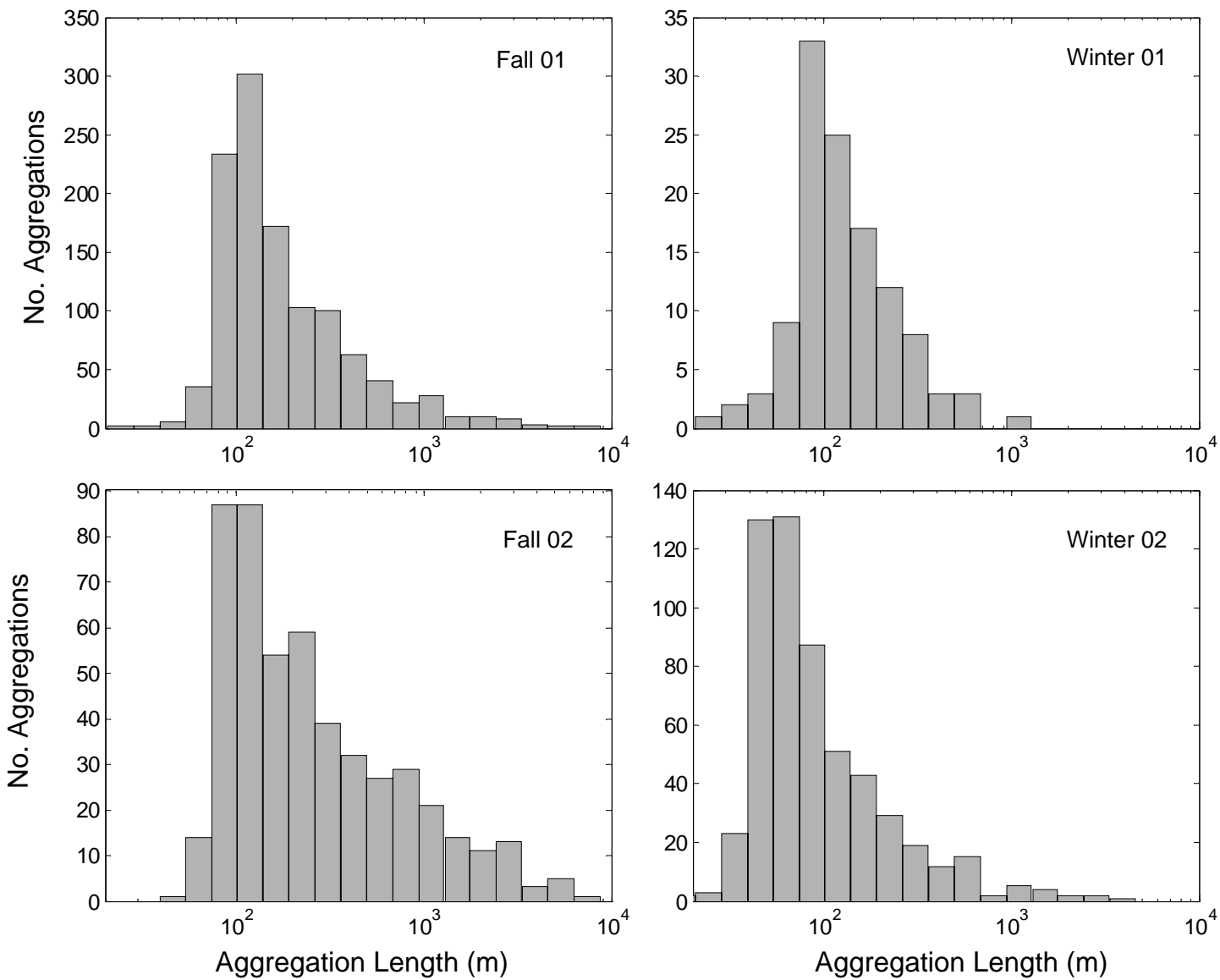

Figure 5.3 - Distribution of aggregation lengths (m, log-scale) observed during each survey. 

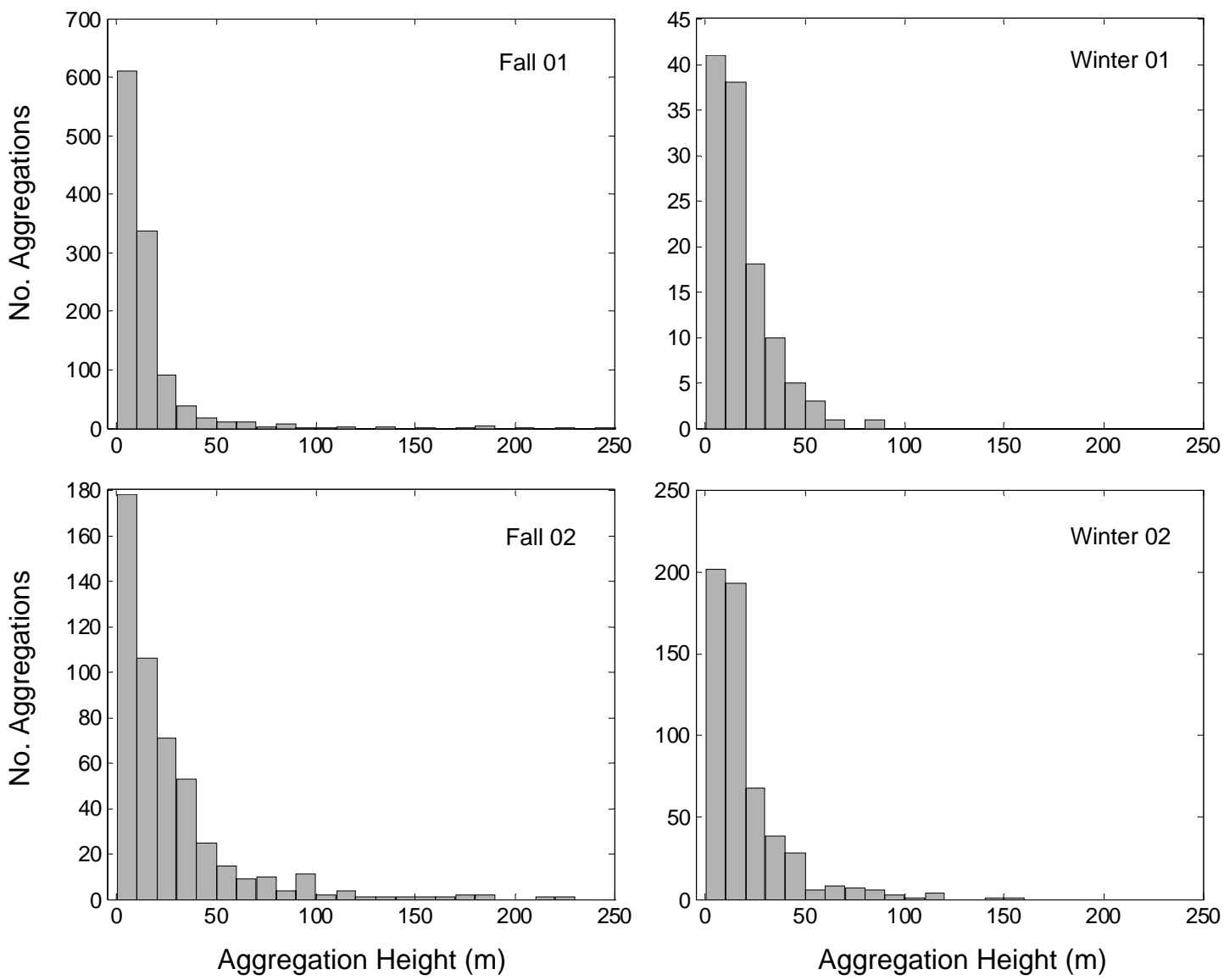

Figure 5.4 - Distribution of aggregation heights (m) observed during each survey. 

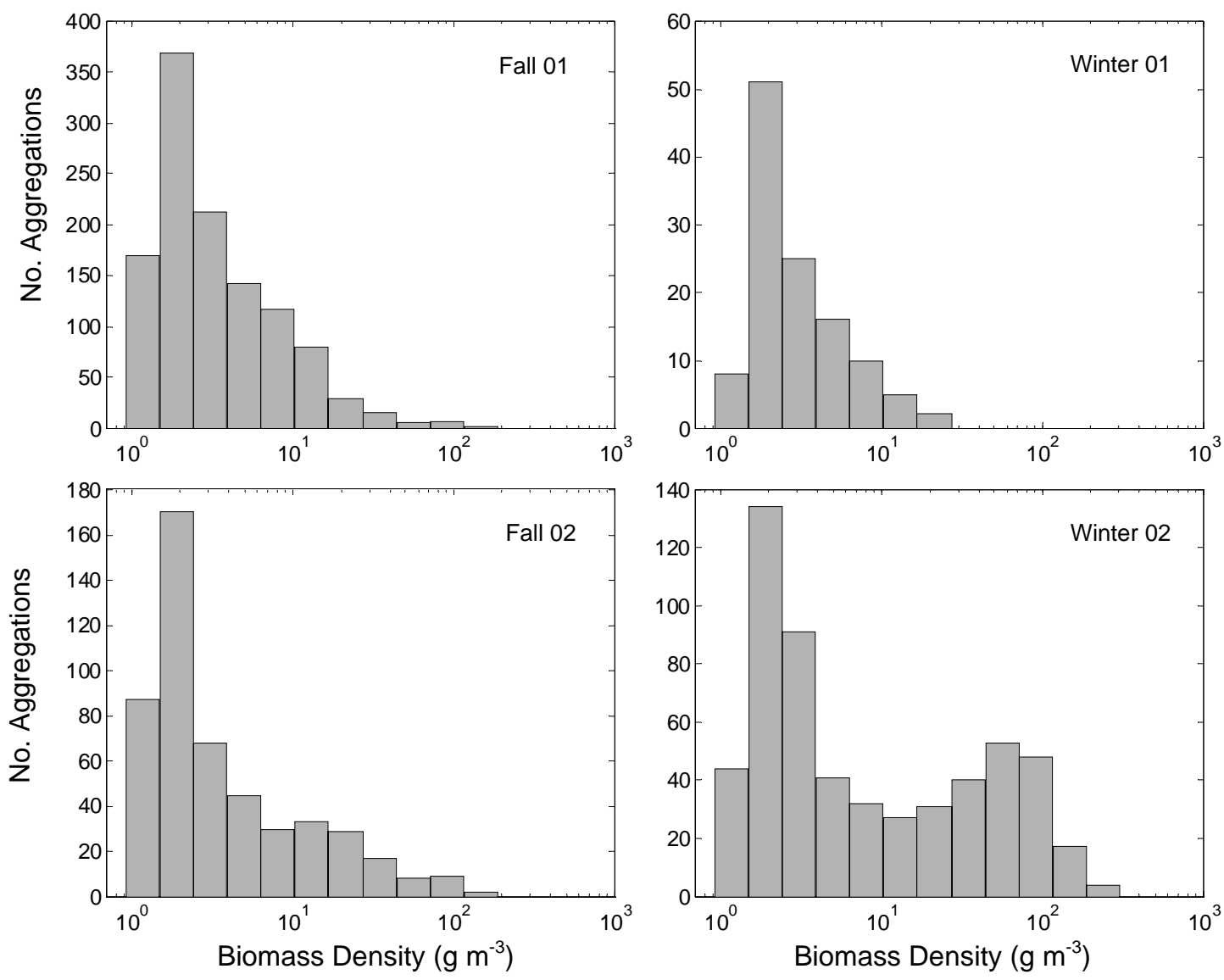

Figure 5.5 - Distribution of aggregation mean density of biomass $\left(\mathrm{g} \mathrm{m}^{-3}, \log\right.$-scale $)$ observed during each survey. 

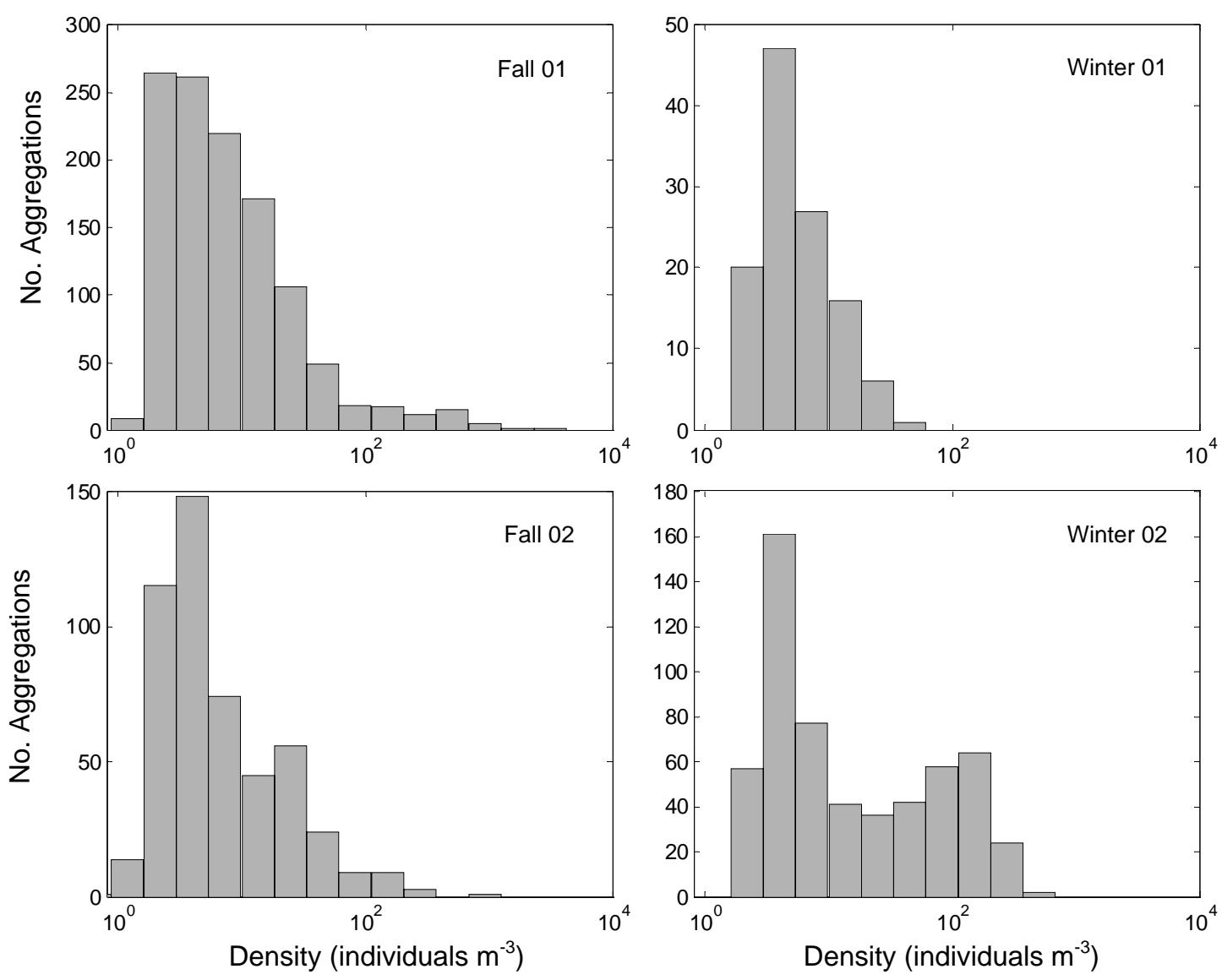

Figure 5.6 - Distribution of aggregation density by numbers of animals (individuals $\mathrm{m}^{-3}$, log-scale) observed during each survey. 
(Hastings and Sugihara, 1993). Plotting the distributions of aggregation lengths in such a fashion suggested that at lengths larger than $100 \mathrm{~m}$, the relationship was indeed linear, with slopes of -1.23 to -1.93 (regression analysis results indicated $r^{2}$ values of 0.90 to 0.99; Figure 5.7). The distribution observed during the fall of 2002 appeared somewhat more curvilinear than the other surveys, especially at larger aggregation lengths. This is perhaps due to a real change in the distribution of aggregations at large sizes during that time period, or to under-sampling of these larger aggregations. The slight flattening of the relationship at aggregation lengths smaller than $100 \mathrm{~m}$ (i.e., for the smallest length bin shown in Figure 5.7) is due to the varying limit to measurable aggregation length set by the horizontal resolution of the acoustic system. This limit varies with the speed of the vessel, and very small lengths of aggregations could only be detected infrequently, when the vessel was moving at slow speeds; as such, only small numbers of aggregations were observed at these small lengths. The distributions of aggregation height, in contrast, were more curvilinear (Figure 5.7), indicating that these distributions were not scale-invariant.

\subsubsection{Diel patterns}

Some evidence of diel vertical migrations was observed in all four survey periods, with aggregations tending to be found deeper in the water column during the day and shallower by night (Figure 5.8). Nonlinear regression fits of the sinusoidal model given by Equation 5.1 to observed mean depth of the center of aggregation biomass supported the existence of diel changes in vertical position with a 24 hour periodicity (Table 5.1). In the winter of 2001, when very few aggregations were observed, the least indication of any migration was evident. The $95 \%$ confidence interval did not exclude the possibility of no diel variation, although the deepest aggregations were observed during the day (Figure 5.8). In the fall of 2001, the evidence was also somewhat ambiguous, as a large number of aggregations were present at shallow depths during the day (Figure 5.8); because these were of small total biomass indices, however, they had only a slight impact on the center of mass-based analysis, which did suggest a significant diel trend (Table $5.1)$. 


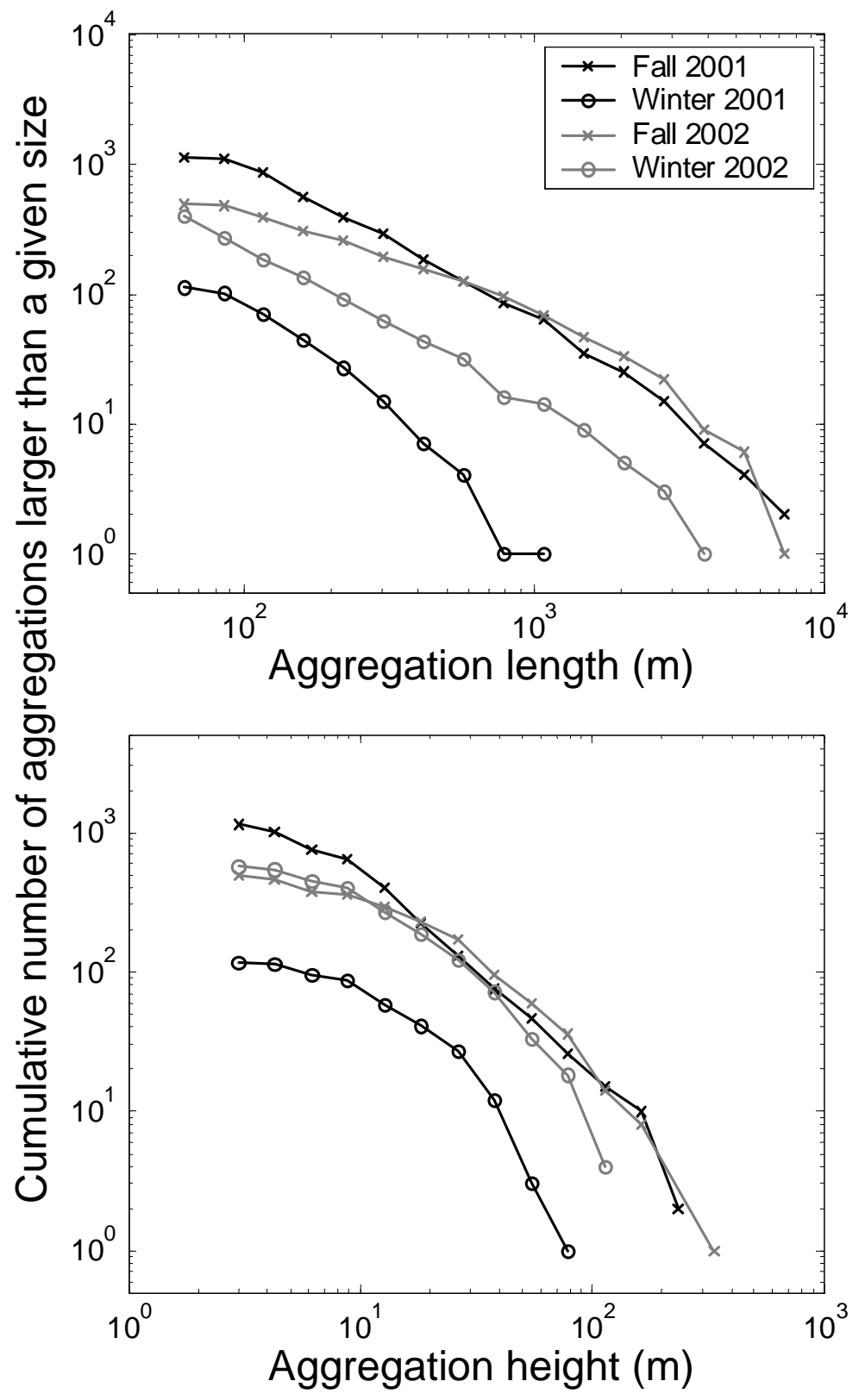

Figure 5.7 - Distributions of the cumulative number of aggregations larger than a given length or height, plotted on a log-log scale relative to aggregation length (top plot) and height (bottom plot). Linearity in such plots is indicative of a self-similar, or fractal, distribution. 
Table 5.1 - Results of nonlinear regression fits of the sinusoidal model given by Equation 1 to observed mean depth of the center of aggregation biomass averaged in 2hour intervals, $H(t)$, for each survey period. Parameters estimated by these fits include the mean depth of the center of krill aggregation biomass $(A)$, and the amplitude $(B)$ and phase $(\varnothing)$ of krill diel vertical migration. Negative amplitudes indicate that the sinusoidal function starts at shallower depths during the night (near 0 hours) and that biomass moves deeper during the day. 95\% confidence intervals about each parameter estimates indicated in parentheses. Deviance explained was calculated by comparing residual deviance in the sinusoidal model relative to the null model $H(t)=A$. For the fall 2001 data, analyses were performed for all aggregations combined, for small and large krill separately, and for regions of high and low chlorophyll $a$ (chl-a) concentrations separately. In fall 2002, too few aggregations where small krill lengths were estimated were available, and so analyses were performed only for the all aggregations combined and regions of high versus low chlorophyll.

\begin{tabular}{|c|c|c|c|c|}
\hline Cruise & $\begin{array}{c}\text { Mean depth of } \\
\text { center of } \\
\text { biomass (m) }\end{array}$ & $\begin{array}{c}\text { Amplitude of } \\
\text { DVM (m) }\end{array}$ & $\begin{array}{c}\text { Phase shift of } \\
\text { DVM } \\
\text { (hours) } \\
\end{array}$ & $\begin{array}{l}\text { Deviance } \\
\text { explained } \\
\end{array}$ \\
\hline \multicolumn{5}{|l|}{ Fall 2001} \\
\hline & (109.1 to 150.9 ) & $(-69.4$ to -10.3$)$ & $(-1.94$ to 3.73$)$ & $50.8 \%$ \\
\hline Small krill & 26.8 & -3.7 & 3.76 & \\
\hline$(<20 \mathrm{~mm})$ & (20.6 to 32.9 ) & $(-12.5$ to 5.0$)$ & $(-5.22$ to 12.75$)$ & $19.9 \%$ \\
\hline Large krill & 133.5 & -39.1 & 1.28 & \\
\hline$(>20 \mathrm{~mm})$ & (111.6 to 155.5 ) & $(-70.2$ to -8.0$)$ & $(-1.75$ to 4.32$)$ & $47.4 \%$ \\
\hline Low chl-a & 122.6 & -36.0 & -0.26 & \\
\hline$\left(<10 \mathrm{mg} \mathrm{m}^{-2}\right)$ & (89.5 to 155.8$)$ & $(-82.9$ to 10.9$)$ & $(-5.23$ to 4.71$)$ & $25.1 \%$ \\
\hline High chl-a & 33.1 & 6.6 & -5.45 & \\
\hline$\left(>10 \mathrm{mg} \mathrm{m}^{-2}\right)$ & (28.8 to 37.5 ) & (0.2 to 12.9$)$ & $(-8.92$ to -1.98$)$ & $41.3 \%$ \\
\hline \multicolumn{5}{|l|}{ Winter 2001} \\
\hline Overall & $\begin{array}{c}71.9 \\
\text { (43.9 to } 100.0)\end{array}$ & $\begin{array}{c}-23.6 \\
(-63.3 \text { to } 16.1)\end{array}$ & $\begin{array}{c}0.42 \\
(-6.00 \text { to } 6.84)\end{array}$ & $16.8 \%$ \\
\hline \multicolumn{5}{|l|}{ Fall 2002} \\
\hline Overall & $\begin{array}{c}140.1 \\
\text { (119.5 to } 160.7)\end{array}$ & $\begin{array}{c}-60.9 \\
(-90.1 \text { to }-31.7)\end{array}$ & $\begin{array}{c}-0.88 \\
(-2.71 \text { to } 0.95)\end{array}$ & $71.3 \%$ \\
\hline $\begin{array}{l}\text { Low chl-a } \\
\left(<10 \mathrm{mg} \mathrm{m}^{-2}\right)\end{array}$ & $\begin{array}{c}124.2 \\
(84.3 \text { to } 164.0)\end{array}$ & $\begin{array}{c}-51.5 \\
(-106.6 \text { to }-3.6)\end{array}$ & $\begin{array}{c}-0.87 \\
(-5.14 \text { to } 3.40)\end{array}$ & $36.9 \%$ \\
\hline $\begin{array}{l}\text { High chl-a } \\
\left(>10 \mathrm{mg} \mathrm{m}^{-2}\right)\end{array}$ & $\begin{array}{c}80.5 \\
\text { (51.6 to } 109.4)\end{array}$ & $\begin{array}{c}-44.0 \\
(-85.5 \text { to }-2.6)\end{array}$ & $\begin{array}{c}1.45 \\
(-2.05 \text { to } 4.94)\end{array}$ & $43.1 \%$ \\
\hline \multicolumn{5}{|l|}{ Winter 2002} \\
\hline & $\begin{array}{c}119.3 \\
\text { (86.3 to } 152.3)\end{array}$ & $\begin{array}{c}-89.9 \\
(-136.5 \text { to }-43.3)\end{array}$ & $\begin{array}{c}-1.10 \\
(-3.08 \text { to } 0.88)\end{array}$ & $67.9 \%$ \\
\hline
\end{tabular}



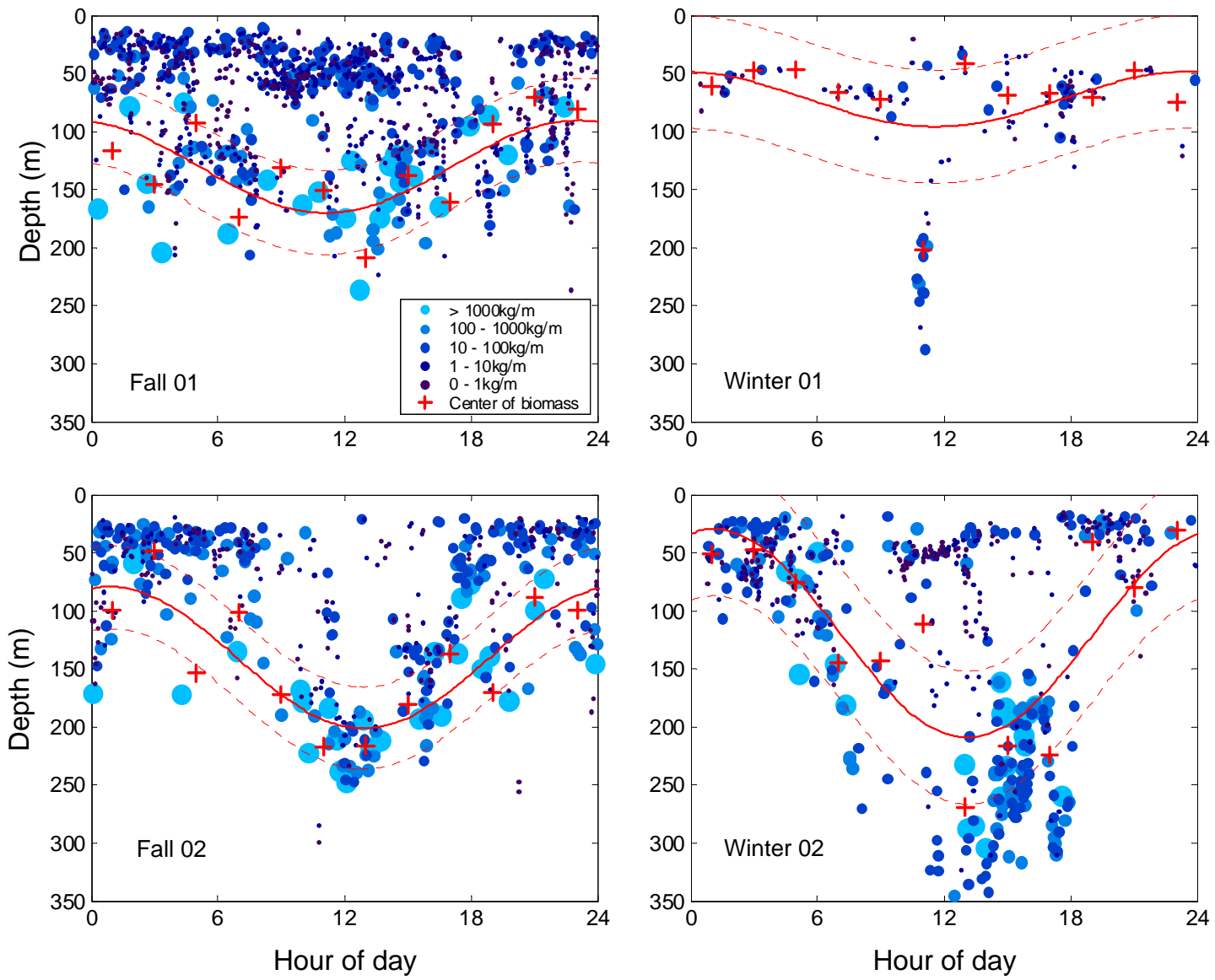

Figure 5.8 - Vertical distribution of krill aggregations. Blue dots indicate the depth of the centroid of each acoustically-identified aggregation; lighter blue and larger dot size indicates greater total biomass index $\left(\mathrm{kg} \mathrm{m}^{-1}\right)$. Red line shows the inferred diel vertical migration based on nonlinear regression fits of the sinusoidal model given by Equation 5.1 to observed mean depths of center of aggregation biomass, averaged in 2-hour intervals (shown as red + symbols). Dashed lines indicate $95 \%$ confidence interval. 
During both 2002 surveys the diel trends in the vertical positioning of aggregations were more clear (Figure 5.8). The cluster of aggregations observed during the winter of 2002 near $50 \mathrm{~m}$ in depth between 1100 and $1300 \mathrm{~h}$ that do not follow the expected deep-bynight trend were all observed on September 2, and had more of an appearance of a scattering layer than typical krill aggregations (Figure 5.9). No large krill were observed with the Video Plankton Recorder as the BIOMAPER-II repeatedly passed through the layer, suggesting that they may have been composed of small euphausiids. Since these aggregations were of low estimated total biomass index, they did not contribute substantially to calculations of mean depth of center of mass. These calculations revealed a strong diel trend in both seasons (Table 5.1). The deepest aggregations in the winter of 2002 were found deeper than in fall. There was also some indication that the migrations observed during the winter of 2002 were of larger amplitude, extending on average to similar daytime depths as in fall, but to shallower depths during night (Figure 5.8), although comparing the confidence intervals about these estimates of migratory amplitude suggests that this difference was not significant (Table 5.1).

Defining 'daytime' as the period between local daily sunrise and sunset, significant diel changes were also evident in aggregation biomass density (Figure 5.10). During all survey periods, the greatest densities were observed during the day, and distributions of densities shifted towards lower densities by night. The shift to greater densities during day was particularly dramatic in the winter of 2002; this explains the bimodal density distribution for this survey as a whole noted earlier.

No evidence of diel changes in the size of aggregations, as assessed by their height, length, or area, were evident (not shown). Height and length tended to increase with one another, but with a great deal of variability in this relationship, and no obvious differences between day and night (Figure 5.11). Biomass density showed no association with aggregation length or height (not shown). 


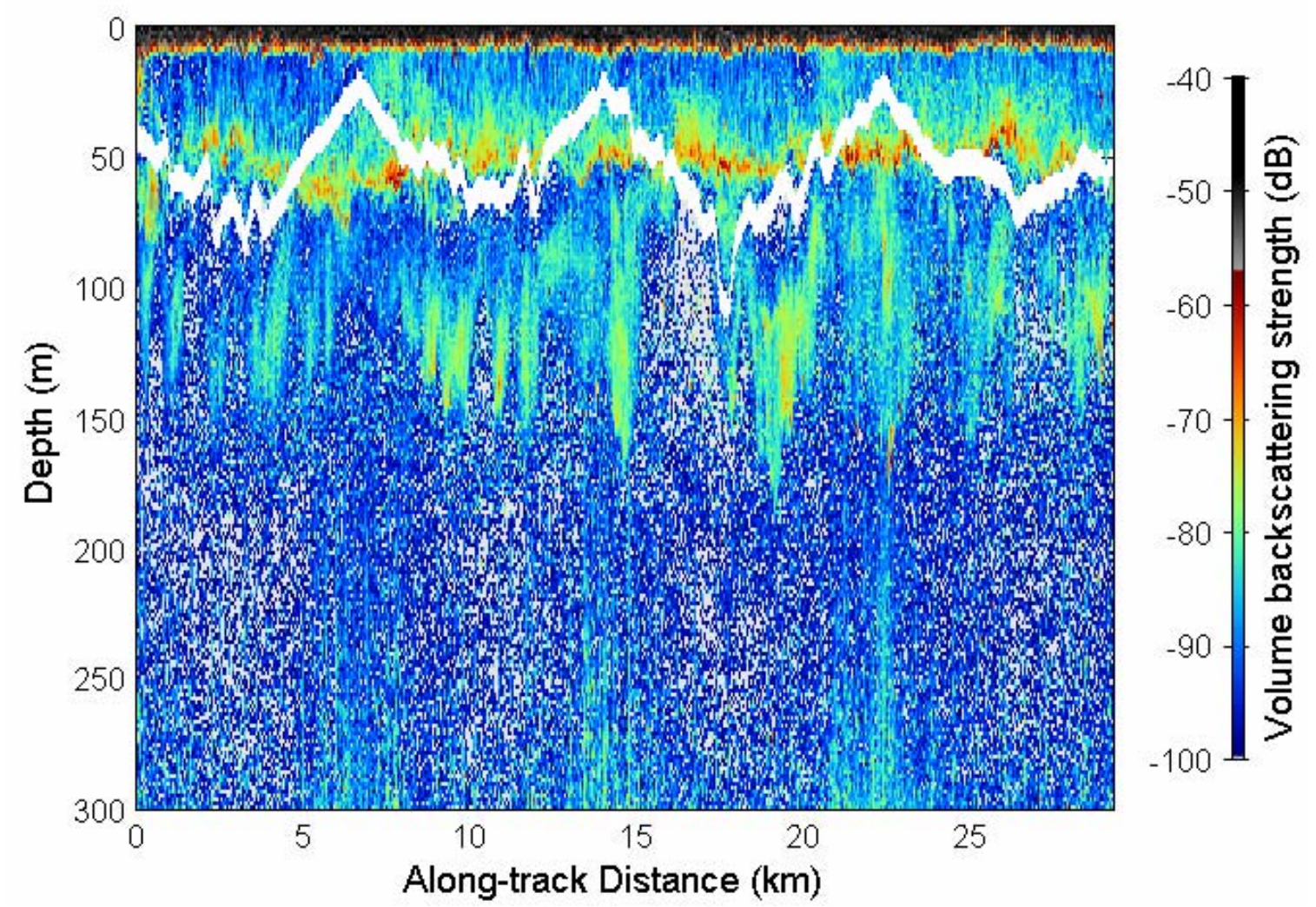

Figure 5.9 - Acoustic volume backscattering strength data $(120 \mathrm{kHz})$ observed in offshelf waters on September 2 of the 2002 winter. The cluster of aggregations during that survey observed at shallow depths $(\sim 50 \mathrm{~m})$ during the day, thereby providing exceptions to the pattern otherwise observed of aggregations being shallow by night and deep by day (see Figure 5.5), all were extracted from this portion of the survey grid. The shallow layer evident near a depth of $50 \mathrm{~m}$ intermittently exceeded the threshold defined here for what constitutes a separate 'aggregation,' resulting in a large number of aggregations (101) being extracted from this otherwise continuous feature. In the absence of net samples or sufficient multi-frequency acoustic data, it is not clear whether these putative aggregations are in fact krill. The deeper more discrete acoustic features did not exceed the $-70 \mathrm{~dB}$ threshold and so were not extracted as aggregations. 

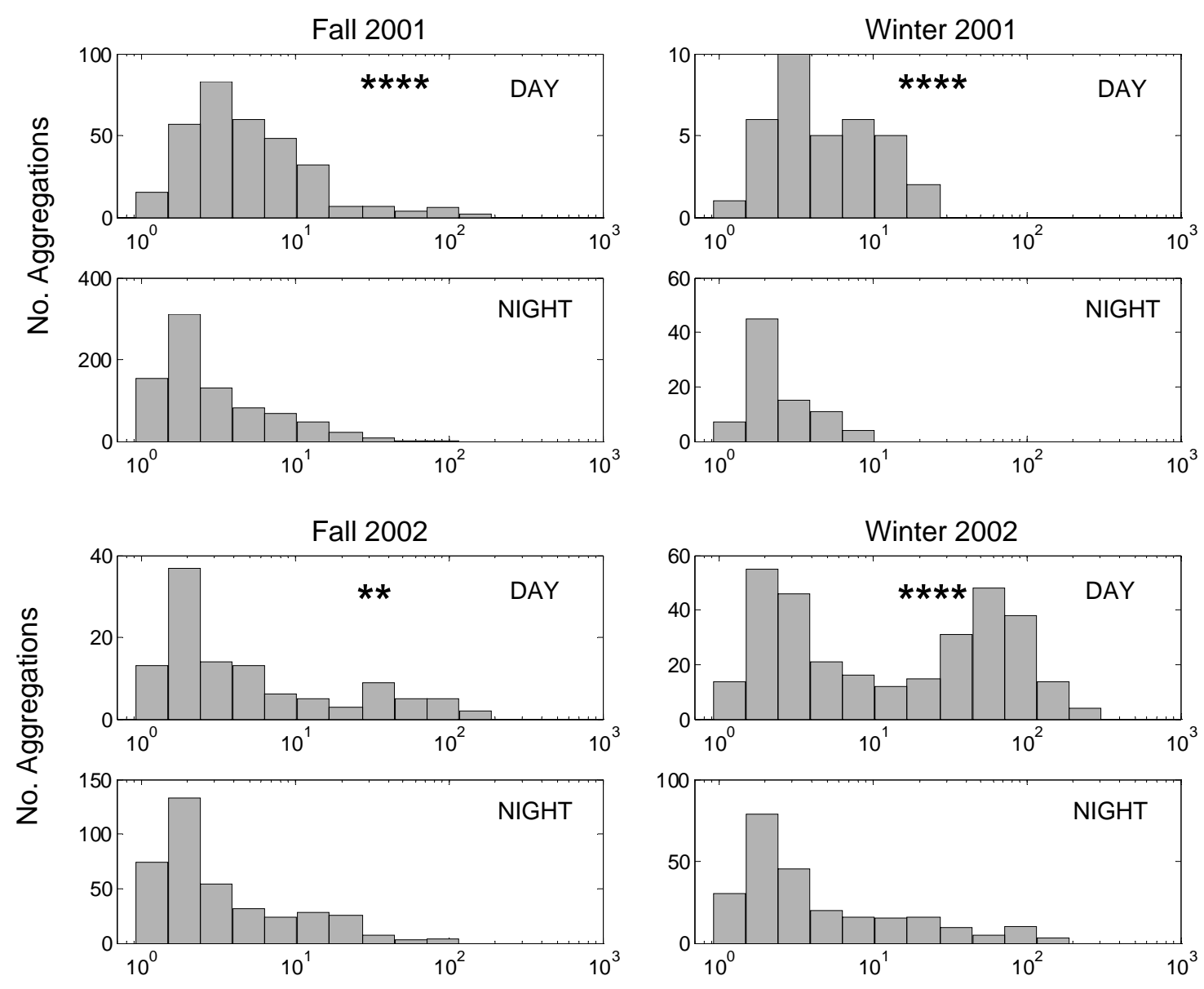

Biomass Density $\left(\mathrm{g} \mathrm{m}^{-3}\right)$
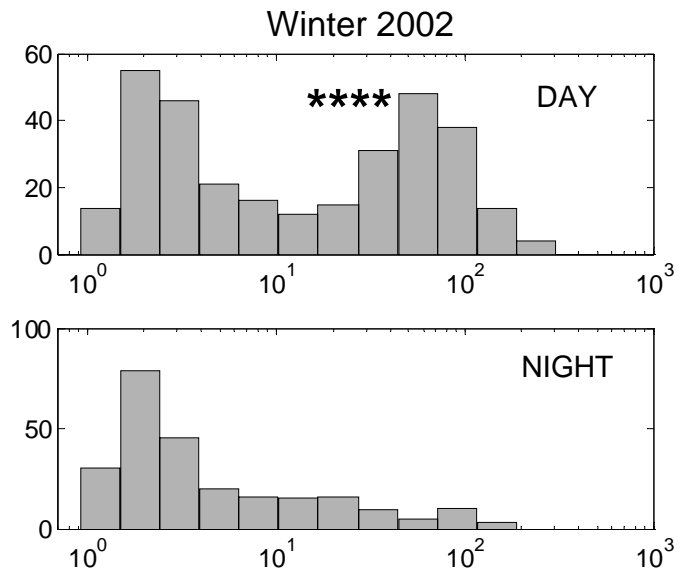

Biomass Density $\left(\mathrm{g} \mathrm{m}^{-3}\right)$

Figure 5.10 - Aggregation mean biomass density $\left(\mathrm{g} \mathrm{m}^{-3}\right.$; log scale) during the day and night for each survey period. The mode of smaller densities during daytime in the winter of 2002 mostly correspond to the large number of small aggregations observed on September 2, which may not have been composed of large krill (see Figure 5.9 and text). Asterisks indicate the results of a Mann-Whitney U-test comparing densities observed during day to those observed during night. This is a rank-based (i.e., non-parametric) test for comparing the distributions of two variables: $* * * *$ denotes $p<0.0001, * * p<0.01$. 

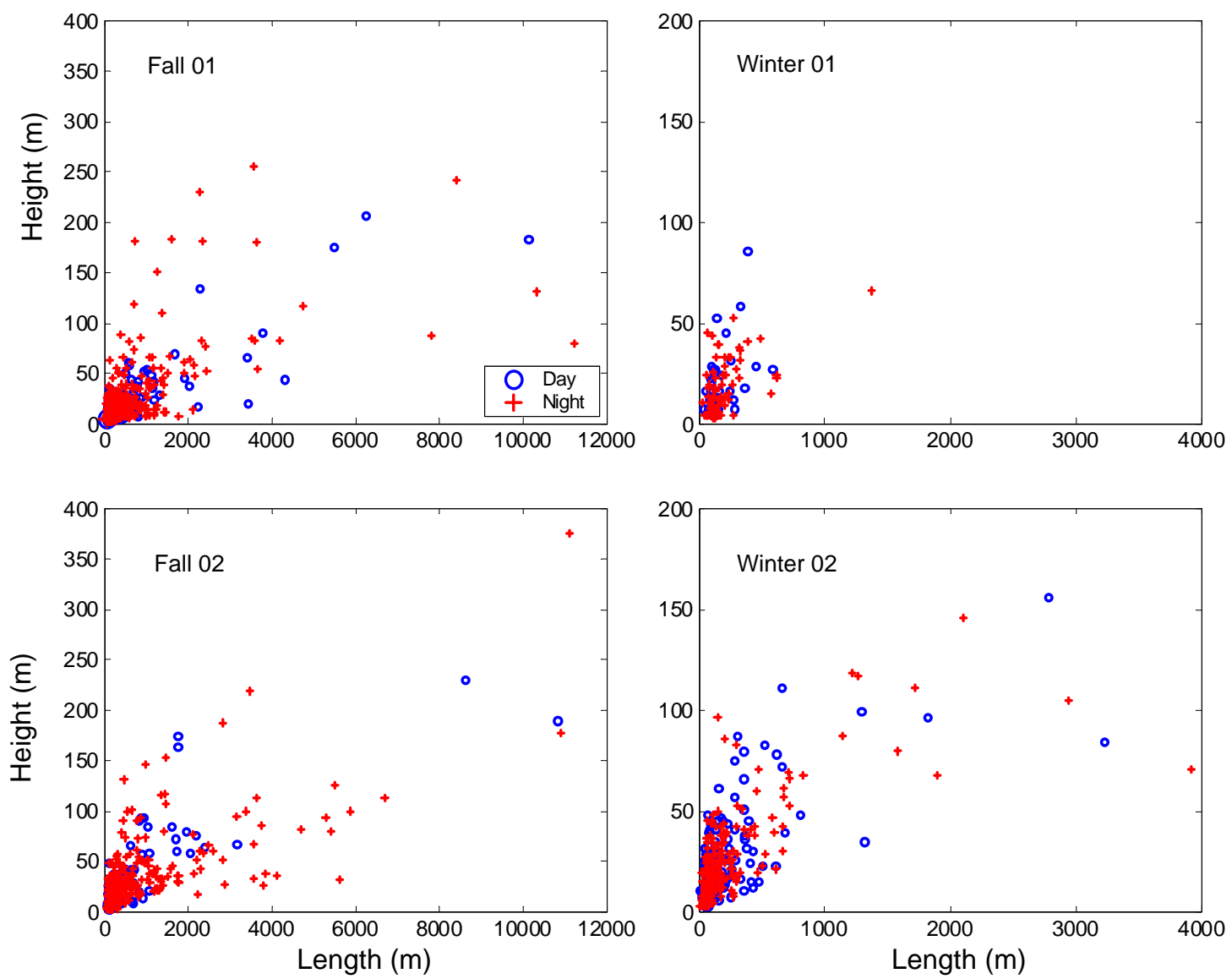

Figure 5.11 - Aggregation height $(\mathrm{m})$ in relation to length $(\mathrm{m})$, plotted for day and night separately. Note that the axes limits differ between the fall and winter plots. 


\subsubsection{Influence of krill length}

Acoustic estimates of the weighted mean length of krill in certain aggregations were available for the two surveys performed in fall. The few aggregations detected in the fall of 2001 where small $(<20 \mathrm{~mm})$ weighted mean lengths of member animals were estimated all were found at shallow depths ( $<80 \mathrm{~m}$; Figure 5.12), and showed little evidence of diel vertical migration (Figure 5.13; Table 5.1). No trend was evident in the vertical position of aggregations and weighted mean length for larger sizes (>20 $\mathrm{mm})$ during either fall (Figure 5.12). Similarly, no obvious relationships were evident between the height, length, or area of aggregations and estimated krill length, other than that in the fall of 2001 small dimensions were associated with small krill lengths (Figures 5.14 and $5.15)$.

\subsubsection{Environmental influences}

\subsection{3.a Aggregation depth}

In examining the influence of environmental properties on aggregation depth, it is important to account for the diel variability described in the section 5.3.1. This was done here by examining the day- and night-time depth of aggregations separately.

During the night in the fall surveys, when aggregations would be expected to be in the shallow feeding phase of the typical vertical migration, aggregations in regions of higher chlorophyll $a$ ( $>10 \mathrm{mg} \mathrm{m}^{-2}$ ) were mostly found at relatively shallow depths $(<100 \mathrm{~m}$; Figure 5.16). In regions of lower chl- $a$, however, aggregations during night were found at both shallow and deep depths. Examining all hours of day, there was also some indication of reduced vertical migrations in regions of higher chlorophyll, particularly during the fall of 2001 (Figure 5.17; Table 5.1). In winter, chlorophyll was always low $\left(<3 \mathrm{mg} \mathrm{m}^{-2}\right)$ and will not be considered further. 

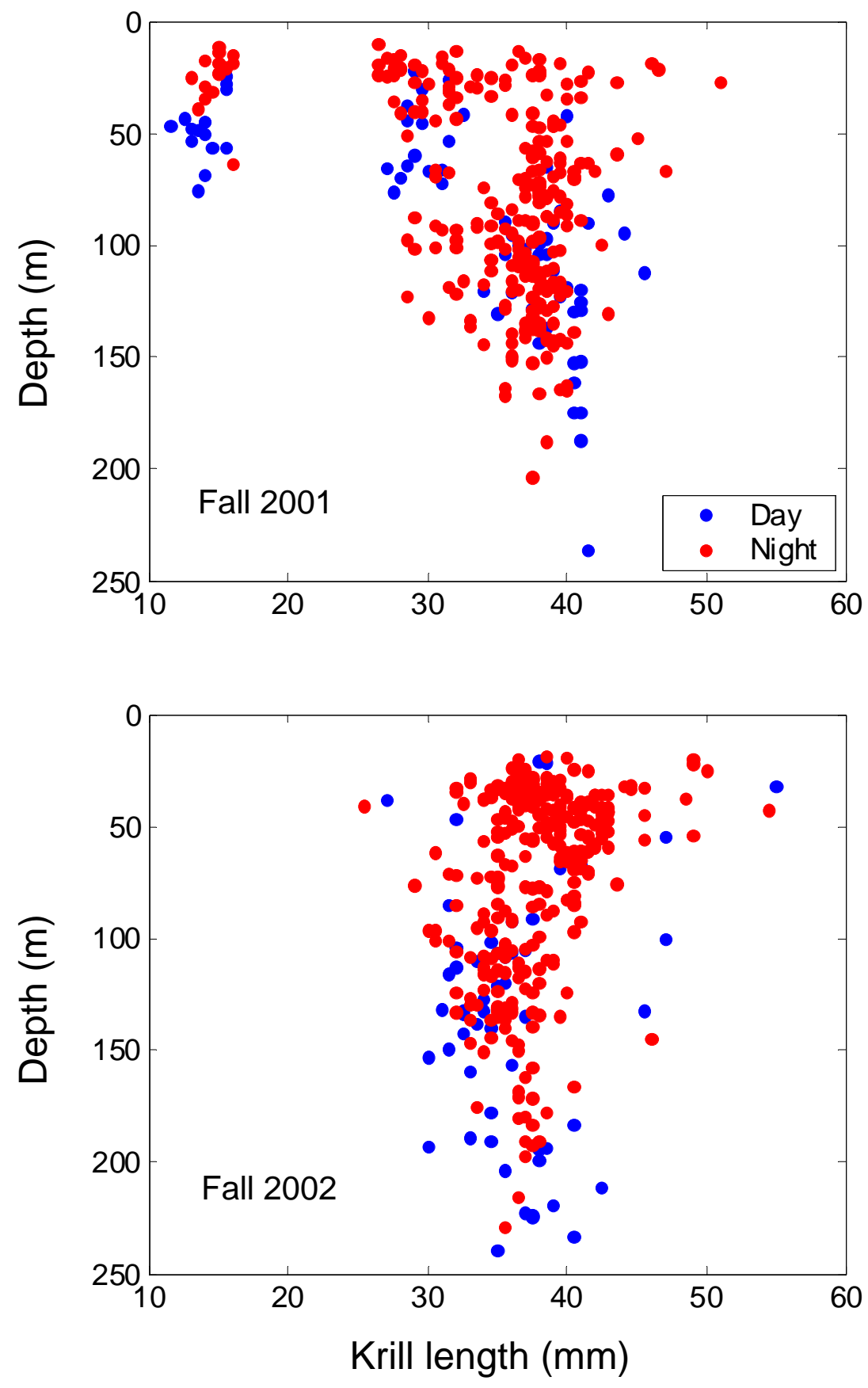

Figure 5.12 - Aggregation depth $(\mathrm{m})$ in relation to estimated weighted mean length of krill (mm). Due to malfunctions of the acoustic system, length could only be estimated during the fall surveys. 


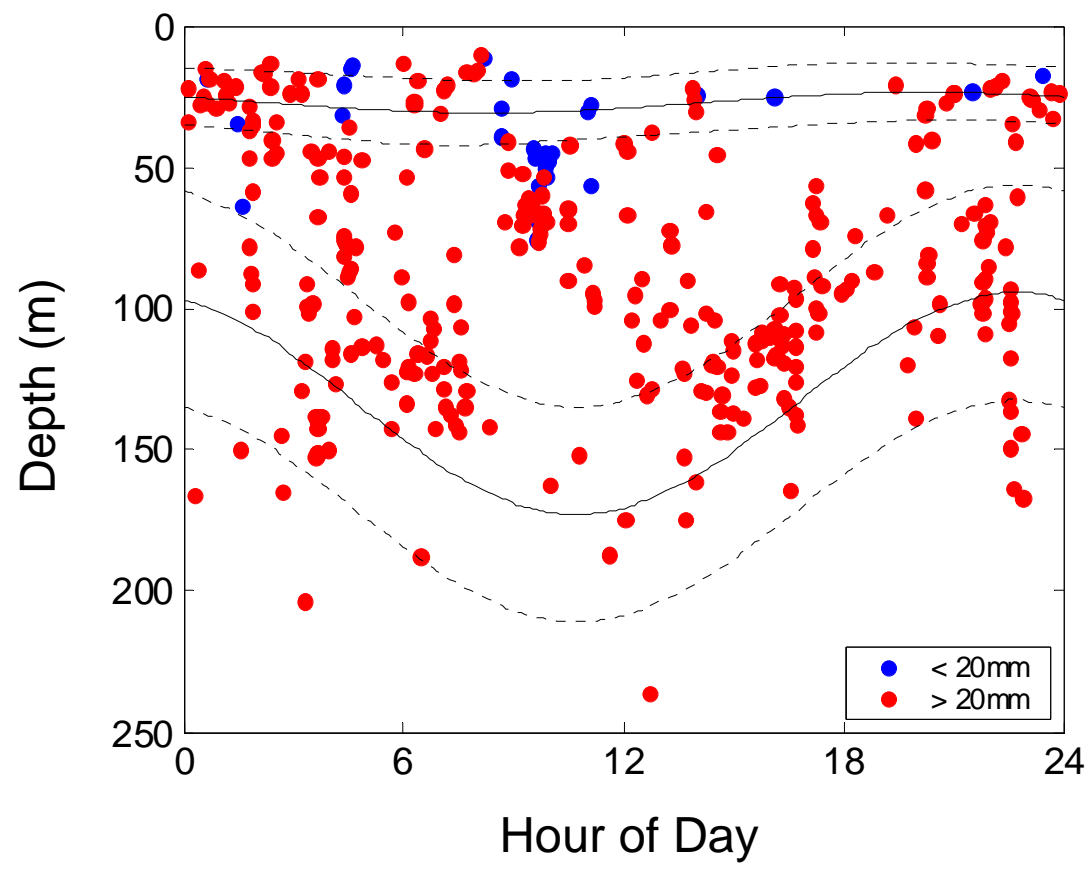

Figure 5.13 - Aggregation depth $(\mathrm{m})$ in relation to time of day, for small $(<20 \mathrm{~mm})$ and large (> $20 \mathrm{~mm}$ ) krill observed in fall 2001. Black lines shows inferred diel vertical migration for each size class based on nonlinear regression fits of the sinusoidal model given by Equation 5.1 to observed mean depths of center of aggregation biomass, averaged in 2-hour intervals. Dashed lines indicate 95\% confidence interval. 

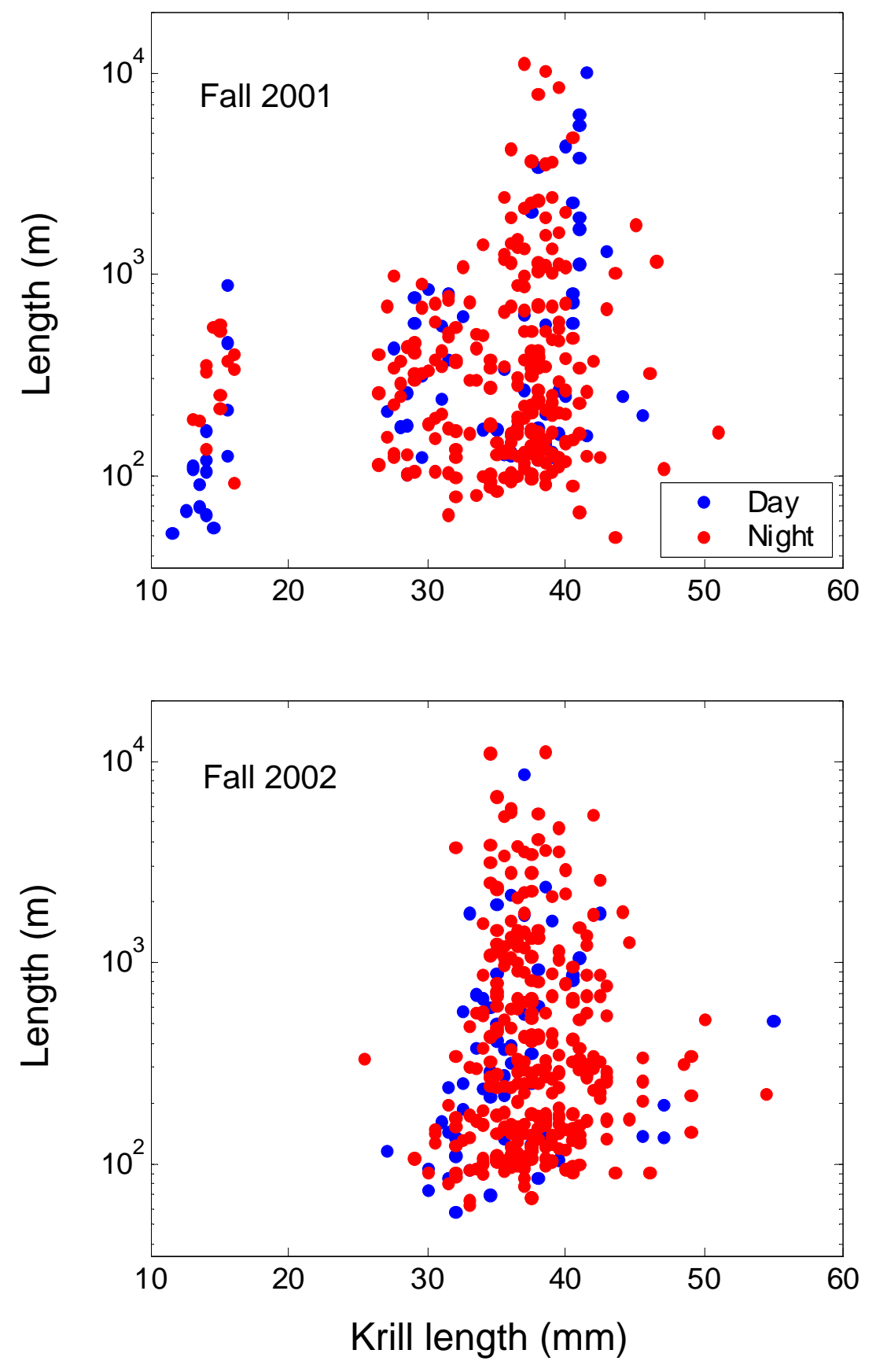

Figure 5.14 - Aggregation length ( $\mathrm{m}$; log-scale) in relation to estimated weighted mean krill length $(\mathrm{mm})$. 

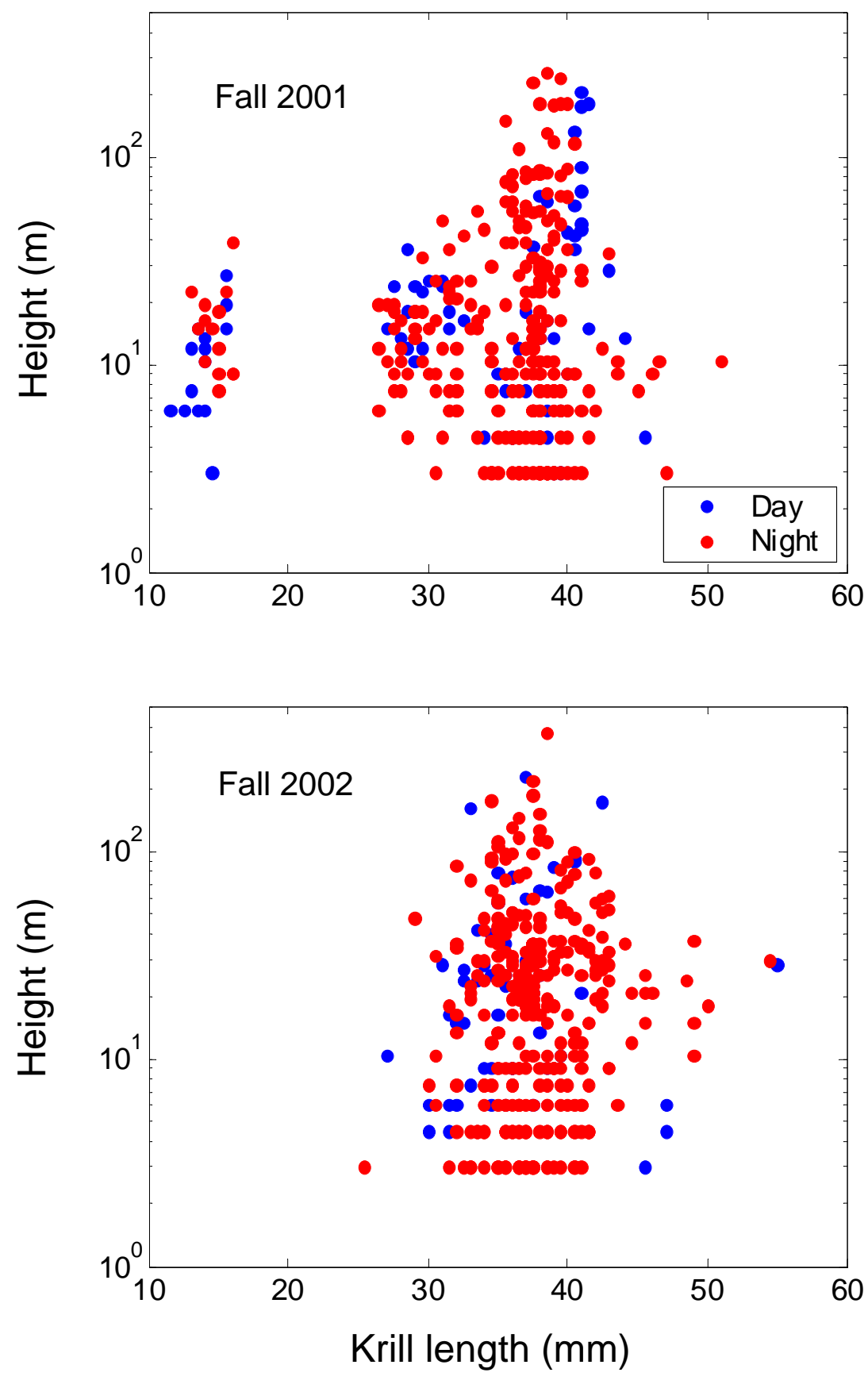

Figure 5.15 - Aggregation height $(\mathrm{m})$ in relation to estimated weighted mean krill length $(\mathrm{mm})$. 

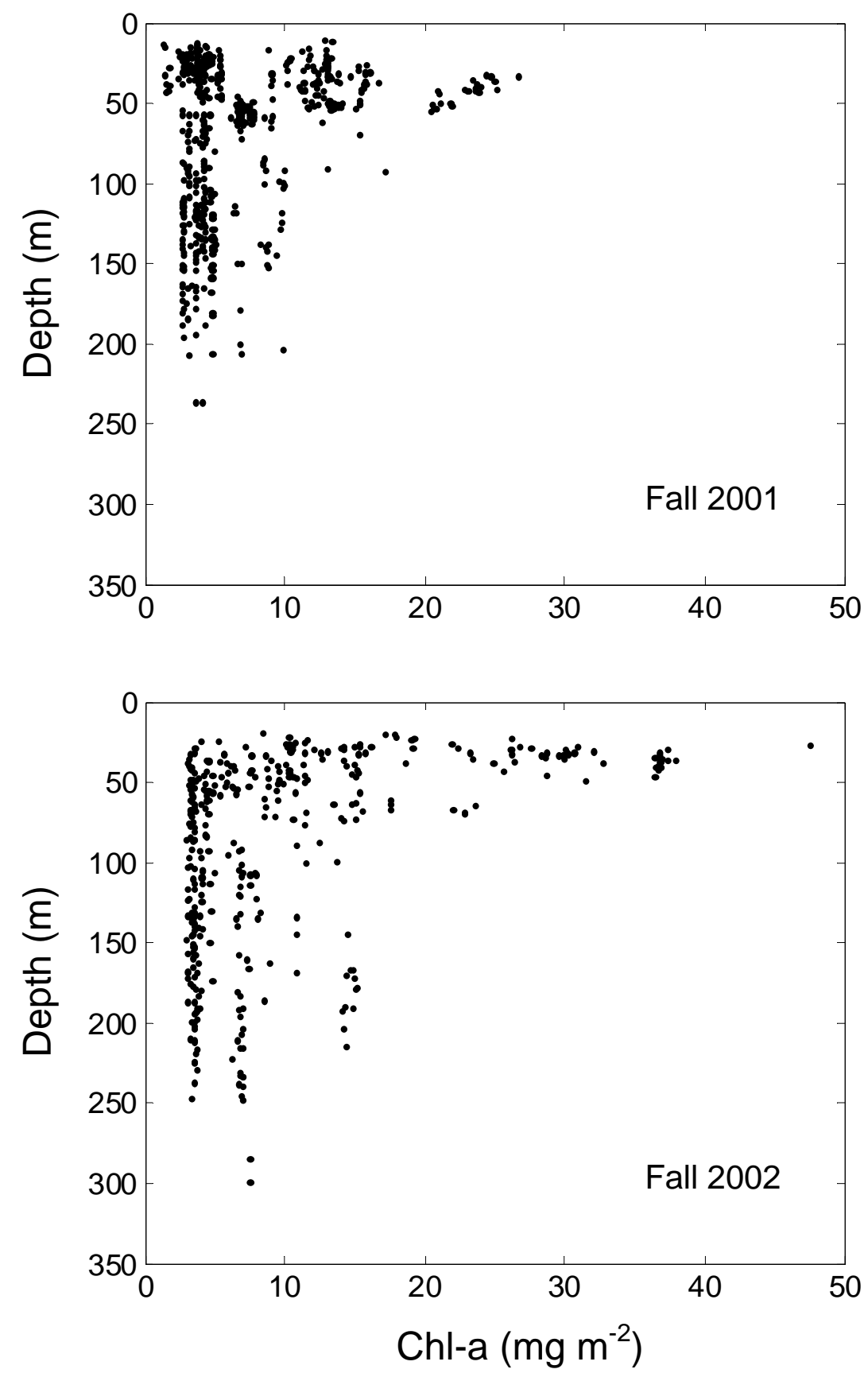

Figure 5.16 - Depths (m) of aggregations observed during the night in relation to cholorphyll $a$ concentrations integrated from the surface to a depth of $\left.30 \mathrm{~m}_{(\mathrm{mg} \mathrm{m}}^{-2}\right)$. 

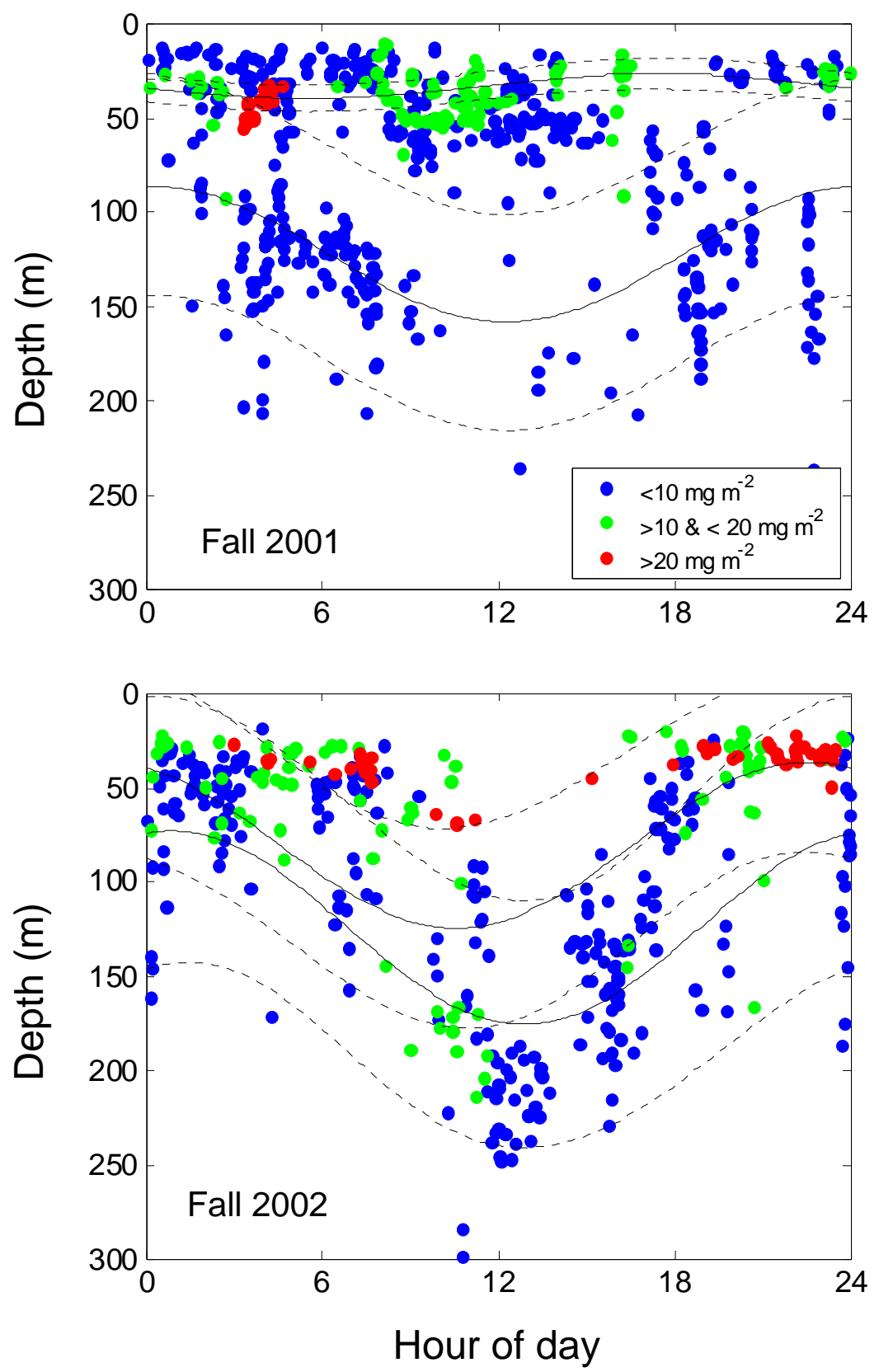

Figure 5.17 - Diel patterns in aggregation depth in regions of high $\left(>20 \mathrm{mg} \mathrm{m}^{-2}\right)$, medium $\left(>10\right.$ and $\left.<20 \mathrm{mg} \mathrm{m}^{-2}\right)$, and low $\left(<10 \mathrm{mg} \mathrm{m}^{-2}\right)$ chlorophyll concentrations. Black lines shows inferred diel vertical migration for chl-a $>10 \mathrm{mg} \mathrm{m}^{-2}$ (shallow lines) and $<10 \mathrm{mg} \mathrm{m}^{-2}$ (deeper lines), based on nonlinear regression fits of the sinusoidal model given by Equation 5.1 to observed mean depths of center of aggregation biomass, averaged in 2-hour intervals (Table 5.1). Dashed lines indicate 95\% confidence interval. 
In examining the influence of ice cover, only the 2002 surveys were considered, since in the fall of 2001 virtually no sea ice was present during acoustic surveying, and in the winter of 2001 only very few aggregations were observed. During the fall of 2002, no influence of ice cover on aggregation depth was evident (Figure 5.18). In winter of that year, aggregations observed during the day in regions of high ice cover ( $>8$ tenths) occupied a range of depths that included both shallow and deep depths, while in more ice-free regions, daytime aggregations were found only deeper in the water column. The cluster of aggregations evident in figure 5.18 near $50 \mathrm{~m}$ in depth and ice concentrations of 5-8 tenths that obscure this trend again correspond to the atypical scattering observed on September 2 (Figure 5.9). Night-time depths in the winter of 2002 also tended to be shallower in regions of greater ice cover. These patterns in the association of aggregations with ice concentration are somewhat compromised by variable survey effort in areas of high versus low ice cover. During the winter survey in particular, only $16 \%$ of acoustically-surveyed waters were covered by less than eight tenths of ice. Low survey effort and low numbers of aggregations observed in regions of low ice cover thus may limit inferences that can be made for the winter. During fall of 2002, 34\% of acousticallysurveyed waters were covered by eight tenths or more ice, perhaps lending more confidence to comparisons of ice-covered and ice-free waters.

No relationship was evident between aggregation depth and current shear, for the two fall surveys when ADCP current data were available (not shown).

\subsection{3.b Aggregation biomass density}

Chlorophyll $a$ concentration and ice cover were also associated with aggregation biomass density. Maximal densities during fall occurred in regions of lowest chl- $a$ (Figure 5.19). Ice cover had little obvious association with biomass density in the fall of 2002, although the greatest densities were observed in regions of high ice cover ( $>8$ tenths; Figure 5.20). In the winter of 2002, the most dense aggregations during both day and night were found in association with the highest ice cover (Figure 5.20). 

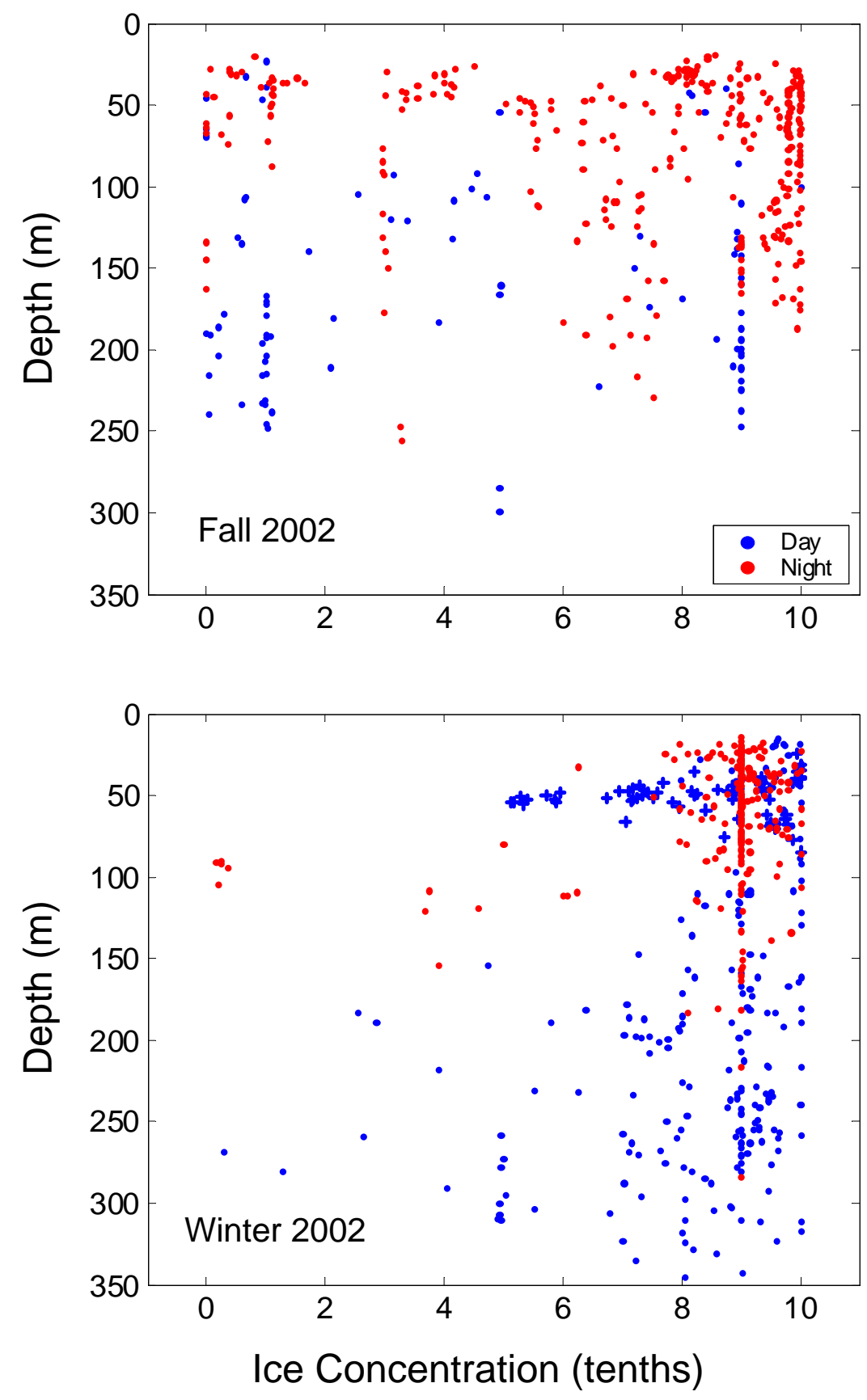

Figure 5.18 - Aggregation depth (m) in relation to ice concentration. Blue dots indicate aggregations observed during the day, red indicates night. For the winter 2002 survey, blue + symbols denote aggregations observed on September 2 that did not have the typical appearance of krill aggregations (see Figure 5.6). 

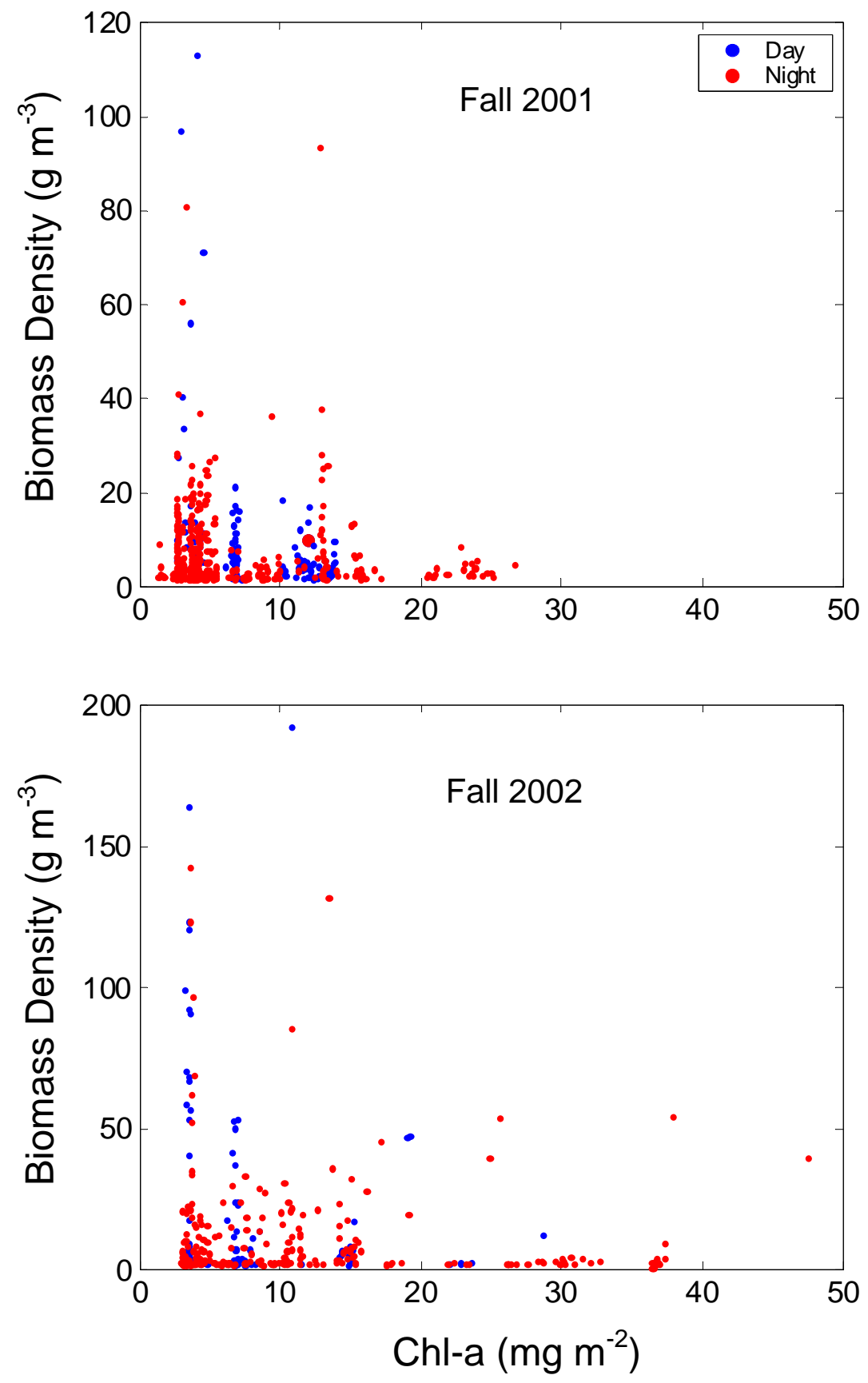

Figure 5.19 - Aggregation biomass density $\left(\mathrm{g} \mathrm{m}^{-3}\right)$ in relation to chlorophyll $a$ concentration. Blue dots indicate aggregations observed during the day, red indicates night. 

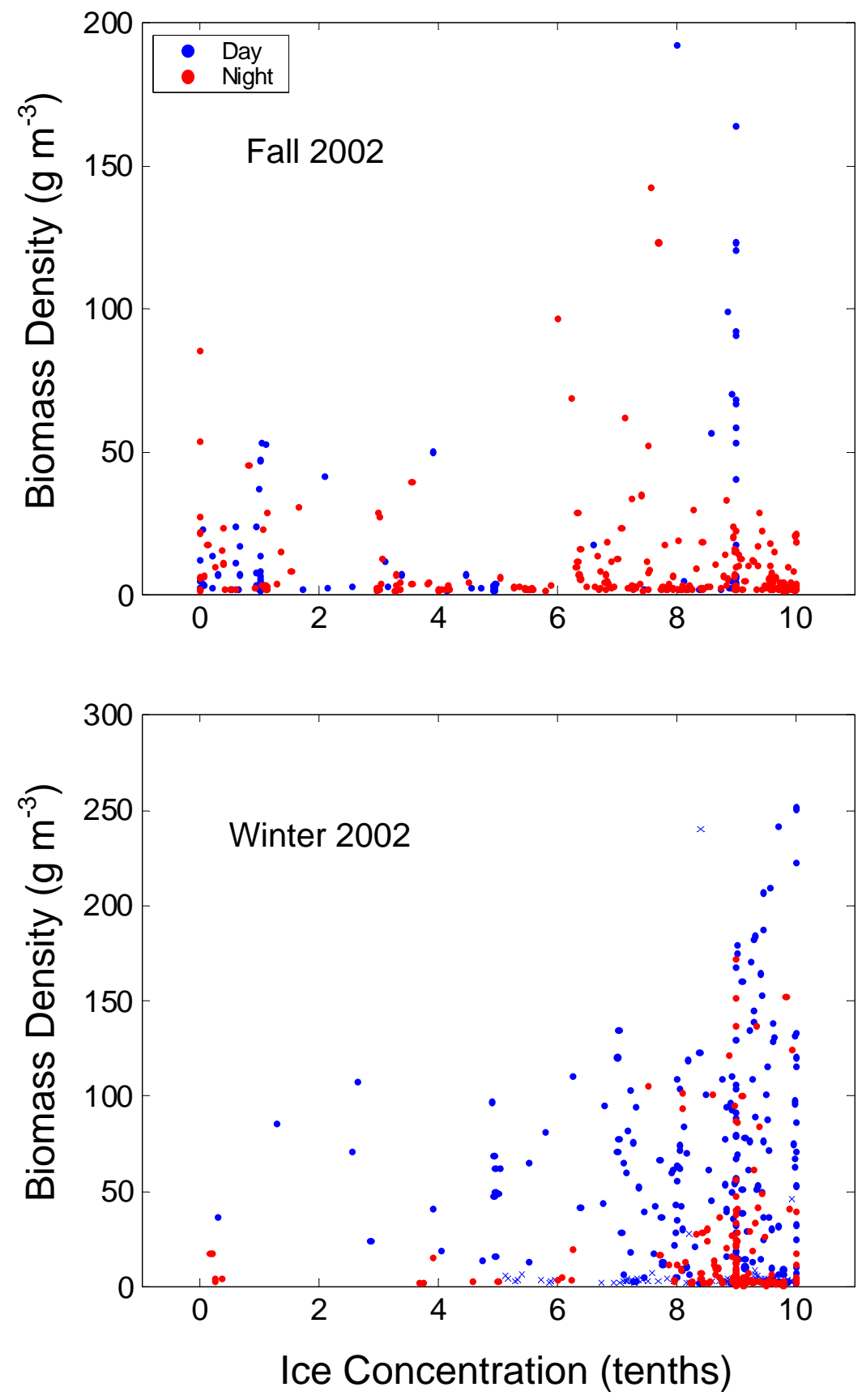

Figure 5.20 - Aggregation biomass density $\left(\mathrm{g} \mathrm{m}^{-3}\right)$ in relation to ice concentration (tenths). Blue dots indicate aggregations observed during the day, red indicates night. 


\subsection{3.c Aggregation size}

Aggregation size was assessed via total length and height. Area was also examined but showed comparable trends, and so is not reported. Aggregation length showed little variation with the depth occupied by the aggregation, while height showed an increase (Figure 5.21). In fall, aggregations were of largest extent in regions of lowest chlorophyll concentrations (Figure 5.22). No pattern in size variation with ice concentration was evident (not shown).

During fall when current data were available, the largest aggregations in terms of both length and height were associated with regions of the smallest estimated horizontal shear (Figure 5.23). The association of aggregation height and length with vertical shear was less clear and suggested that maximal aggregation size was associated with mid-ranges of vertical shear (Figure 5.24). Numerous small aggregations were also present in low-shear regions, but only small aggregations were present in regions of high shear.

\subsubsection{Influence of predators}

Krill aggregations observed during time periods of concurrent predator surveying were examined for differences between cases where predators were present or absent. Predator surveys were only conducted during daylight hours, and so the influence of the presence or absence of predators could only be examined for aggregation characteristics during daytime; the potentially confounding effect of diel variability therefore does not need to be taken into account.

Aggregation depth showed little consistent association with the presence of whales, although low numbers of whales observed and thereby low numbers of aggregations found associated with whales make firm interpretations difficult: in the winter of 2001 and fall of 2002, only two aggregations were found in association with whales (Figure 5.25a). Many seals were observed, however, in association with krill aggregations; in 

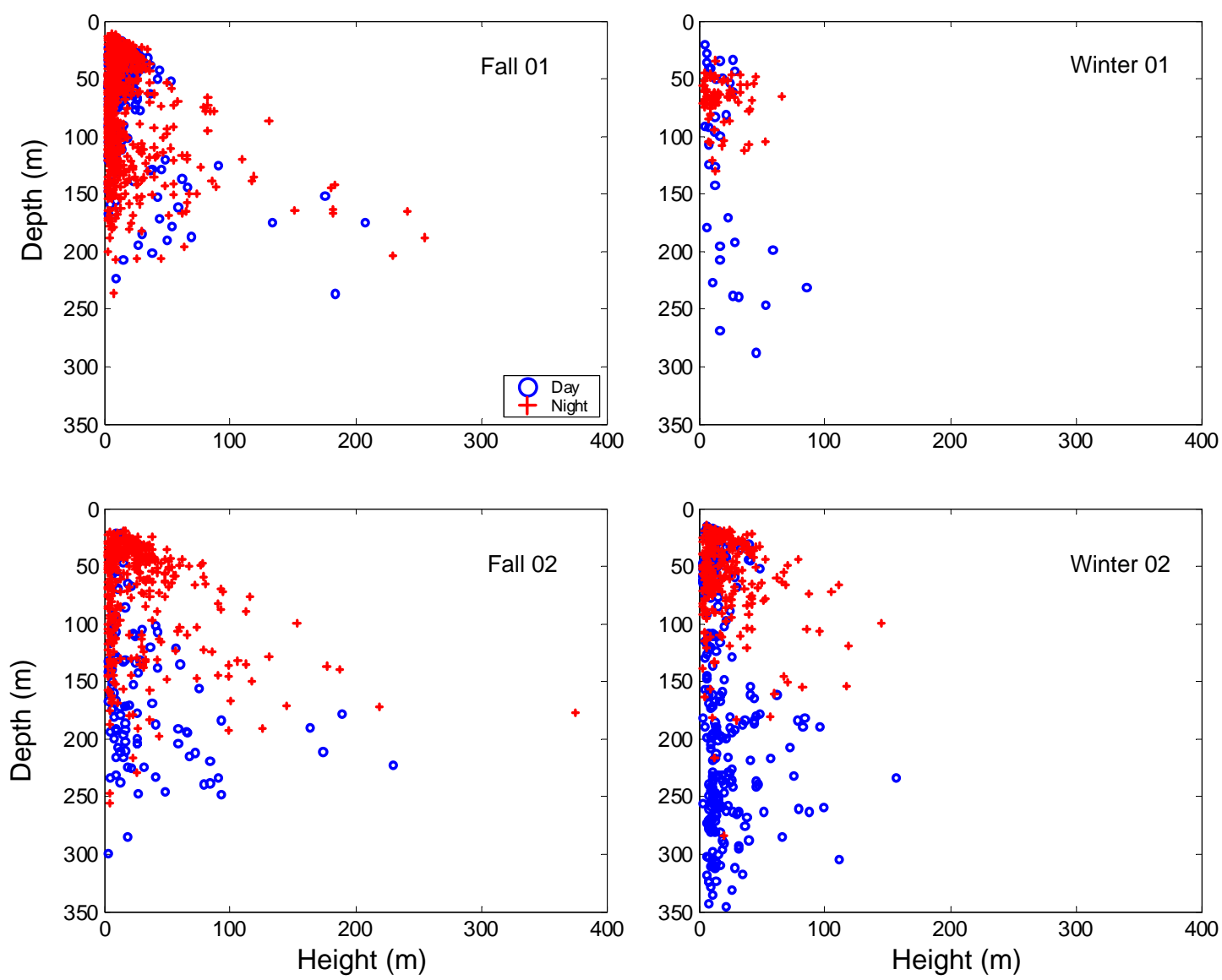

Figure 5.21 - Aggregation height vs. aggregation depth (m). Blue circles indicate aggregations observed during daytime, red + symbols indicate nighttime aggregations. 

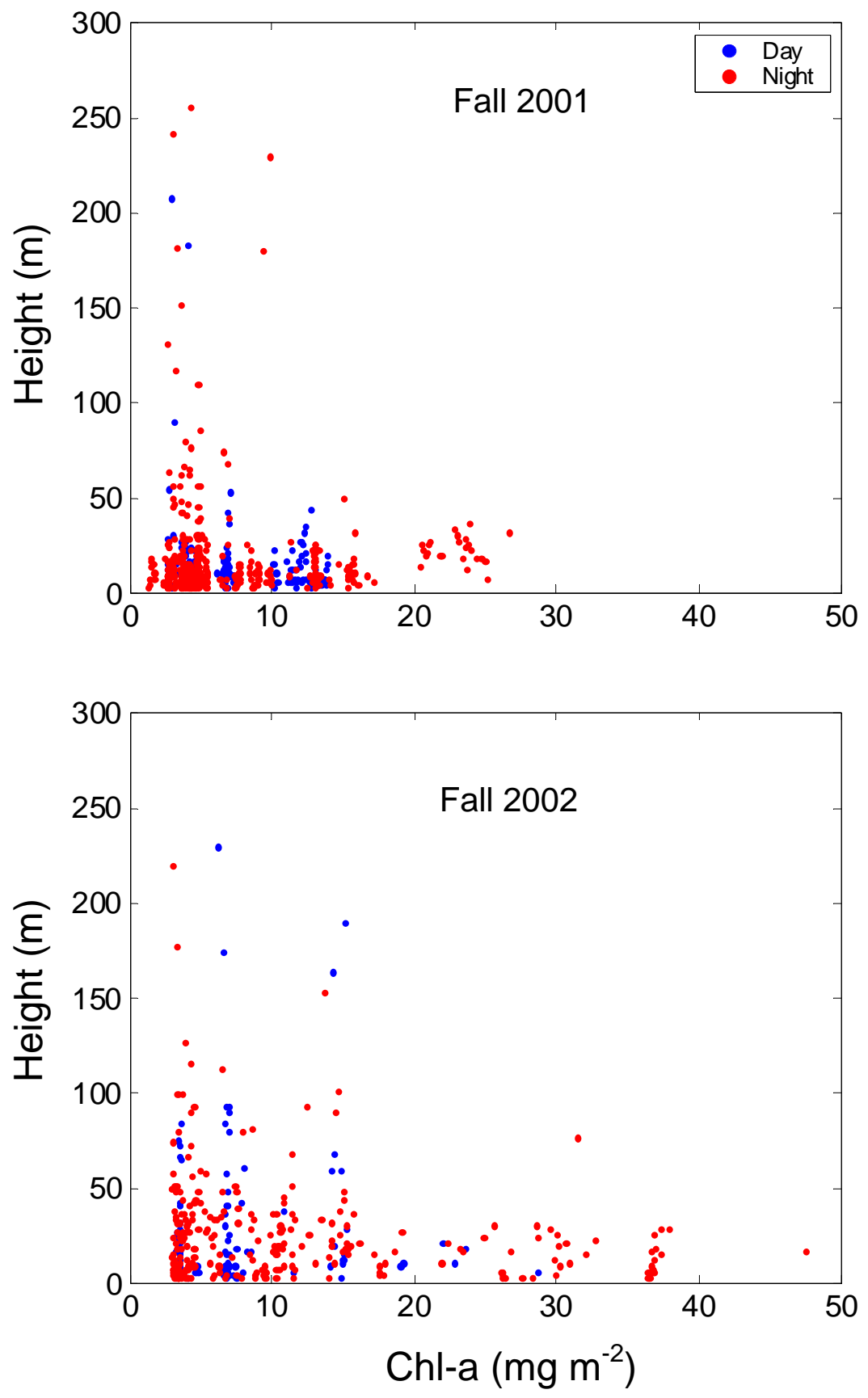

Figure 5.22 - Aggregation height (m) in relation to chlorophyll $a$ concentration. Blue dots indicate aggregations observed during the day, red indicates night. Similar patterns of largest aggregations associated with lower chlorophyll levels were evident for aggregation length and area, but are not shown. 

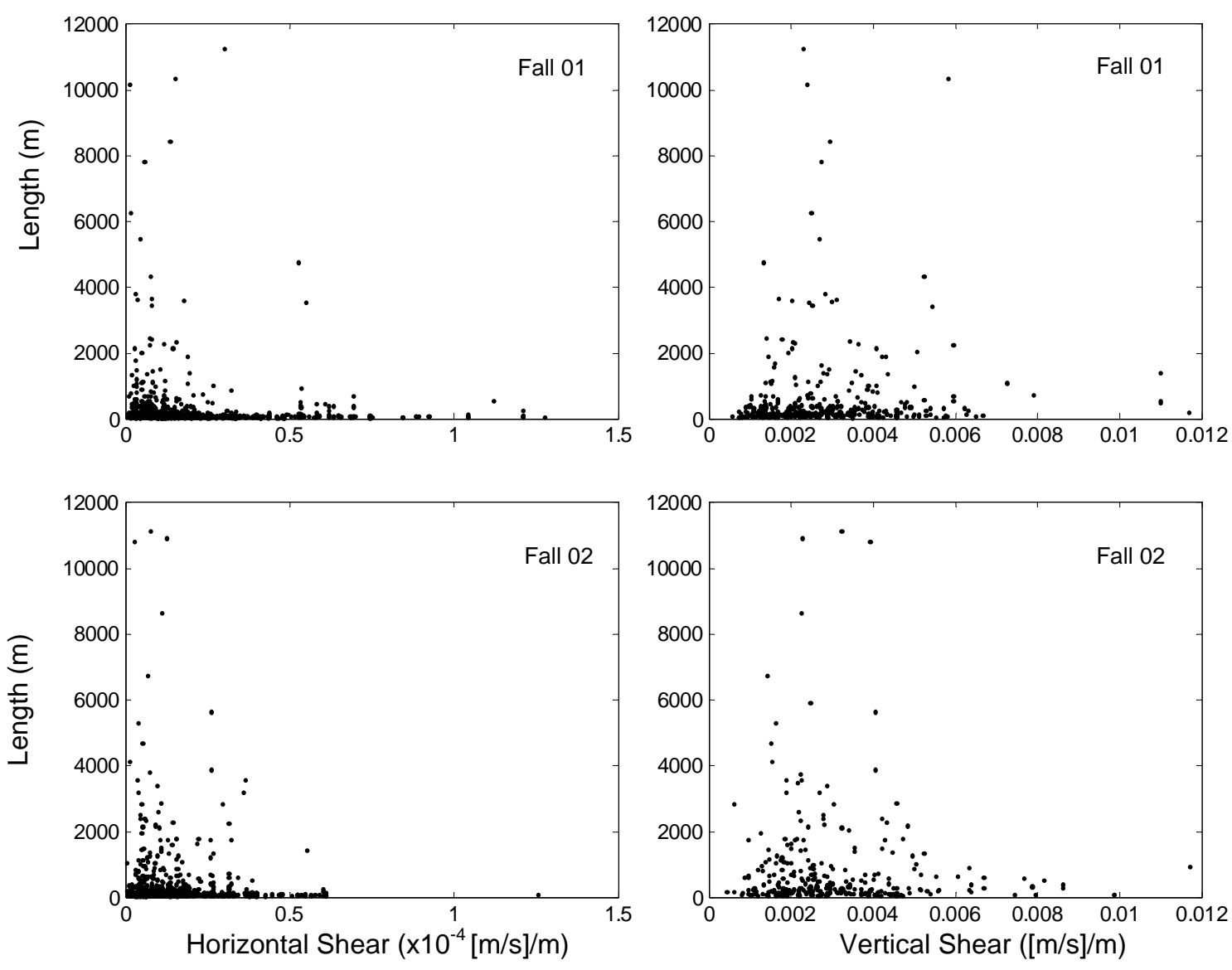

Figure 5.23 - Aggregation length $(\mathrm{m})$ in relation to horizontal (left-hand plots) and vertical (right-hand) current shear. Current data were only available for the two fall surveys. 

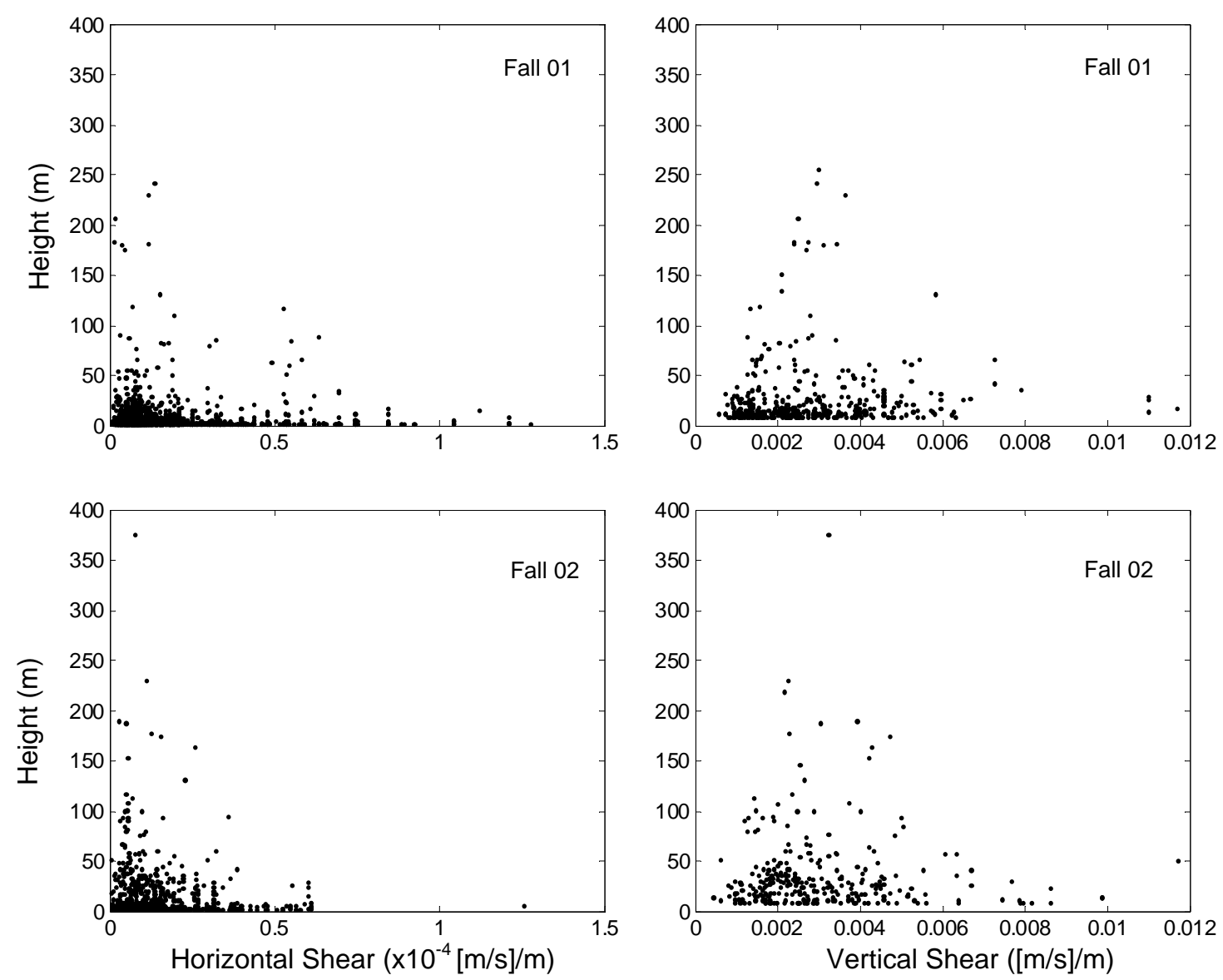

Figure 5.24 - Aggregation height (m) in relation to horizontal (left-hand plots) and vertical (right-hand) current shear. 
both 2002 surveys, more aggregations were found associated with seals than with seals absent (Figure 5.25b). The presence of seals was significantly associated with aggregation depth (Figure 5.25b). In fall, when seals were present, aggregation daytime depths were generally deep ( $>100 \mathrm{~m})$, whereas when seals were absent, daytime depths were shallow $(<100 \mathrm{~m})$. During winter, some aggregations were found at shallow depths when seals were both present and absent, but proportionally more aggregations were found deeper in the water column when seals were present. The depths occupied by aggregations when seals were present during the winter of 2002 were also deeper than that fall. The relationship between depth and the presence of penguins was less clear. During the winter of 2002 when the most aggregations were observed in regions where penguins were present, no obvious variation in depth was apparent between instances when penguins were present or absent (Figure 5.25c). During the fall of 2002, aggregations were not found at shallow depths $(<80 \mathrm{~m})$ when penguins were present, although such depths were occupied when penguins were absent; note though that this difference in the distribution of depths occupied was not significant (Figure 5.25c).

Aggregation biomass density showed less clear relationships with the presence or absence of each predator type (Figure 5.26). Overall, however, there was a certain tendency towards denser aggregations when predators were present, for all three predator types. This increase in density was especially noticeable during the winter of 2002 in comparing cases when whales and seals were present versus absent. Particularly in the case of seals and penguins, the very largest densities were also found in regions where predators were present.

Aggregation size showed little consistent association with the presence of predators (Figure 5.27). The only obvious relationship was that the distribution of aggregation lengths (Figure 5.27b) and heights (not shown) included tails that extended towards larger sizes when seals were present than when they were absent. 
FALL 01

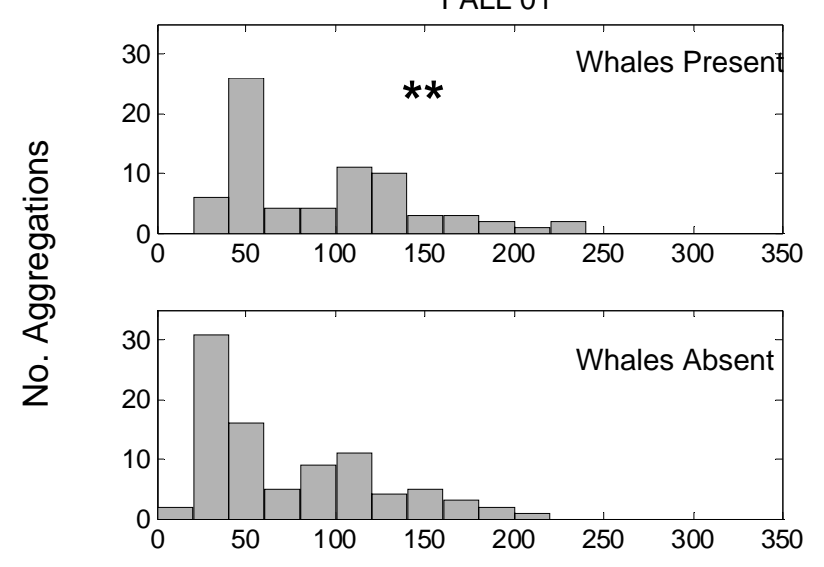

FALL 02

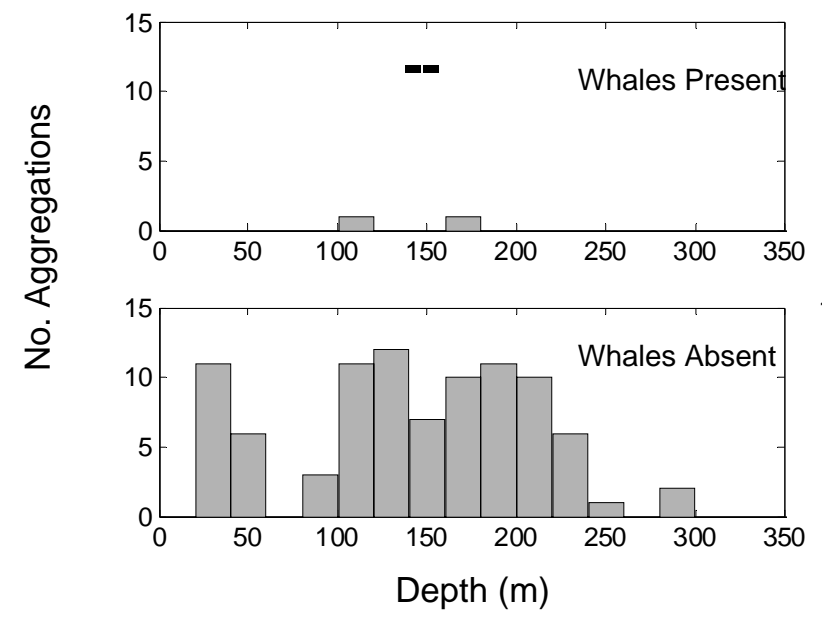

WINTER 01
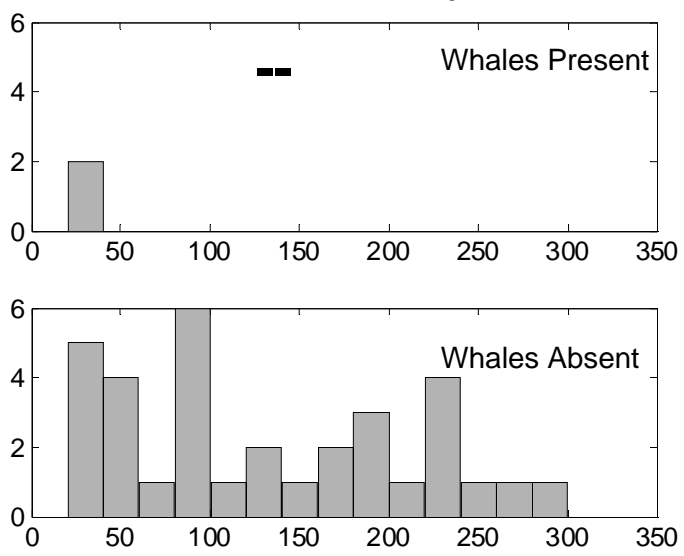

WINTER 02
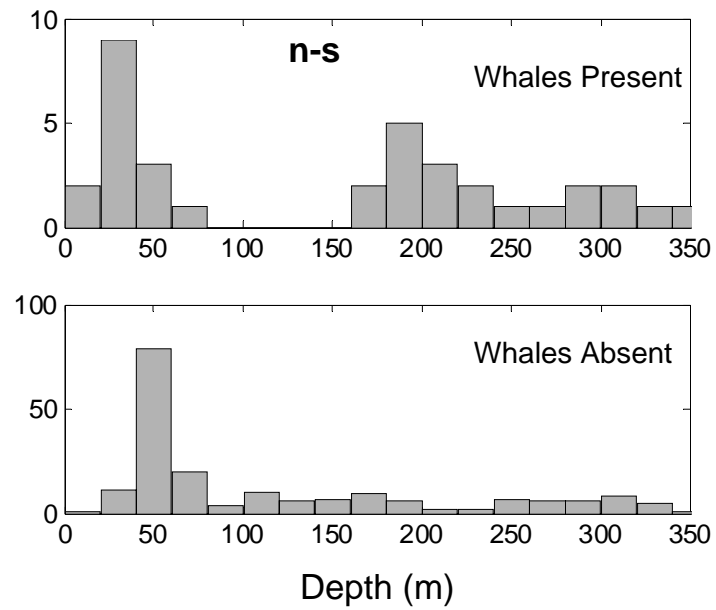

Figure 5.25 - Aggregation depth (m) during each survey, for predators present or absent. Presence was defined as at least one predator within $10 \mathrm{~km}$ of a given aggregation. Predator surveys were conducted during daylight hours and so only daytime aggregations are considered. Note that $y$-axes for each present/absent pair are not always the same. Asterisks indicate the results of Mann-Whitney U-tests comparing depths observed when predators were present to those observed when predators were absent. This is a rankbased (i.e., non-parametric) test for comparing the distributions of two variables: **** denotes $p<0.0001, * * * p<0.001, * * p<0.01, * p<0.05$. n-s indicates tests where the difference was non-significant $(p>0.05),--$ indicates that no test was performed.

(A) Whales 

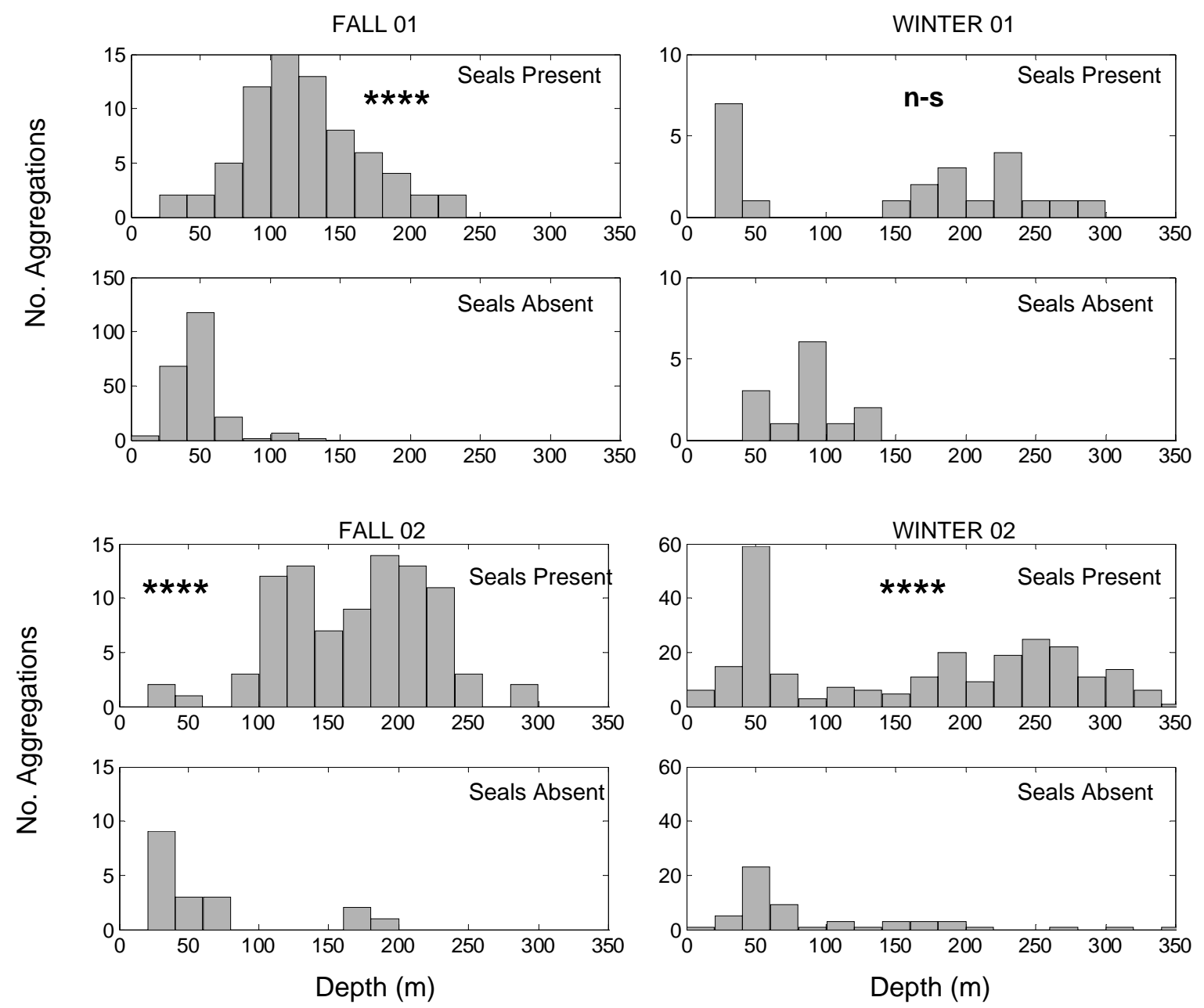

Figure 5.25 - (B) Seals 

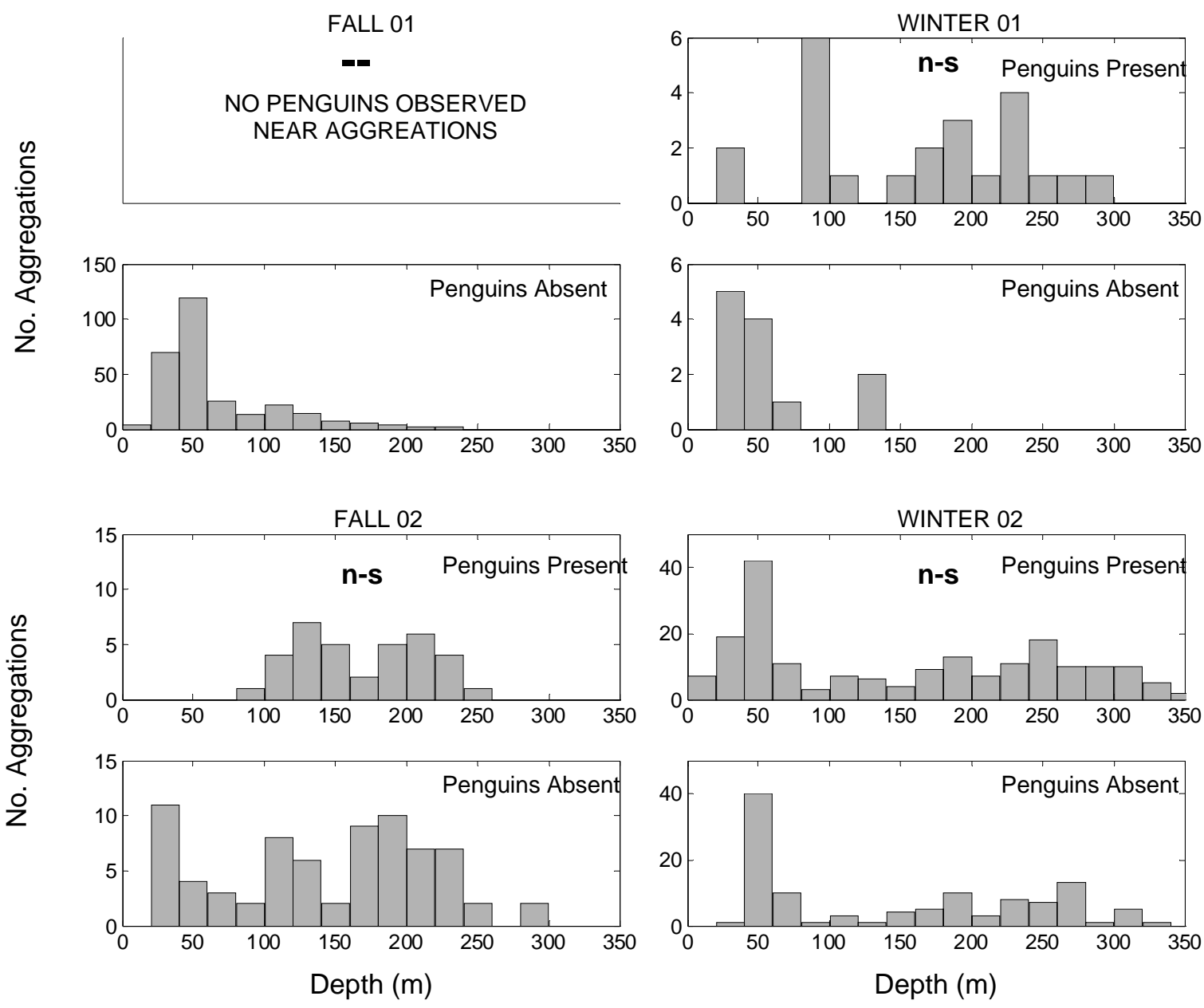

Figure 5.25 - (C) Penguins 

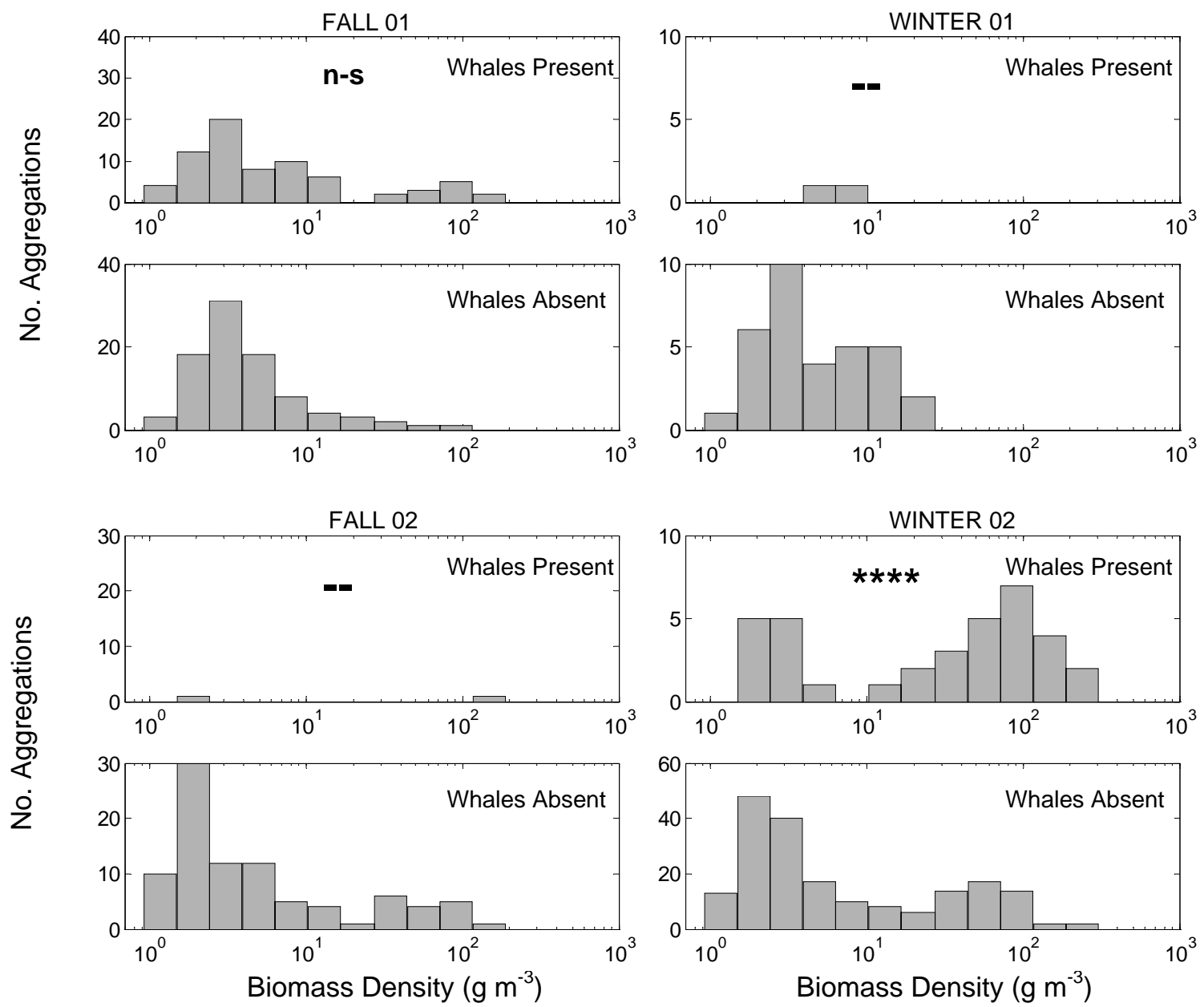

Figure 5.26 - Aggregation density of biomass $\left(\mathrm{g} \mathrm{m}^{-3}\right)$ during each survey, for predators present or absent. Asterisks indicate the results of Mann-Whitney U-tests comparing densities observed when predators were present to those observed when predators were absent: $* * * *$ denotes $p<0.0001,{ }^{* * *} p<0.001, * * p<0.01, * p<0.05$. n-s indicates tests where the difference was non-significant $(p>0.05)$, -- indicates that no test was performed.

\section{(A) Whales}



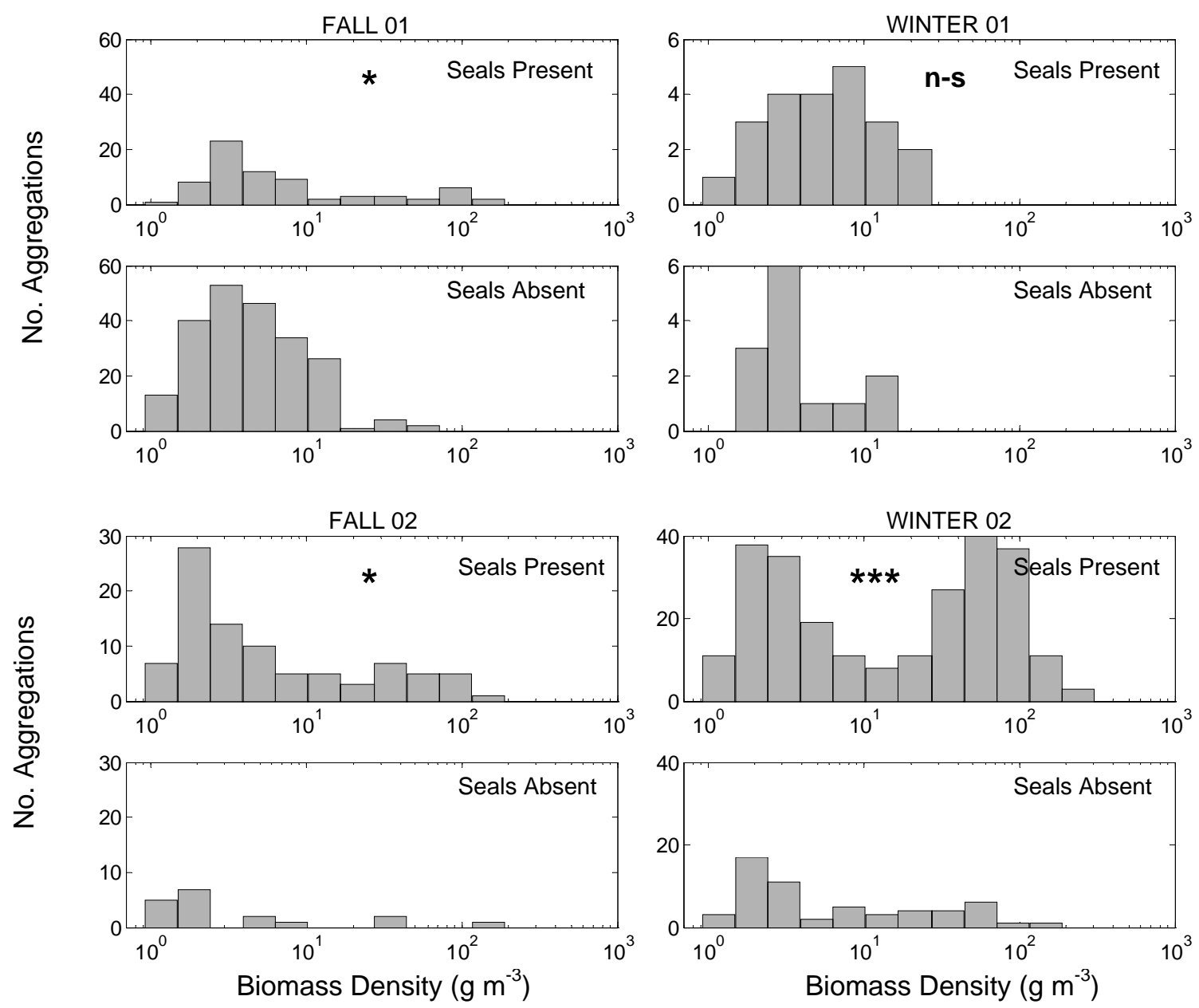

Figure 5.26 - (B) Seals 

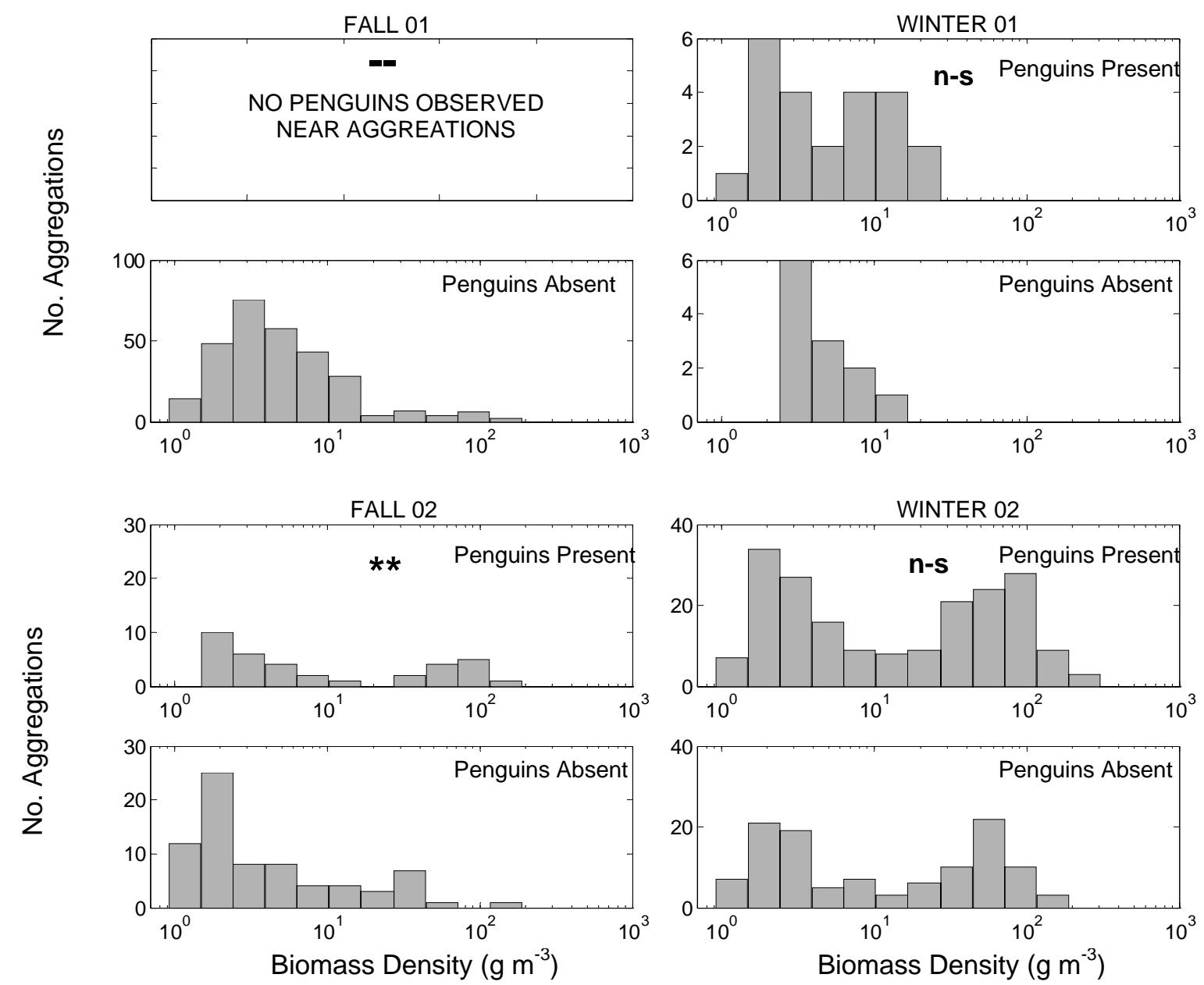

Figure 5.26 - (C) Penguins 

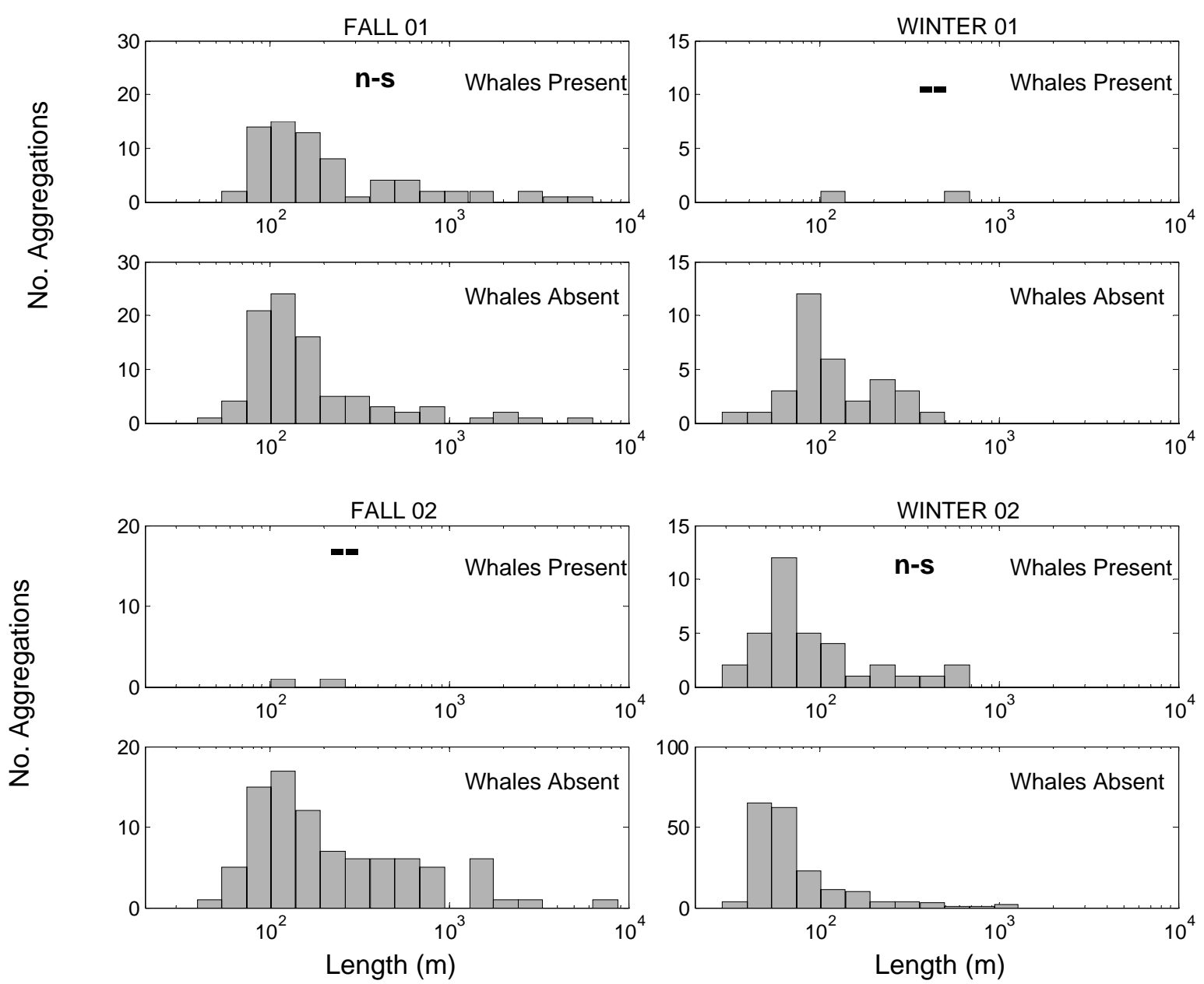

Figure 5.27 - Aggregation length (m) during each survey, for predators present or absent. Asterisks indicate the results of Mann-Whitney U-tests comparing lengths observed when predators were present to those observed when predators were absent: $* * * *$ denotes $p<0.0001, * * * p<0.001, * * p<0.01, * p<0.05$. n-s indicates tests where the difference was non-significant $(p>0.05)$, -- indicates that no test was performed.
(A) Whales 

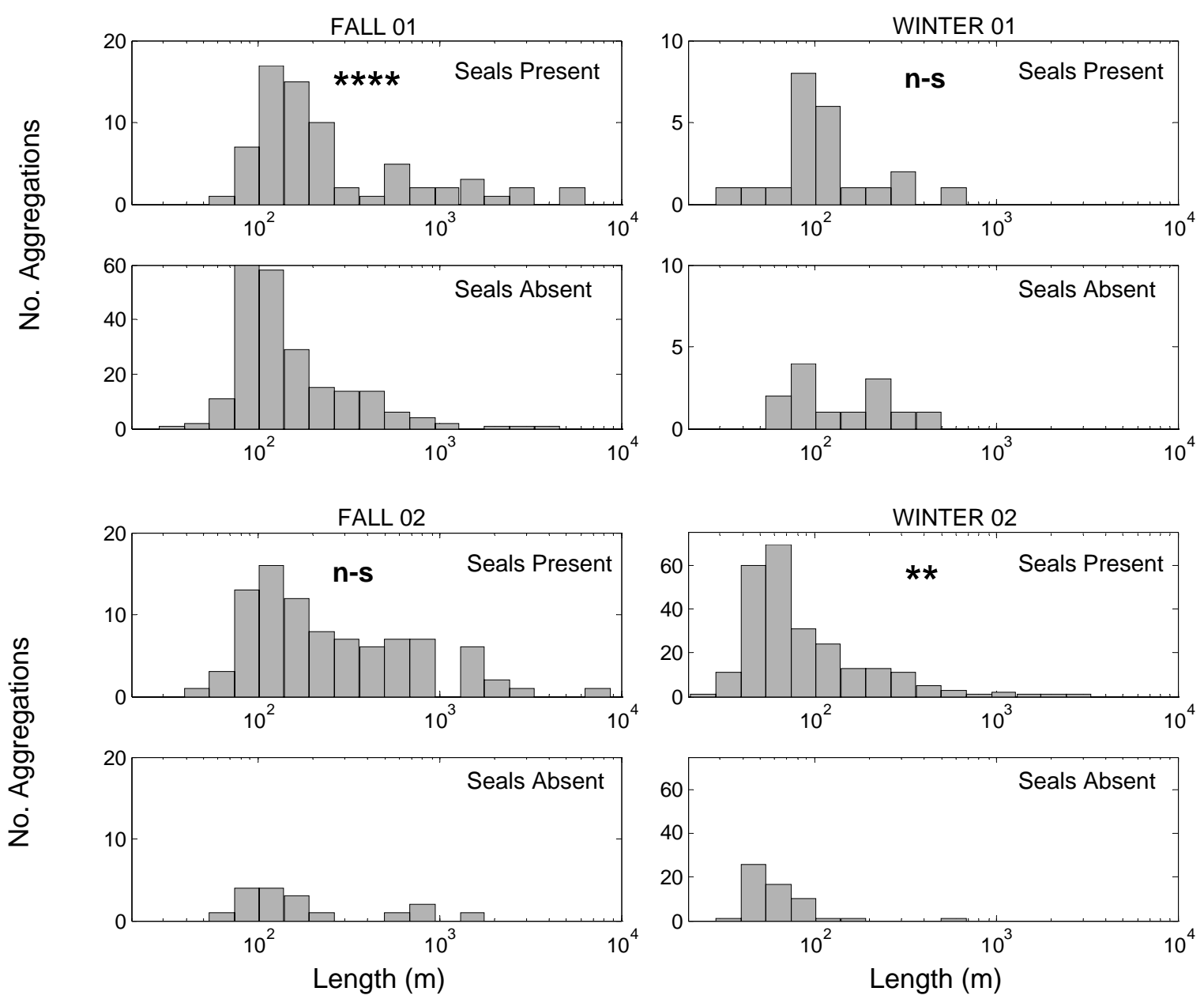

Figure 5.27 - (B) Seals 

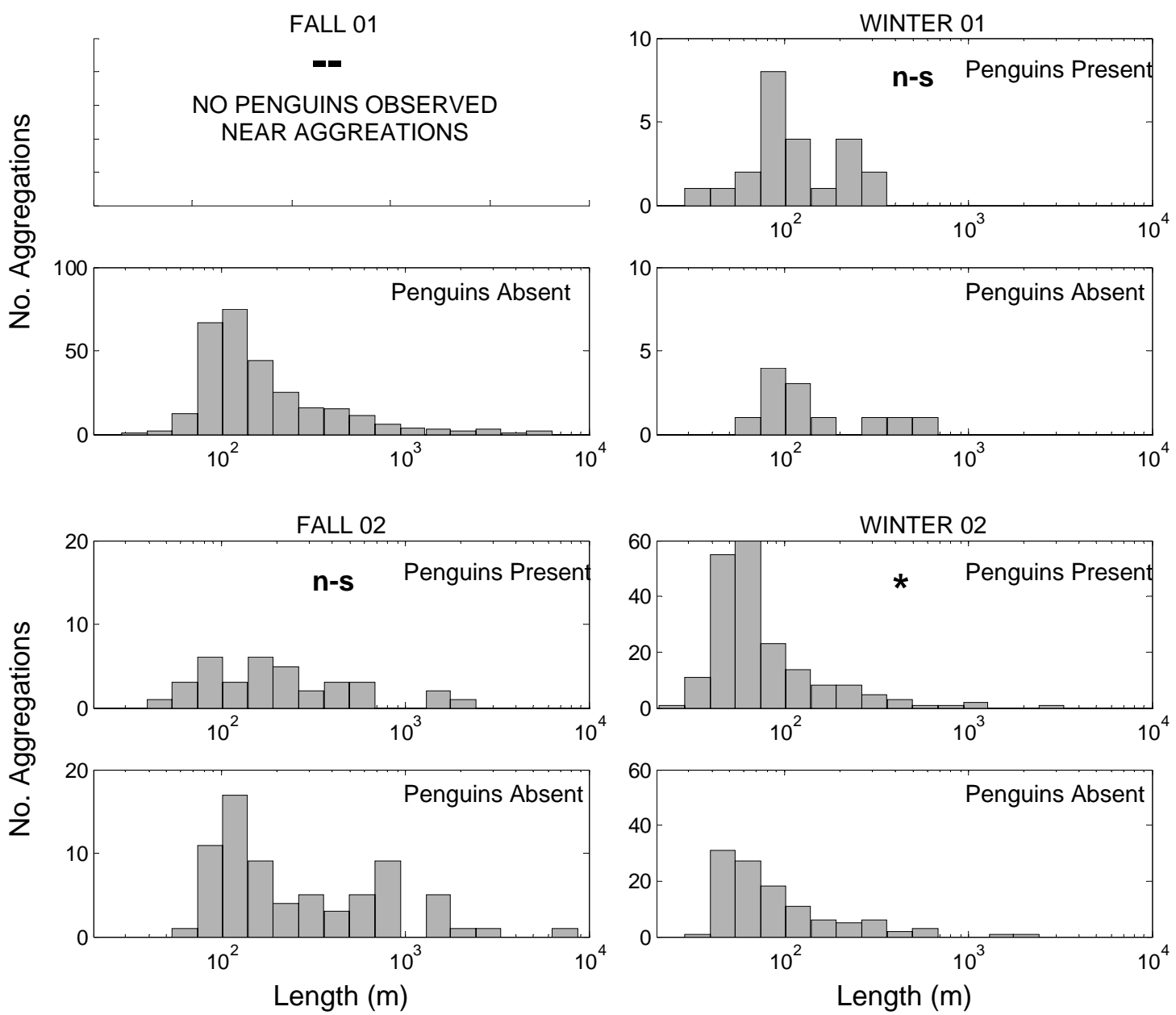

Figure 5.27 - (C) Penguins 


\subsubsection{Variability in density and size within individual aggregations}

Certain aggregations from the two surveys conducted in fall were also selected for more detailed examination of within-aggregation variation in the density and size of krill. Aggregations were chosen to represent the very large aggregation type present in coastal areas that accounted for a majority of overall regional biomass (see Chapter 4). The multi-frequency inversion method of Chapter 4 was applied to estimate the weighted mean length and density represented by each acoustic element in these aggregations.

These inversions suggested that for all but one of the aggregations considered, the distributions over all elements of estimated weighted mean lengths were uni-modal and quite narrowly distributed about the dominant mode (representative aggregations shown in Figures 5.28-5.29). Furthermore, in all but the one atypical aggregation, little sizesegregation within aggregations was evident: estimated length did vary slightly from element to element, but not in any systematic fashion. For the aggregation observed on May 14, 2002 (Figure 5.28a), there was some suggestion of slightly smaller estimated lengths in between those regions of the aggregation where scattering was very high (Figure 5.28d). There was also some suggestion of smaller weighted mean lengths estimated immediately below the BIOMAPER-II, and larger lengths immediately above (indicated by arrows in Figure 5.28d). The aggregations observed on May 8, 2002, similarly showed no evidence of size-segregation, aside again from slightly smaller lengths estimated immediately below the towed body in those instances where the towed body passed through the aggregation (Figure 5.29d). This tendency to infer smaller weighted mean lengths immediately below the towed body and larger immediately above, in aggregations where otherwise uniform length distributions were observed, may reflect an artifact, perhaps related to greater error in acoustic measurements made near to the towed body where sample volumes are particularly small. It may also reflect avoidance by the krill of the oncoming towed body, with larger krill of greater swimming speeds evading the towed body more effectively (thereby deflating length estimates just below 

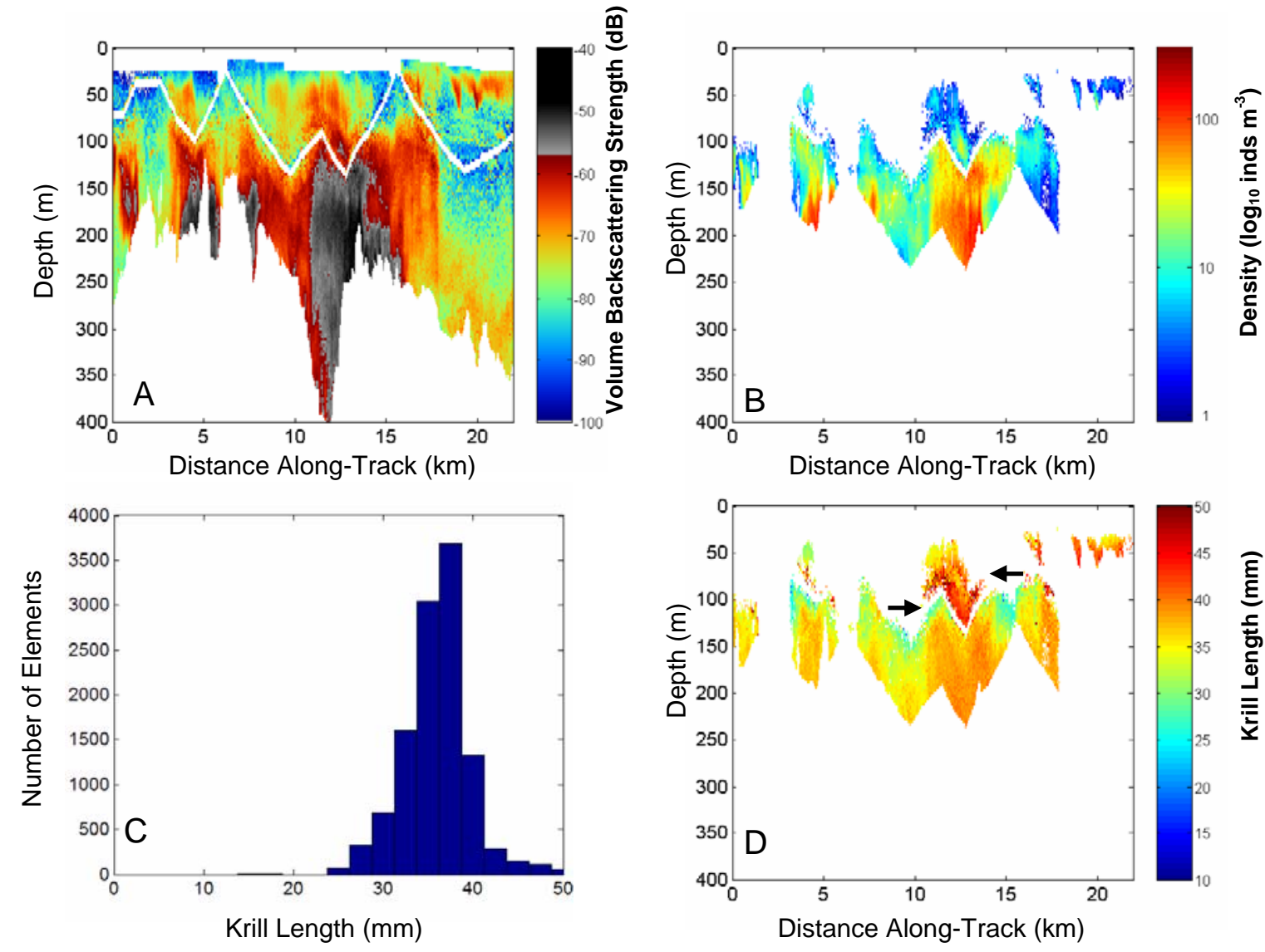

Figure 5.28 - Variability in acoustic estimates of the size and numerical density of krill in a large aggregation observed on May 14 (yearday 134) during the fall of 2002. In addition to the multi-frequency acoustic evidence, net and video samples confirmed that the aggregation was composed of krill, of mean length $39.9 \mathrm{~mm}$ (see Chapter 4 for additional details on net samples in this region). (A) Acoustic volume backscattering strength data collected at $120 \mathrm{kHz}$ in decibels (dB). Higher scattering could result in principle from either more or larger animals. White at the top and bottom of the echogram indicate regions where surface and bottom scattering were excised, respectively. The zigzagging white trace indicates the position of the BIOMAPER-II towed body. (B, D) Acoustic estimates of the density and weighted mean length of animals in each acoustic element shown via the color scale, relative to depth and along-track distance. These estimates are based on inversions of the multi-frequency acoustic data, which were only performed on acoustic elements meeting the threshold backscattering and mean volume backscattering difference criteria necessary to be attributed to krill (see methods section 5.2.3). As such, only a subset of all acoustic elements evident in (A) are associated with length and density estimates in (B) and (D). Furthermore, inversions were only performed for elements where measurements were available at all four acoustic frequencies. The varying lower bound to the length and density estimates is determined by the 100 $\mathrm{m}$ range limit of the $420 \mathrm{kHz}$ system. Note that density is plotted on a log-scale. Right-pointing arrow indicates region where length estimates were made from data collected immediately below the towed body and were smaller than elsewhere in the aggregation. Left-pointing arrow indicates region where length estimates were atypically large and were made from data collected immediately above the body. (C) Frequency distribution of estimated krill lengths over all acoustic elements in the aggregation. 

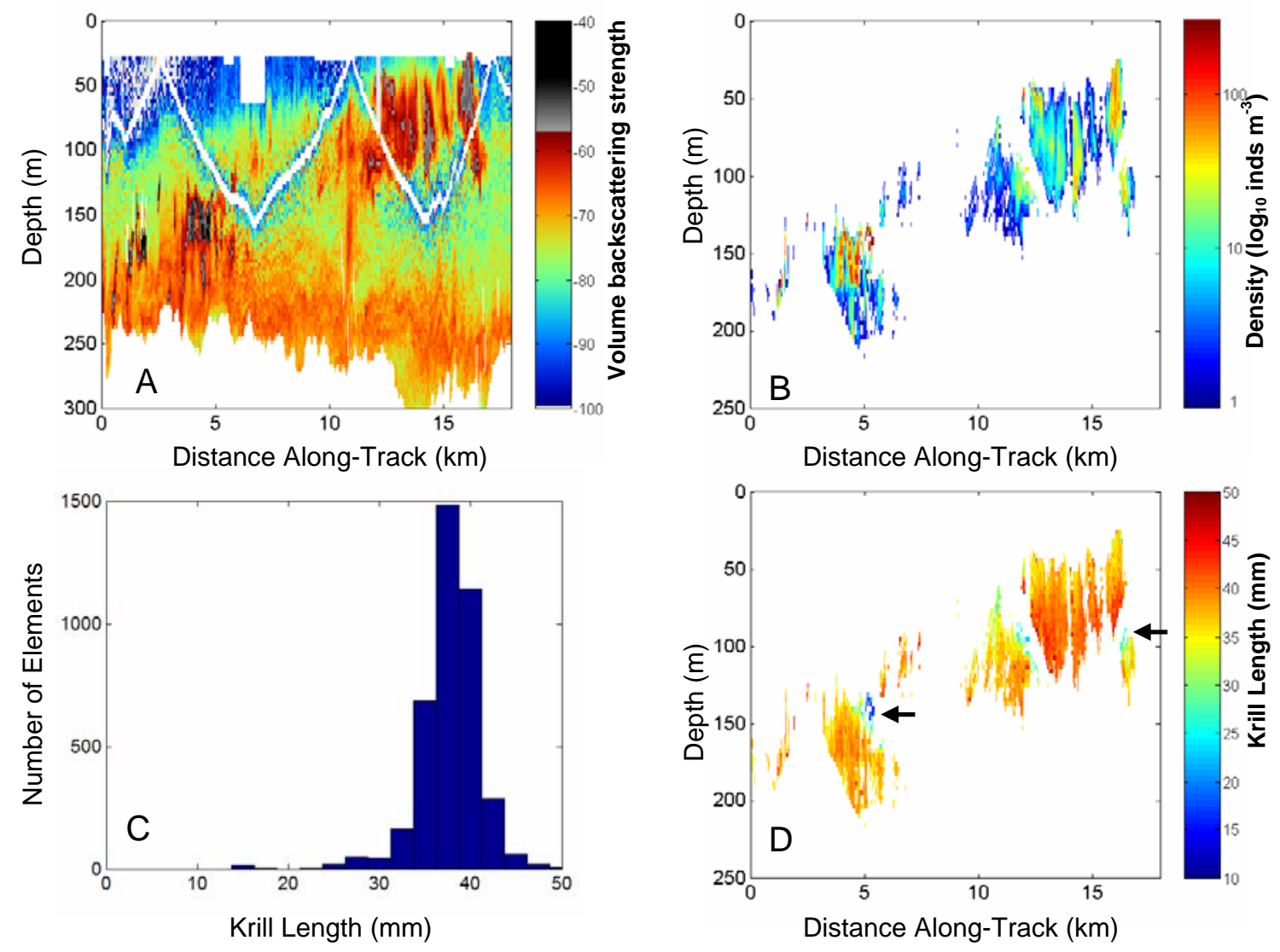

Figure 5.29 - Variability in acoustic estimates of the size and numerical density of krill in a large aggregation observed on May 8 (yearday 128) during the fall of 2002. (A) Acoustic volume backscattering strength at $120 \mathrm{kHz}$ in decibels (dB). The data span a time period of two hours, from 1611 to $1811 \mathrm{~h}$, on a day when sunset was at $1538 \mathrm{~h}$. (B, D) Acoustic estimates of the density and mean length of animals in each acoustic element shown via the color scale, relative to depth and along-track distance. Arrows indicate regions where length estimates were made from data collected immediately below the towed body and were smaller than elsewhere in the aggregation. (C) Frequency distribution of estimated krill lengths over all acoustic elements in the aggregation. See caption to Figure 5.25 for additional details. 

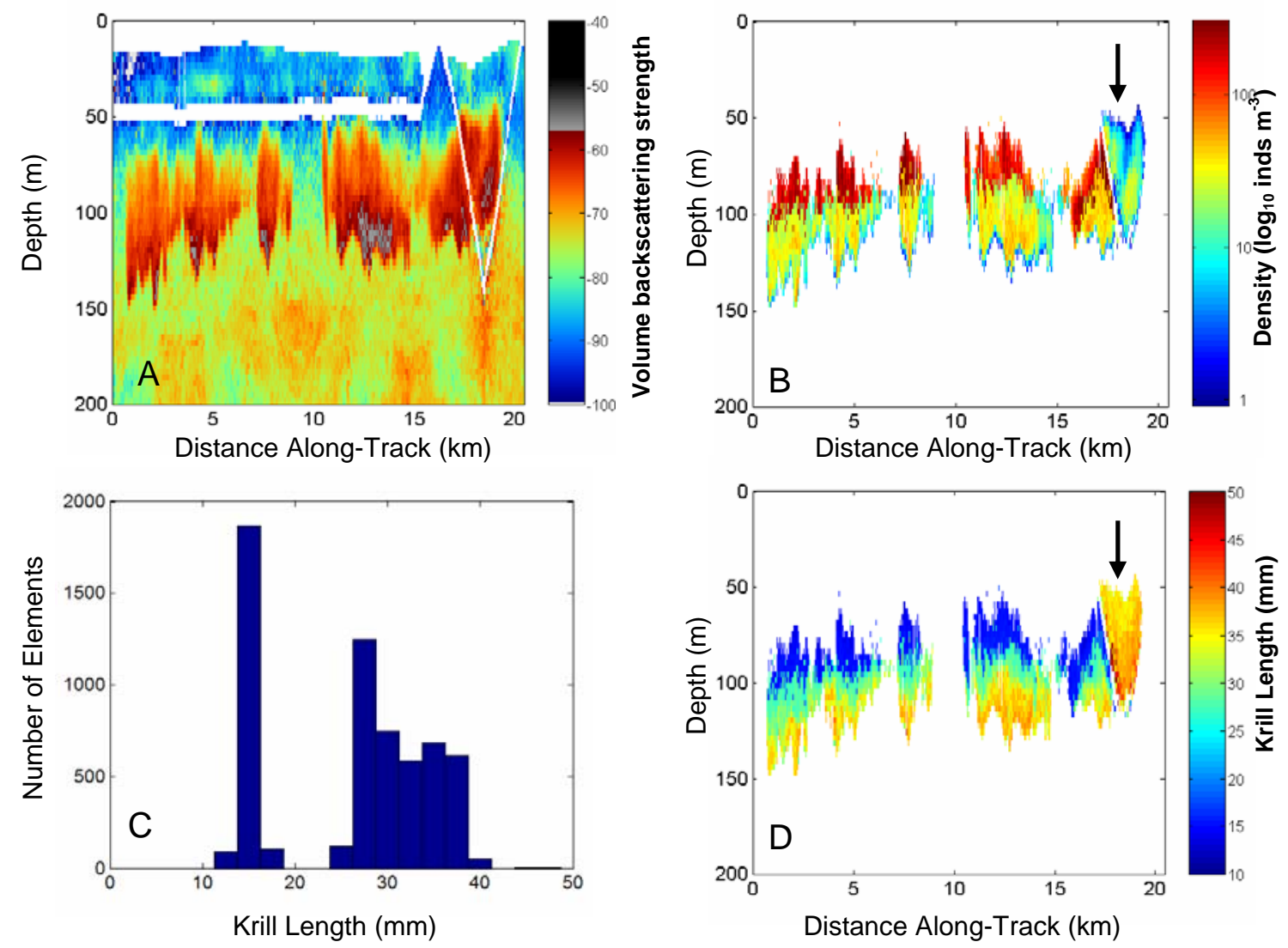

Figure 5.30 - Variability in acoustic estimates of the size and numerical density of krill in a large aggregation observed on May 24 (yearday 144) during the fall of 2001. In addition to the multi-frequency acoustic evidence, video samples confirmed that the aggregation was composed of krill. (A) Acoustic volume backscattering strength at 120 $\mathrm{kHz}$ in decibels (dB). (B, D) Acoustic estimates of the density and mean length of animals in each acoustic element shown via the color scale, relative to depth and alongtrack distance. Arrow indicates region where length and density estimates are thought to be erroneous, likely due to calibration issues concerning acoustic data collected with the up-looking transducers (see text). (C) Frequency distribution of estimated krill lengths over all acoustic elements in the aggregation. See caption to Figure 5.25 for additional details. 
the towed body) and reforming aggregations once the towed body passed more rapidly (thereby increasing length estimates just above the body).

The only exception to this general lack of systematic intra-aggregation variation in estimated length was the aggregation observed on May 24, 2001, where a distinct pattern of size-segregation was apparent. Smaller weighted mean lengths were estimated for krill shallower in the aggregation, grading to larger sizes with increasing depth (Figure 5.30d). Estimates of weighted mean length made from data collected by the upwards-facing transducers in this aggregation did not show this same trend in the vertical distribution of estimated lengths (indicated by arrow in Figure 5.30d). This most likely is an artifact related to calibration error associated with these transducers, which in 2001 were less thoroughly calibrated than the downwards-facing transducers. It is also conceivable that the presence of the towed body had some influence on the behavior of the krill, or that the turbulent wake left behind the tow cable enhanced the observed scattering levels (similar to what was observed in a freshwater experimental setting by Thorpe and Brubaker, 1983). The alternative explanation of some range-related error associated with measurements by the down-looking transducers, such as noise contamination or issues to do with noise thresholds, leading to an apparent increase in krill length at greater depths below the body seems less likely. The fact that the depth at which the transition from small to large sizes occurs varies within the aggregation even while the towed boy was held at constant depth, would argue that the pattern is real and not some consequence of range-related acoustic error.

In contrast to length, estimates of krill numerical density within these case-study aggregations showed more variability (Figures 5.28b-5.30b). Within single aggregations, density varied by one to two orders of magnitude. In the aggregation from May 8, 2001, where strong size variability was evident, the smaller krill occurred at much higher densities than the larger length mode (Figure 5.30b). It is also interesting to note that the acoustic data from May 24, 2002, spanned a time period of two hours, from 1611 to $1811 \mathrm{~h}$, on a day when sunset was at $1538 \mathrm{~h}$. The change in vertical position of the krill 
aggregations along the transect illustrates the upwards migration of krill from their deep daytime to shallower nighttime depths (Figure 5.29a). Note also the change in density: aggregations were more dense earlier in this time span when present deeper in the water column than when they later occupied shallower depths (Figure 5.29b).

\subsection{DISCUSSION}

Krill aggregations observed in this study displayed distinct variability in vertical position and structure. The associations of these aggregation characteristics with features of the physical and biological environment allow important insight into the likely impetus and forces underlying krill aggregation and vertical migration.

As has been observed previously, overall distributions of aggregations were dominated by small sizes and densities (Sprong and Schalk, 1992; Miller et al., 1993; Ross et al., 1996; Lascara et al., 1999). Previous studies of krill aggregations in fall and winter, however, have been few (Zhou et al., 1994; Ross et al., 1996; Lascara et al., 1999). In surveys along the Western Antarctic Peninsula north of the present study area, Ross et al. (1996) saw an increase in aggregation size between fall and winter surveys, associated with a decrease in aggregation density and reduction in overall numbers of aggregations encountered. A similar trend was observed by Lascara et al. (1999) in surveys that overlapped with the northern reaches of the area examined here. In the present study, a decrease in both aggregation size and density was evident between the fall and winter of 2001. During 2002, aggregation size was comparable between fall and winter, while densities shifted towards higher values. In both years, the seasonal trends thus differed from those observed in previous studies. This likely relates to some combination of spatial variability, the vertical limits of the acoustic systems employed by these earlier studies (maximum depths of 300 and $189 \mathrm{~m}$ for the Ross et al., (1996) and Lascara et al., (1999) studies, respectively), and to their low numbers of aggregations observed overall in winter (117 and 56 aggregations observed by the Ross et al., (1996) and Lascara et al., (1999) studies, respectively, as compared to 566 wintertime aggregations in 2002 in the 
present study). The minimum detectable sizes in terms of horizontal extent in these earlier studies were smaller than in the present study (2- $25 \mathrm{~m})$, and so their lower numbers of aggregations observed in winter is not due to multiple small aggregations being perceived by their acoustic systems as single larger aggregations due to a coarse resolution.

The observation that log-log plots of the number of aggregations larger than a given size relative to aggregation size displayed linear slopes suggests that the distributions of aggregation lengths were fractal, or more specifically, self-similar (Hastings and Sugihara, 1993). In contrast, the distributions of aggregation height were not self-similar. This agrees with the findings of Krause (1998), who also found evidence of selfsimilarity in krill aggregation length but not height when re-analyzing the acoustic observations of krill aggregations of Sprong and Schalk (1992). The latter study was conducted during austral summer, and Krause (1998) measured a slope of -0.89 in the relationship between the logarithm of the number of aggregations longer than a given length versus the logarithm of length. The steeper slopes estimated in the present work (1.23 to -1.93 ) may relate to seasonal differences, or possibly to the different thresholds used by the present study as compared to Sprong and Schalk (1992) for defining aggregations in the acoustic record. The mechanisms underlying the fractal nature of aggregation length and the exact slopes observed remain unclear, and would be an interesting avenue of further investigation. Most likely they represent an interaction between physical processes and krill behavior. Irrespective of the causes, however, the fact that the distribution is self-similar provides a convenient means of describing the distribution of krill aggregation lengths over a wide range of spatial scales, which could be useful in modeling studies of krill aggregative behavior or in interpolating acoustic fields for the un-surveyed regions between survey lines. 


\subsubsection{Strengths and weaknesses of the acoustic analyses}

The present study has certain strengths that are perhaps unusual among acoustic studies of krill aggregations in some respects. A particular strength is that the results suffer little from concerns that krill were present at depths beyond the range of the acoustic system, as the BIOMAPER-II was able to survey to the bottom over much of this continental shelf region. Furthermore, while multi-frequency techniques for discriminating acoustic scattering arising due to krill from that of other zooplankton have been available for some time (see review in Watkins and Brierley, 2002) and are now in widespread use in biomass surveys for the krill fishery (e.g., Hewitt et al., 2003), they have seldom been employed in studies of individual krill aggregations (e.g., Brierley and Watkins, 2000). More typically, krill aggregations have been identified through some combination of threshold levels of volume backscattering strength or biomass, visual scrutiny, and comparisons to limited net samples (e.g., Miller et al., 1989; Sprong and Schalk, 1992; Ross et al., 1996; Lascara et al., 1999). The present study also marks the first time that multi-frequency methods like those developed in Chapter 4 have been used in the Antarctic to estimate the length of animals in acoustically-observed aggregations, in order to make inferences about potential size-related changes in krill aggregative behavior.

Nonetheless, certain sources of uncertainty in the present acoustic analyses must also be acknowledged. The greatest uncertainty surrounds the specific composition of the acoustically-identified aggregations. Identification of krill was done via multi-frequency analyses in combination with some visual scrutiny of the acoustic record. In the fall of 2001 and both winters, concerns with the sensitivity and proper functioning of the $43 \mathrm{kHz}$ system led to greater uncertainty in identifying krill than in the fall of 2002 (Chapter 4). The results of these surveys should thus be approached with greater caution. For the same reasons, greater uncertainty surrounds the estimates of the weighted mean length of krill in aggregations observed in fall of 2001 than in 2002. 
Equally important is the fact that the acoustic methods employed do not discriminate among the different species of aggregating euphausiids that are known to inhabit this region. Thysanoessa macrura has been observed to form diffuse swarms detectable by acoustic instruments, at densities of animals described as similar to "background" levels of Antarctic krill (Daly and Macaulay, 1988). It is quite likely that any such diffuse aggregations would be filtered out by the application here of a threshold scattering level. Both Euphausia superba and E. crystallorophias, however, regularly form dense aggregations (Everson, 2000b; Ross et al., 1996). E. crystallorophias is a smaller species, and lengths observed in net samples made by companion studies during the survey periods did not exceed $30 \mathrm{~mm}$ (K. Daly, personal communication). In comparison, weighted mean lengths estimated for the aggregations examined here mostly exceeded 30 $\mathrm{mm}$. Nonetheless, it must still be acknowledged that our inferences concerning aggregative and vertical migratory behavior may be confounded by potential interspecific behavioral differences, particularly for those aggregations where smaller weighted mean lengths were estimated.

Aggregations were defined in part by a threshold volume backscattering strength, derived on the basis of the numerical density of animals that corresponds to the maximum visual sensing distance over which a given animal can maintain some association with its nearest neighbor, and thereby with the aggregation as a whole (Chapter 4). Although this threshold thus does have some biological justification, its application did sometimes result in somewhat arbitrary distinctions between volume backscattering deemed to be 'within aggregations' and immediately neighboring measurements considered to be 'background.' The large number of very small aggregations extracted from the acoustic data collected on September 2 during the winter of 2002, which opposed many of the overall trends otherwise observed in aggregation depth, illustrate such a situation. Repeated fluctuations in volume backscattering strength above and below the threshold led to the identification of a number of apparent aggregations from what appears to the eye to be an otherwise continuous feature, more like a layer than a typical krill aggregation (Figure 5.9). Some uncertainty thus may be introduced into the present 
estimates of aggregation size due to the division of what the krill might perceive as single aggregations into smaller units meeting the present definition of aggregations.

Mean volume backscattering strength in acoustically-identified aggregations and estimates of aggregation horizontal extent are also influenced by the nature of the acoustic beam. The sample volumes during the first and last pings in a given aggregation are likely not completely filled with krill, leading to a distortion of estimates of aggregation length and mean volume backscattering (Reid, 2000). Since the acoustic beam widens with depth, these distorting effects are magnified for deeper aggregations. Methods for correcting estimated aggregation length for the effects of beam width have been proposed, based on simulated fish schools (Reid, 2000). As noted earlier, the coarse resolution of the present data makes it unclear that these corrections are warranted, and in any case, the trends reported here did not differ whether the corrections were made or not. Likewise, no attempt was made to correct the measurements of mean volume backscattering used in estimating krill length for the effects of beam pattern. Again, the coarse nature of the data (averaging over four-ping cycles) makes it unclear that correcting for potential bias in the first and last pings within the aggregation would be appropriate. Furthermore, the application of the threshold scattering level used in defining aggregations may serve to exclude edge measurements potentially biased by beam width effects. Nonetheless, it is important to acknowledge that some uncertainty related to beam width may exist in the krill length and density estimates, particularly for smaller and deeper aggregations.

A related issue is that the acoustic system does not measure the horizontal extent of aggregations in an across-track direction. Total biomass in aggregations was therefore considered here via the index of biomass per across-track meter. This likely penalizes longer aggregations, however, which may well be equally large across-track as they are in the observed along-track dimension; were this across-track distance known, the calculated total biomass of larger aggregations might exceed those of smaller aggregations by an even greater amount. This therefore introduces uncertainty into our 
use of the mean depth of the center of krill biomass to examine vertical migratory behavior of the local krill population as a whole. Estimates of aggregation depth and size are also affected by the resolution of the data ( $1.5 \mathrm{~m}$ vertically by $\sim 35 \mathrm{~m}$ horizontally), which by many acoustic standards is quite coarse. Aggregation depth and size varied substantially, however. The horizontal extent of aggregations, for instance, varied over orders of magnitude. It therefore seems unlikely that the present insights into aggregation structure would be much improved by having data of finer resolution.

Additional uncertainty may be associated with the estimates of krill biomass density due to other aspects of the acoustic methods, notably in the acoustic inversion for the weighted mean length of animals in each aggregation and the target strength estimates. As demonstrated by the calculations of Hewitt and Demer (1993), however, the error introduced into acoustic estimates of density by uncertainty in the length estimates used to calculate target strength are small when the density of biomass is considered instead of the density of individuals. The error propagated into biomass density estimates due to uncertainty in the weighted mean lengths estimated by the acoustic inversion should thus be minor. Finally, application of the Lawson et al. (2006) target strength model assumes that aside from animal length, the various model parameters (e.g., krill orientation, shape, acoustic material properties) do not vary spatially or temporally; some uncertainty may be introduced into the biomass estimates by this assumption, but too little evidence exists to verify it rigorously. Note that additional comments on the various sources of acoustic uncertainty and a comprehensive scrutiny of the validity of the acoustic inversion method can be found in Chapter 4.

\subsubsection{Diel vertical migration}

The vertical position of krill aggregations was observed to vary on a diel basis, with aggregations deeper in the water column during the day. From this, it can be inferred that the krill migrate vertically on a diel basis, although we are of course not making observations of individual animals. Aggregations were also more dense during the day 
than at night. These observations thus conform to the standard pattern in diel vertical migration often observed in acoustic studies of krill aggregations in other regions and times of year (reviewed in Godlewska, 1996, and see exceptions to the typical pattern listed therein). The present study also provides the first direct documentation of diel vertical migration by krill in winter. It thus contrasts with the Ross et al. (1996) study where no evidence was found for vertical migrations during surveys conducted in June through early July, and supports the inferences made from krill fishery catch data by Taki et al. (2005) that diel vertical migrations do occur in winter, with greater maximal depths and migratory amplitudes.

The method of fitting a sinusoidal function of time to the mean depth of the center of aggregation biomass employed here to describe krill diel vertical migration was proposed by Godlewska and Klusek (1987) as a highly useful means of standardizing across krill studies and comparing migratory patterns between regions and times. Godlewska (1993) argued that the approach of weighting the depths occupied by krill by biomass is preferable to examining the depth of individual aggregations since it provides information on how the bulk of the krill population under investigation are behaving and accounts for the large differences that can occur in the size and density of individual krill aggregations. A similar approach has also been successfully applied to the study of vertical migrations by other zooplankton elsewhere (e.g., in the Mid-Atlantic Bight, Ashjian et al., 1998). Zhou et al. (2005) recently made observations of euphausiid diel vertical migrations off northern Norway and found that the upward migrations occurred very rapidly, in a way that could not be described by a sinusoid, and that might rather be better captured by a step function. It is possible that the individual krill aggregations examined here similarly migrated rapidly between deep daytime and shallow nighttime depths. Nonetheless, the high levels of deviance explained by the sinusoidal models used here might suggest that the approach of fitting a sinusoidal curve was appropriate in examining the patterns in vertical migrations over a large number of aggregations. The description provided by the parameters estimated for the sinusoidal model (e.g., amplitude) also allowed revealing comparisons between the survey periods. 
In an examination of overall patterns in the same acoustic volume backscattering data from which the krill aggregations studied here were extracted, Lawson et al. (2004) observed little difference between day and night in mean volume backscattering at 120 $\mathrm{kHz}$ in shallow (25-100 m) versus deep (100-300 and 300-500 m) depth strata. If the zooplankton as a whole were migrating upwards at night the expectation would be of an increase in volume backscattering in the shallower depth layers from day to night, associated with decreases in the deeper strata. The lack of any such change was taken as evidence that diel vertical migration by the zooplankton responsible for the observed levels of volume backscattering had little impact on the overall patterns examined. As noted in that study, however, the observation of no difference in mean volume backscattering between day and night did not preclude the possibility that some component of the zooplankton community did migrate on a diel basis. Lawson et al. (2004) also demonstrated that krill were the dominant contributor to total volume backscattering at only limited times and places. The present observation of diel vertical migration by krill aggregations is thus consistent with the findings of that earlier study. The potentially confounding influence of krill vertical migration on mean levels of volume backscattering appears to be mitigated by the krill being a lesser component of the overall zooplankton scattering community in much of the study region.

The accepted explanation for diel vertical migration is that krill migrate upwards in the water column during the night to feed, returning to greater depths by day to avoid visual predators (Watkins, 2000). Under low chlorophyll $a$ conditions, krill have been observed to migrate with smaller amplitude than when food was more plentiful, arguably because the need for food outweighs the predation risks of remaining in shallow waters during the day (Godlewska, 1996). Otherwise, the evidence underlying the proposed explanation for krill vertical migrations has been mostly indirect or drawn by analogy to studies of other euphausiid and mysid species (Ritz, 1994). The present study is unusual in having direct and concurrent measurements of many of the environmental properties potentially driving krill vertical migrations. 


\subsection{2.a Influence of food availability during fall}

Patterns in the distribution of aggregation depths observed here during fall indicated that night-time depth distributions included substantially larger depths in the regions of lowest chlorophyll, and also suggested a greater tendency to migrate vertically in regions of lower chlorophyll. This latter trend was evident in both years but more obvious in the fall of 2001. Godlewska (1996) found that vertical migrations were less pronounced in conditions of low food, but even the highest levels of chlorophyll observed here were lower than what that previous study of spring and summer migrations considered to be 'low' food conditions (43 $\mathrm{mg} \mathrm{m}^{-2}$ ). Two separate patterns may have occurred in the present study region. In portions of the study area where chlorophyll was relatively high, a small-amplitude migration with krill remaining at quite shallow depths even during day was observed, similar to Godlewska's (1996) 'low' chlorophyll scenario. In regions where phytoplankton prey was effectively absent, aggregations occupied deeper waters during both day and night and also migrated vertically with a greater amplitude. Alternately, it is possible that food levels in terms of chlorophyll concentration were so low that they had no effect on krill migrations, and that the observed relationships were in fact due to some other factor that was correlated with chlorophyll concentration.

Aggregation biomass density in fall decreased in regions of higher food conditions, and also during the night relative to the day, supporting the hypothesis that krill aggregative behavior is disrupted somewhat during feeding (Everson and Ward, 1980). Aggregations did not disperse completely however, and night-time densities were only slightly lower than during the day, consistent with the suggestion that aggregation and feeding are not incompatible activities (Antezana and Ray, 1984).

\subsection{2.b Influence of predators}

Added to this association with food availability is the impact of the presence of predators. Depths occupied by aggregations during the day in both falls and the winter of 2002 were 
significantly greater when seals were present than when they were absent. Crabeater seals have been thought to forage primarily in the upper $50 \mathrm{~m}$ of the water column, based on observations made mostly during summer, but a companion Southern Ocean GLOBEC study observed that seals in the present study area dove to much deeper depths (55\% of all dives were to depths greater than $50 \mathrm{~m}$, and $34 \%$ deeper than $100 \mathrm{~m}$; Burns et al., 2004). The deepest dive (664 m) ever recorded was in fact for a seal tagged by this study. Burns et al. (2004) also observed that dive depths varied over the course of the day, becoming deepest near midday, with the diel trend becoming more pronounced and deeper maximal daytime depths achieved from April to September. The diving abilities and behaviors of the seal predators are thus consistent with the hypothesis that krill aggregations migrated to deeper depths during the day to avoid this visual predator, and with the observation that deeper daytime depths were occupied during winter than fall.

Similarly, there was some evidence that shallow depths were not occupied during the day when penguins were present in the fall of 2002. Adelie penguins are capable of diving to depths of $175 \mathrm{~m}$ (Whitehead, 1989), although the main depth ranges over which they forage most intensively is generally shallower and varies between regions. For instance, $98 \%$ of dives were shallower than $20 \mathrm{~m}$ during the December chick-rearing period near the Japanese Syowa Station (Naito et al., 1990) versus $70 \%$ of dives occurring to maximum depths between 79 and $175 \mathrm{~m}$ during the December to January period in Prydz Bay (Whitehead, 1989). The depths to which these penguins dive also has been reported to increase during the day (although Chappell et al. (1993) report an exception to this pattern), and observations of the stomach contents of penguins tagged with both depth loggers and light sensors have suggested that reduced light levels decrease foraging success during the night (Wilson, et al., 1993). The present observation that krill aggregations did not occupy shallow depths during the fall of 2002 when penguins were present may suggest that the presence of this predator influences krill vertical migratory behavior; the lack of statistical support for this observation though precludes firm conclusions. Furthermore, the fact that this pattern did not persist during winter, combined with the observation that krill occupied both deep and shallow depths during 
fall when penguins were absent (unlike when seals were absent in this season and only shallow depths were selected), may suggest that krill vertical migratory behavior is more strongly influenced by the deeper diving seals than the penguins. Additional information on the relative abundance of these two predators, as well as their relative degrees of dependence on krill as a food source, might aid in differentiating their effects on krill behavior.

It is also important to recognize that both chlorophyll $a$ concentrations and predator occurrence varied substantially across the surveyed region, and teasing apart the relative effects of food availability and predation pressure on aggregation depth is not straightforward. Regions characterized in fall by low chlorophyll also tended to be located in waters closer to the continent (see Chapter 4), where seal and penguin predators were most abundant during fall (Chapman et al., 2004). Predation pressure and food availability likely interact to determine the vertical position of aggregations. Overall these observations are consistent though with the notion that during fall in the regions of low food availability where visual predators were present, krill aggregations occupied deep waters during the day to avoid predation. During the night, some aggregations migrated to shallower depths, but many aggregations remained at depth, perhaps because food levels were too low to merit the energetic cost of migrating upwards. In regions of higher food availability where predators tended to be absent, the krill remained at more shallow depths during both day and night.

During both fall and winter, little association was evident between krill vertical migrations and the presence of whales. This may relate to the low numbers of whales observed, or to the nature of whale feeding versus that of seals or penguins. The minke and humpback whales observed here consume large 'mouthfuls' of krill at a time. Although by aggregating the krill may be harder to find than if they were more uniformly distributed, once located, being in an aggregation does not seem like a sensible strategy to avoid consumption by whales. In contrast, seals and penguins feed on small numbers of krill at a time, and being in an aggregation may dilute the risk of predation experienced 
by an individual krill (Folt and Burns, 1999). It is also important to note that we are not able to consider here the impact of pelagic or benthic predators such as squid or fishes, which may exert strong and chronic predation pressure on the krill, at a variety of depths.

For all three predator types considered, aggregation densities during both seasons tended to be higher when predators were present. In the case of aggregation depth, it seems reasonable to infer that the krill occupy deeper depths as a response to the presence of seal predators, rather than that the seals deliberately select locations where aggregations are positioned deep in the water column over regions where aggregations are more shallow. In the case of biomass density, however, it is not obvious whether higher densities are a response to predation pressure, or whether the predators choose to forage in regions where more dense aggregations tend to occur. Similarly, in the case of aggregation length, the association of seals with larger aggregations may relate to the foraging preferences of seals, or to the anti-predatory behavior of the krill, or both.

\subsection{2.c Influence of ice cover during winter}

During winter, krill aggregations were present at shallower depths during both day and night in regions where ice cover was greatest. Notably, shallow depths $(<100 \mathrm{~m})$ were only occupied during the daytime in regions where ice cover was high ( $>8$ tenths). This again may relate to predation pressure. The air-breathing predators considered here require some gaps in the ice cover, and very high ice cover may provide a refuge from predation during these daytime periods when predation by visual predators would otherwise be high (Zhou and Dorland, 2004). Although the exact association of the predators observed here with ice concentration is not known, the fact that krill aggregations in winter again occupied deeper depths during day when seal predators were present is at least consistent with this scenario. The observation that, unlike in fall when only deeper depths were occupied by aggregations when seals were present, krill aggregations were found during winter at both deep and shallow depths may relate to the scale over which a given aggregation was said to be in the presence of a predator (10 km) 
being less appropriate during the winter survey. Ice cover varied substantially over quite small scales, and it is possible that aggregations found within $10 \mathrm{~km}$ of a given predator might have in fact been unattainable to it due to increased ice cover at the aggregation's location. The lack of any apparent association of aggregation biomass density or depth with ice cover in the fall of 2002 may relate to the sea ice in that survey mostly having been very recently formed. An alternate explanation for the shallower depths occupied by aggregations under-ice is that ice cover reduced the penetration of light into the water column such that if the krill's depth distribution were light-dependent, it would shift shallower. This seems unlikely, however, given that the deepest depths occupied by aggregations did not likewise become shallower under-ice, and in fact became even deeper than in more ice-free waters.

It is also interesting that the increase in aggregation density between night and day was much more dramatic during the winter of 2002 than in fall. This may represent an antipredation tactic associated with more of the aggregations occupying shallow depths during day when under the ice, where they would be more vulnerable to predation. Some support for this hypothesis comes from the finding that the daytime density of aggregations during the winter of 2002 was significantly larger when either seals or whales were present than when they were absent.

Wintertime vertical migratory and aggregative behavior thus appear in part related to the avoidance of predation risk. Given the low water column chlorophyll levels observed during this season, however, it is not certain what benefit is gained by the krill occupying shallower waters during the day; most likely though it relates to feeding. Large krill were not observed immediately under the ice by divers as part of companion studies conducted during the present survey period (K. Daly personal communication). Under-ice surveys with a remotely operated vehicle (ROV) observed large krill in only one instance out of 26 surveys during the winter of 2002, at which time the adult krill observed were found from immediately under the ice to a depth of $60 \mathrm{~m}$ at densities exceeding 100 individuals $\mathrm{m}^{-3}$ (S. Gallager unpublished data, and see US SO GLOBEC, 2002). It is conceivable 
that the present acoustically-observed aggregations migrated to shallow depths during the night in order to feed on ice-associated algae. Alternately, krill are known to be omnivorous and may have been feeding on zooplankton found in shallow portions of the water column. Acoustic scattering at $120 \mathrm{kHz}$ aside from that associated with krill aggregations was generally low in winter at shallow depths (Lawson et al., 2004), perhaps suggesting that any such prey would be relatively small (e.g., microzooplankton)

and hence less detectable at $120 \mathrm{kHz}$. It is noteworthy that the only previous study of krill vertical migratory behavior during winter by Ross et al. (1996) found that krill were always associated with relatively shallow depths $(<100 \mathrm{~m})$; it seems that krill in that surveyed region may have had the same causes, perhaps feeding-related, for occupying shallow depths, but may have lacked the impetus of predators to migrate deeper during the day.

\subsubsection{Variability in aggregation size}

In contrast to depth and biomass density, aggregation size showed little variation on diel time-scales. Suggestive associations were observed, however, between aggregation size and current shear. The largest aggregation horizontal extents $(>3 \mathrm{~km})$ were found only in regions of low horizontal shear. Shear forces will tend to stretch aggregations apart, and as aggregations become larger or as shear increases, the krill will have a harder time maintaining aggregation cohesion. There thus may be a maximum aggregation horizontal size beyond which aggregation continuity can not be maintained over the aggregation's full length and aggregations are pulled apart (Zhou and Dorland, 2004). The finding that very large aggregations were only present where horizontal shear was low is consistent with this hypothesis. The largest aggregations in fall were also, however, found in regions of lowest chlorophyll concentrations. As was noted earlier, it must be acknowledged that the tendency for krill to form the largest aggregations in regions where chlorophyll and horizontal shear were low may reflect some other aspect of krill behavior or habitat choice, and that chlorophyll or shear may simply covary with whatever environmental property is actually influencing aggregation size. Seals were more common in these 
coastal regions where the largest aggregations were present, for instance, and the krill may form these very large aggregations to enhance the effect of diluting predation pressure.

Variations in currents with depth, or vertical shear, similarly might be expected to set limits on the maximum vertical extent of krill aggregations (Zhou and Dorland, 2004). For the aggregations considered here, the largest heights were observed for middle ranges of estimated vertical shear magnitude, while aggregations of smaller vertical extent were present in regions of low to high vertical shear. This is not incompatible with the hypothesis that vertical shear limits aggregation height, but nor does it provide equivocal support. Again, it raises the question of whether krill height being maximal in regions of mid-range vertical shear may relate to some covarying environmental feature.

\subsubsection{Behavior in relation to krill length}

Estimates of the weighted mean length of krill made directly from acoustic measurements were available for a subset of aggregations observed during the fall surveys. Only a small number of these were estimated to be composed of small krill, but there was some suggestion that these small krill aggregations migrated vertically less and were found at relatively shallow depths. This is consistent with the study of vertical migration by Godlewska (1996), and with the observations of Daly and Macaulay (1988) of a shallow distribution of acoustically-observed aggregations near where nets sampled larval and juvenile krill. Aggregations composed of smaller krill also tended to be smaller in vertical and horizontal extent.

The largest aggregations in terms of horizontal and vertical extent were composed of krill of weighted mean length that corresponded to the regionally dominant length mode of approximately $40 \mathrm{~mm}$ (see Chapter 4). Otherwise, there was little association of aggregation vertical position and size with estimated krill length for this larger length mode. This analysis of hundreds of aggregations thus supports the previous work by 
Ricketts et al. (1992), who examined the size and other characteristics of krill sampled directly with a modified Longhurst-Hardy plankton recorder in relation to the acoustically-determined depth, density, length, and height of aggregations, for 30 aggregations sampled simultaneously by both techniques. These findings may suggest that above some threshold length surpassed by the dominant length mode present here, aggregation structure is not limited by the size and size-related swimming abilities of member animals.

\subsubsection{Intra-aggregation variability in animal density and size}

Examination of the mean numerical density and weighted mean length of krill estimated on an element-by-element basis for a selection of very large aggregations found in coastal reaches of the study area in fall revealed interesting patterns in variability. These aggregations were chosen for this more detailed analysis as they accounted for the majority of overall estimated krill biomass in the study region (see Chapter 4). Representative aggregations were presented here, and the patterns they illustrate are typical of other similar aggregations analyzed.

The inversion method employed here to estimate length and numerical density assumes that total volume backscattering is the sum of the contributions from each scattering krill, which requires that the scatterers are randomly distributed within the sampled volume (Greenlaw and Johnson, 1983). This is likely to be true for the averages over all acoustic elements within entire aggregations considered in the estimation of weighted mean length for each aggregation as a whole. An added benefit of examining the large and dense aggregations found in coastal regions is that each individual element within the aggregations is also more likely to meet this assumption. It is possible, however, that in the analysis of each element within these case study aggregations, densities in some elements may not meet this assumption. This introduces greater uncertainty into these small-scale length and density estimates. A final concern is that the inversion method also makes the unverified assumption that variability in volume backscattering is due only to 
variation in density or length, and that all other factors upon which scattering depends (e.g., orientation, acoustic material properties) remain constant within the aggregation.

Variability in estimates of the weighted mean length made for each acoustic element was low in most aggregations. Uni-modal length distributions with relatively low variability have been demonstrated previously for smaller aggregations $(<1 \mathrm{~km}$ in length; Watkins, 1986), and it is interesting that this trend holds for the larger (many km) aggregations considered here. This is indicative of a single cohort of animals in each aggregation. Wiebe et al. (2004), however, observed a strongly bimodal distribution of lengths (modes near 8 and $40 \mathrm{~mm}$ ) in a series of net samples through a large aggregation observed acoustically during the fall 2001 survey (see also Chapter 4). As discussed in Chapter 4, the scattering from animals of the larger length mode, if present, will overwhelm any contributions from the smaller individuals. The weighted mean lengths reported here thus relate to the adult krill present in the region, and likely obscure any smaller (e.g., larval) krill that may be present in a given aggregation.

In addition, little evidence was found for size segregation, or tendencies for length to vary in a systematic manner, within aggregations. What variability was observed may relate to actual small-scale variation in krill length, or to variability introduced by the stochastic nature of krill scattering. The exception to this overall pattern was the aggregation observed on May 24, 2001, where the weighted mean length varied in a systematic fashion with depth in the aggregation, increasing from a length mode near $15 \mathrm{~mm}$ at shallow depths to larger sizes at greater depths. It is interesting, but not obvious, why the small krill should be found shallower within the aggregation. Following on the point made above, it is possible that a smaller length mode is more commonly present in these large aggregations but hidden from our acoustic analyses by the dominant scattering of the larger animals, and in this one case the smaller krill were spatially separated from their larger relatives. 
The analyses discussed in sections 5.4.1 to 5.4.4 and in Chapter 4 involved estimates of a single weighted mean length and density of krill in each acoustically-identified aggregation, based on inversions of mean volume backscattering averaged over all acoustic elements within the aggregation. This approach was necessitated by constraints imposed by computer processing time and a desire to examine every krill aggregation identified. In contrast, the application discussed here of the inverse method to each acoustic element capitalized fully on the high resolution of the acoustic data and provided information on intra-aggregation variability. It is pertinent to compare the results of the inversions based on mean volume backscattering to the by-element analyses presented here. The distribution of weighted mean lengths estimated on a by-element basis for the large aggregation observed in Crystal Sound on May 14, 2002 (Figure 5.28) compares favorably to the distribution of weighted mean lengths estimated on a by-aggregation basis for the various krill aggregations observed in this same region and general time period (upper-right panel, Figure 4.6). Correspondingly, the median over all estimated weighted mean lengths for all elements from the by-element analysis was $36 \mathrm{~mm}$, while that from the by-aggregation analysis was $37.5 \mathrm{~mm}$.

Unlike length, the numerical density of animals varied substantially within individual aggregations. This suggests that the often strong variability in volume backscattering evident in the acoustically-identified krill aggregations relates more to variability in abundance than size, under the assumption made by the acoustic inversion method of constant krill orientation, shape, and acoustic material properties within the aggregation. The driving forces behind this small-scale intra-aggregation variability pose an intriguing question for future study.

\subsection{CONCLUSIONS}

The present examination of the size, density, and vertical position of individual krill aggregations in relation to a variety of properties of the physical and biological environment has allowed a number of interesting ecological insights. Most notably, krill 
aggregations were observed to exhibit diel changes in vertical position and biomass density; such diel vertical migrations had not previously been observed for krill during winter. Concurrent observations of chlorophyll $a$ concentrations and the occurrence of predators, including whales, seals, and penguins, suggested that food availability and predation pressure were important drivers of krill aggregation and vertical migration. During the winter of 2002, the presence of pack ice also showed some association with these behaviors. The relative influences of these various factors on aggregation structure and vertical position could not be assessed, however, and would represent an interesting avenue of further study. There was little association between the characteristics of individual aggregations and the weighted mean length of krill estimated acoustically, and thus little evidence for any size-related changes in aggregative behavior, for the sizes of krill present in this region. Finally, the application of the inverse method for estimating acoustically the weighted mean length and density of krill in each acoustic element (1.5 by ca. $35 \mathrm{~m}$ ) demonstrated the full potential of acoustic techniques to provide high resolution information on ecologically-relevant quantities, and in one instance also revealed an intriguing pattern in the size-segregation of individuals within a large krill aggregation. 


\section{Chapter 6}

\section{Conclusions}

The work presented in this thesis makes contributions to the fields of both zooplankton acoustics and Antarctic krill ecology, and more broadly to the study of zooplankton patchiness in general. It is also of central importance to ongoing collaborative work in the Southern Ocean GLOBEC program aimed at understanding the interactions of krill with their predators. Rather than repeat the material found in the discussion and concluding sections to each of the preceding chapters, the emphasis here will be on assessing the broader significance of the present findings.

\subsection{ANTARCTIC ZOOPLANKTON ACOUSTICS}

Initial application of acoustic techniques for the quantification of Antarctic krill abundance was motivated by a need for accurate estimates of total stock size for prudent management of the krill fishery (Everson and Miller, 1994). Perhaps by virtue of having their origins in fisheries management, acoustic methods applied to the study of krill were largely modeled after the single-frequency techniques commonly in use in fisheries acoustics. In the field of fisheries acoustics, the study species is typically a large and strongly-scattering swimbladdered fish, for which the assumptions of single-frequency methods are often more appropriate, and target strength is estimated on the basis of empirical models derived from in situ observations of animals of varying length (Maclennan and Simmonds, 1992). 
Only more recently have multi-frequency techniques been applied to acoustic surveys for Antarctic krill. The multi-frequency approach has long been a key feature of the field of zooplankton acoustics, however, dating to the seminal work of McNaught in the 1960s and Holliday in the 1970s (McNaught, 1968, 1969; Holliday, 1977). Unlike swimbladdered fish, which scatter sound strongly and are often found in mono-specific aggregations, zooplankton are typically weak scatterers, barely different in acoustic terms from the surrounding seawater, and usually occur in heterogeneous communities with animals of diverse sizes, shapes, and acoustic material properties. Multi-frequency techniques can help discriminate among the different sizes and scatterer types present in such communities. Furthermore, due to the small size of zooplankton and their tendency to occur in these heterogeneous communities, most of the current understanding of their target strength has been derived from physics-based modeling in combination with tankbased experimental studies.

An important contribution of this thesis therefore has been to continue the process of bringing to the field of Antarctic krill acoustics the knowledge gained by zooplankton acousticians in other regions. The demonstration in Chapter 2 that krill are the dominant scatterer only at very particular times and places confirms that the assumption that all scattering stems from krill is inappropriate, and is consistent with the findings in other oceans where the dominant zooplankton scatterer varies substantially over space and time (Lavery et al., submitted). Chapter 3 carries on the work initiated by Stanton et al. (1993), who developed the first incarnation of the modern sophisticated and broadlyapplicable scattering models for elongated zooplankton such as euphausiids, which was then subsequently refined through the efforts, among others, of Stanton et al. (1998), McGehee et al. (1998), and Lavery et al. (2002). Application of these models has been plagued by concerns over the appropriate parameterization of the angle of acoustic incidence, however, and the central contribution of Chapter 3 is to parameterize fully such a theory-based model for krill target strength and then rigorously verify it with in situ observations. 
The Greene et al. (1991) semi-empirical model of krill target strength in widespread use in krill acoustics was proposed as a highly useful and practical means of estimating krill target strength, at a time when sophisticated theoretical models of euphausiid target strength were still in development. Certainly since the Stanton et al. (1993) model, however, doubts have existed concerning the validity of the Greene et al. (1991) approach. The fully parameterized and verified target strength model of Chapter 3 presents a means of predicting krill target strength that is arguably preferable to this semiempirical model. The work of Chapter 3 has further demonstrated the validity and flexibility of the theoretical approach to understanding krill scattering, which is in common use elsewhere in zooplankton acoustics.

The comparison to fisheries acoustics is not completely misplaced, however, as the krill do form aggregations that are mostly mono-specific in composition and uni-modal in length distribution. This greatly simplifies the circumstances relative to other applications in zooplankton acoustics, where the degree of heterogeneity in community composition can make quantitative estimates of abundance difficult even with multi-frequency techniques (Lavery et al., submitted). Chapter 4 has provided some additional verification of the robust nature of established multi-frequency methods for discriminating the krill aggregations from other sources of scattering. By virtue of being able to assume that these acoustically-identified aggregations are composed only of krill of a single length mode, the process of estimating krill density and length is also greatly simplified. The potential for multi-frequency data and mathematical inverse techniques to be used for the simultaneous and quantitative estimation of zooplankton abundance and size has been known since Holliday (1977), but Chapter 4 of this thesis marks the first time that such methods have been applied to broad-scale data from Antarctic krill surveys. Due to constraints imposed by computer processing time, the analyses of Chapter 4 estimated only a single mean length and density for each acoustically-observed krill aggregation. The application of the inverse method in Chapter 5 to estimate the length and density of krill for each acoustic element in certain krill aggregations of particular interest then capitalized fully on the high resolution of the acoustic data. The demonstration that multi- 
frequency acoustic data can be used to estimate krill length and abundance over large survey areas without recourse to net samples should provide the antarctic researcher with a valuable tool. It is important to note, however, that these various acoustic methods are not without their limitations, and important caveats listed in Chapters 3 and 4 accompany their use.

The combined application of the various acoustic methodologies developed in this work has yielded rigorous estimates of biologically-meaningful quantities that have allowed otherwise unattainable insight into the ecological questions that constitute the focus of the later thesis components.

\subsection{ANTARCTIC KRILL ECOLOGY}

A variety of hypotheses have been proposed by previous investigators concerning seasonal variability in krill distribution, but testing of these hypotheses has been limited by a paucity of suitable observations during fall and winter. Similarly, while it is generally accepted that aggregation and vertical migration by the Antarctic krill represent a trade-off between the avoidance of visual predators and feeding on shallowlydistributed phytoplankton prey, this hypothesis has emerged largely on the basis of circumstantial evidence. The nature of the various datasets collected for and available to the present work have thus afforded a number of important insights into outstanding questions in the field of Antarctic krill ecology.

The examination of the broad-scale distribution of first zooplankton volume backscattering strength and then krill biomass in particular in Chapters 2 and 4 makes a fundamental contribution to current understanding of the ecology of a poorly-understood region and time of year. The coupling between antarctic zooplankton distributions and physical processes and environmental conditions has not previously been explored to the level of detail that was possible here. The suggestion from Chapter 2 that the advective features of intrusions of circumpolar deep water onto the shelf and meso-scale gyres play 
an important role in determining the overall distribution of zooplankton is particularly intriguing.

The work of Chapter 4 has likewise allowed important insight into the distribution of krill in particular, as well as into the various hypotheses that exist concerning its seasonal variability. The present observation of very large krill aggregations at depth over the continental shelf region under thick ice in the winter of 2002 is quite unusual, and provides further confirmation that the entire krill population does not spend the winter in immediate association with the under-ice environment, as suggested by Marschall (1988). It is also not fully consistent with the hypothesis of Siegel (1988) that krill migrate during fall from their summertime spawning grounds along the shelf break to over-winter in inshore waters. Tantalizing associations were also evident between krill biomass and regions close to the continent where water temperatures at depth were relatively cool, although the exact impetus behind such associations remains unclear.

Taken as a whole, this work depicts a species with enormous variability in its distribution, in both a seasonal, inter-annual, and spatial sense. To some extent, this variability likely relates to physical processes: the results of the present work and earlier studies suggest that currents play a part in determining krill distribution and aggregation structure. The krill is a competent swimmer, however, and many of the present results are also consistent with the notion of active behaviors and habitat choice. The observation made in Chapter 4 of large aggregations present at depth in coastal waters where krill are not known to congregate in spring and summer (Lascara et al., 1999), for instance, seems most likely the result of active behavioral decisions. As noted in a recent review by Nicol (2006), there is a tendency in the field of krill ecology to view the krill either as being similar to schooling fish species, capable of swimming fast enough to be free of the constraints of currents and thereby being distributed mostly on the basis of active habitat choices, or as enjoying a mostly passive planktonic existence and a distribution dictated primarily by advection and physical processes. This is perhaps analogous to the division between the 'fisheries' and 'zooplankton' approaches to krill acoustics, and similarly 
might reflect scientific interest in the krill originating in the disciplines of either fisheries science or biological oceanography. It is well beyond the scope of the present work to decide unequivocally between these two positions, but the results reported here, as well as intuition, might suggest that some combination of both physical forces and active behaviors is in fact the case.

The final contribution of this work lies in its examination of the attributes of individual krill aggregations, where perhaps the most exciting ecological advances were achieved. Prior to this work, diel vertical migration of krill aggregations had not been demonstrated directly during winter. This study is also unusual in its having direct observations of many of the environmental properties hypothesized to influence krill aggregation and vertical migrations, and the analyses of Chapter 5 have afforded revealing inferences concerning the causes and nature of these behaviors. An especially novel aspect of Chapter 5 has been the direct examination of the impact of a variety of predators on krill aggregations, resulting in the suggestion that abundant crabeater seals may have the strongest influence on krill behavior, rather than the more rare whale and smaller penguin predators. Although there remains some uncertainty in teasing apart the relative influences of food availability and predation pressure on the structure and vertical positioning of krill aggregations, the work of this chapter has afforded substantial insight.

While the present work provides some interesting descriptions of krill distribution and aggregative behavior, and allows inferences as to the impetus behind these phenomena, it leaves a number of intriguing questions unanswered. For instance, the exact reasons why the krill form such large aggregations in coastal regions in fall remain unknown. Similarly, although the work of Chapter 5 provides a strong suggestion that food availability and predation pressure are important drivers of krill aggregation, a more definite understanding of the interactions of these two forces awaits further and more direct study. 
Many of these questions might most profitably be addressed in two ways. First, based on the understanding of krill distribution gained from these surveys of fixed sampling grids, a sensible next step might be to conduct studies wherein individual aggregations are located and followed for some period of time. The response of these aggregations to changing environmental conditions and the presence of different types of predators would be invaluable in teasing apart the relative impact of these forces identified in the present work as likely being important. Second, theoretical models that couple krill aggregative behavior to physical flow might allow an examination of the relative importance of the two in determining distribution and aggregation structure. The results of the present work, combined with previous studies of krill swimming speed and other behaviors, could provide a strong empirical basis for all necessary parameterization.

\subsection{RELATION TO OTHER WORK}

The present work also makes key contributions to collaborative work in the Southern Ocean GLOBEC program aimed at understanding the interactions of top antarctic predators with their krill prey and the functioning of the ecosystem as a whole. A distinctive feature of the SO GLOBEC broad-scale surveys is that in addition to the quantification of the distribution of krill reported in the present work, concurrent visual observations were made of the along-track abundance of various krill predators. The quantitative descriptions of krill distribution that have resulted from the present work form the foundation for detailed investigations of how the distribution of these predators is associated with that of their prey.

These investigations are ongoing, but some very interesting early associations have already been revealed. The distributions of minke and humpback whales during fall in the study region both appear to be associated with the distribution of krill biomass measured in the present work (Figure 6.1; Friedlaender et al., in press, submitted). Examining the characteristics of the individual krill aggregations identified here, moreover, reveals differences in the depths of aggregations targeted by these two whales, potentially 


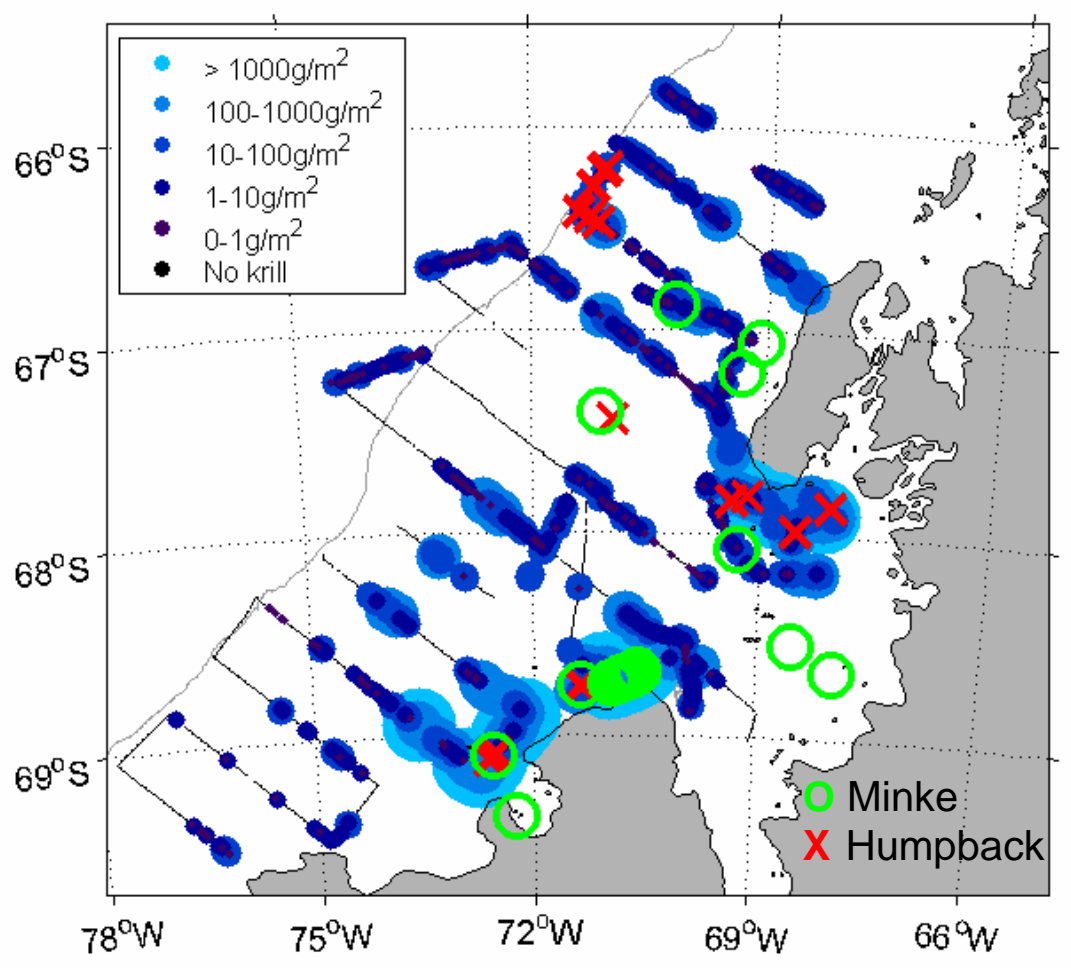

Figure 6.1 - Distribution of minke $(O)$ and humpback $(X)$ whales in the survey region during the fall of 2001, in relation to the concurrently-measured krill biomass. Biomass values plotted here are the water column $(1-600 \mathrm{~m})$ averages in 1-km along-track intervals described in Chapter 4. Figure was prepared by G.L. Lawson for Friedlaender $e t$ al. (submitted). 
explaining how two such closely related species can have evolved to inhabit the same region and feed upon the same prey item without experiencing inter-specific competition (Friedlaender et al., submitted). Perhaps unsurprisingly in light of the associations between aggregation depth and the presence of seal predators, examinations of the distribution of seals in winter along short subsections of the survey lines studied here have likewise found a strong correlation with krill biomass (e.g., Figure 6.2; Ribic et al., submitted). The Ribic et al. (submitted) study also found the distribution of Adélie penguins to be inconsistently associated with krill biomass, significantly correlated on some transects but not others, and the distribution of more shallow-foraging snow petrels to be mostly independent of that of the krill. Finally, an assessment of the distribution of blue and fin whales during fall based on the measurements of passive listening buoys deployed during the surveys considered here found an inverse correlation with krill biomass (Širović, 2006). This may relate to these whales being in transit rather than a feeding behavioral mode. Alternately, the fact that whale distribution was positively associated with chlorophyll $a$ concentrations may suggest top-down control of the food web: in regions where they are present, these large whales may substantially deplete the local krill populations that would otherwise graze down phytoplankton stocks, thereby releasing these primary producers from grazing pressure and allowing them to achieve high concentrations (Širović, 2006).

Still other predator datasets have yet to be considered in light of the present findings concerning krill distribution and aggregation structure. For instance, seals tagged during the SO GLOBEC program showed patterns of habitat use, including deeper dives during fall and winter than are typical of spring and summer (Burns et al., 2004), that will likely prove to be related to the dynamics of their krill prey (e.g., Figure 6.3). Comparison of these records from tagged seals to the patterns of aggregation vertical migrations inferred here may also allow additional insight into this complex krill behavior.

Many of the questions that emerge from the current work will also be addressed as the results of the U.S. Southern Ocean GLOBEC program are synthesized with related 

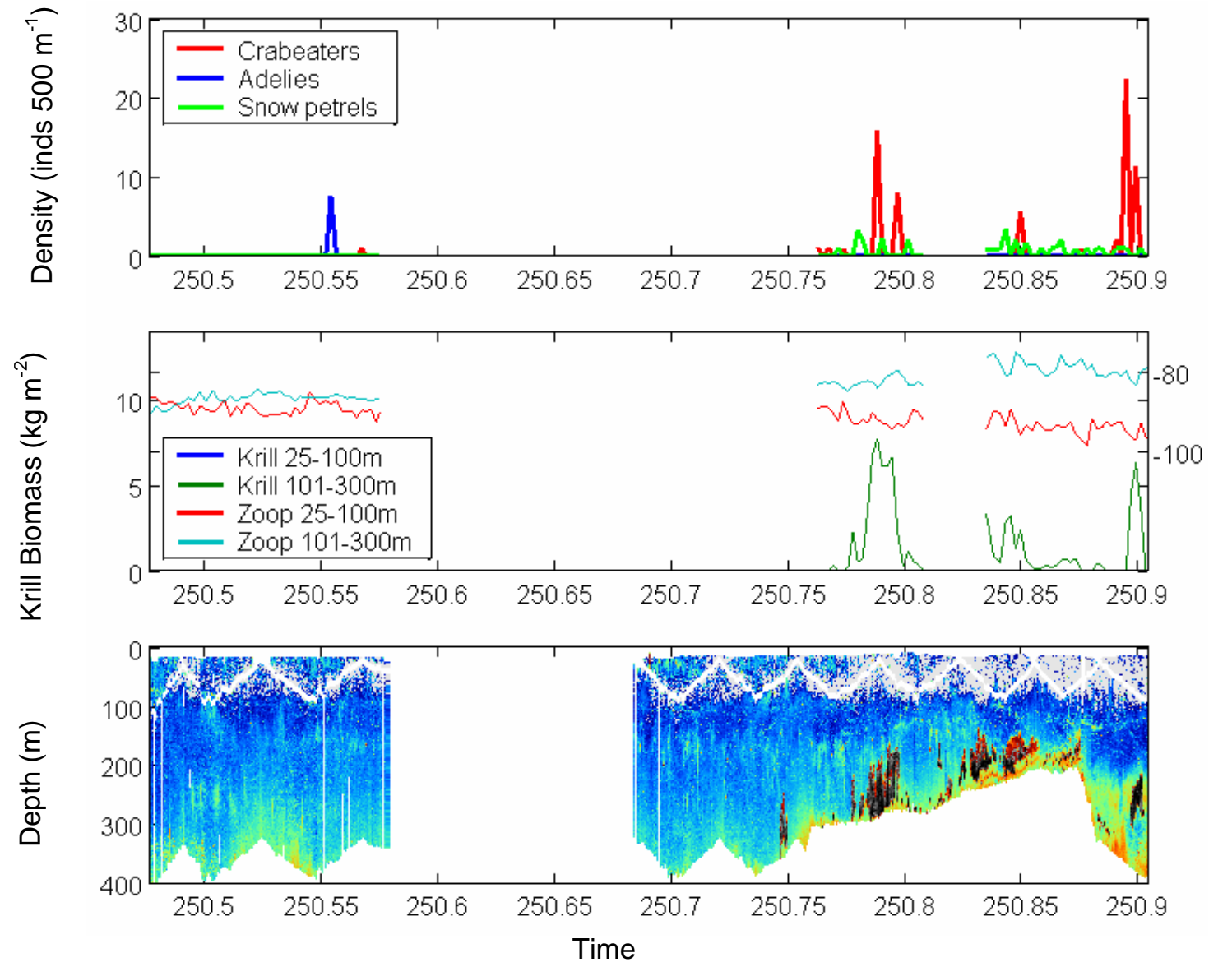

Figure 6.2 - Associations of bird and seal predators with the distribution of krill biomass. Top plot shows the densities (individuals $500 \mathrm{~m}^{-1}$ ) of crabeater seals, Adélie penguins, and snow petrels measured by bird observers concurrent to acoustic surveying, relative to along-track time. Middle plot shows on the left-hand y-axis acoustically-estimated krill biomass, averaged over the same 500-m along-track intervals as the predator densities, in depth ranges of 25-100 and 101-300 m. Right-hand y-axis shows the volume backscattering remaining after krill scattering was excised, similarly averaged and used here as an index of the biomass of other, non-krill, zooplankton biomass. Bottom plot shows echogram of the raw acoustic volume backscattering strength data at $120 \mathrm{kHz}$ (same color-scale as elsewhere in the thesis, e.g., Figure 5.28). Gaps in the echogram indicate gaps in surveying. Figure prepared by G.L. Lawson for Ribic et al. (submitted). 


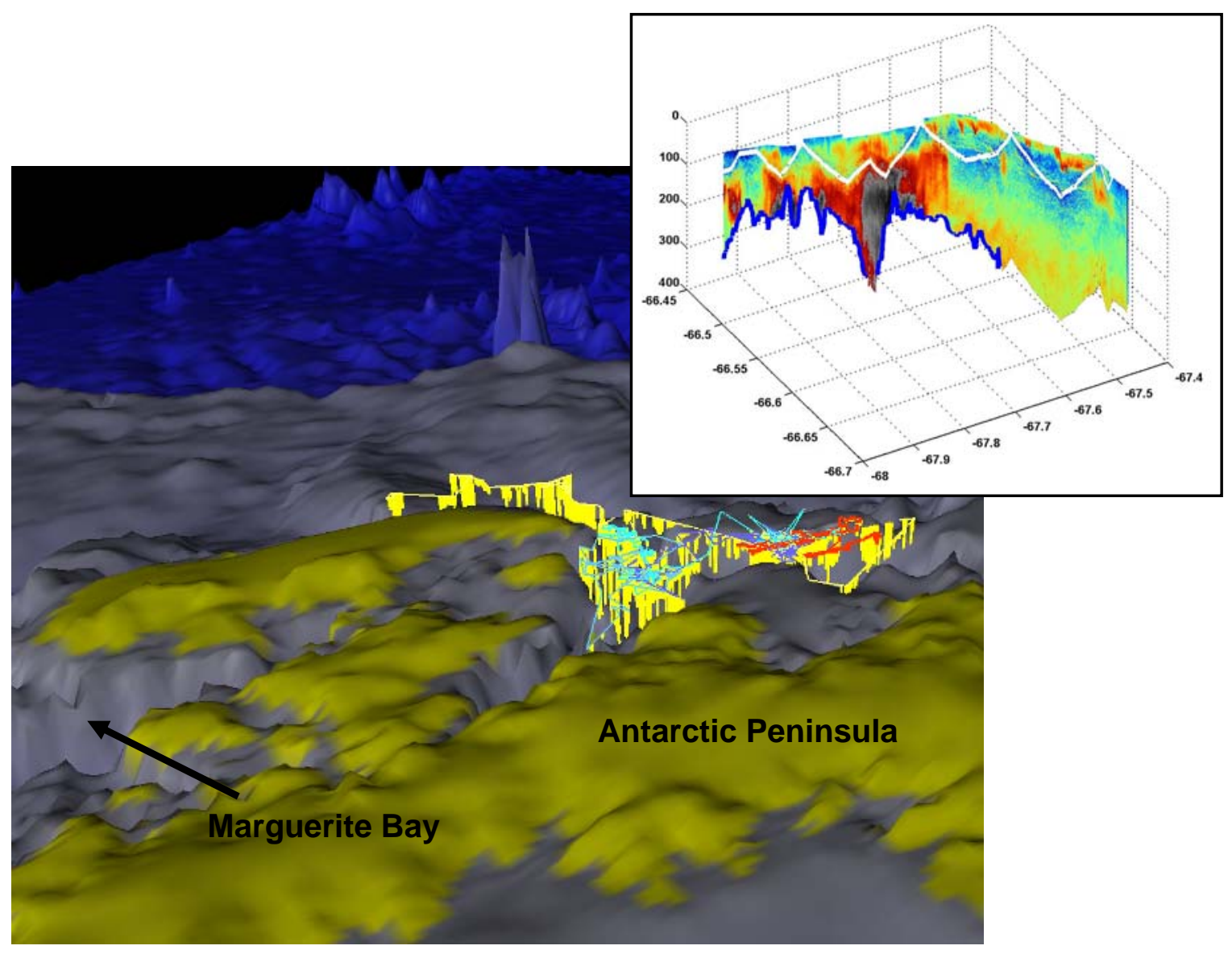

Figure 6.3 - Diving behavior of crabeater seals observed during August of 2002 in the vicinity of Crystal Sound, north of Marguerite Bay. Main plot shows the dive profiles in depth and horizontal position for individually-tagged seals. Upper-right plot shows 120 $\mathrm{kHz}$ acoustic data collected on May 142002 (yearday 134) in the same region used by these seals, at which time the very large krill aggregation described in more detail in Chapters 4 and 5 was observed (see Table 4.1 and Figure 5.28). Blue line indicates where the bottom echo was excised. Seal plot provided by D. Costa (personal communication). 
research initiatives. The understanding reached in the present research concerning seasonal and inter-annual variability in krill distribution and abundance, for example, is somewhat compromised by a lack of knowledge of processes occurring in the springs and summers immediately preceding and succeeding the survey periods considered here. Similarly, the lack of knowledge concerning krill abundance in waters adjacent to the SO GLOBEC survey site sets limits to the conclusions that can be drawn; as discussed in Chapter 4, the extreme variability evident between the winters of 2001 and 2002 in krill distribution and abundance might be clarified if the variability in krill abundance at upstream locations were known.

Fortunately, ongoing work by the Palmer Long Term Ecological Research program considers krill distribution and other processes occurring at a variety of times of year in a study region that includes the northern portion of the SO GLOBEC site and waters farther north (Quetin and Ross, 1992). Likewise, the German Southern Ocean GLOBEC program has conducted research cruises to nearby and overlapping waters during time periods adjacent to those studied here (e.g., the early fall of 2001; Pakhomov et al., 2004). Finally, there exist a wealth of historical data; the distribution of whaling vessels in off-shelf waters of the Bellingshausen Sea, for example, provides an indication that the whale's krill prey was found in these oceanic waters at some times of year. Undoubtedly as these various sources of information are combined with the results of the present work and other companion studies within the SO GLOBEC program, new and exciting findings will emerge.

\subsection{BROADER IMPACT}

In more general terms, this work has yielded insight into the spatial and temporal variability of antarctic zooplankton distributions, as well as into the causes and nature of krill aggregative behavior. Such information is relevant to studies of the ecological role played by zooplankton in the Antarctic, the design and implementation of krill fishery stock assessment surveys, and the biogeochemistry of the Southern Ocean. 
The work also has broader implications to the application of acoustic techniques to the study of zooplankton beyond the Antarctic. The confluence of favorable circumstances: a study species that forms mono-specific aggregations that have a mostly uni-modal size composition and are sufficiently distinct in scattering characteristics that they can be distinguished from other animals, combined with a fully parameterized scattering model, together may serve to make this study distinctive in the field of zooplankton acoustics for its ability to make quantitative, rigorous, and defensible estimates of abundance of the study zooplankter. The parameterization of the theoretical DWBA-based scattering model developed here was intended specifically for application to the Antarctic krill, but the general approach of fully and carefully parameterizing all necessary parameters based on measurements of the actual animal under investigation in the time and region of surveying is certainly more broadly applicable to the study of other zooplankton. In fact, the variability in parameter values suggested by comparison of the present results to other studies would suggest that this approach is not just applicable but also highly desirable. Comparison of model predictions to in situ observations then provides additional verification; in the present case, this comparison was highly favorable, which also provides further validation of the model-based approach to understanding zooplankton scattering. The overall tactic of using multi-frequency acoustic data in combination with other lines of evidence to identify regions of the acoustic record where a single taxon and size group dominated scattering, and then only for those regions seeking to make quantitative estimates of animal length, abundance, and biomass, is likewise more generally applicable to acoustic studies elsewhere. This two-stage approach, together with the fully parameterized and verified target strength model, in sum lend substantial confidence to the resultant estimates of biologically-relevant quantities.

The work also contributes more broadly to current understanding of the physical and biological forces that drive zooplankton patchiness in continental shelf regions beyond the Southern Ocean. In fact, the present results are perhaps most revealing in comparison to similar acoustic studies of euphausiids made in GLOBEC programs elsewhere. In the Northeast Pacific, for example, related but smaller euphausiid species (e.g., Euphausia 
pacifica, ca. $16 \mathrm{~mm}$ in length) also form large acoustically-recognizable aggregations, and the distribution of these appeared to relate primarily to retention by meso-scale circulation features and bottom topography (Ressler et al., 2005). This parallels the findings of the present work, although the distribution of the larger and more strongly swimming Antarctic krill studied here may be influenced to a larger extent by active behavioral choices. In contrast, work in the Gulf of Maine GLOBEC study region has suggested that euphausiids are rarely the dominant zooplankton present, in terms of either acoustic returns or biomass (Lavery et al., submitted). The ecological role fulfilled in the Southern Ocean by the Antarctic krill is presumably replaced by some other group, perhaps by the small pelagic schooling fishes which are absent in the Antarctic continental shelf ecosystem.

Our understanding of the coupling of biological and physical forces in determining the distribution and population dynamics of zooplankton, including euphausiids, has increased dramatically as the various GLOBEC programs of the world's oceans have investigated their various localities. These initiatives have now attained a high degree of maturity, and are poised to allow a synthesis of their collective findings. From this synthesis a new understanding and predictive capacity should emerge concerning how this diverse and highly important zooplanktonic component of the marine ecosystem interacts with its environment and might be expected to respond to environmental change. 


\section{Bibliography}

Alonzo, S.H., Mangel, M., 2001. Survival strategies and growth of krill: avoiding predators in space and time. Marine Ecology Progress Series, 209: 203-217.

Amos, A.F., 1984. Distribution of krill (Euphausia superba) and the hydrography of the Southern Ocean: large-scale processes. Journal of Crustacean Biology 4(Spec. No. 1), 306-329.

Anderson, V.C., 1950. Sound scattering from a fluid sphere. Journal of the Acoustical Society of America $22,426-431$.

Antezana, T., Ray., K., 1984. Active feeding of Euphausia superba in a swarm north of Elephant Island. Journal of Crustacean Biology 4(Spec. No. 1), 142-155.

Ashjian, C.J., Rosenwaks, G.A., Wiebe, P.H., Davis, C.S., Gallager, S.M., Copley, N.J., Lawson, G.L., Alatalo, P., 2004. Distribution of zooplankton on the continental shelf of Marguerite Bay, Antarctic Peninsula, during austral fall and winter, 2001. Deep-Sea Research II 51, 2073-2098.

Ashjian, C.J., Sharon, L.S., Flagg, C.N., Wilson, C., 1998. Patterns and occurrence of diel vertical migration of zooplankton biomass in the Mid-Atlantic Bight described by an Acoustic Doppler Current Profiler. Continental Shelf Research 18, 831-858.

Atkinson, A., Schnack-Schiel, S.B., Ward, P., Marin, V., 1997. Regional differences in the life cycle of Calanoides acutus (Copepoda: Calanoida) within the Atlantic sector of the Southern Ocean. Marine Ecology Progress Series 150, 195-210.

Atkinson, A., Whitehouse, M.J., Priddle, J., Cripps, G.C., Ward, P., Brandon, M.A., 2001. South Georgia, Antarctica: a productive, cold water, pelagic ecosystem. Marine Ecology Progress Series 216, 279-308.

Azzali, M., Leonori, I., Lanciani, G., 2004. A hybrid approach to acoustic classification and length estimation of krill. CCAMLR Science 11, 33-58.

Barry, S.C., Welsh, A.H., 2002. Generalized additive modeling and zero inflated count data. Ecological Modelling 157, 179-188.

Beardsley, R.C., Limeburner, R., Owens, W.B., Drifter Measurements of Surface Currents Near Marguerite Bay on the West Antarctic Peninsula Shelf During Austral Summer and Fall. Submitted to Deep-Sea Research II Southern Ocean GLOBEC Special Issue. 
Benfield, M. C., Davis, C. S., Gallager, S. M., 2000. Estimating the in situ orientation of Calanus finmarchicus on Georges Bank using the Video Plankton Recorder. Plankton Biology and Ecology 47, 69-72.

Benfield, M.C., Lavery, A., Wiebe, P.H., Greene, C.H., Stanton, T.K., Copley N.C., 2003. Distributions of physonect siphonulae in the Gulf of Maine and their potential as important sources of acoustic scattering. Canadian Journal of Fisheries and Aquatic Sciences 60, 759-772.

Bolmer, S.T., Beardsley, R.C., Pudsey, C., Morris, P., Wiebe. P., Hofmann, E., Anderson, J., Maldonados,A., 2004. A High-Resolution Bathymetry Map of Marguerite Bay and adjacent Western Antarctic Peninsula Shelf Southern Ocean GLOBEC Program. Woods Hole Oceanographic Institution Technical Report WHOI-2004-02.

Brierley, A.S., Fernandes, P.G., Brandon, M.A., Armstrong, F., Millard, N.W., McPhail, S.D., Stevenson, P., Pebody, M., Perrett, J., Squires, M., Bone, D.G., Griffiths, G., 2002. Antarctic krill under sea ice: elevated abundance in a narrow band just south of ice edge. Science 295, 1890-1892.

Brierley, A.S., Ward, P., Watkins, J.L., Goss, C., 1998. Acoustic discrimination of Southern Ocean zooplankton. Deep-Sea Research II 45, 1155-1173.

Brierley, A.S., Watkins, J.L., Murray, A.W.A., 1997. Interannual variability in krill abundance at South Georgia. Marine Ecology Progress Series 150, 87-98.

Brinton, E., 1991. Distribution and population structure of immature and adult Euphausia superba in the western Bransfield Strait region during the 1986-87 summer. Deep-Sea Research II 38, 1169-1193.

Bucklin, A., Wiebe, P.H., Smolenack, S. B., Copley, N.J., Clarke, M.E., 2002. Integrated biochemical, molecular genetic, and bioacoustical analysis of mesoscale variability of the euphausiid Nematoscelis difficilis in the California Current. Deep-Sea Research I 49, 437-462.

Burns, J.M., Costa, D.P., Fedak, M., Bradshaw, C.J.A., Hindell, M.A., McDonald, G., Trumble, S.J., Chittick, E., Gray, M., Gales, N., Barnes, J., Shaffer, S., Kuhn, K., Lovell, P., Crocker, D., 2004. Winter habitat use and foraging behavior of crabeater seals along the Western Antarctic. Deep-Sea Research II 51, 2279-2303.

Cassie, R.M., 1963. Microdistribution of plankton. Oceanography and Marine Biology Annual Review 1, 223-252.

Chapman, E.W., Ribic, C.A., Fraser, W.R., 2004. The distribution of seabirds and pinnipeds in Marguerite Bay and their relationship to physical features during austral winter 2001. Deep-Sea Research II 51, 2261-2278.

Chappell, M.A., Shoemaker, V.H., Janes, D.N., Bucher, T.L., 1993. Diving behavior during foraging in breeding Adelie penguins. Ecology 74, 1204-1215.

Chu, D., 2000. The GLOBEC Kriging Software Package - EasyKrig2.1, May 1, 2000. WWW Page, http://globec.whoi.edu/software/kriging/easy_krig/easy_krig.html.

Chu, D., Foote, K.G., Stanton, T.K., 1993. Further analysis of target strength measurements of Antarctic krill at 38 and $120 \mathrm{kHz}$ : Comparison with deformed cylinder model and inference of orientation distribution. Journal of the Acoustical Society of America 93, 2985-2988. 
Chu, D., Wiebe, P. H., 2005. Measurements of acoustic material properties of zooplankton in Antarctic waters. ICES Journal of Marine Science 62, 818-831.

Chu, D., Wiebe, P. H., Copley, N., 2000a. Inference of material properties of zooplankton from acoustic and resistivity measurements. ICES Journal of Marine Science 57, 1128-1142.

Chu, D., Wiebe, P.H., Copley, N.J., Lawson, G.L. Estimation of the size, orientation, and abundance of marine organisms using an acoustic scattering model-based inversion. Submitted to Journal of the Acoustical Society of America, January 2006.

Chu, D., Wiebe, P.H., Copley, N.J., Lawson, G.L., Puvanendran, V., 2003. Material properties of North Atlantic cod eggs and early stage larvae and their influence on acoustic scattering. ICES Journal of Marine Science 60, 508-515.

Chu, D., Wiebe, P.H., Stanton, T.K., Hammar, T.R., Doherty, K.W., Copley, N.J., Zhang, J., Reeder, D.B., Benfield, M.C., 2000b. Measurements of the material properties of live marine organisms and their influence on acoustic scattering. Proceedings of the OCEANS 2000 MTS/IEEE International Symposium, Sept. 11-14, 2000, Providence, RI, Vol. 3, pp. 1963-1967.

Costa, D.P., Crocker, D.E., 1996. Marine mammals in the Southern Ocean. In: Ross, R.M., Hofmann, E.E., Quetin, L.B. (Eds.), Foundations for Ecological Research West of the Antarctic Peninsula. Antarctic Research Series. American Geophysical Union, Washington, D.C., pp 287-301.

Daly, K.L., 2004. Overwintering growth and development of larval Euphausia superba: an interannual comparison under varying environmental conditions west of the Antarctic Peninsula. Deep-Sea Research II 51, 2139-2168.

Daly, K.L., Macaulay, M.C., 1988. Abundance and distribution of krill in the ice edge zone of the Weddell Sea, austral spring 1983. Deep-Sea Research 35, 21-41.

Daly, K.L., Macaulay, M.C., 1991. Influence of physical and biological mesoscale dynamics on the seasonal distribution and behavior of Euphausia superba in the Antarctic marginal ice zone. Marine Ecology Progress Series 79, 37-66.

Davis, C.S., Gallager, S.M., Marra, M., Stewart, W.K., 1996. Rapid visualization of plankton abundance and taxonomic composition using the Video Plankton Recorder. Deep-Sea Research II 43, 1947-1970.

Davis, C. S., Gallager, S. M., Solow, A.R., 1992. Microaggregations of oceanic plankton observed by towed video microscopy. Science 257, 230-232.

Davis, C.S., Wiebe, P.H., 1985. Macrozooplankton biomass in a warm-core Gulf Stream ring: Time series changes in size structure, taxonomic composition, and vertical distribution. Journal of Geophysical Research 90, 8871-8882.

Demer, D.A. 2004. An estimate of error for the CCAMLR 2000 survey estimate of krill biomass. Deep-Sea Research II 51, 1237-1251.

Demer, D. A., Conti, S. G., 2003. Reconciling theoretical versus empirical target strengths of krill: effects of phase variability on the distorted-wave Born approximation. ICES Journal of Marine Science 60, 429-434.

Demer, D. A., Conti, S. G., 2005. New target-strength model indicates more krill in the Southern Ocean. ICES Journal of Marine Science 62, 25-32. 
Demer, D. A., Hewitt, R. P., 1995. Bias in acoustic biomass estimates of Euphasia superba due to diel vertical migration. Deep-Sea Research I 42, 455-475.

Dinniman, M.S., Klinck, J.M., 2004. A model study of circulation and cross shelf exchange on the west Antarctic Peninsula continental shelf. Deep-Sea Research II 51, 2003-2022.

Ehrenberg, J.E., Torkelson, T.C., 2000. FM slide (chirp) signals: a technique for significantly improving the signal-to-noise performance in hydroacoustic assessment systems. Fisheries Research 47, 193-199.

Endo, Y., 1993. Orientation of Antarctic krill in an aquarium. Nippon Suisan Gakkaishi 59, 465-468.

Everson, I. 2000a. Ecosystem dynamics involving krill. In: Everson, I. (Ed.), Krill: Biology, Ecology and Fisheries. Blackwell Science, Oxford, pp. 202-227.

Everson, I. 2000b. Distribution and standing stock: The Southern Ocean. In: Everson, I. (Ed.), Krill: Biology, Ecology and Fisheries. Blackwell Science, Oxford, pp. 63-79.

Everson, I., Bone, D.G., 1986. Effectiveness of the RMT8 system for sampling krill (Euphausia superba) swarms. Polar Biology 6, 83-90

Everson, I., Miller, D.G.M., 1994. Krill mesoscale distribution and abundance: results and implications of research during the BIOMASS programme. In El-Sayed, S.Z. (Ed.), Southern Ocean ecology: the BIOMASS perspective. Cambridge University Press, New York, pp 129-143.

Everson, I., Ward, P., 1980. Aspects of Scotia Sea zooplankton. Biological Journal of the Linnaean Society $14,93-101$.

Fach, B.A., Hofmann, E.E., Murphy, E.J., 2002. Modeling studies of antarctic krill Euphausia superba survival during transport across the Scotia Sea. Marine Ecology Progress Series 231, 187-203.

Filin, A.A., Gorchinsky, K.V., Kiseleva, V.M., 1991. Biomass of myctophids in the Atlantic sector of the Southern Ocean as estimated by acoustic surveys. SC-CAMLR Selected Scientific Papers 1990, 417429.

Folt, C.L., Burns, C.W., 1999. Biological drivers of zooplankton patchiness. Trends in Ecology and Evolution. 14, 300-305.

Foote, K. G., 1990. Speed of sound in Euphausia superba. Journal of the Acoustical Society of America $87,1405-1408$.

Foote, K.G., Aglen, A., Nakken, O., 1986. Measurement of fish target strength with a split-beam echo sounder. Journal of the Acoustical Society of America 80, 612-621.

Foote, K. G., Chu, D., Stanton, T. K., 1992. Status of krill target strength, in Selected Scientific Papers, 1992, SC-CAMLR-SSP/9 (Committee for the Conservation of Antarctic Marine Living Resources, Hobart, Australia), pp. 101-126.

Foote, K.G., Everson, I., Watkins, J.L., Bone, D.G., 1990. Target strengths of Antarctic krill (Euphausia superba) at $38120 \mathrm{kHz}$. Journal of the Acoustical Society of America 87, 16-24.

Foote, K.G., Knudsen, H.P. ,Vestnes, G., MacLennan, D.N., Simmonds, E.J., 1987. Calibration of acoustic instruments for fish density estimation: a practical guide. ICES Cooperative Research Report 144. 
Foote, K.G., Stanton, T.K., 2000. Acoustical methods. In: Harris, R.P., Wiebe, P.H., Lenz, J., Skjoldal, H.R., and Huntley, M. (Eds.), ICES Zooplankton Methodology Manual. Academic Press, Boston, pp. 223-258.

Fraser, F.C., 1936. On the development and distribution of the young stages of krill (Euphasia superba). Discovery Reports 14, 1-192.

Fraser, W.R., Trivelpiece, W.Z., 1996. Factors controlling the distribution of seabirds: winter-summer heterogeneity in the distribution of Adélie penguin populations. In: Ross, R.M., Hofmann, E.E., Quetin, L.B. (Eds.), Foundations for Ecological Research West of the Antarctic Peninsula. Antarctic Research Series. American Geophysical Union, Washington, D.C., pp 257-272.

Friedlaender, A.S., Halpin, P.N., Qian, S., Lawson, G.L., Wiebe, P.H., Thiele, D., Read, A.J., In press. Whale distribution in relation to prey and oceanographic processes in the Western Antarctic Peninsula shelf waters. Marine Ecology Progress Series.

Friedlaender, A.S., Lawson, G.L., Halpin, P.N. Evidence of resource partitioning and niche separation between humpback and minke whales in Antarctica. Submitted to American Naturalist, April 2006.

Gallager, S.M., Daly, K., Fisher, K., Lawson, G., Davis, C.S., Ashjian, C., Wiebe, P.H., 2002. Seasonal changes in the association of larval krill with its potential microplankton food resource along the Western Antarctic Peninsula. Eos, Transactions of the American Geophysical Union, 84, Ocean Sciences Meeting Supplement, Abstract OS51A-13.

Godlewska, M., 1993. Acoustic observations of krill (Euphausia superba) at the ice edge (between Elephant I. and South Orkney I., Dec. 1988/Jan. 1989. Polar Biology 13, 507-514.

Godlewska, M., 1996. Vertical migrations of krill (Euphausia superba Dana). Polish Archives of Hydrobiology 43, 9-63.

Godlewska, M., Klusek, Z., 1987. Vertical distribution and diurnal migrations of krill - Euphausia superba Dana - from hydroacoustical observations, SIBEX, December 1983/January 1984. Polar Biology 8, $17: 22$

Greene, C. H., Stanton, T. K., Wiebe, P. H., McClatchie, S., 1991. Acoustic estimates of Antarctic krill. Nature 349, 110.

Greene, C. H., Wiebe, P. H., Burczynski, J., 1989. Analyzing zooplankton size distributions using highfrequency sound. Limnology and Oceanography 34, 129-139.

Greene, C.H., Wiebe, P.H., Pelkie, C., Benfield, M.C., Popp., J.M., 1998. Three-dimensional acoustic visualization of zooplankton patchiness. Deep-Sea Research II 45, 1201-1217.

Greenlaw, C.F., 1979. Acoustical estimation of zooplankton populations. Limnology and Oceanography 24, 226-242.

Greenlaw, C. F., Johnson, R. K., 1983. Multiple-frequency acoustical estimation. Biological Oceanography 2, 227-252.

Gulland, J.A., 1970. The development of the resources of the Antarctic Seas. In: Holdgate, M.W. (Ed.), Antarctic Ecology, Vol. 1. Academic Press, New York, pp 217-223. 
Gutt, J., Siegel, V., 1994. Benthopelagic aggregations of krill (Euphausia superba) on the deeper shelf of the Weddell Sea (Antarctic). Deep-Sea Research I 41, 169-178.

Hamner, W.M., Carleton, J.H., 1979. Copepod swarms: attributes and role in coral reef ecosystems. Limnology and Oceanography 24, 1-14.

Hamner, W.M., Hamner, P.P., 2000. Behavior of Antarctic krill (Euphausia superba): schooling, foraging, antipredatory behavior. Canadian Journal of Fisheries and Aquatic Sciences 57(Suppl. 3), 192-202.

Hamner, W.M., Hamner, P.P., Obst, B.S., Carleton, J.H., 1989. Field observations on the ontogeny of schooling of Euphausia superba furciliae and its relationship to ice in Antarctic waters. Limnology and Oceanography 34, 451-456.

Hamner, W.M., Hamner, P.P., Strand, S.W., Gilmer, R.W., 1983. Behavior of Antarctic krill, Euphausia superba: chemoreception, feeding, schooling, and molting. Science 220, 433-435.

Hastie, G.D., Swift, R.J., Slesser, G., Thompson, P.M., Turrell W.R., 2005. Environmental models for predicting oceanic dolphin habitat in the Northern Atlantic. ICES Journal of Marine Science 62, 760770 .

Hastie T.J., Tibshirani R.J., 1990. Generalized Additive Models. Chapman and Hall. New York.

Hastings, H.M., Sugihara, G.S., 1993. Fractals: A User's Guide for the Natural Sciences. Oxford University Press. New York.

Haury, L.R., McGowan, J.A., Wiebe, P.H., 1978. Patterns and processes in the time-space scales of plankton distributions. In Steele, J. (Ed.), Spatial Patterns in Plankton Communities. Plenum Press, New York, pp. 277-327.

Heywood, R.B., Everson, I., Priddle, J., 1985. The absence of krill from the South Georgia zone, winter 1983. Deep-Sea Research 32, 369-378.

Hewitt, R.P., Demer, D.A., 1991. Target strength of Antarctic krill. Nature 353, 310.

Hewitt, R.P., Demer, D.A., 1993. Dispersion and abundance of Antarctic krill in the vicinity of Elephant Island in the 1992 austral summer. Marine Ecology-Progress Series 99, 29-39.

Hewitt, R.P., Demer, D.A., 2000. The use of acoustic sampling to estimate the dispersion and abundance of euphausiids, with an emphasis on Antarctic krill, Euphausia superba. Fisheries Research 47, 215-229.

Hewitt, R.P., Demer, D.A., Emery, J.H., 2003. An 8-year cycle in krill biomass density inferred from acoustic surveys conducted in the vicinity of the South Shetland Islands during the austral summers of 1991-1992 through 2001-2002. Aquatic Living Resources 16, 205-213.

Hiller-Adams, P., Case, J.F., 1984. Optical parameters of euphausiid eyes as a function of habitat depth. Journal of Comparative Physiology A 154, 307-318.

Hofmann, E.E., Capella, J.E., Ross, R.M., Quetin, L.B., 1992. Models of the early life history of Euphausia superba - Part I. Time and temperature dependence during the ascent-descent cycle. Deep-Sea Research 39, 1177-1200. 
Hofmann, E.E., Klinck, J.M., 1998. Hydrography and circulation of the Antarctic continental shelf: $150^{\circ} \mathrm{E}$ eastward to the Greenwich Meridian. In: Robinson, A.R., Brink, K.H. (Eds.), The Sea, The Global Coastal Ocean, Regional Studies and Synthesis, Vol. 11, 997-1042.

Hofmann, E.E., Klinck, J.M., Costa, D.P., Daly, K.D., Torres, J.J., Fraser, W.R., 2002. U.S. Southern Ocean Global Ocean Ecosystem Dynamics Program. Oceanography 15, 64-74.

Holliday, D.V., 1977. Extracting bio-physical information from the acoustic signature of marine organisms. In: Anderson, N.R., Zahuranec, B.J. (Eds.), Oceanic Sound Scattering Prediction. Plenum Publishing Corp. New York, pp 619-624.

Holliday, D.V., Pieper, R.E., 1980. Volume scattering strengths zooplankton distributions at acoustic frequencies between $0.53 \mathrm{MHz}$. Journal of the Acoustical Society of America 67, 135-146.

Huntley, M.E., Brinton, E., 1991. Mesoscale variation in growth and early development of Euphausia superba Dana in the western Bransfield Strait region. Deep-Sea Research II 38, 1213-1240.

Huntley, M.E., Lopez, M.D.G., Karl, D.M., 1991. Top predators in the Southern Ocean: a major leak in the biological carbon pump. Science 253, 64-66.

Ichii, T., 2000. Krill harvesting. In: Everson, I. (Ed.), Krill: Biology, Ecology and Fisheries. Blackwell Science, Oxford, pp. 228-261.

Ichii, T., Katayama, K., Obitsu, N., Ishii, H., Naganobu, M., 1998. Occurrence of Antarctic krill (Euphausia superba) concentrations in the vicinity of the South Shetland Islands: relationship to environmental parameters. Deep-Sea Research I 45, 1235-1262.

Johnson, R.K., 1977. Sound scattering from a fluid sphere revisited. Journal of the Acoustical Society of America 61, 375-377.

Jolly, G.M., Hampton, I., 1990. A stratified random transect design surveys of fish stocks. Canadian Journal of Fisheries and Aquatic Sciences 47, 1282-1291.

Kawaguchi, K., Matsuda, O., Ishikawa, S., Naito, Y., 1986. A light trap to collect krill and other micronektonic and planktonic animals under the Antarctic coastal fast ice. Polar Biology 6, 37-42.

Kils, U., 1981. Swimming behavior, swimming performance and energy balance of Antarctic krill Euphausia superba. BIOMASS Scientific Series 3, 1-122.

Klevjer, T. A., Kaartvedt, S., 2003. Split-beam target tracking can be used to study the swimming behaviour of deep-living plankton in situ. Aquatic Living Resources 16, 293-298.

Klinck, JM, Hofmann, E.E., Beardsley, R.C., Salihoglu, B., Howard, S., 2004. Water Mass Properties and Circulation on the west Antarctic Peninsula Continental Shelf in Austral Fall and Winter 2001. DeepSea Research II 51, 1925-1946.

Koslow, J.A., Kloser, R., Stanley, C.A., 1995. Avoidance of a camera system by a deepwater fish, the orange roughy (Hoplostethus atlanticus). Deep-Sea Research I 42, 233-244.

Krause, D.C., 1998. Implications of a fractal distribution of plankton patchiness. In: Pierrot-Bults, A.C., van der Spoel, S. (Eds.), Pelagic Biogeography ICoPB II, Proceedings of the Second International Conference. International Oceanographic Commission Workshop Report No. 142. UNESCO. Paris, pp 220-232. 
Kristensen, Å, Dalen, J., 1986. Acoustic estimation of size distributions and abundance of zooplankton. Journal of the Acoustical Society of America 80, 601-611.

Land, M.F., 1984. Crustacea. In: Ali, M.A. (Ed.), Photoreception and Vision in Invertebrates. Plenum Press. New York, pp 401-438.

Lascara, C.M., Hofmann, E.E., Ross, R.M., Quetin, L.B., 1999. Seasonal variability in the distribution of Antarctic krill, Euphausia superba, west of the Antarctic Peninsula. Deep-Sea Research I 46, 951-984.

Laws, R.M., 1977. Seals and Whales of the Southern Ocean. Philosophical Transacations of the Royal Society of London B 279, 81-96.

Laws, R.M., 1985. The ecology of the Southern Ocean. American Scientist 73, 26-40.

Lawson, G.L., Wiebe, P.H., Ashjian, C.J., Chu, D., Stanton, T.K., 2006. Improved parameterization of Antarctic krill target strength models. Journal of the Acoustical Society of America 119, 232-242.

Lawson, G.L., Wiebe, P.H., Ashjian, C.J., Gallager, S.M., Davis, C.S., Warren, J.D., 2004. Acousticallyinferred zooplankton distribution in relation to hydrography west of the Antarctic Peninsula. Deep-Sea Research II 51, 2041-2072.

Lavery, A. C., Stanton, T. K., McGehee, D. E., Chu, D., 2002. Three-dimensional modeling of acoustic backscattering from fluid-like zooplankton. Journal of the Acoustical Society of America 111, 11971210 .

Lavery, A.C., Wiebe, P.H., Stanton, T.K., Lawson, G.L., Benfield, M.C., Copley, N.J. Determining dominant scatterers of sound in mixed zooplankton populations. Submitted to Journal of the Acoustical Society of America, April 2006.

Le Fèvre, J., Legendre, L., Rivkin, R.B., 1998. Fluxes of biogenic carbon in the Southern Ocean: roles of large microphagous zooplankton. Journal of Marine Systems 17, 325-345.

Loeb, V. Siegel, V., Holm-Hansen, O., Hewitt, R., Fraser, W., Trivelpiece, W., Trivelpiece, S., 1997. Effects of sea-ice extent and krill or salp dominance on the Antarctic food web. Nature 387, 897-900.

Ligowski, R., 2000. Benthic feeding by krill, Euphausia superba Dana, in coastal waters off West Antarctica and in Admiralty Bay, South Shetland Islands. Polar Biology 23, 619-625.

Macaulay, M.C., English, T.S., Mathisen, O.A., 1984. Acoustic characterization of swarms of Antarctic krill (Euphausia superba) from Elephant Island and Bransfield Strait. Journal of Crustacean Biology 4 (Spec. No. 1), 16-44.

MacLennan, D.N. and Simmonds, E.J. 1992. Fisheries Acoustics. Chapman and Hall, London.

Madureira, L.S.P., Ward, P., Atkinson, A., 1993. Differences in backscattering strength determined at 120 and $38 \mathrm{kHz}$ for three species of Antarctic macroplankton. Marine Ecology Progress Series 93, 17-24.

Makarov, R.R., Naumov, A.G., Shevtsov, V.V., 1970. The biology and distribution of the Antarctic krill. In: Holdgate, M.W. (Ed.), Antarctic Ecology, Vol. 1. Academic Press, New York, pp 173-176. 
Mamylov, V.S., 1988. Results of "in situ" target strength measurements at $38 \mathrm{kHz}$ for major commercial species in the North Atlantic. (In Russian) In: Instrumental Methods of Evaluation of the Stock Size of Commercially Important Species. Murmansk, pp. 3-18.

Marin, V.H., Brinton, E., Huntley, M., 1991. Depth relationships of Euphausia superba eggs, larvae and adults near the Antarctic Peninsula, 1986-87. Deep-Sea Research 38, 1241-1249.

Marr, J.W.S., 1962. The natural history and geography of the Antarctic krill (Euphausia superba Dana). Discovery Reports 32, 33-464.

Marschall, H.-P., 1988. The overwintering strategy of Antarctic krill under the pack-ice of the Weddell Sea. Polar Biology 9, 129-135.

Mauchline, J., 1980a. The biology of mysids and euphausiids. Advances in Marine Biology 18, 1-681.

Mauchline, J., 1980b. Measurement of body length of Euphausia superba Dana. BIOMASS Handbook No. 4, pp. 4-9.

Mauchline, J., 19980c. Studies on patches of krill Euphausia superba Dana. BIOMASS Handbook No. 6, pp. 1-36.

McClatchie, S., Greene, C.H., Macaulay, M.C., Sturley, D.R.M., 1994. Spatial and temporal variability of Antarctic krill: implications for stock assessment. ICES Journal of Marine Science 51, 11-18.

McGehee, D. E., O’Driscoll, R. L., Martin-Traykovski, L. V., 1998. Effects of orientation on acoustic scattering for Antarctic krill at $120 \mathrm{kHz}$. Deep-Sea Research II 45, 1273-1294.

McNaught, D. C., 1968. Developments in acoustical plankton sampling. Proceedings of the 11th Conference on Great Lakes Research, 76-84.

McNaught, D. C., 1969. Acoustical determination of zooplankton distributions. Proceedings of the 12th Conference on Great Lakes Research, 61-68.

Medwin, H., Clay, C.S., 1998. Fundamentals of Acoustical Oceanography. Academic Press, Boston.

Miller, D.G.M., Barange, M., Klindt, H., Murray, A.W.A., Hampton, I., Siegel, V., 1993. Antarctic krill aggregation characteristics from acoustic observations in the South West Atlantic Ocean. Marine Biology 117, 171-183.

Miller, D.G.M., Hampton, I., 1989. Biology and ecology of the Antarctic krill (Euphausia superba Dana): a review. BIOMASS Scientific Series No. 9.

Mitson, R.B., Simard, Y., Goss, C., 1996. Use of a two-frequency algorithm to determine size and abundance of plankton in three widely spaced locations. ICES Journal of Marine Science 53, 209-215.

Miyashita, K., Aoki, I., Inagaki, T., 1996. Swimming behavior target strength of isada krill (Euphausia pacifica). ICES Journal of Marine Science 53, 303-308.

Moiseev, P.A., 1970. Some aspects of the commercial use of the krill resources of the Antarctic seas. In: Holdgate, M.W. (Ed.), Antarctic Ecology, Vol. 1. Academic Press, New York, pp 213-216.

Morse, P.M., Ingard, K.U., 1968. Theoretical Acoustics. Princeton University Press, Princeton, NJ. 
Murphy, E.J., Trathan, P.N., Everson, I., Parkes, G., Daunt, F., 1997. Krill fishing in the Scotia Sea in relation to bathymetry, including the detailed distribution around South Georgia. CCAMLR Science 4, $1-17$.

Murray, A.W.A., Watkins, J.L., Bone, D.G., 1995. A biological acoustic survey in the marginal ice-edge zone of the Bellingshausen Sea. Deep-Sea Research II 42, 1159-1175.

Naito, Y., Asaga, T., Ohyama, Y., 1990. Diving behavior of Adelie penguins determined by time-depth recorder. The Condor 92, 582-586.

Nero, R.W., Magnuson, J.J., 1989. Characterization of patches along transect using high-resolution $70-\mathrm{kHz}$ integrated acoustic data. Canadian Journal of Fisheries and Aquatic Sciences 46, 2056-2064.

Nero, R.W., Magnuson, J.J., Brandt, S.B., Stanton, T.K., Jech, J.M., 1990. Fine-scale biological patchiness of $70 \mathrm{kHz}$ acoustic scattering at the edge of the Gulf Stream-EchoFront 85. Deep-Sea Research 37, 999-1016.

Nicol, S., 1994. Antarctic krill - Changing perceptions of its role in the antarctic ecosystem. In: Hempel, G. (Ed.), Antarctic Science: Global Concerns. Springer-Verlag, New York, pp. 145-166.

Nicol, S., 2006. Krill, currents, and sea ice: Euphausia superba and its changing environment. Bioscience $56,111-120$.

Nicol, S., Pauly, T., Bindoff, N.L., Wright, S., Thiele, D., Hosie, G.W., Strutton, P.G., Woehler, E., 2000. Ocean circulation off east Antarctica affects ecosystem structure and sea-ice extent. Nature 406, 504507.

Nordhausen, W., 1994. Winter abundance and distribution of Euphausia superba, E. crystallorophias, and Thysanoessa macrura in Gerlache Strait and Crystal Sound, Antarctica. Marine Ecology Progress Series 109, 131-142.

O’Brien, D.P., 1987. Description of escape responses of krill (Crustacea: Euphausiacea), with particular reference to swarming behavior the size proximity of the predator. Journal of Crustacean Biology 7 , 449-457.

Onsrud, M.S.R., Kaartvedt, S., 1998. Diel vertical migration of the krill Meganyctiphanes norvegica in relation to physical environment, food and predators. Marine Ecology Progress Series 171, 209-219.

Pakhomov, E.A., Atkinson, A., Meyer, B., Oettl, B., Bathmann, U., 2004. Daily rations and growth of larval Euphausia superba in the Eastern Bellingshausen Sea during austral autumn. Deep-Sea Research II 51, 2185-2198.

Patria, M.P., Wiese, K., 2004. Swimming in formation in krill (Euphausiacea), a hypothesis: dynamics of the flow field, properties of antennular sensor systems and a sensory-motor link. Journal of Plankton Research 26, 1315-1325.

Pauly, T., Nicol, S., Higginbottom, I., Hosie, G., Kichener, J., 2000. Distribution and abundance of Antarctic krill (Euphausia superba) off East Antarctica (80-150 E) during the Austral summer of 1995/1996. Deep-Sea Research II 47, 2465-2488.

Pauly, T., Penrose, J.D., 1998. Laboratory target strength measurements of free-swimming Antarctic krill (Euphausia superba). Journal of the Acoustical Society of America 103, 3268-3280. 
Perovich, D.K., Elder, B.C., Claffey, K.J., Stammerjohn, S.E., Smith, R.C., Ackley, S.F., Krouse, H.R., Gow, A.J., 2004. Winter sea-ice properties in Marguerite Bay, Antarctica. Deep-Sea Research II 51, 2023-2039.

Pitcher, T.J., 1973. The three-dimensional structure of schools in the minnow, Phoxinus phoxinus (L.). Animal Behaviour 21, 673-686.

Prézelin, B.B., Hofmann, E.E., Moline, M., Klinck, J.M., 2004. Physical forcing of phytoplankton community structure and primary production in continental shelf waters of the Western Antarctic Peninsula. Journal of Marine Research 62, 419-460.

Priddle, J., Smetacek, V., Bathmann, U., 1992. Antarctic marine primary production, biogeochemical carbon cycles and climatic change. Philosophical Transactions of the Royal Society of London B 338, 289-297.

Quetin, L.B., Ross, R.M., 1992. A long-term ecological research strategy for polar environmental research. Marine Pollution Bulletin 25, 233-238.

Quetin, L.B., Ross, R.M., Frazer, T.K., Haberman, K.L., 1996. Factors affecting distribution and abundance of zooplankton, with an emphasis on Antarctic krill, Euphausia superba. In: Ross, R.M., Hofmann, E.E., Quetin, L.B. (Eds.), Foundations for Ecological Research West of the Antarctic Peninsula. Antarctic Research Series. American Geophysical Union, Washington, D.C., pp 357-371.

R Development Core Team, 2006. R: A Language and Environment for Statistical Computing. R Foundation for Statistical Computing, Vienna, Austria. http://www.R-project.org.

Ragulin, A.G., 1969. Underwater observations of krill. Trudy VNIRO 66, 231-234.

Reid, D.G., (Ed.), 2000. Report on Echo Trace Classification. ICES Cooperative Research Report No. 238.

Reid, D.G., Simmonds, E.J., 1993. Image analysis techniques for the study of fish school structure from acoustic survey data. Canadian Journal of Fisheries and Aquatic Sciences 50, 1264-1272.

Reid, K., Croxall, J.C., 2001. Environmental responses of upper trophic-level predators reveals a system change in an Antarctic marine ecosystem. Proceedings of the Royal Society of London 268, 377-384.

Ressler, P.H., Brodeuer, R.D., Peterson, W.T., Pierce, S.D., Vance, M.P., Røstad, A., Barth, J.A., 2005. The spatial distribution of euphausiid aggregations in the Northern California Current during August 2000. Deep-Sea Research II 52, 89-108.

Ribic, C.A., Chapman, E., Fraser, W.R., Lawson, G.L., Wiebe, P.H. Winter distributions of seabirds and pinnipeds in Marguerite Bay, Antarctica, and their relationship to environmental features. Submitted to Deep-Sea Research II, April 2006.

Ricketts, C., Watkins, J.L., Morris, D.J., Buchholz, F., Priddle, J., 1992. An assessment of the biological and acoustic characteristics of swarms of Antarctic krill. Deep-Sea Research I 39, 359-371.

Ritz, D.A., 1994. Social aggregation in pelagic invertebrates. Advances in Marine Biology 30, 155-216.

Ross, R.M., Quetin, L.B., Lascara, C.M., 1996. Distribution of Antarctic krill and dominant zooplankton west of the Antarctic Peninsula. In: Ross, R.M., Hofmann, E.E., Quetin, L.B. (Eds.), Foundations for Ecological Research West of the Antarctic Peninsula. Antarctic Research Series. American Geophysical Union, Washington, D.C., pp 199-217. 
Sahrhage, D., 1989. Hydroacoustic detection of krill during "Polarstern" cruises ANT V/1 and ANT VI/2 (1987). Archiv für Fischereiwissenschaft 39, 73-80.

Sameoto, D. D., 1980. Quantitative measurements of euphausiids using a $120 \mathrm{kHz}$ sounder their in situ orientation. Canadian Journal of Fisheries and Aquatic Sciences 37, 693-702.

Sameoto, D.D., Cochrane, N., Herman, A., 1993. Convergence of acoustic, optical, and net-catch estimates of euphausiid abundance: use of artificial light to reduce net avoidance. Canadian Journal of Fisheries and Aquatic Sciences 50, 334-346.

SC-CAMLR., 1991. Report of the 10th Meeting of the Scientific Committee (SC-CAMLR-X). Committee for the Conservation of Antarctic Marine Living Resources, Hobart, Australia (CCAMLR), Hobart, Australia, pp. 117-121.

Schnack-Schiel, S.B., Hagen, W., Mizdalski, E., 1998. Seasonal carbon distribution of copepods in the eastern Weddell Sea, Antarctica. Journal of Marine Systems 17, 305-311.

Serebrennikova, Y.M., Fanning, K.A., 2005. Spatial, seasonal, and interannual variations in nutrients in the Southern Ocean GLOBEC region: water circulation and nutrient cycling. Deep Sea Research II 51, 1981-2002.

Siegel, V., 1988. A concept of seasonal variation of krill (Euphausia superba) distribution and abundance west of the Antarctic Peninsula. In: Sarhage, D. (Ed.), Antarctic Ocean and Resources Variability. Springer -Verlag, Berlin, Heidelberg, pp. 219-230.

Siegel, V., 1989. Winter and spring distribution and status of the krill stock in Antarctic Peninsula waters. Archiv für Fischereiwissenschaft 39, 45-72.

Siegel, V., 2000. Krill (Euphausiacea) demography and variability in abundance and distribution. Canadian Journal of Fisheries and Aquatic Sciences 57 (Supplement 3), 151-167.

Siegel, V., 2005. Distribution and population dynamics of Euphausia superba: summary of recent findings. Polar Biology 29, 1-22.

Širović, A. 2006. Blue and fin whale acoustics and ecology off Antarctic Peninsula. Dissertation. Scripps Institution of Oceanography. University of California San Diego, San Diego, CA.

Smith, D.A., Hofmann, E.E., Klink, J.M., Lascara, C.M., 1999. Hydrography and circulation of the west Antarctic Peninsula continental shelf. Deep-Sea Research I 46, 925-949.

Sokal, R.R., Rohlf, F.J., 2000. Biometry: The Principles and Practice of Statistics in Biological Research. W.H. Freeman and Co., New York.

Sprong, I., Schalk, P.H., 1992. Acoustic observations on krill spring-summer migration and patchiness in the northern Weddell Sea. Polar Biology 12, 261-268.

Stammerjohn, S.E., Smith, R.C., 1996. Spatial and temporal variability of western Antarctic Peninsula sea ice coverage. In: Ross, R.M., Hofmann, E.E., Quetin, L.B. (Eds.), Foundations for Ecological Research West of the Antarctic Peninsula. Antarctic Research Series. American Geophysical Union, Washington, D.C., pp 81-104. 
Stanton, T.K., Chu, D., 2000. Review and recommendations for the modelling of acoustic scattering by fluid-like elongated zooplankton: euphausiids and copepods. ICES Journal of Marine Science 57, 793807.

Stanton, T.K., Chu, D., Reeder, D.B., 2004. Non-Rayleigh acoustic scattering characteristics of individual fish zooplankton. IEEE Journal of Oceanic Engingeering 29, 260-268.

Stanton, T.K., Chu, D., Wiebe, P.H., 1998. Sound scattering by several zooplankton groups. II. Scattering models. Journal of the Acoustical Society of America 103, 236-253.

Stanton, T. K., Chu, D., Wiebe, P. H., Clay, C.S., 1993. Average echoes from randomly oriented randomlength finite cylinders: Zooplankton models. Journal of the Acoustical Society of America 94, 34633472 .

Stanton, T.K., Wiebe, P.H., Chu, D., Benfield, M.C., Scanlon, L., Martin, L., Eastwood, R.L., 1994. On acoustic estimates of zooplankton biomass. ICES Journal of Marine Science 51, 505-512.

Steele, J.H., 1974. The Structure of Marine Ecosystems. Harvard University Press, Cambridge, MA.

Taki, K., Hayashi, T., Naganobu, M., 2005. Characteristics of seasonal variation and aggregation of Antarctic krill (Euphausia superba) in the Scotia Sea, using Japanese fishery data. CCAMLR Science 12.

Thiele, D., Chester, E., Moore, S., Friedlaender, A., Širovic, A., Hildebrand, J., 2004. Exploring the impacts of physical variability in the Antarctic marine environment on baleen whale distribution: IWC - SO GLOBEC collaboration 2001 - 2002. Deep-Sea Research II 51, 2311-2325.

Thorpe, S.A., Brubaker, J.M., 1983. Observations of sound reflection by temperature microstructure. Limnology and Oceanography 28, 601-613.

Trathan, P.N., Brierley, A.S., Brandon, M.A., Bone, D.G., Goss, C., Grant, S.A., Murphy, E.J., Watkins, J.L., 2003. Oceanographic variability and changes in Antarctic krill (Euphausia superba) abundance at South Georgia. Fisheries Oceanography 12, 569-583.

U.S. Southern Ocean GLOBEC, 2001a. Report of RVIB Nathaniel B. Palmer Cruise NBP01-03 to the Western Antarctic Peninsula 24 April to 5 June 2001. United States Southern Ocean Global Ocean Ecosystems Dynamics Program Report Number 2. Old Dominion University, Norfolk, VA.

U.S. Southern Ocean GLOBEC, 2001b. Reports of RVIB Nathaniel B. Palmer Cruise NBP01-04 and R/V Lawrence M. Gould Cruise LMG01-06 to the Western Antarctic Peninsula 24 July to 31 August 2001 and 21 July to 1 September 2001. United States Southern Ocean Global Ocean Ecosystems Dynamics Program Report Number 3. Old Dominion University, Norfolk, VA.

U.S. Southern Ocean GLOBEC, 2002a. Report of the RVIB Nathaniel B. Palmer Cruise 02-02 to the Western Antarctic Peninsula, 9 April to 21 May 2002. United States Southern Ocean Global Ocean Ecosystems Dynamics Program Report Number 6. Old Dominion University, Norfolk, VA. 190 pp.

U.S. Southern Ocean GLOBEC, 2002b. Report of RVIB Nathaniel B. Palmer Cruise NBP02-04 to the Western Antarctic Peninsula 31 July to 18 September 2002. United States Southern Ocean Global Ocean Ecosystems Dynamics Program Report Number 8. Old Dominion University, Norfolk, VA.

Voronina, N.M., 1998. Comparative abundance and distribution of major filter-feeders in the Antarctic pelagic zone. Journal of Marine Systems 17, 375-390. 
Warren, J.D., Stanton, T.K., Benfield, M.C., Wiebe, P.H., Chu, D., Sutor, M., 2001. In situ measurements of acoustic target strengths of gas-bearing siphonophores. ICES Journal of Marine Science 58, 740749.

Warren, J.D., Stanton, T.K., Wiebe, P.H., Seim, H.E., 2003. Inference of biological and physical parameters in an internal wave using multiple-frequency, acoustic-scattering data. ICES Journal of Marine Science 60, 1033-1046.

Watkins, J.L., 1986. Variations in the size of Antarctic krill, Euphausia superba Dana, in small swarms. Marine Ecology Progress Series 31, 67-73.

Watkins, J.L., 1991. Krill target strength estimated by underwater photography acoustics, (WG-Krill-9140), CCAMLR, Hobart, Australia. As cited in Foote, K. G., Chu, D., Stanton, T. K., 1992. Status of krill target strength, in Selected Scientific Papers, 1992, SC-CAMLR-SSP/9, pp. 101-126.

Watkins, J.L., 2000. Aggregation and Vertical Migration. In: Everson, I. (Ed.), Krill: Biology, Ecology and Fisheries. Blackwell Science, Oxford, pp. 80-102.

Watkins, J.L., Brierley, A.S., 2002. Verification of the acoustic techniques used to identify Antarctic krill. ICES Journal of Marine Science 59, 1326-1336.

Watkins, J.L., Morris, D.J., Ricketts, C., Murray, A.W.A., 1990. Sampling biological characteristics of krill: effect of heterogeneous nature of swarms. Marine Biology 107, 409-415.

Watkins, J.L., Morris, D.J., Ricketts, C., Priddle, J., 1986. Differences between swarms of Antarctic krill and some implications for sampling krill populations. Marine Biology 93, 137-146.

Weber, L.H., El-Sayed, S.Z., Hampton, I., 1986. The variance spectra of phytoplankton, krill and water temperature in the Antarctic ocean south of Africa. Deep-Sea Research 33, 1327-1343.

Weeks, A.R., Griffiths, G., Roe, H., Moore, G., Robinson, I.S., Atkinson, A., Shreeves R., 1995. The distribution of acoustic backscatter from zooplankton compared with physical structure, phytoplankton and radiance during the spring bloom in the Bellingshausen Sea. Deep-Sea Research II 42, 997-1019.

Whitehead, M.D., 1989. Maximum diving depths of the Adelie penguin, Pygoscelis adeliae, during the chick rearing period, in Prydz Bay, Antarctica. Polar Biology 9, 329-332.

Wiebe, P.H., Ashjian, C.J., Gallager, S.M., Davis, C.S., Lawson, G.L., Copley, N.J., 2004. Using a high powered strobe light to increase the catch of Antarctic krill. Marine Biology 144, 493-502.

Wiebe, P.H., Boyd, S.H., Davis, B.M., Cox, J.L., 1982. Avoidance of towed nets by the euphausiid Nematoscelis megalops. Fisheries Bulletin (Washington D.C.) 80, 75-91.

Wiebe, P. H., Greene, C. H., Stanton, T. K., Burczynski, J., 1990. Sound scattering by live zooplankton micronekton: Empirical studies with a dual-beam acoustical system. Journal of the Acoustical Society of America 88, 2346-2360.

Wiebe, P.H., Morton, A.W., Bradley, A.M., Backus, R.H., Craddock, J.E., Cowles, T.J., Barber, V.A., and Flierl, G.R., 1985. New developments in the MOCNESS, an apparatus for sampling zooplankton and micronekton. Marine Biology 87, 313-323. 
Wiebe, P.H., Mountain, D., Stanton, T.K., Greene, C., Lough, G., Kaartvedt, S., Manning, J., Dawson, J., Martin, L., Copley, N., 1996. Acoustical study of the spatial distribution of plankton on Georges Bank and the relation of volume backscattering strength to the taxonomic composition of the plankton.

Deep-Sea Research II 43, 1971-2001.

Wiebe, P.H., Stanton, T.K., Greene, C.H., Benfield, M.C., Sosik, H.M., Austin, T., Warren, J.A., Hammar, T., 2002. BIOMAPER II: An integrated instrument platform for coupled biological and physical measurements in coastal and oceanic regimes. IEEE Journal of Oceanic Engineering 27, 700-716.

Wiese, K., 1996. Sensory capacities of euphausiids in the context of schooling. Marine and Freshwater Behaviour and Physiology 28, 183-194.

Wilson, R.P, Puetz, K., Bost, C.A., Culik, B.M., Bannasch, R., Reins, T., Adelung, D., 1993. Diel dive depths in penguins in relation to diel vertical migration of prey: whose dinner by candlelight? Marine Ecology Progress Series 94, 101-104.

Witek, Z., Kalinowski, J., Grelowski, A., 1988. Formation of Antarctic krill concentrations in relation to hydrodynamic processes and social behavior. In: Sarhage, D. (Ed.), Antarctic Ocean and Resources Variability. Springer-Verlag. Berlin, pp. 237-244.

Woodd-Walker, R.S., Watkins, J.L., Brierley, A.S., 2003. Identification of Southern Ocean acoustic targets using aggregation backscatter and shape characteristics. ICES Journal of Marine Science 60, 641-649.

Zane, L., Ostellari, L., Maccatrozzo, L., Bargelloni, L., Battaglia, B., Patarnello, T., 1998. Molecular evidence for genetic subdivision of Antarctic krill (Euphausia superba Dana) populations. Proceedings of the Royal Society of London B 265, 2387-2391.

Zhou, M., Dorland, R.D., 2004. Aggregation and vertical migration behavior of Euphausia superba. DeepSea Research II 51, 2119-2137.

Zhou, M., Nordhausen, W., Huntley, M., 1994. ADCP measurements of the distribution and abundance of euphausiids near the Antarctic Peninsula in winter. Deep-Sea Research I 41, 1425-1445.

Zhou, M., Zhu, Y., Peterson, J.O., 2004. In situ growth and mortality of mesozooplankton during the austral winter in Marguerite Bay and its vicinity. Deep-Sea Research II 51, 2099-2118.

Zhou, M., Zhu, Y., Tande, K.S., 2005. Circulation and behavior of euphausiids in two Norwegian subArctic fjords. Marine Ecology Progress Series 300, 159-178. 